University of Rhode Island

DigitalCommons@URI

Open Access Master's Theses

2017

\title{
Use of Ground-Penetrating Radar for Monitoring Bridge Scour and the Identification of Shallow Bedrock
}

Moritz Kanter

University of Rhode Island, moritz.kanter@gmail.com

Follow this and additional works at: https://digitalcommons.uri.edu/theses

\section{Recommended Citation}

Kanter, Moritz, "Use of Ground-Penetrating Radar for Monitoring Bridge Scour and the Identification of Shallow Bedrock" (2017). Open Access Master's Theses. Paper 1082.

https://digitalcommons.uri.edu/theses/1082

This Thesis is brought to you for free and open access by DigitalCommons@URI. It has been accepted for inclusion in Open Access Master's Theses by an authorized administrator of DigitalCommons@URI. For more information, please contact digitalcommons-group@uri.edu. 
USE OF GROUND-PENETRATING RADAR FOR MONITORING BRIDGE

SCOUR AND THE IDENTIFICATION OF SHALLOW BEDROCK

BY

MORITZ KANTER

A THESIS SUBMITTED IN PARTIAL FULFILLMENT OF THE REQUIREMENTS FOR THE DEGREE OF

MASTER OF SCIENCE

IN

OCEAN ENGINEERING

UNIVERSITY OF RHODE ISLAND 


\section{MASTER OF SCIENCE THESIS}

OF

MORITZ KANTER

APPROVED:

Thesis Committee:

Major Professor Christopher Baxter

Aaron Bradshaw

Gopu Potty

Nasser H. Zawia

DEAN OF THE GRADUATE SCHOOL

UNIVERSITY OF RHODE ISLAND

2017 


\section{ABSTRACT}

Ground-penetrating radar (GPR) is increasingly being used in transportation projects to monitor the performance of roadways and bridges and to identify buried structures. The objective of this thesis was to evaluate the use of GPR for the identification of bridge scour and to estimate the depth of shallow rock for geotechnical site investigations. The ability to understand and predict scour at bridges is a requirement for safe, economical foundation design and is important for the development of feasible scour monitoring systems. Accurate assessment of the depth to rock is essential for designing and constructing foundations for buildings and transportation infrastructure. Misinterpretation of the depth to bedrock can dramatically increase construction costs.

GPR surveys were performed at two bridge locations across shallow streams, on land at four shallow rock locations, and at three other test sites in Rhode Island.

During the bridge site tests, the GPR was maneuvered in a small pontoon boat across the water surface from one river side to the other while towed from the bridge deck. The acquired two-dimensional data sets from the shallow streams accurately image the channel bottom, demonstrating that the GPR is an effective and safe tool for measuring or monitoring scour. However, infilled scour features could not be identified due to the presence of cobble armoring layers.

During the tests on land, the GPR was placed on a survey cart and pushed along to create a linear profile. The acquired two-dimensional data sets from the 
shallow rock locations were compared to boring logs and shear wave velocity profiles taken previously at the sites and showed good agreement between the different estimated depths to rock. These results showed that GPR is a useful, cost effective tool for the identification of shallow rock layers. 


\section{ACKNOWLEDGMENT}

The completion of my Master's Thesis and my success studying abroad at the University of Rhode Island would not be possible without the help of my professors, colleagues, and friends.

A very special thanks goes out to Professor Baxter, my Thesis advisor, for his support of me. As an exchange student, everything was new to me and Professor Baxter was always there to provide advice and guidance. He always made sure to share opportunities for extending my education by participating in conferences, trainings, and field trips. Professor Baxter's enthusiasm for geotechnical engineering was contagious and he inspired me to rise to higher standards.

I would like to thank my committee members, Professor Aaron Bradshaw, Professor Gopu Potty, for their advice and guidance through the thesis process. I would like to especially thank Professor Bradshaw for his help with the surveys and his support of me.

There are several others I would like to thank for their help during my surveys. Fatih Karaceik, Kelly Wharton, and Dr. Shilun Feng. Thank you to Robin Freeland for building the research vessel and helping during my surveys. Thank you to Fred Pease for his advice during the surveying.

Special thanks to Rachel Chambers for your support and advice during the thesis, you were always a source of motivation and helped me even on your vacation. 
I would like to thank those in Germany who encouraged and supported my studies in the US. 


\section{Table of Contents}

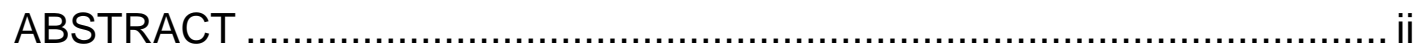

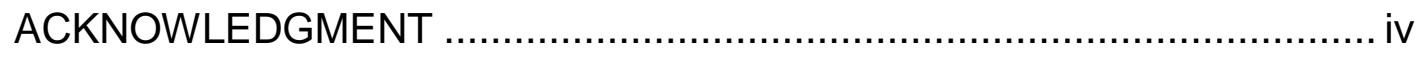

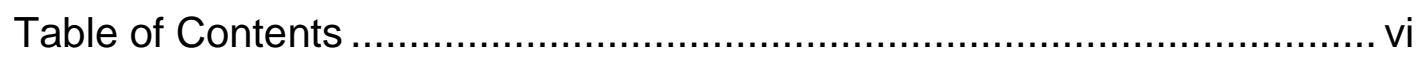

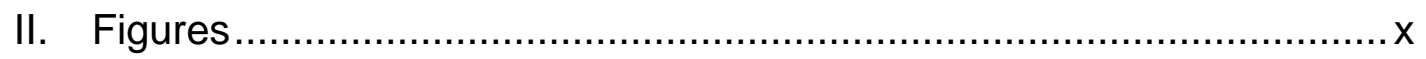

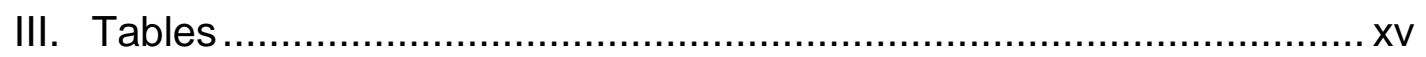

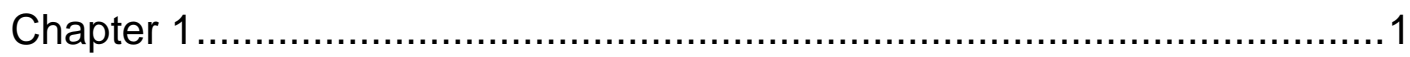

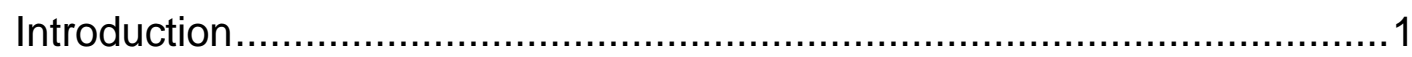

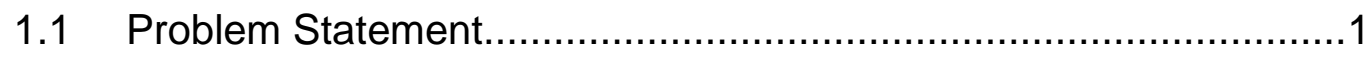

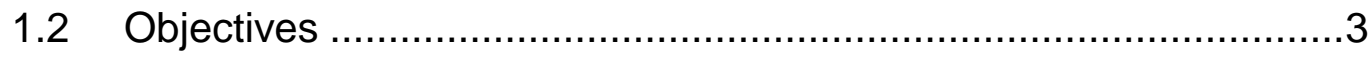

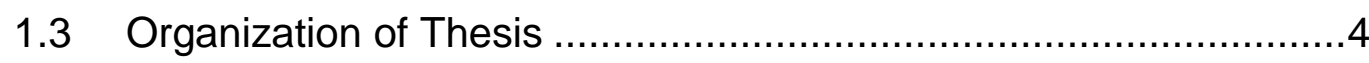

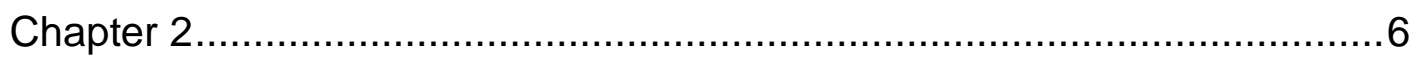

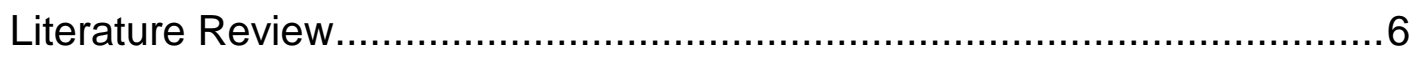

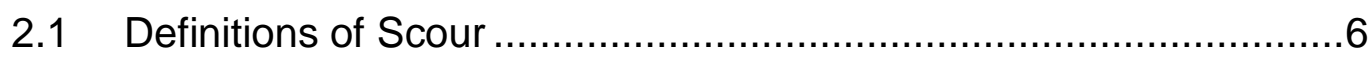

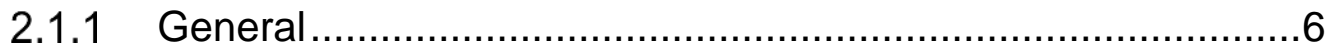

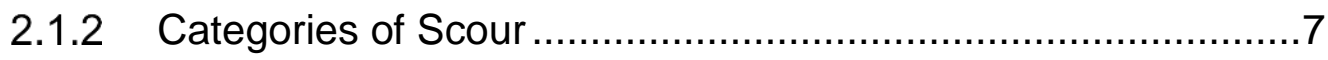

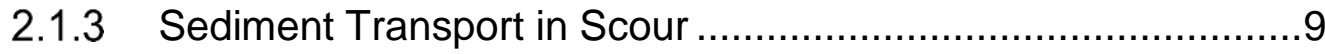

2.2 Introduction to Ground Penetrating Radar.................................10

2.2.1 GPR Setup and Working Principles .................................10 
2.2.2 Electromagnetic Wave Propagation.....................................14

2.2.3 Electrical Properties Affecting Wave Propagation..................16

2.2.4 Reflection and Polarity ......................................................

2.2.5 Penetration Depth and Resolution ....................................18

2.2.6 Advantages and Disadvantages .......................................22

2.2.7 Applications in Civil Engineering ......................................25

2.3 Use of the Ground-Penetrating Radar System for Assessing Bridge Scour 27

2.3.1 Use of a Ground-Penetrating Radar System to Detect Pre- and Post-Flood Scour at Selected Bridge Sites in New Hampshire, 1996-98...27

2.3.2 Use of a GPR System at Ten Bridge sites in Missouri. 29

2.4 Use of the GPR for Geotechnical Site Investigations ...................31

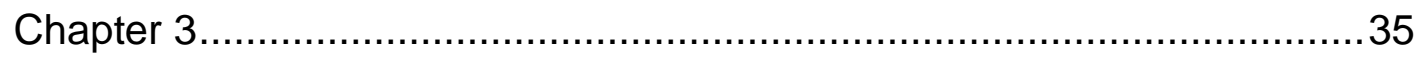

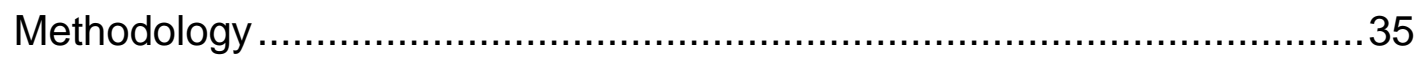

3.1 Equipment Used in this Study ...............................................35

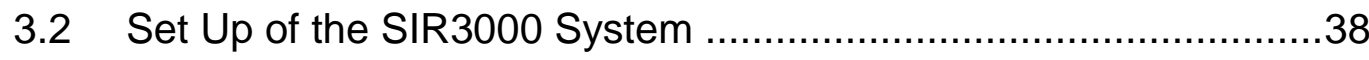

3.3 Data Processing in RADAN 7 ...............................................4

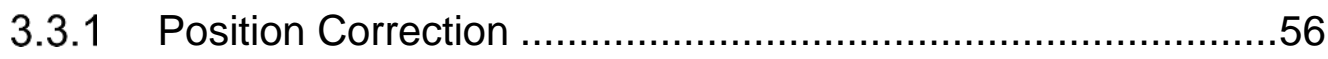

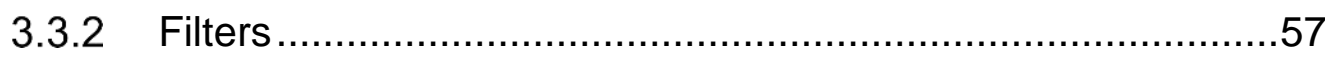

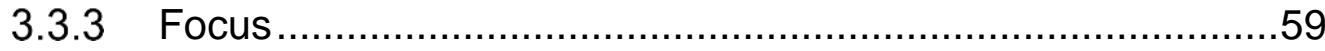


3.3.4 Other Useful Functions

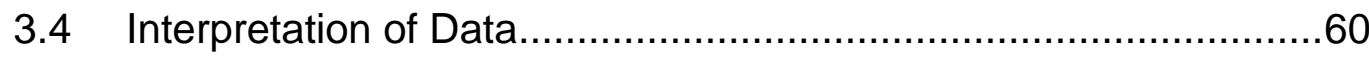

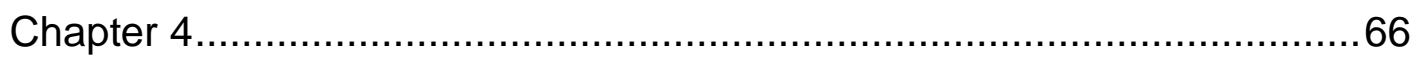

Investigation of GPR in a Controlled Environment..................................66

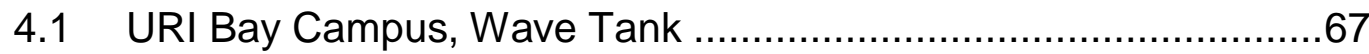

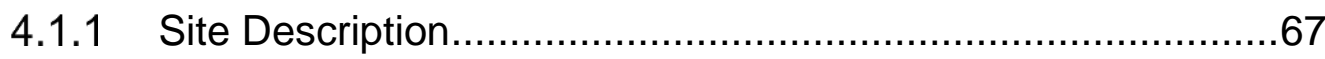

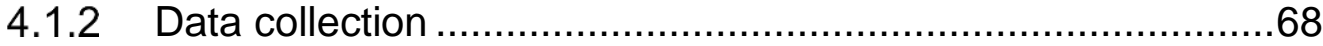

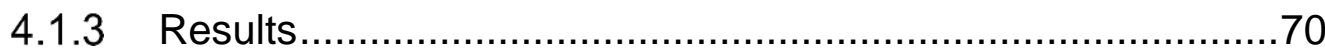

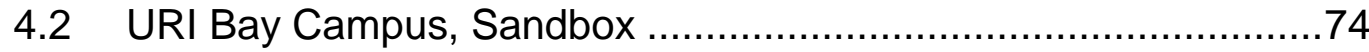

4.2.1 Site Description...........................................................

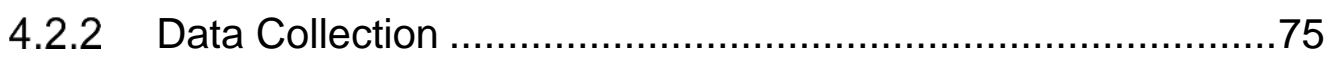

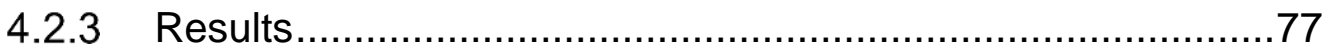

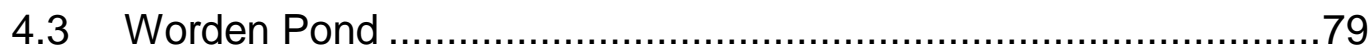

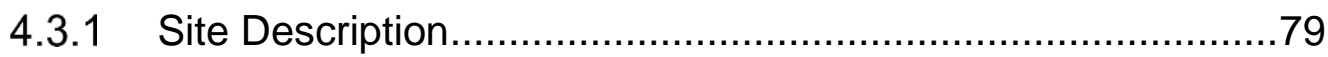

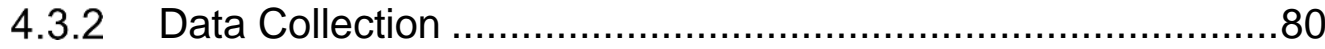

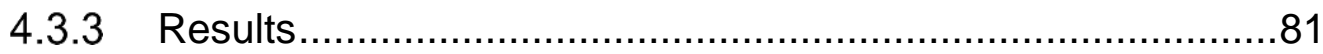

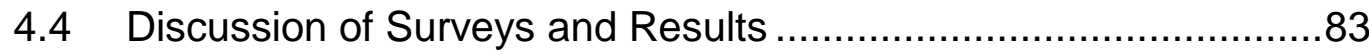

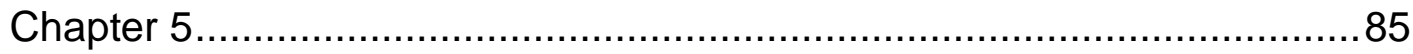

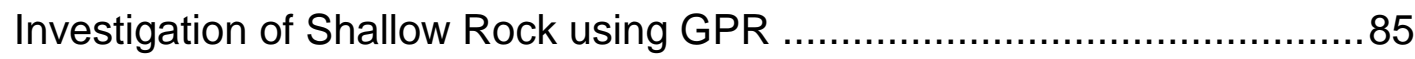




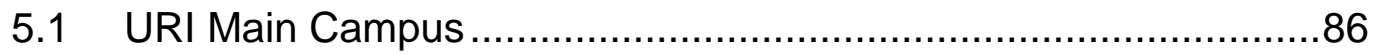

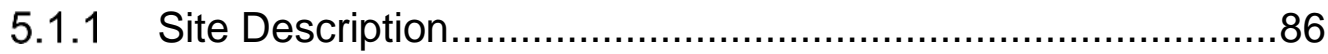

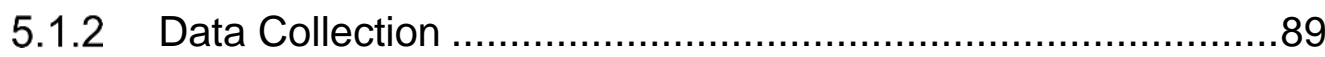

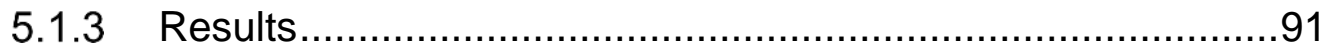

5.2 URI Bay Campus, Middleton Building …..................................93

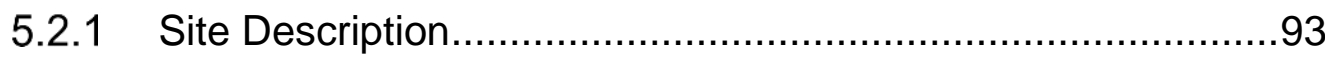

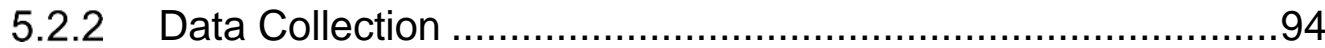

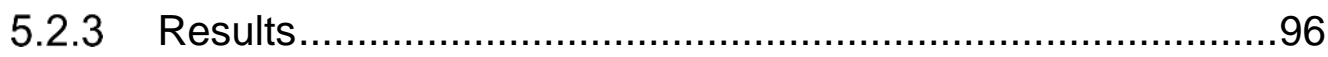

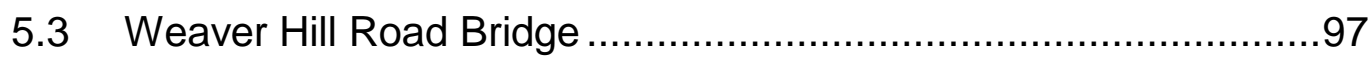

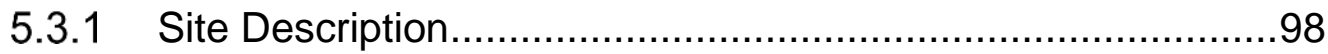

5.3.2 Data Collection .............................................................101

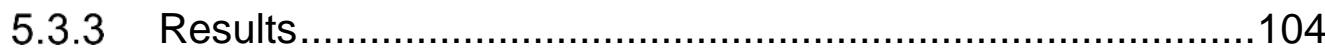

5.4 Baker Pines Road Bridge ..................................................106

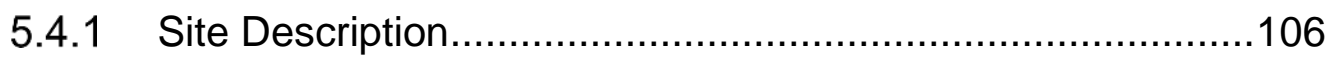

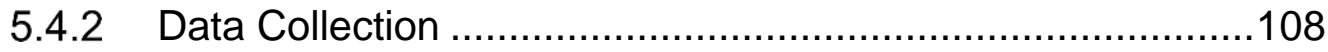

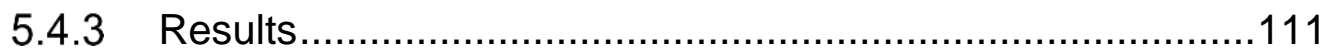

5.5 Discussion of Surveys and Results ......................................113

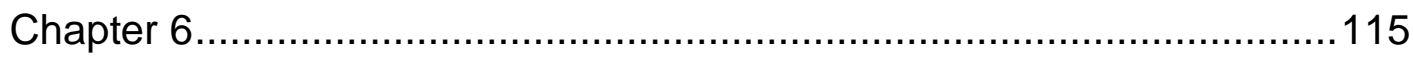

Investigation of Scour at Bridge Sites using GPR …..........................115 
6.1 Kenyons Bridge, Charlestown RI

6.1.1 Site Description.......................................................116

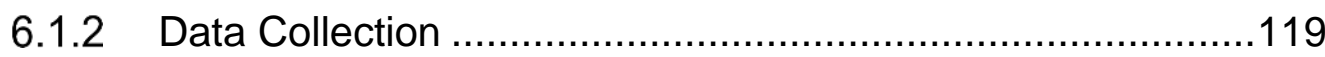

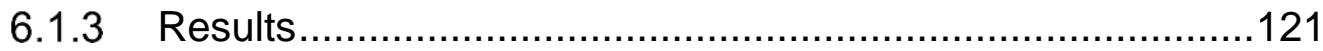

6.2 First Barberville Bridge, Hopkinton, RI ..................................126

6.2.1 Site Description......................................................126

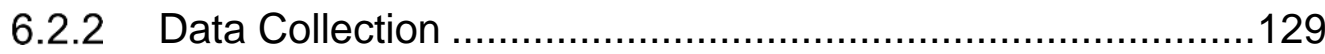

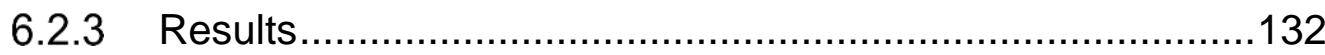

6.3 Discussion of Surveys and Results ......................................136

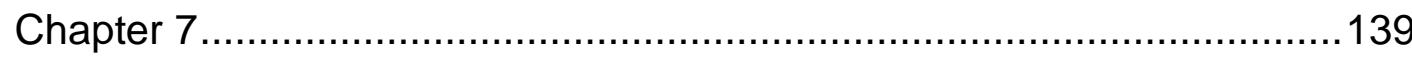

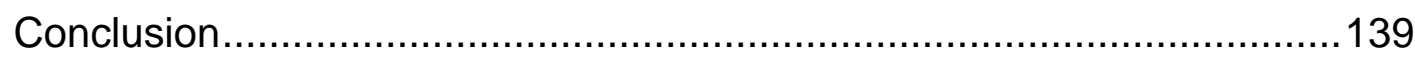

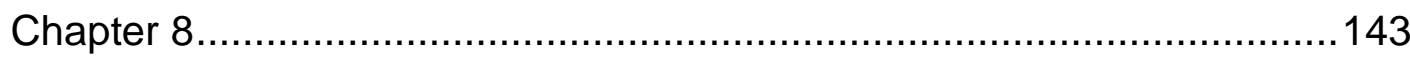

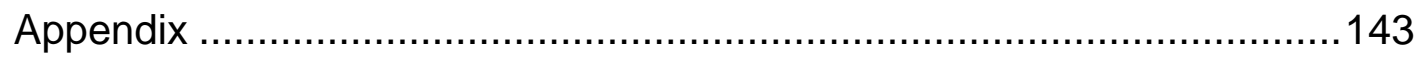

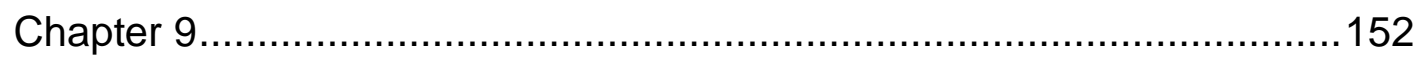

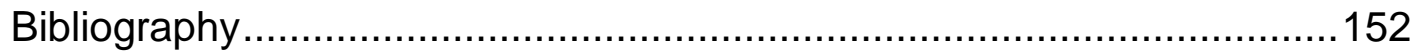

\section{Figures}

Figure 1. Contraction Scour (Anderson, et al., 2007) .................................

Figure 2. Vortex development at a cyclic pier (Arneson, et al., 2012)...............8

Figure 3. Pier Scour Depth as a function of time (Arneson, et al., 2012). ..........9 
Figure 4. Interaction between the single components of the GPR (Persico, 2004). 11

Figure 5. GPR System (double antenna) (Persico, 2004) 12

Figure 6. a) Three antenna positions during a GPR survey b) Same positions displayed in the wiggle mode c) Processed data from one antenna position, and d) photograph of the GPR equipment and survey cart (Møller, 2006). 14

Figure 7. Center Frequency, Depth of Penetration and Typical Applications of GPR Antennas (GSSI, 2016).

Figure 8. Comparison of $100 \mathrm{MHz}$ and $200 \mathrm{MHz}$ antenna (Møller, 2006). 21

Figure 9. Example of a measurement of a road with three selected asphalt layers (Benedetto \& Pajewski, 2015). 25

Figure 10. GPR System on a bridge deck (left) and the results from the measurements (right) (Benedetto \& Pajewski, 2015). 26

Figure 11. A survey van equipped with a GPR System in a tunnel (Benedetto \&

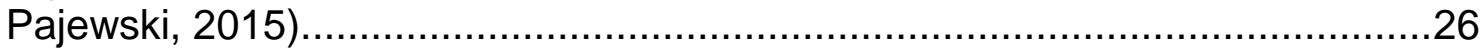

Figure 12. GPR profile of a cross section (Olimpio, 2000)...........................28

Figure 13. GPR profiles at a bridge site either parallel or perpendicular (Webb, et al., 2002). . .30

Figure 14. Processed and interpreted data at one survey location (Anderson, et al., 2007). 31

Figure 15. Ground-Penetrating Radar Suitability Map (USDA, 2009). 33

Figure 16. Comparison of a radar image to the real soil profile (Doolittle, 2009). 34

Figure 17. GPR-System (SIR-3000 and $400 \mathrm{MHZ}$ antenna)........................36

Figure 18. Research Vessel for Bridge Surveys. .............................................

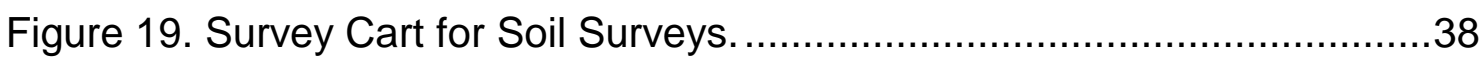

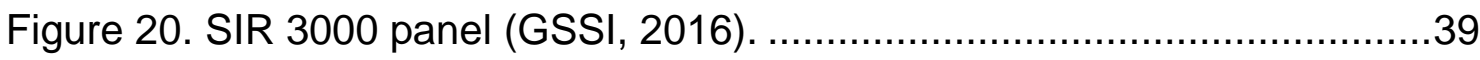

Figure 21. SIR 3000 front panel (GSSI, 2016) .........................................39

Figure. 22 Starting screen on SIR3000 ....................................................40

Figure 23. Starting window in TerraSIRch Mode..............................................41

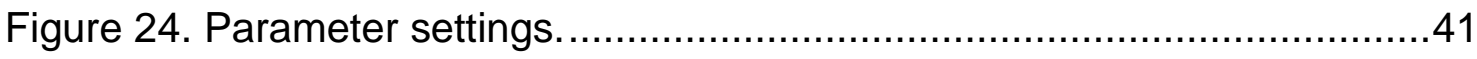

Figure 25. Dielectric value of different materials (GSSI, 2016) ....................43

Figure 26. Illustration of Wave travel time in different materials (GSSI, 2016)..44

Figure 27. Main screen in RADAN 7 (GSSI, 2012)...................................48

Figure 28. Properties Pane. .................................................................. 49 
Figure 29. Structure and Functions Ribbon. ...........................................50

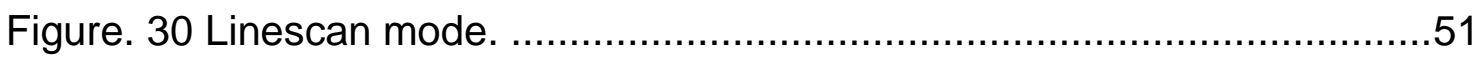

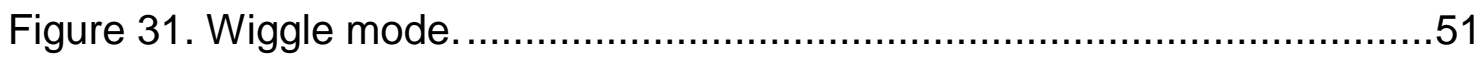

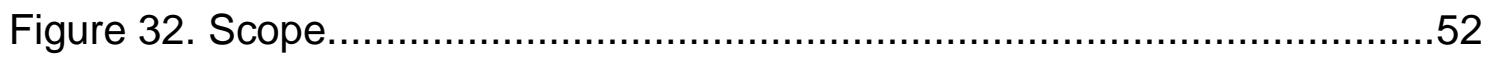

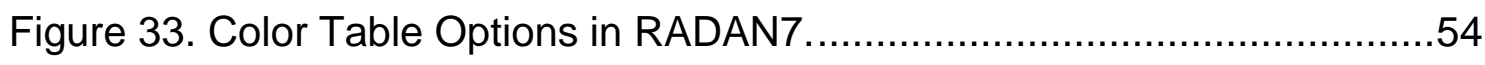

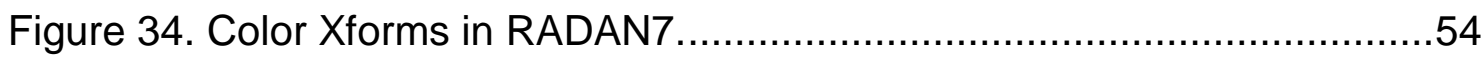

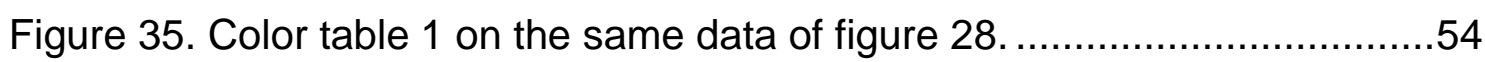

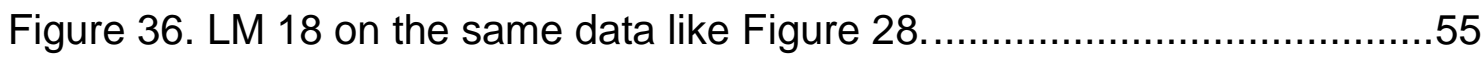

Figure 37. Data before and after time adjusting (GSSI, 2012) ......................56

Figure 38. Time adjusting in the wiggle mode (GSSI, 2012) ........................57

Figure 39. Background removal in RADAN (GSSI, 2012) ............................58

Figure 40. EZ Tracker used to show different soil layers. ..............................60

Figure 41. Example for a point reflector: a buried pipe in soil (Olhoeft, 1999). .62

Figure 42. Example for lateral changes: a new soil layer in GPR data (Banks \&

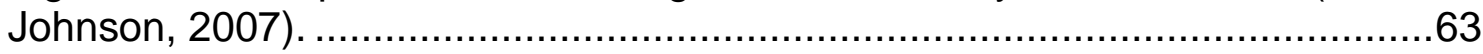

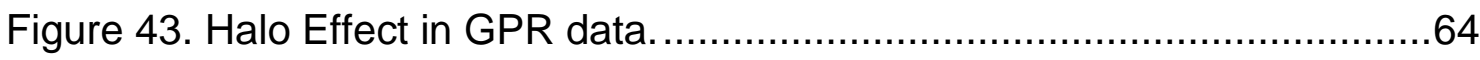

Figure 44. Relation between some radar reflections to soil properties (Milan \&

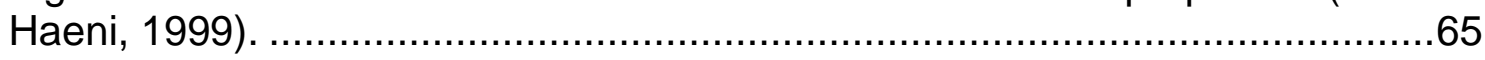

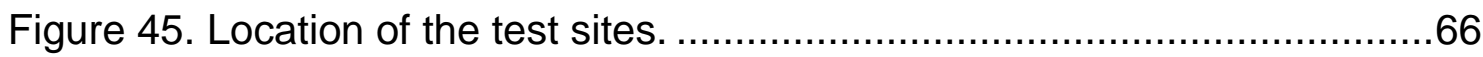

Figure 46. 100 foot-long wave tank at the University of Rhode Island. .............68

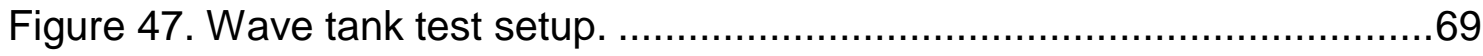

Figure 48. Parameters for wave tank test. ................................................ 70

Figure 49. Unprocessed wave tank data................................................. 71

Figure 50. Wave Tank Data (processed) .................................................. 72

Figure 51. Clipping effect at $0.8 \mathrm{~m}$ depth. ................................................. 74

Figure 52. Layer 1 construction (Parent, et al., 2017) ................................... 75

Figure 53. Layer 1 compaction (Parent, et al., 2017)....................................75

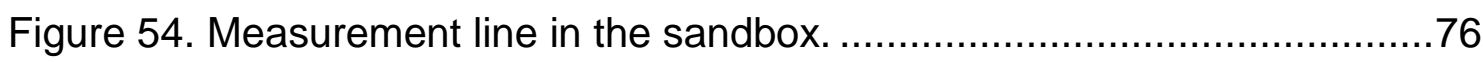

Figure 55. Processed \& Interpreted Sandbox data. ......................................78

Figure 56. Location of the Worden Pond near Wakefield, RI (Google Maps, 2017).

Figure 57. Worden Pond near Wakefield, RI........................................... 79

Figure 58. Test set up at the Worden Pond. ................................................ 80 
Figure 59. Worden Pond with $180 \mathrm{~ns}$ range (processed).

Figure 60. Worden Pond with 180 ns range (interpreted, not whole measurement is shown) 82

Figure 61. Worden Pond with 310 ns range (processed) .............................83

Figure 62. Shallow rock survey locations. 85

Figure 63. GPR suitability map for Massachusetts, Connecticut and Rhode Island (USDA, 2009) 86

Figure 64. Boring Locations at the URI Main Campus. 87

Figure 65. Closest accessible location for the GPR survey (red) and boring location GZ-4 (green).

Figure 66. a) Boring log and b) shear wave velocity profile at URI Main Campus GZ-4 (Wulff, 2016). 89

Figure 67. Measurement Line at URI Main Campus. 90

Figure 68. Measurement Line and Orientation at URI Main Campus (Construction

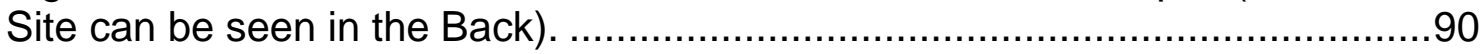

Figure 69. Processed GPR Image at URI Main Campus..............................92

Figure 70. Processed and interpreted GPR Image at URI Main Campus. ........92

Figure 71. Location of the survey: Middleton Building, URI (Google Maps, 2017).

93

Figure 72. Shear wave velocity profile at the Middleton Building, URI (Wulff,

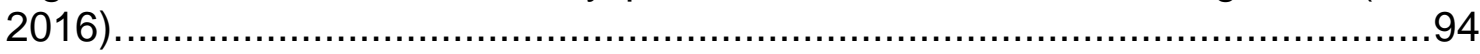

Figure 73. Measurement Line at the URI Bay Campus................................95

Figure 74. Data collection with the help of the survey cart at the Middleton

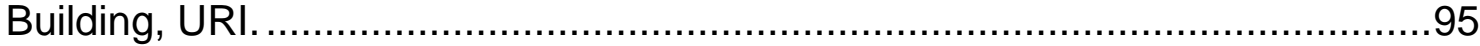

Figure 75. Processed radar image at the Middleton Building, URI..................97

Figure 76. Interpreted radar image at the Middleton Building, URI. ................97

Figure 77. Measurements at Weaver Hill Road Bridge (Google Maps, 2017). .98

Figure 78. Weaver Hill Road Bridge, Test Location 1 ..................................99

Figure 79. Weaver Hill Road Bridge Test Location 2 ..................................99

Figure 80. a) Boring log and b) shear wave velocity profile at location 1 at Weaver

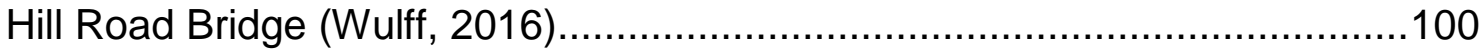

Figure 81. a) Boring log and b) shear wave velocity profile at location 2 at Weaver

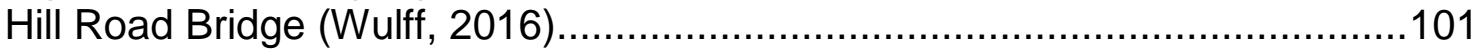

Figure 82. Measurement Lines at Weaver Hill Road Bridge. ........................102

Figure 83. Data Collection at Line 1 Weaver Hill Road Bridge........................103 
Figure 84. Data Collection at Line 2 Weaver Hill Road Bridge......................103

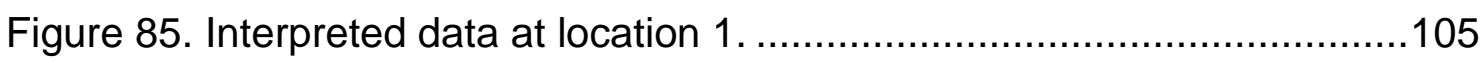

Figure 86. Interpreted data at location 2 ............................................106

Figure 87. Measurement locations at Baker Pines Road Bridge (Google Maps,

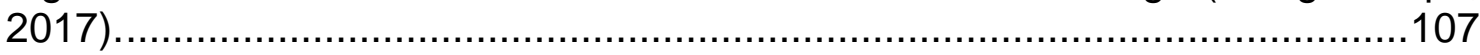

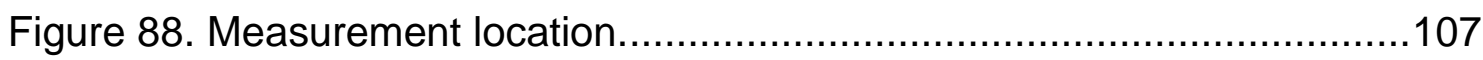

Figure 89. a) Boring log and b) Shear wave velocity profile at location 1 (black) and 2 (red) at Baker Pines Road (Wulff, 2016)......................................108

Figure 90. Measurement Lines at Baker Pines Road Bridge. .......................109

Figure 91. Data collection at Baker Pines Road Bridge. ...............................110

Figure 92. Processed and interpreted data at location 1 .............................112

Figure 93. Processed and interpreted data at location 2 .............................113

Figure 94. Survey Locations of scour critical bridges.................................116

Figure 95. Location of the Kenyons Bridge (Google Maps, 2017) .................117

Figure 96. Kenyons Bridge (Laurent, 2016) ...........................................117

Figure 97. Grain size distribution for Kenyons Bridge, RI (Laurent, 2016).....118

Figure 98. Bottom conditions in the Pawcatuck River downstream the Kenyons

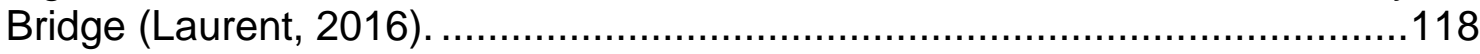

Figure 99. Bathymetric surface at the Kenyons Bridge in $\mathrm{ft}$ (Laurent, 2016)...119

Figure 100. Measurement lines at the Kenyons Bridge. ..............................120

Figure 101. Research Vessel in the Pawcatuck River. .................................121

Figure 102. GPR System operated from the Bridge Deck. ..........................121

Figure 103. Unprocessed data and data Clipping Problem at upstream cross section at Kenyons Bridge. ..............................................................122

Figure 104. Processed Radar Image Downstream at Kenyons Bridge. ..........123

Figure 105. Interpreted Radar Image Downstream (with Migration) at Kenyons

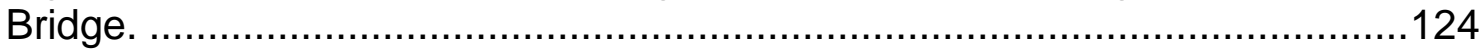

Figure 106. Processed Radar Image Upstream at Kenyons Bridge................125

Figure 107. Processed \& Interpreted Radar Image Upstream at Kenyons Bridge. 125

Figure 108. Location of the First Barberville Bridge, Hopkinton, RI (Google Maps, 2017) 127

Figure 109. First Barberville Bridge (Laurent, 2016) . ................................127

Figure 110. Grain size distribution at First Barberville Bridge (Laurent, 2016). 
Figure 111. Bottom conditions in the Wood River at the First Barberville Bridge (Laurent, 2016). 128

Figure 112. Bathymetric surface data at the First Barberville Bridge in $\mathrm{ft}$ (Laurent, 2016) 129

Figure 113. Measurement lines at the First Barberville Bridge. 130

Figure 114. Data collection at the First Barberville Bridge. 131

Figure 115. SIR3000 operated from the bridge deck. 132

Figure 116. Processed Radar image downstream at First Barberville Bridge. 133 Figure 117. Processed and interpreted radar image downstream at First Barberville Bridge 134

Figure 118. Processed Radar Image Upstream at First Barberville Bridge.....135 Figure 119. Processed and interpreted GPR image upstream at First Barberville Bridge. 135

\section{Tables}

Table 1. Resolution limits [m] for different antenna types [f] and dielectric constants based on $14 \lambda$ (D6432-11, 2011). 20

Table 2. Advantages and disadvantages of the GPR (Anderson, et al., 2007). 24

Table 3. GPR scour data for bridges in New Hampshire (Olimpio, 2000)........29

Table 4. Parameter Overview for the bridge surveys. ....................................46

Table 5. Parameter setup at the sandbox test. ...............................................76

Table 6. Parameter Set Up at the Worden Pond......................................... 81

Table 7. Parameter Set Up at the URI Main Campus. ......................................91

Table 8. Parameter set up at the Middleton Building, URI. ............................95

Table 9. Parameter Setup at Weaver Hill Road Bridge.................................103

Table 10. Parameter Setup at Baker Pines Road Bridge ...............................110

Table 11. Parameter settings at Kenyons Bridge ........................................120

Table 12. Parameter settings at the First Barberville Bridge.........................130 


\section{Chapter 1}

\section{Introduction}

\subsection{Problem Statement}

Ground Penetrating Radar (GPR) is a radar system that utilizes electromagnetic waves to perform non-destructive ground surveys. The main advantage of the GPR is its ability to provide continuous profiles quickly and with little cost. It was invented in 1904 and is now commercialized and used in a variety of applications. The GPR has become an increasingly important tool as its applications range widely in the field of engineering from detecting reinforced rods in concrete to the detection of contaminated soils or leaks in pipes (Bristow \& Jol, 2003). One unusual but unique application of GPR is the measurement of scour, or erosion, in streams and rivers around bridges. Because only a few studies have tested the GPR's ability to measure scour, there is a limited amount of research in this area and a lot of potential benefits if scour could be measured. It would be particularly useful if GPR could be used to measure the thickness of previous scour features that have since been infilled. Since the GPR is often used on land to determine soil features, it should theoretically work in rivers to determine features in a river bed. Use of the GPR for scour measurement would mean more efficient monitoring methods, more accurate scour predictions, and ultimately safer bridges. Another unusual use of the GPR is to identify shallow rock layers. The GPR has the ability to detect soil layers and should be able to 
detect shallow rock layers as well, which will provide important soil property information for engineers.

The incentive to find a new method to measure scour comes from the Federal Highway Administration's (FHWA) requirement that all highway bridges in the United States need a classification stating their vulnerability to scour and erosion. The primary cause of bridge failure in the United States is scour that occurs during flood events. Scour failures are especially dangerous because there are often no warning signs (Lee \& Park, 2004). In the state of Rhode Island alone there are 127 bridges that are currently rated 'scour critical', meaning they require costly monitoring and scour countermeasures. The existing methodologies used to predict scour are based on small-scale laboratory flume experiments. These experiments are highly variable and tend not to consider variables such as cobbles, vegetation, and soil cohesion (Laurent, 2016). The ability to understand, monitor, and predict scour at bridges is a requirement for safe, economical foundation designing and is important for the development of feasible monitoring systems (Anderson, et al., 2015). With such a high number of bridges susceptible to erosion because of scour, there is a need for more accurate methods of assessing and predicting scour. Ground Penetrating Radar may be the key to finding an economical way to analyze scour at bridges. The GPR's ability to see soil layers under water can help identify and measure infilled scour holes, thus changing the way scour is predicted and bridges are rated.

Another interesting use of GPR is for the identification of shallow rock layers. GPR has the ability to detect soil layers and should be able to detect shallow rock 
layers as well. Knowledge of soil and rock properties is essential for designing and constructing foundations and transportation infrastructure. Although rock is an excellent foundation material, if it is located close to the ground surface it often needs to be removed. Geotechnical site investigations are performed to identify problematic foundation materials, however the most common investigation method is drilling bore holes, which is time consuming and is only performed at scattered locations within a site. The stratigraphy of the entire site is then inferred from these borings and a knowledge of the local geology, and areas of shallow rock can be missed. When it comes time to construct, any surprises on the worksite can lead to schedule delays and change orders, causing an increase in the project cost. With the help of the GPR as a non-destructive evaluation technique, areas between borings could be surveyed and used to improve the knowledge of the site conditions

A commercially-available Ground Penetrating Radar system has been provided to the University of Rhode Island by the Rhode Island Department of Transportation. This provides the opportunity to test and evaluate the GPR for both applications described above.

\subsection{Objectives}

The first objective of this thesis is to investigate the use of GroundPenetrating Radar (GPR) for monitoring bridge scour. This thesis will focus on the collection and evaluation of GPR data at two selected bridge sites in Rhode Island that have been identified as 'scour critical'. 
The second objective is to investigate the use of Ground-Penetrating Radar (GPR) for identifying shallow rock. Four locations at which shallow rock exists were used by Wulff (2016) to compare shear wave velocity profiles to boring logs. These sites will be used and surveyed with the GPR to identify shallow rock layers.

As part of this study, investigation of GPR was extended to different survey locations to learn more about the GPR and its working principles and limitations. In addition to surveying bridges and shallow rock sites, the GPR was used on testing sites with a controlled environment with known properties to better understand its advantages and disadvantages.

\subsection{Organization of Thesis}

This thesis is organized to give an overview about the theoretical background of the Ground Penetrating Radar and its general application as well as its application for monitoring bridge scour and identifying shallow rock layers. Chapter Two contains a literature review starting with a brief summary of scour followed by an introduction to the GPR with an overview of the equipment, working principles, limitations, advantages, disadvantages, and different applications within Civil Engineering. At the end of Chapter Two, a review of the literature specific to the applications studied in this thesis is presented.

Chapter Three focuses on the methods used in this thesis to investigate the use of the GPR including details about the equipment and programs. The analysis of the test surveys is presented in Chapter Four, the shallow rock 
surveys are in Chapter Five, and the analysis of the bridge surveys are in Chapter Six. Chapter Seven summarizes the results and makes recommendations for further studies with the GPR. 


\section{Chapter 2}

\section{Literature Review}

To understand how the Ground Penetrating Radar applies to the evaluation of scour, there must first be an understanding of scour and the GPR. This chapter provides a short explanation of basic concepts and definitions related to scour, background material related to GPR, and an overview of the equipment, the working principles, and different applications in Civil Engineering. In addition, examples are provided on how GPR has been used related to bridge scour and soil surveys.

\subsection{Definitions of Scour}

\subsubsection{General}

As flowing water navigates down a river it excavates river bed materials and carries them downstream. This excavation and sediment transport leaves a void in the streambed, and is termed scour (Arneson, et al., 2012). Different streambed materials affect the rates of scour, however the ultimate depth in cohesive or cemented soils can be as deep as in non-cohesive soils. Assessing the amount of scour is extremely difficult for a number of reasons, both in estimating the amount of scour and accurate measurement of the depth of scour. The latter is particularly difficult because scour holes can be refilled with sediment, thus masking the true depth. 


\subsubsection{Categories of Scour}

The total scour rate at bridge sites is a combination of three types of scour: long-term degradation of a river bed, contraction scour, and local scour at the abutments and piers.

Degradation of the river bed can be caused by natural trends as well as human activities such as modifications to the streambed. The long-term degradation of the river bed results in a lowering, or scouring, of the river channel due to the missing sediment supply from upstream. This process occurs over long distances and can change throughout the lifetime of a bridge.

Contraction scour occurs when the flow area of a stream is reduced due to natural contraction or by a bridge (Figure 1) which results in an increase in average velocity to satisfy continuity of flow. A higher velocity results in higher erosive shear stresses on the sediment and this, in turn, means a lowering of the natural bed elevation until there is a new equilibrium. In some circumstances, an equilibrium never occurs and the process never stops. This can be particularly detrimental to a bridge foundation because the depth of the scour can reach the bottom of the pier footings, weakening or even causing the bridge to fail.
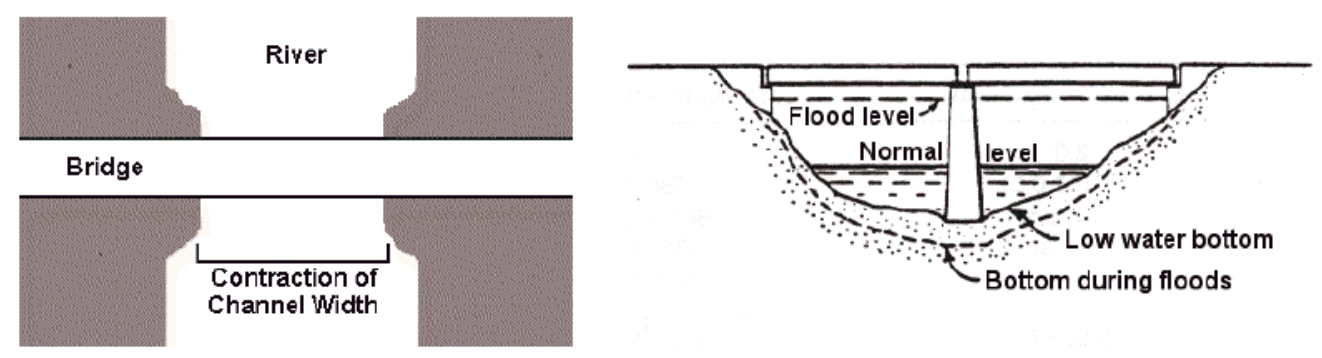

Figure 1. Contraction Scour (Anderson, et al., 2007). 
Local scour occurs when a pier or abutment is disturbing the water flow and vortices develop at their base (Figure 2). The vortex is generated by the pileup of water on the upstream side of the surface and the resultant acceleration of the flow around the structure. As a consequence of this acceleration, bed material is removed from around the base and a scour hole develops. Equilibrium is reached in a live-bed scour situation where the material inflowing equates the material outflowing. For clear-water scour, equilibrium is reached when the shear stress caused by horseshoe vortex is equal to the critical shear stress of the soil at the bottom of the hole. Another effect is the development of vertical vortices, or wake vortices, at the backside of the pier where the loosened material settles down.

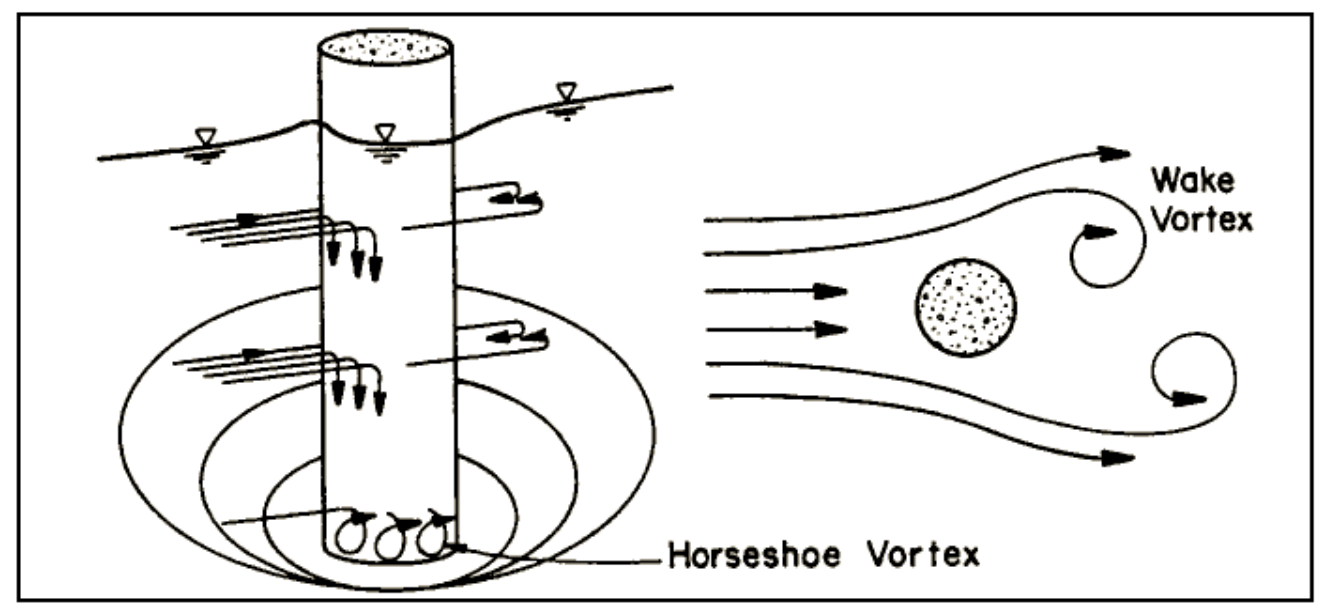

Figure 2. Vortex development at a cyclic pier (Arneson, et al., 2012). 


\subsubsection{Sediment Transport in Scour}

All three categories of scour can happen with or without sediment transport. Clear-water scour is when there is no transport of the bed material or the bed material transported is less than the capacity of the flow. Live-bed scour is when there is a transport of bed material. As the water flows around piers or abutments, it starts to accelerate and moves the materials surrounding the structures. In clear-water scour the scour depth is growing (see Figure 3) because there is no movement of bed material in the flow upstream. In live-bed scour the scour is cyclic which means that the scour holes develop at rising stages and will refill again in falling stages. Live-bed scour reaches the maximum scour depth after a short period of time whereas clear water scour needs several flood events to reach its maximum depth potential.

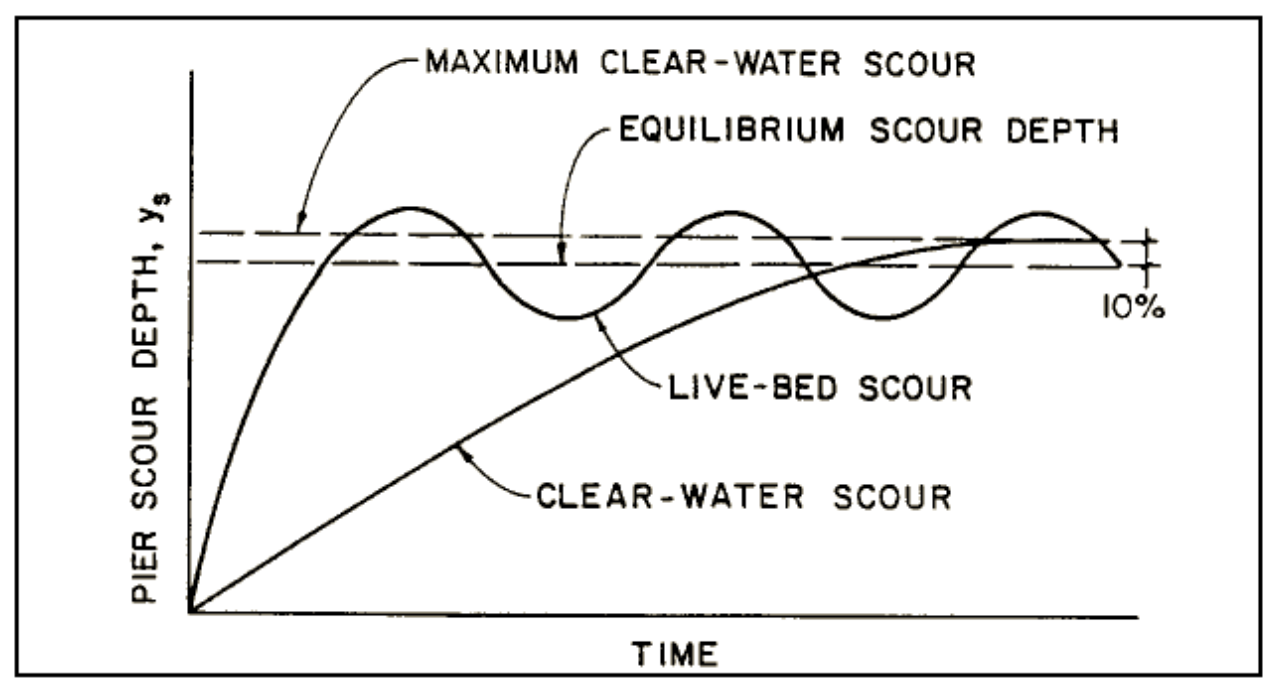

Figure 3. Pier Scour Depth as a function of time (Arneson, et al., 2012). 


\subsection{Introduction to Ground Penetrating Radar}

GPR is a radar which allows the user to look into soils and walls and is often used for geophysical surveying. GPR provides continuous high-resolution images of the streambed profiles and characteristics around bridge structures (Lee \& Park, 2004). GPR dates back to the early 1900s when in 1904 Christian Huelsmeyer of Duesseldorf, Germany invented and patented the "telemobiloscope", a system that used electrical waves to detect subsurface metallic objects. Huelsmeyer's telemobiloscope was originally used by ships to detect other ships when they were not visible. The system Huelsmeyer designed

was based on a continuous wave transmission radar system that was unidirectional, the machine only worked when pointed in the direction of the object, or in other words, the waves transmitted were not conical (Hollmann, 2007). In 1926 Dr. Hulsenbeck of Germany invented the first pulsed radar system, improving the depth resolution of the radar (Twizere, 2011). It is from the Hulsenbeck model that the current GPR is derived from. Today, the GPR is commercialized and is used in a lot of different geophysical fields.

\subsubsection{GPR Setup and Working Principles}

The GPR machine can be divided into four major components. The components are (1) a central unit, (2) a transmitting antenna, (3) a receiving antenna and (4) a computer (Persico, 2004). Figure 4 shows the interaction between the transmitting and receiving antenna of the GPR. An electromagnetic signal, or electromagnetic pulse, is generated by the central unit and emitted into 
the soil through the transmitting antenna. The signal spreads in the soil conically but the electromagnetic waves will be dispersed in all directions if the signal hits an obstacle, which can be a buried object, an interface between two geological layers, a cavity, etc. The dispersion of the signal is dependent on the type of discontinuity, which helps identify the obstacle. Some of the waves will be reflected into the receiving antenna. Most times the transmitting and receiving antenna are combined in one place/device. The reflected signal is shown on a computer screen and stored on the computer or a portable storage.

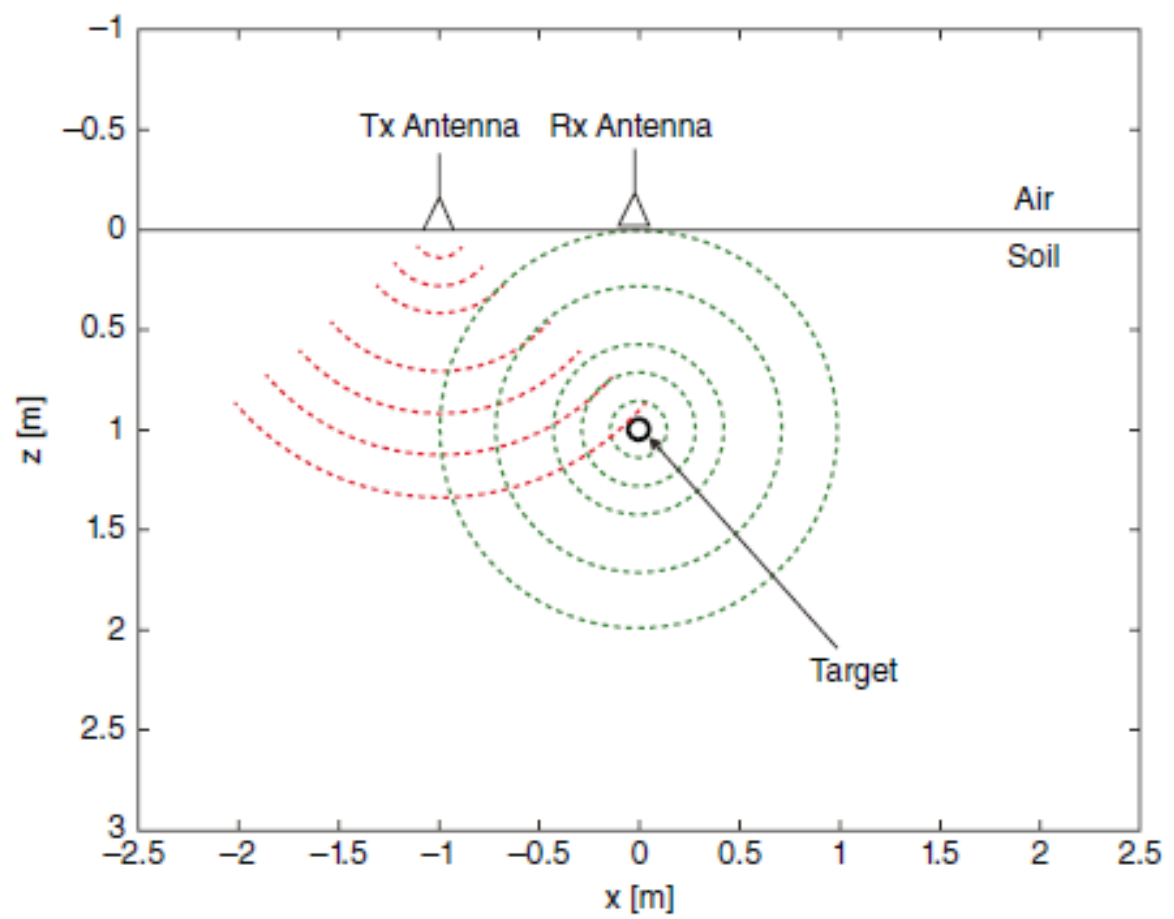

Figure 4. Interaction between the single components of the GPR (Persico, 2004).

Figure 5 shows the typical setup and main components of a GPR System. The cart is optional but very useful for most applications. The GPR in the picture uses 
an odometer that stores the distances for the measured data which is important because the GPR is moved by a human operator and is consequently not moved with a constant velocity. In cases where it is impossible to use the odometer such as the usage of the radar on a water surface or usage of the car on a sandy soil, it is necessary to mark the planned line in segments. In these cases the velocity can be constant only in those segments and does not require a constant velocity along the entire distance. Furthermore, modern GPR Systems often use a GPS that provides a geo-reference for each point.

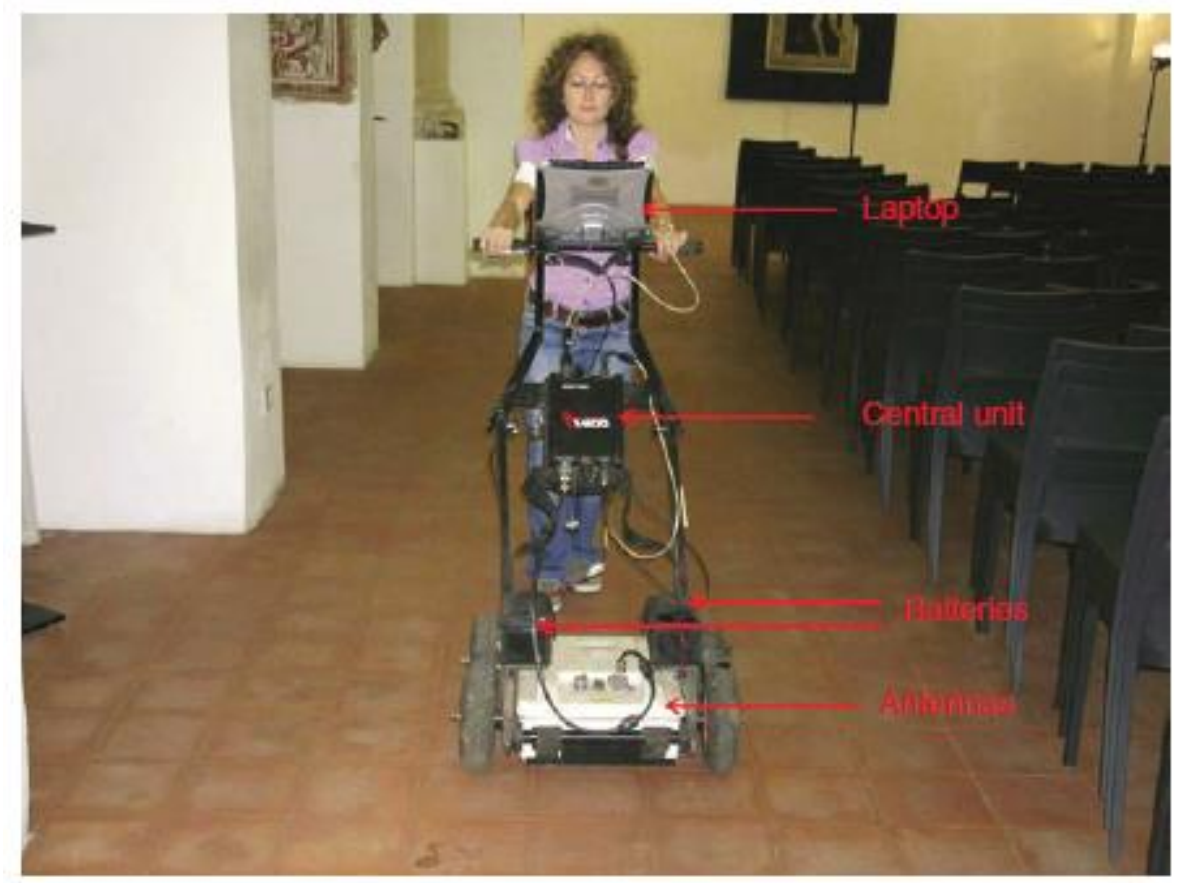

Figure 5. GPR System (double antenna) (Persico, 2004).

The operating principle of the GPR is similar to a conventional radar, however there are some important differences. The GPR works with static targets and the interpretation is usually performed in post processing as opposed to real time. 
Furthermore, the GPR operates in the ground which is more complicated than air due to heterogeneous, anisotropic, and/or magnetic soils.

There are different types of antennas with a range of frequencies available and the required band of frequencies depends on the application. Lower frequency antennas better penetrate structures but at the same time provide less resolution of features in comparison to high frequency antennas. If the application needs a survey with depths $5-7 \mathrm{~m}$ or more, a low frequency antenna, below 200 $\mathrm{MHz}$, is required. Consequently, mid-range radio frequencies, $200-700 \mathrm{MHz}$, can reach a depth of $3 \mathrm{~m}$, and higher radio frequencies, $700-3000 \mathrm{MHz}$, provide a maximum depth of $1 \mathrm{~m}$.

The mode used for the surveys described in this thesis is called reflection profiling d (Møller, 2006). In reflection profiling the antenna is moved along a profile (Figure $6 d$ ) at a fixed time or in a distance interval while the signal can be seen on the monitor (SIR3000). The data is collected in single profiles to obtain 2D information as shown in Figure 6c. Figure 6a shows three different example antenna positions which are obtained from the data in Figure 6c. The signal of these single measurements is shown in the wiggle mode (single radar wave) in Figure $6 b$. 

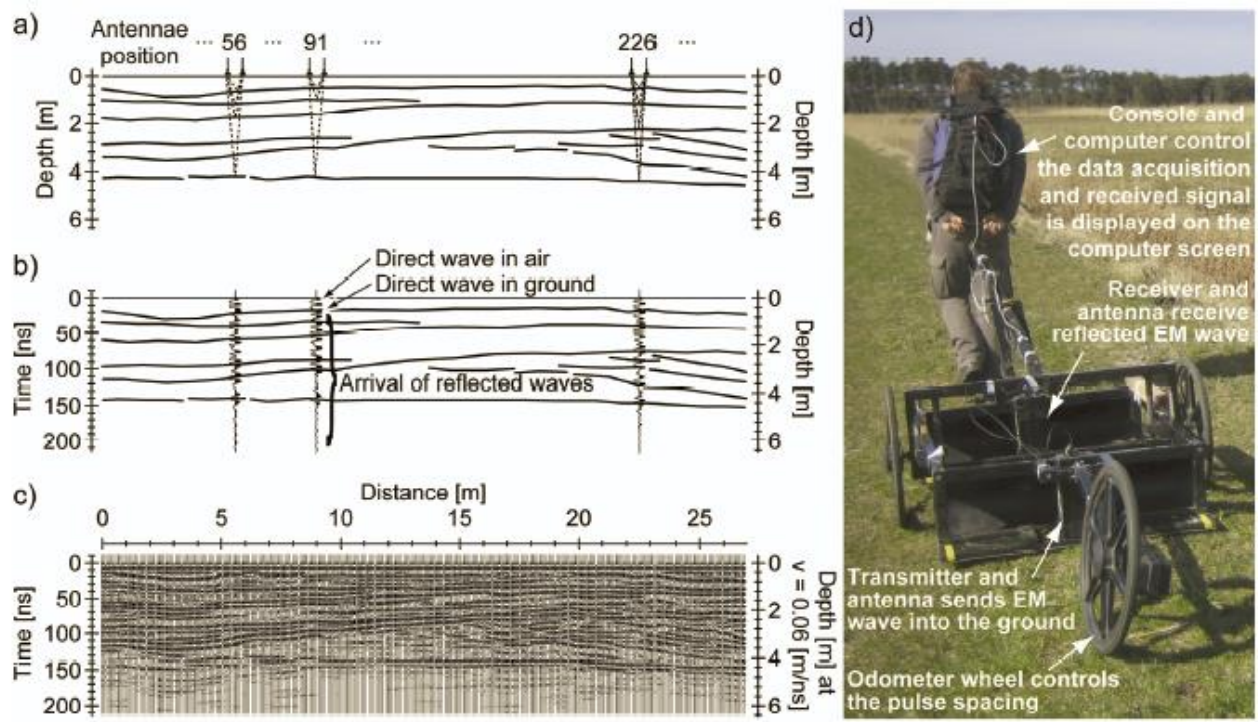

Figure 6. a) Three antenna positions during a GPR survey b) Same positions displayed in the wiggle mode c) Processed data from one antenna position, and d) photograph of the GPR equipment and survey cart (Møller, 2006).

\subsubsection{Electromagnetic Wave Propagation}

As an electromagnetic wave travels through soil, abrupt changes in the dielectric constant cause reflections of the wave, which are recorded by the receiving antenna as amplitude and polarity versus two-way travel time (Møller, 2006).The speed of an electromagnetic wave, $v$, in a medium can be expressed

as.

$$
v=\frac{c}{\sqrt{\varepsilon_{r} \mu_{r} \frac{1+\sqrt{1+(\sigma / \omega \epsilon)^{2}}}{2}}}
$$


where:

$$
\begin{aligned}
& \varepsilon_{r}=\text { dielectric permittivity } \\
& \mu_{r}=\text { relative magnetic permeability } \\
& \sigma=\text { electrical conductivity } \\
& c=\text { electromagnetic wave velocity in vacuum } \\
& =(0.3 \mathrm{~m} / \mathrm{ns}) \\
& \epsilon=\text { dielectric permitivity }=\varepsilon_{r} \varepsilon_{0} \\
& \varepsilon_{0}=\text { dielectric permitivity in free space } \\
& =\left(8.854 * 10^{12} \mathrm{~F} / \mathrm{m}\right) \\
& \omega=\text { angular frequency }=2 \pi f
\end{aligned}
$$

In clean, non-magnetic $\left(\mu_{r}=1\right)$ materials with low loss like (e.g. sand) the loss factor $(\sigma / \omega \epsilon)$ is equal to zero and equation 1 can be expressed as:

$$
v=\frac{c}{\sqrt{\varepsilon_{r}}}
$$

Both equations show that the velocity of the wave in soil will be decreased, with a factor of nine decrease in soil relative to air. This decrease is due to attenuation, spherical spreading of the energy, reflection/transmission losses at the interface and scattering of energy. Scattering is caused by objects which have a dimension similar to the wavelength. This is often the case by using high 
frequency waves. The most important factor is the attenuation, $\alpha$, which is calculated by

$$
\alpha=\omega \sqrt{\varepsilon \mu \frac{\sqrt{1+(\sigma / \omega \epsilon)^{2}}-1}{2}}
$$

In low loss materials the loss factor is again equal to zero and the equation can be reduced to:

$$
\alpha=\frac{\sigma}{2} \sqrt{\frac{\mu}{\varepsilon}}
$$

It can be seen that the attenuation is proportional to the electrical conductivity, which means a high attenuation for materials with a high electrical conductivity.

\subsubsection{Electrical Properties Affecting Wave Propagation}

Wave propagation in a material is significantly affected by the dielectric value (relative permittivity) and the electrical conductivity of a material. The dielectric value is a permittivity ratio that characterizes a material's ability to hold electrical charge for a long period of time (Rouse, 2015). Permittivity is expressed in Farads/Meter, or in other words measures capacitance over a unit length. The number representing a dielectric constant is a simplification of the actual permittivity of a material. The dielectric number is the ratio of the permittivity of a material to the permittivity of a vacuum. Water, for example, has a dielectric value of 81 . This means that the ratio of the permittivity of water compared to the 
permittivity of a vacuum is $81: 1$. Permittivity can be quantified as a material's ability to concentrate electric flux, or a material's ability to hold charge inside the given area of that material (N.N., 2017). This can increase or decrease in density depending on the material and the temperature. Materials with a higher magnetic flux density, such as metals, can hold large electrical charges for long periods of time, thus making them impenetrable to electromagnetic waves. High dielectric materials are impenetrable because the electrostatic energy in the electromagnetic waves is stored within the material and cannot pass through it, limiting the depth that the waves travel. Materials with low dielectrics, such as air, cannot store electrostatic energy as well and the waves that were not stored can pass through to reveal what is underneath. The dielectric value of a material is an important factor and limitation for the penetration depth in soils.

The electrical conductivity of a material is determined by the ability of free charges to move in the medium. Charges are moved by external electric fields and the more free charges, ions, and electrons in a medium can be moved, the higher the conductivity of a material. A high conductivity means a high attenuation of the GPR waves and less depth penetration.

\subsubsection{Reflection and Polarity}

The reflection coefficient of a GPR signal propagating from one medium to another can be calculated with (Ullberg, 2011). 


$$
R=\frac{\sqrt{\varepsilon_{1}}-\sqrt{\varepsilon_{2}}}{\sqrt{\varepsilon_{1}}+\sqrt{\varepsilon_{2}}}
$$

where:

$$
\begin{aligned}
& \varepsilon_{1}=\text { dielectric value medium } 1 \\
& \varepsilon_{2}=\text { dielectric value medium } 2
\end{aligned}
$$

According to equation 5 the polarity of a reflection changes if the dielectric value $\varepsilon_{1}$ is smaller than $\varepsilon_{2}$. In case $\varepsilon_{1}$ is higher than $\varepsilon_{2}$ the polarity remains the same as it was at the interface. The polarity is defined as positive when $\epsilon_{\text {upper }}<$ $\epsilon_{\text {lower }}$, meaning the radar wave slows down due to the higher electric value. When $\epsilon_{\text {upper }}>\epsilon_{\text {lower }}$ the wave speed increases due to a lower dielectric value and the polarity is called negative. Changes in polarity are shown as layering in a GPR image and are used for interpretation of GPR data.

\subsubsection{Penetration Depth and Resolution}

The penetration depth depends on three factors: the center frequency, the electrical conductivity, and the attenuation of the surveyed material (Møller, 2006). In general, a low center frequency leads to a high penetration depth whereas a high center frequency leads to a low penetration depth. Figure 7 shows typical penetration depths of different GPR antennas and their applications. 


\begin{tabular}{|c|c|c|}
\hline Center Frequency & Depth of Penetration* & Typical Applications \\
\hline $2600 \mathrm{MHz}$ & to $0.4 \mathrm{~m}(12 \mathrm{in})$ & Concrete Evaluation \\
\hline $2000 \mathrm{MHz}$ Palm & to $0.4 \mathrm{~m}(12 \mathrm{in})$ & Concrete Evaluation \\
\hline $1600 \mathrm{MHz}$ & to $0.5 \mathrm{~m}(18 \mathrm{in})$ & Concrete Evaluation \\
\hline $900 \mathrm{MHz}$ & $0-1 \mathrm{~m}(0-3 \mathrm{ft})$ & Concrete Evaluation, Void Detection \\
\hline $400 \mathrm{MHz}$ & $0-4 \mathrm{~m}(0-12 \mathrm{ft})$ & $\begin{array}{l}\text { Utility, Engineering, Environmental, } \\
\text { Void Detection }\end{array}$ \\
\hline $270 \mathrm{MHz}$ & $0-6 \mathrm{~m}(0-18 \mathrm{ft})$ & Utility, Engineering, Geotechnical \\
\hline $200 \mathrm{MHz}$ & $0-9 \mathrm{~m}(0-30 \mathrm{ft})$ & Geotechnical, Engineering, Enwironmental \\
\hline \multicolumn{3}{|l|}{ International } \\
\hline $100 \mathrm{MHz}$ & $2-15 \mathrm{~m}(5-50 \mathrm{ft})$ & Geotechnical, Engineering, Mining \\
\hline $16-80 \mathrm{MHz}$ & $0-50 \mathrm{~m}(0-150 \mathrm{ft})$ & Geotechnical \\
\hline
\end{tabular}

Figure 7. Center Frequency, Depth of Penetration and Typical Applications of GPR Antennas (GSSI, 2016).

The vertical resolution can be calculated and depends on the propagating electromagnetic wavelength, $\lambda$. The wavelength can be calculated by using the equation $\lambda=\frac{v}{f}$ where $\mathrm{f}$ is the center frequency of the GPR in $\mathrm{GHz}$ and $\mathrm{v}$ is the velocity of the ground material (Møller, 2006). The theoretical distance between two reflectors is equal to $1 / 4-1 / 2$ of the wavelength but in real applications it should be $1 / 2$ - 1 . Using a $400 \mathrm{MHz}$ antenna, the resolution would be $0.19 \mathrm{~m}$ in dry sand $(v=0.15 \mathrm{~m} / \mathrm{ns})$ and $0.075 \mathrm{~m}$ in a saturated sand $(\mathrm{v}=0.06 \mathrm{~m} / \mathrm{ns})$. An overview of resolutions for various antenna frequencies and different dielectric constants is shown in Table 1. 
Table 1. Resolution limits [m] for different antenna types [f] and dielectric constants based on $1 / 4 \lambda(D 6432-11,2011)$.

\begin{tabular}{lcccccc}
\hline $\begin{array}{l}\varepsilon_{r} \\
f\end{array}$ & 1 & 5 & 10 & 15 & 25 & 80 \\
\hline $25 \mathrm{MHz}$ & 3.00 & 1.34 & 0.95 & .0 .77 & 0.60 & 0.34 \\
$50 \mathrm{MHz}$ & 1.50 & 0.67 & 0.47 & 0.39 & 0.30 & 0.17 \\
$80 \mathrm{MHz}$ & 0.94 & 0.42 & 0.30 & 0.24 & 0.19 & 0.10 \\
$100 \mathrm{MHz}$ & 0.75 & 0.34 & 0.24 & 0.19 & 0.15 & 0.08 \\
$200 \mathrm{MHz}$ & 0.38 & 0.17 & 0.12 & 0.10 & 0.08 & 0.04 \\
$300 \mathrm{MHz}$ & 0.25 & 0.11 & 0.08 & 0.06 & 0.05 & 0.03 \\
$500 \mathrm{MHz}$ & 0.15 & 0.07 & 0.05 & 0.04 & 0.03 & 0.02 \\
$900 \mathrm{MHz}$ & 0.08 & 0.04 & 0.03 & 0.02 & 0.02 & 0.01 \\
\hline
\end{tabular}

The lateral resolution depends on three factors: the antenna frequency, the rate at which scans are recorded, and the movement speed of the antenna in lateral direction (D6432-11, 2011).

Figure 8 shows a comparison of a $100 \mathrm{MHz}$ and a $200 \mathrm{MHz}$ antenna at the same location with the same soil properties. The $200 \mathrm{MHz}$ antenna has better resolution in comparison to the $100 \mathrm{MHz}$ antenna but the penetration depth is smaller. 

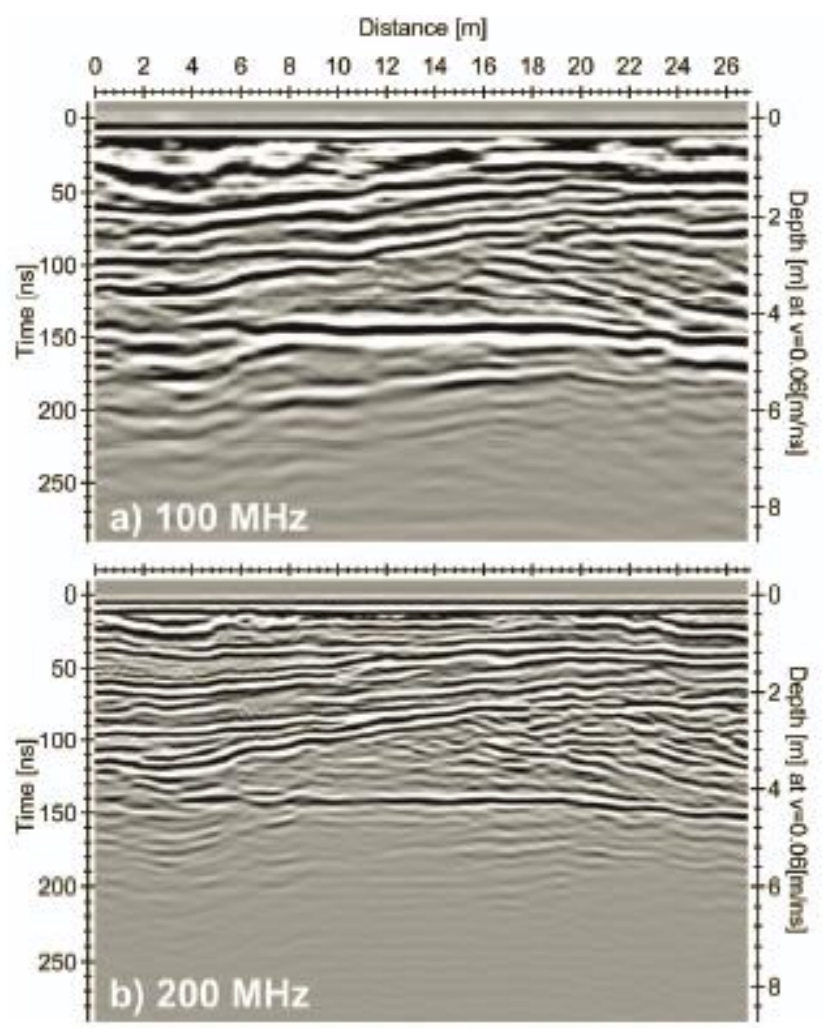

Figure 8. Comparison of $100 \mathrm{MHz}$ and $200 \mathrm{MHz}$ antenna (Møller, 2006).

Limitations in the depth of penetration and resolution of GPR stem from the effects of attenuation, electrical conductivity, and central frequency. Attenuation of the radar signal is due to losses in electrical conduction, dielectric relaxation, and magnetic relaxation, all of which are caused by the conversion of electromagnetic energy into thermal energy (D6432-11, 2011). The conductivity of a material is primarily determined by the water content and concentration of free ions in the solution. For this reason the GPR does not work in a saline environment (high conductivity). Attenuation can also be caused by heterogeneous soils which scatter the EM energy in other directions. 
When looking at geological factors in GPR data the existence of significant property contrasts between different soil layers and buried objects is a critical aspect. Equation (5) shows an approach to calculate the power reflectivity to determine if there is a significant contrast between two materials (D6432-11, 2011).

$$
P_{r}=\left(\left(\sqrt{\left.\varepsilon_{r} \text { Host }-\varepsilon_{r} \text { Target }\right)} /\left(\sqrt{\left.\varepsilon_{r} \text { Host }+\varepsilon_{r} \text { Target }\right)}\right)^{2}\right.\right.
$$

where:

$$
\varepsilon_{r}=\text { relative permittivity }
$$

To see a target/layer in the soil, the power reflectivity should be at least 0.01 . Furthermore, the ratio of the target depth to the smallest lateral target cannot be higher than 10:1.

\subsubsection{Advantages and Disadvantages}

The GPR has both significant advantages and disadvantages in comparison with other devices. The GPR has a wide-spread and successful application in the civil engineering field due to its strength as a radar (Benedetto \& Pajewski, 2015). In comparison to traditional methods, the surveys have notable lower costs due to time efficiency and the GPR has a high-speed data acquisition as well as a high reliability of measurements. Furthermore, the GPR provides a higher resolution compared to other geophysical technologies such as seismic, transient electromagnetic, electrical and magnetic approaches. 
An accurate depth-structure model of the channel bottom can be provided by a GPR equipped with a $200 \mathrm{MHz}$ antenna to depth till $10 \mathrm{~m}$ (Anderson, et al., 2007). During the selected/measured route a continuous image of the streamchannel and sub-channel bottom is given. During a survey on the water surface, the antennae can be moved rapidly and does not need a physical connection to the surface. Furthermore the antenna can be controlled remotely so that use during flood events is possible without any proximity risk to the operator. Another advantage is that the resulting profiles can be extended on sand bars.

The main limitations of the GPR involve noises from multiple resources like reflections and echoes from pier footings because they can influence and contaminate the data. Areas with significant structural relief can require postacquisition processing, which is available with the GPR. In addition, the GPR does not work in saline waters or clayey environments.

A summary of advantages and disadvantages is shown in Table 2. 
Table 2. Advantages and disadvantages of the GPR (Anderson, et al., 2007).

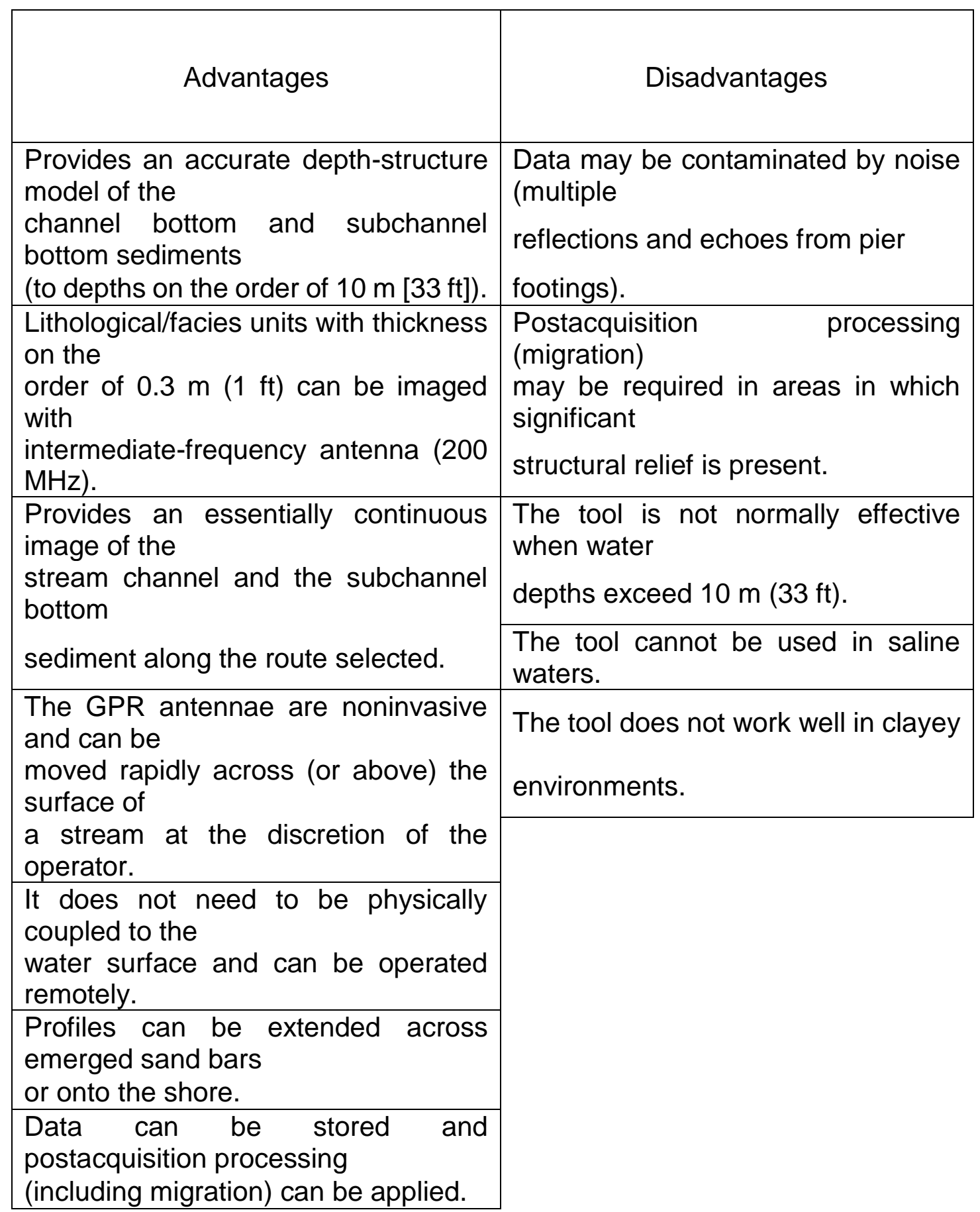




\subsubsection{Applications in Civil Engineering}

The GPR System is well established in the field of Civil Engineering and is used for several applications such as geotechnical investigations, detection of voids, locating steel reinforcement in concrete, environmental, and hydrogeological surveys (Benedetto \& Pajewski, 2015). This section will provide a short overview of the most common applications in the transportation infrastructures.

In the area of highway engineering the GPR System is used on all types of pavements (asphalt layers, concrete layers etc.) and provides information on the layer thickness (see Figure 9) and is used for localizing subsurface reinforcement.

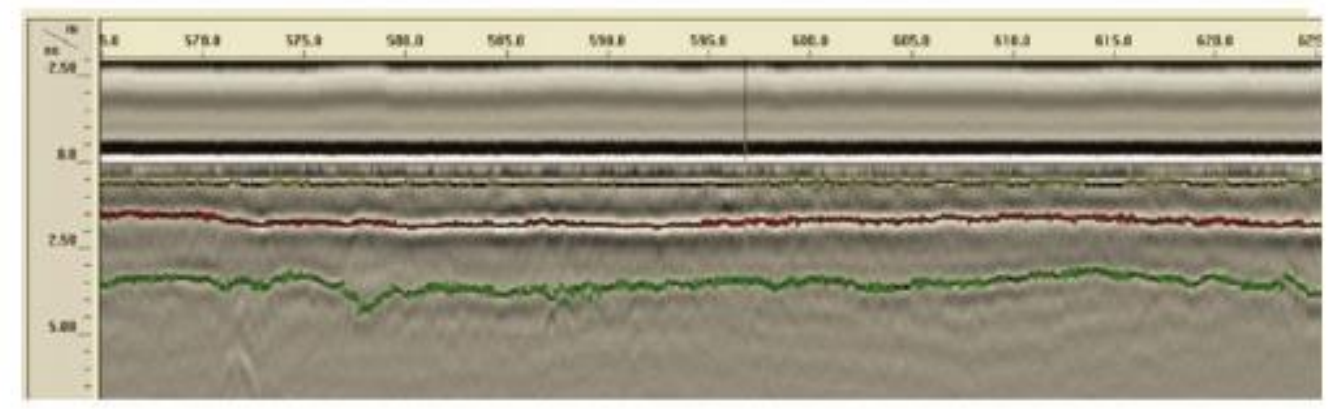

Figure 9. Example of a measurement of a road with three selected asphalt layers (black, red and green line) (Benedetto \& Pajewski, 2015).

The GPR is used on bridges in case of identified problems, such as cracks and rebar erosion, after a visual inspection. The main applications on bridges are evaluating the condition of a bridge and locating reinforcement such as constructions bars and tendons (see Figure 10). 

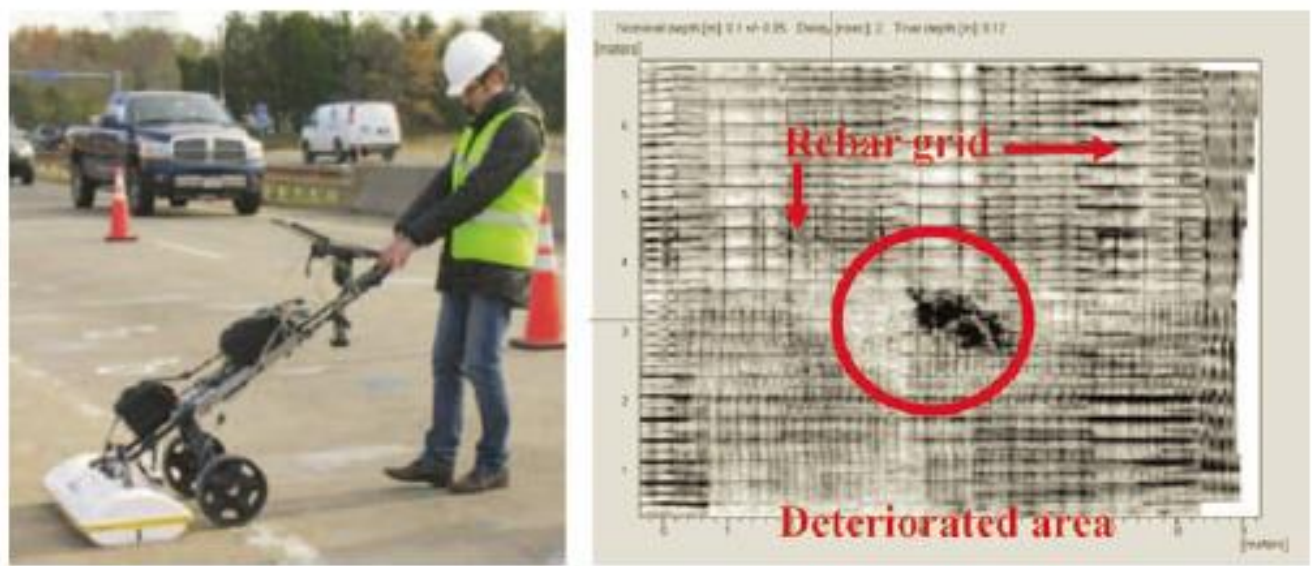

Figure 10. GPR System on a bridge deck (left) and the results from the measurements (right) (Benedetto \& Pajewski, 2015).

Another area of application shown in Figure 11 is tunnel diagnostics where different types of linings can be measured and surveyed. The results help to determine the thickness and condition of the tunnel lining.

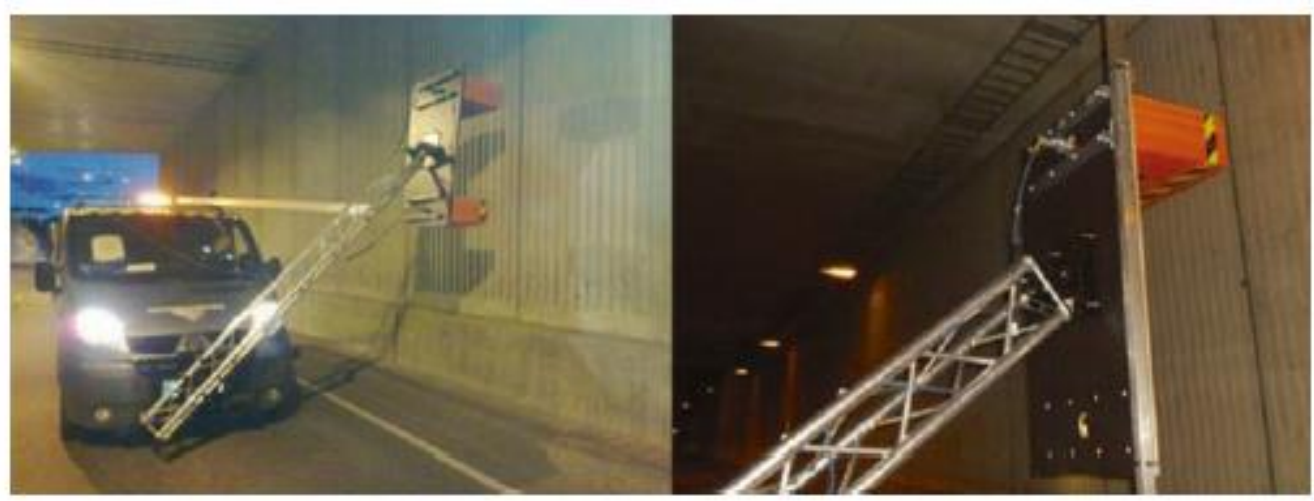

Figure 11. A survey van equipped with a GPR System in a tunnel (Benedetto \& Pajewski, 2015). 


\subsection{Use of the Ground-Penetrating Radar System for Assessing Bridge Scour}

This section presents some projects and studies in which the GPR was successfully to monitor bridge scour.

\subsubsection{Use of a Ground-Penetrating Radar System to Detect Pre- and Post- Flood Scour at Selected Bridge Sites in New Hampshire, 1996-98}

The New Hampshire Department of Transportation (NHDOT) completed a scour assessment of 48 bridges across the state which had signs of scour in 1993 (Olimpio, 2000). Of those bridges, 44 were rated as scour critical, requiring evaluation and monitoring to ensure public safety.

The GPR used for the survey was equipped with a $300 \mathrm{MHz}$-centerfrequency monostatic transmitting and receiving antenna. Lithologic logs and bridge construction plans were used to improve the interpretation of the GPR profiles. The system was placed in a small inflatable boat and it was equipped with a stable platform that had minimal effect on the radar-signal transmission and reception. During the measurements the operator either sat in the boat in deep water or pulled the boat by hand in shallow water.

GPR profiles were collected upstream and downstream from the left to the right bank of the river, directly beneath leading and trailing edges of the bridge. Profiles were also collected parallel to the axis of the river, and up to 20 to $40 \mathrm{ft}$ upstream and downstream of the nose of the pier. Detected scour holes or channels, boulders, and streambeds were then measured directly with a 
surveying rod. The attempts to measure the depth of infilled scour holes by sticking a steel rod into the streambed were not successful due to the presence of cobbles and boulders. The water depth was measured from a known reference point at the bridge sites.

Baseline GPR data were collected at 30 bridges but the pre- and post-flood surveys were only performed at 7 bridge sites where a 2 year or greater recurrence interval flood occurred. The water surface is shown as a reference point in the GPR cross sections.

Figure 12 is an example of a GPR profile of a cross section which shows two detected scour holes. Table 3 shows some of the results of their study. The NHDOT divided their results as existing scour holes, new scour holes, maximum discharge, and infilling (depth observed during the study period in feet).

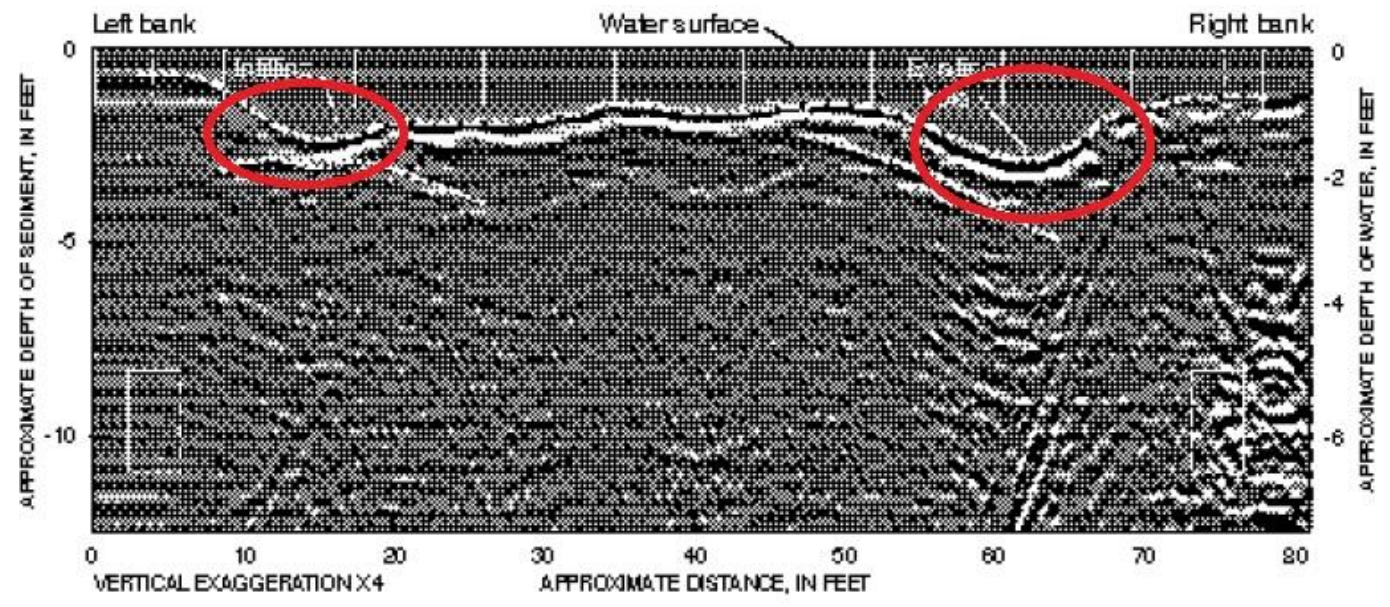

Figure 12. GPR profile of a cross section (Olimpio, 2000). 
Table 3. GPR scour data for bridges in New Hampshire (Olimpio, 2000).

\begin{tabular}{|c|c|c|c|c|c|c|c|}
\hline Site & $\begin{array}{l}\text { Section of river and } \\
\text { figure No. }\end{array}$ & $\begin{array}{l}\text { Ground- } \\
\text { penetrating } \\
\text { radar survey } \\
\text { dates }\end{array}$ & $\begin{array}{l}\text { Existing scour hole } \\
\text { depth observed } \\
\text { during study period, } \\
\text { in feet, and location }\end{array}$ & $\begin{array}{c}\text { New scour hole } \\
\text { depth observed } \\
\text { during study } \\
\text { period, in feet, } \\
\text { and location }\end{array}$ & $\begin{array}{c}\text { Maximum } \\
\text { discharge } \\
\text { observed during } \\
\text { study period, in } \\
\text { cubic feet per } \\
\text { second, and date }\end{array}$ & $\begin{array}{l}\text { Infilling observed } \\
\text { during period, in } \\
\text { feet, and location }\end{array}$ & $\begin{array}{l}\text { Previous streambed } \\
\text { surface depth below } \\
\text { bed bottom, in feet, } \\
\text { and location }\end{array}$ \\
\hline \multicolumn{8}{|c|}{ Routes 3 and 25 over Pemigewasset River in Ashland } \\
\hline $\begin{array}{l}\text { Ashland, Routes } 3 \text { and } 25 \\
\text { over Pemigewasset River }\end{array}$ & $\begin{array}{l}\text { Upstream cross-section } \\
\text { (fig. 11) }\end{array}$ & $\begin{array}{r}10 / 3 / 96 \\
11 / 16 / 98\end{array}$ & $\begin{array}{l}\text { 3.0/1.0 } \\
\text { Left channel/pier }\end{array}$ & $\begin{array}{l}3.5 / 2.0 \\
\text { Left channel/pier }\end{array}$ & $\begin{array}{r}22,200 \\
6 / 14 / 98\end{array}$ & $\begin{array}{l}2.0 \\
\text { Middle of river } \\
\text { channel }\end{array}$ & $\begin{array}{l}\text { 6-8 } \\
\text { Middle of river channel }\end{array}$ \\
\hline \multicolumn{8}{|c|}{ Route 13 over Souhegan River in Milford } \\
\hline $\begin{array}{l}\text { Milford, Route } 13 \text { over } \\
\text { Souhegan River }\end{array}$ & $\begin{array}{l}\text { Downstream cross-section } \\
\text { (fig. 12) }\end{array}$ & $\begin{array}{r}8 / 11 / 96 \\
11 / 20 / 98\end{array}$ & $\begin{array}{l}2.0 \\
\text { Right bank pier }\end{array}$ & $\begin{array}{l}3.0 \\
\text { Right bank pier }\end{array}$ & $\begin{array}{r}6,260 \\
10 / 22 / 96\end{array}$ & None & $\begin{array}{l}2-3 \\
\text { Left bank pier }\end{array}$ \\
\hline $\begin{array}{l}\text { Milford, Route } 13 \text { over } \\
\text { Souhegan River }\end{array}$ & $\begin{array}{l}\text { Right bank pier cross-section } \\
\text { (fig. 13) }\end{array}$ & $\begin{array}{r}8 / 11 / 96 \\
11 / 20 / 98\end{array}$ & $\begin{array}{l}3.0 / 2.0 \\
\text { us pier/ds pier }\end{array}$ & $\begin{array}{l}4.0 / 4.0 \\
\text { us } \mathrm{pier} / \mathrm{ds} \text { pier }\end{array}$ & $\begin{array}{r}6,260 \\
10 / 22 / 96\end{array}$ & $\begin{array}{l}4.0 \\
\text { ds pier }\end{array}$ & None \\
\hline
\end{tabular}

The results of the study were satisfying; the GPR was found to be an effective tool. It is possible to detect existing scour holes, infilled scour holes, and previous scour surfaces at bridge sites. The device helps to measure the maximum extent of scour that has occurred during the period of time. Furthermore, the GPR has shown some advantages in comparison to fixed-instrumentation mounted on bridge peers because it is more versatile and mobile.

\subsubsection{Use of a GPR System at Ten Bridge sites in Missouri}

The University of Missouri-Rolla and the Missouri Department of Transportation (MoDOT) used GPR at ten bridge sites in southeast and central Missouri (Webb, et al., 2002). The objective was to determine variations in the water depth and to assess erosional and depositional patterns. The GPR was equipped with a $200 \mathrm{MHz}$ monostatic antenna, and at some places, duplicate profiles were acquired using a $400 \mathrm{MHz}$ antenna (sampling rate 50 scans/second 
and ranges between 125 and 350 nanoseconds). Stream depth was measured directly using a scaled rod.

Data was collected from the bridge deck, manually, and by boat. Profiles at each site were collected both parallel and perpendicular to the current flow (see Figure 13). Figure 14 shows a processed and interpreted radar image at one of their locations.

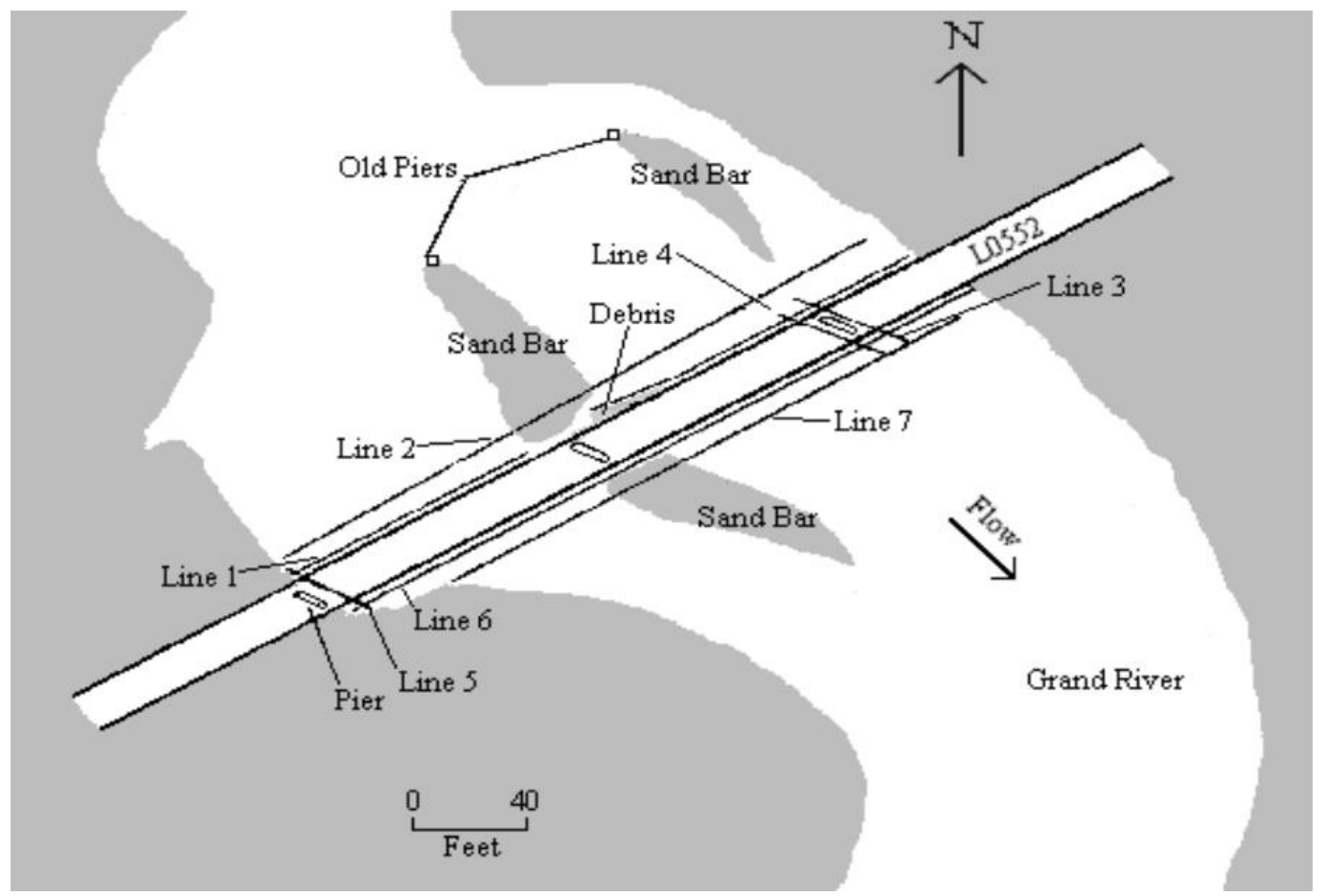

Figure 13. GPR profiles at a bridge site either parallel or perpendicular (Webb, et al., 2002).

The authors reported that GPR was cost-effective for estimating the sediment-water depths and mapping possible infilled scour holes. Detailed images of the sub-bottom provided information about the stratigraphy of the in a 
clastic sedimentary environment. However, the GPR was not able to provide quality images of the sub-bottom strata if significant clay was present.

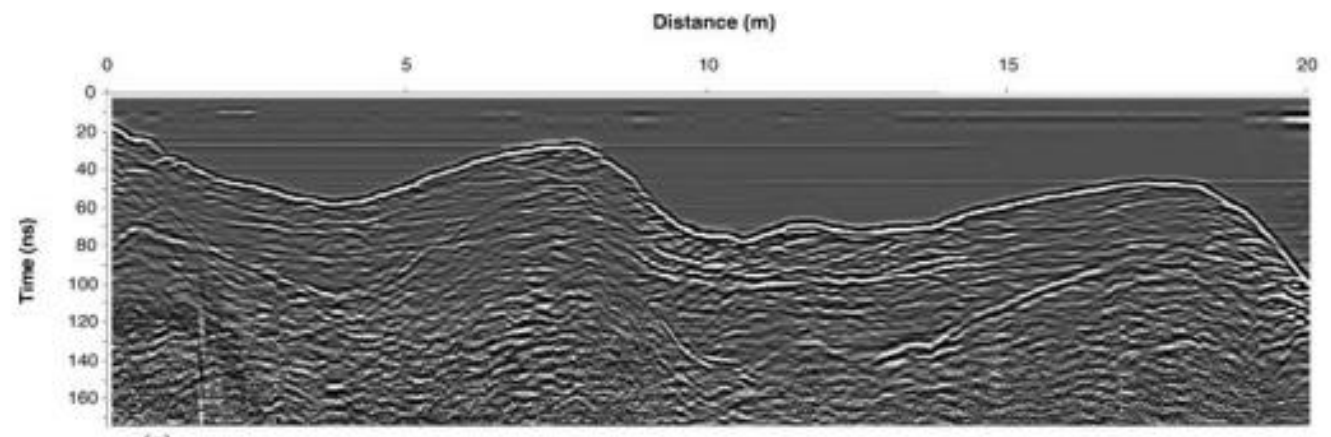

(a)

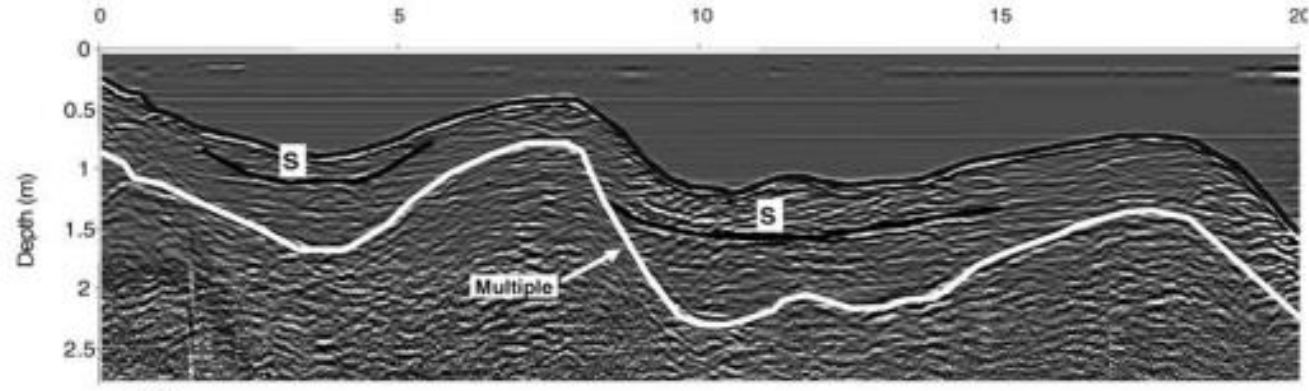

(b)

Figure 14. Processed and interpreted data at one survey location (Anderson, et al., 2007).

\subsection{Use of the GPR for Geotechnical Site Investigations}

Geotechnical site investigations typically involve borings and test pits, which are discrete measurements from which soil layering throughout the site must be inferred. GPR has the potential to provide near continuous measurements of the stratigraphy of a site which can be correlated to data from borings. This section gives an overview about how GPR has been used to supplement traditional site investigation techniques. 
The structure and stratigraphy of soils is highly complex due to different biological, chemical, physical, mineralogical, and electromagnetic properties (Doolittle, 2009). All these properties highly influence the GPR signal in terms of propagation velocity, attenuation, and penetration depth. The penetration depth in soils with high conductivity is limited due to high signal attenuation. This limitation effect is increased by water, soluble salt, and clay contents. If a soil has one or more of these negatively influencing properties, the penetration depth can be decreased to less than $30 \mathrm{~cm}$, which limits the effectiveness of GPR for site investigations.

GPR surveys work well in dry sands and can reach a penetration depth of 50 $m$ with a low frequency antenna. However, only a small change in the soil property by a thin, conductive layer will decrease the signal significantly due to high signal attenuation. The GPR is not effective in saline or sodic soils, where penetration depths of only $25 \mathrm{~cm}$ can be achieved. Wet clays allow a penetration depth of $1 \mathrm{~m}$, which is ineffective in many applications.

A GPR suitability map of the United States is shown in Figure 15. The map is based on a database containing about 18,000 soil interpretation records with information about physical and chemical properties. 


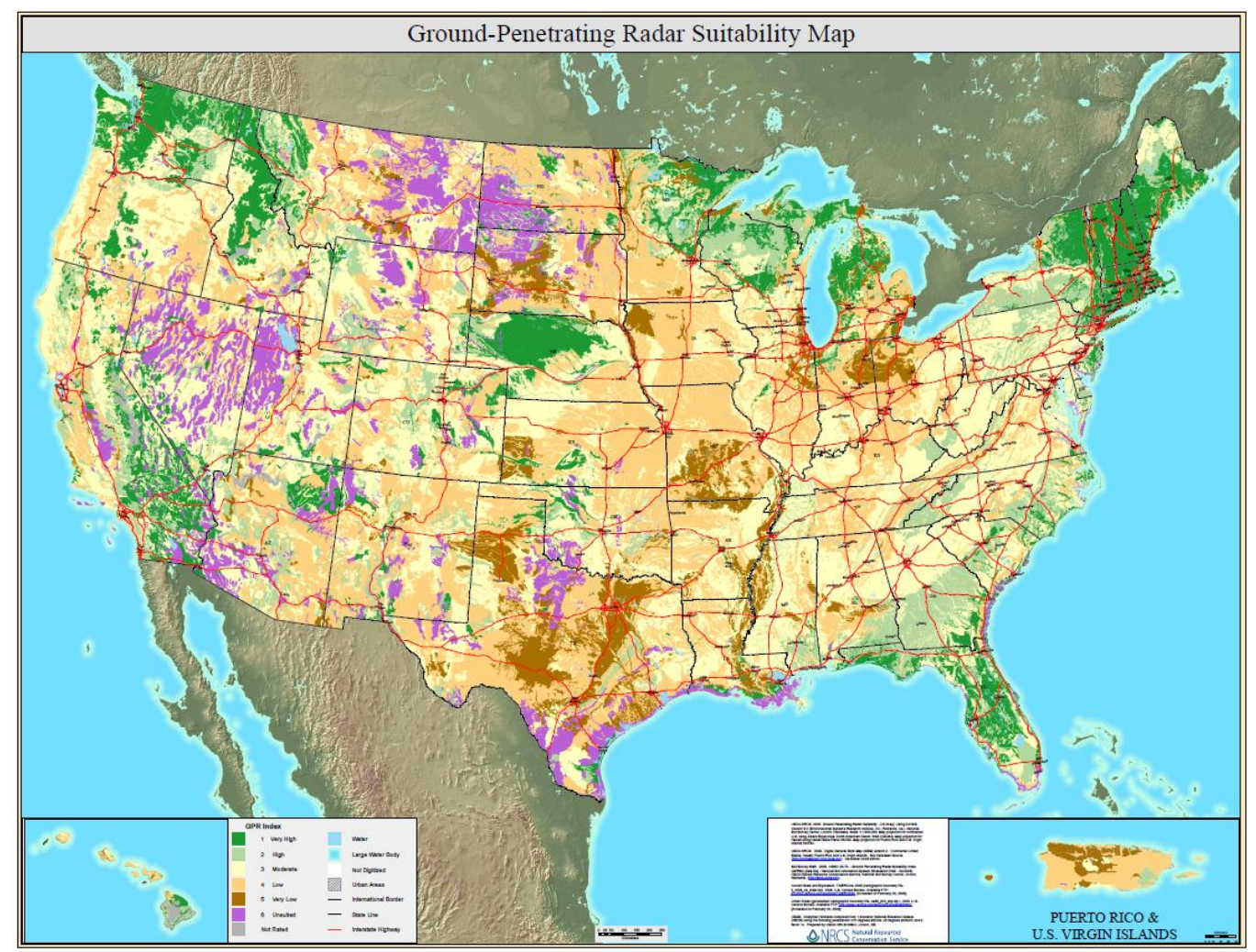

Figure 15. Ground-Penetrating Radar Suitability Map (USDA, 2009).

The map is divided into six categories for suitability from one (green, very high) to six (purple, unsuitable). The lower the index numbers, the lower the rates of signal attenuation, the greater the penetration depth, and the better the site is suited for GPR surveys.

GPR has been used as a quality control tool for soil surveys since the late 1970s. It can be used to show presence, depth, and lateral extent and variability of subsurface horizons (Doolittle, 2009). However, it cannot image subtle changes in soil properties like porosity or structure. 
Figure 16 shows the results from a survey in north-central Florida. The GPR image was taken and then compared to the real soil profile. The shovel in the left picture is about $90 \mathrm{~cm}$ in length and provides a scale. The vertical scale of the right picture is in meters. The reflections from the spodic and argillic horizon are strong due to the abrupt change in soil materials leading to a high amplitude. Spodic layers (i.e. illuvial layers of organic matter) are detectable with the GPR because of differences in their bulk density and water. Argillic layers are detectable with the GPR because of abrupt increases in clay content and bulk density.

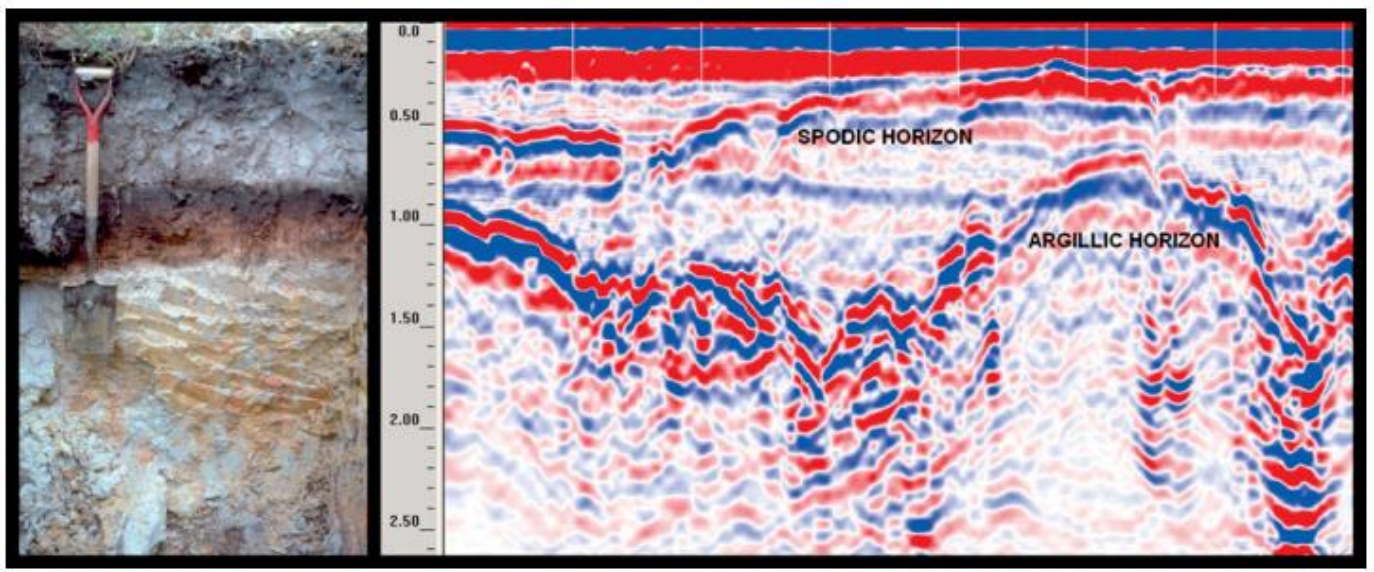

Figure 16. Comparison of a radar image to the real soil profile (Doolittle, 2009). 


\section{Chapter 3}

\section{Methodology}

This chapter provides the methodology that was used for the field surveys described in the next chapter. A description of the equipment, set up for measurements, data processing techniques and interpretation of the data are all provided. Much of this information is from user manuals that give a good overview on how the GPR can be used.

\subsection{Equipment Used in this Study}

The equipment used in this study is a commercially available system from Geophysical Survey Systems, Inc (GSSI), an international company that specializes in GPR manufacturing for a wide range of applications. In order to perform the tests for this study a $400 \mathrm{MHZ}$ antenna was purchased and used with already existing GPR equipment owned by Rhode Island Department of Transportation RIDOT who used it for bridge inspections. The antenna and the SIR 3000 system is shown in Figure 17. 


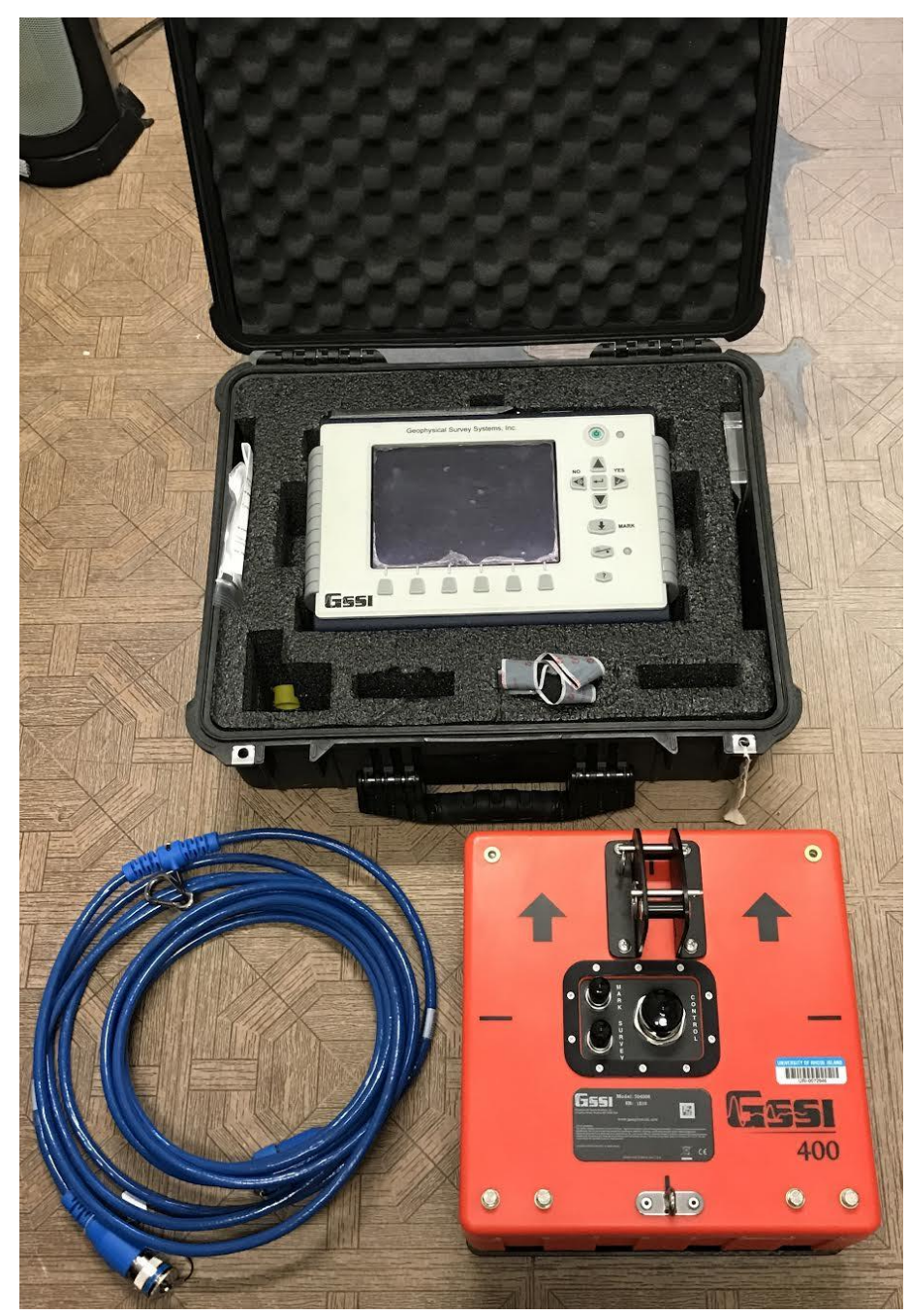

Figure 17. GPR-System (SIR-3000 and 400 MHZ antenna).

The SIR 3000 is a portable ground penetrating radar system also from GSSI. It allows the user to define different parameters for the data acquisition, which is explained in the next section. Also, data in real time or in a playback mode can be seen with the SIR 3000 (GSSI, 2016).

In order to perform GPR surveys on water a small catamaran was constructed, as shown in Figure 18. It consists of two floating bodies straddling a 
waterproof box which carries the antenna and protects it from water. Lines can be mounted in the front and back to pull the vessel from different sides or to attach it to a boat.

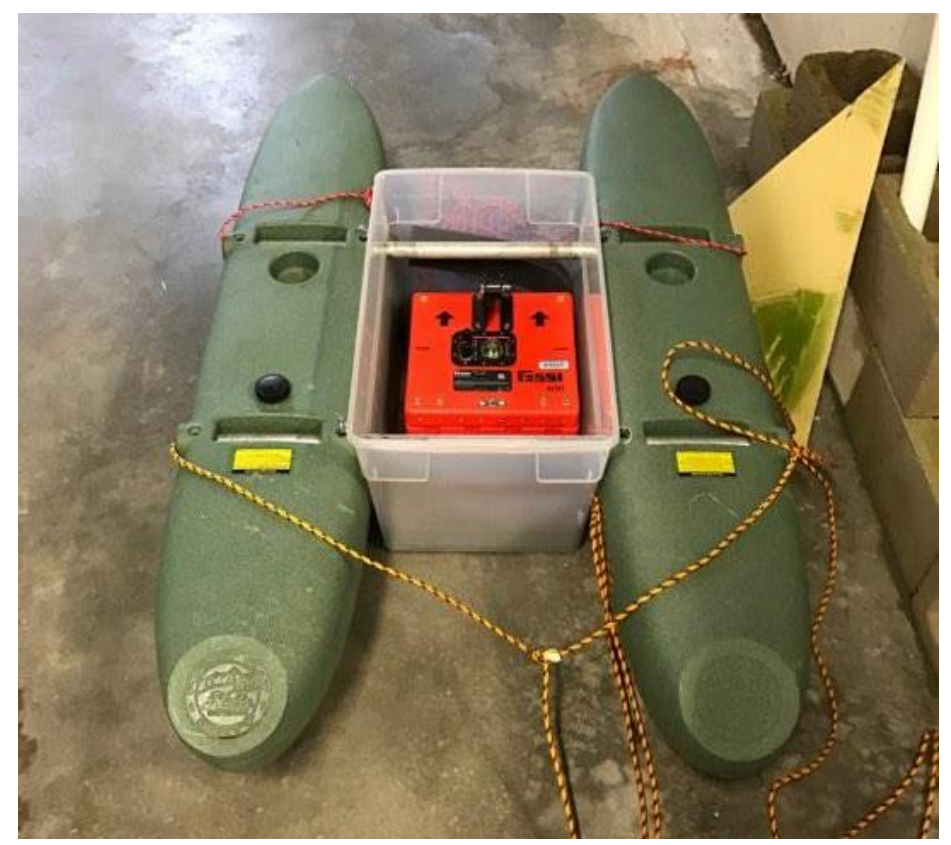

Figure 18. Research Vessel for Bridge Surveys.

For the surveys on land, a GSSI survey cart was used (Figure 19). The SIR3000 can be mounted on the cart with the antenna sitting in a box underneath the cart. The wheels are equipped with an odometer to measure distances. 


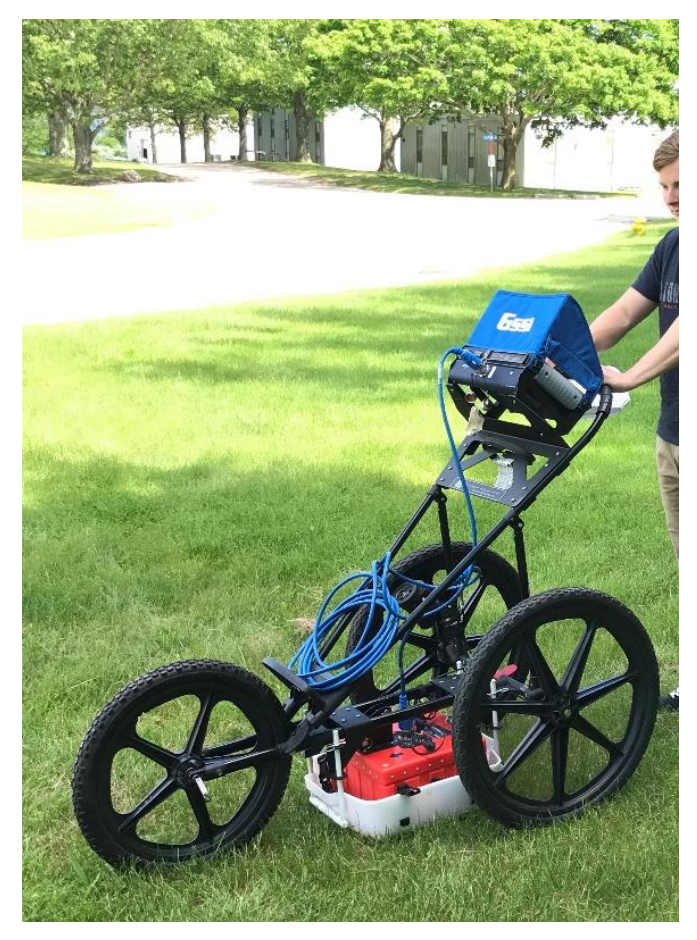

Figure 19. Survey Cart for Soil Surveys.

\subsection{Set Up of the SIR3000 System}

The first step in acquiring GPR data is setting up the hardware for the SIR 3000. This can easily be done by connecting the female end of the antenna exit and the cable to the antenna. The back of the SIR 3000 System can be seen in Figure 20. The front side is shown in Figure 21, the keypad has 15 buttons and two indicator lights. 


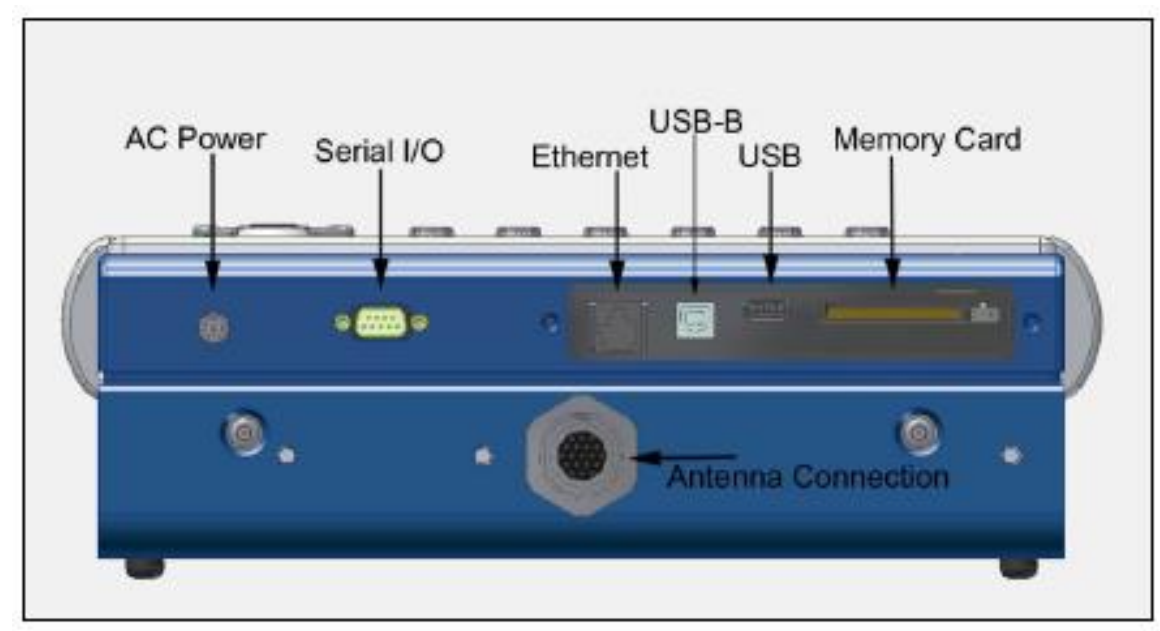

Figure 20. SIR 3000 panel (GSSI, 2016).

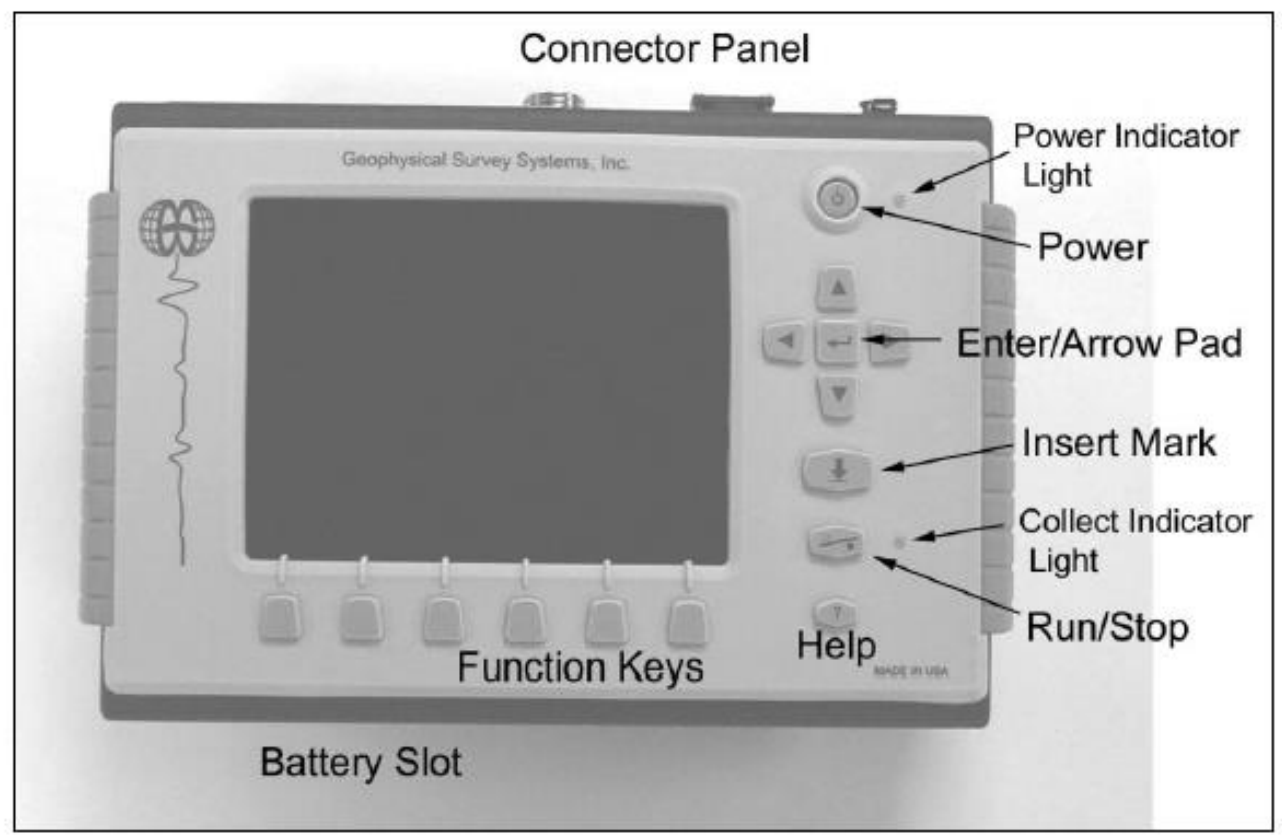

Figure 21. SIR 3000 front panel (GSSI, 2016).

After booting the system an introductory screen can be seen in which six different icons are located (see Figure. 22). The 'Mark' button changes the units from English to Metric. The menu bar shows six different modes at the bottom. 
The TerraSIRch mode is the mode which allows a modification of all collection parameters and is used for all GPR applications.

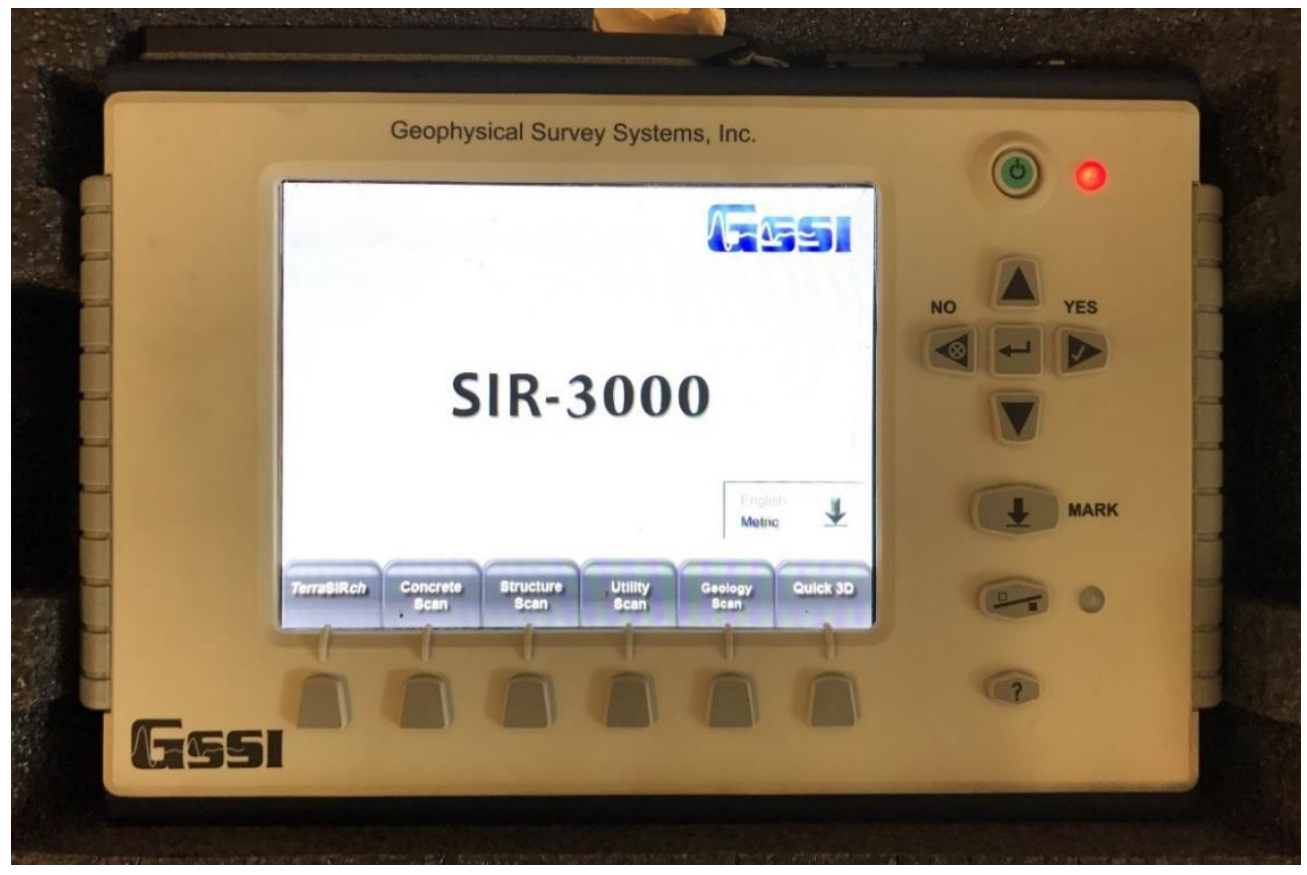

Figure. 22 Starting screen on SIR3000.

After enabling the TerraSIRch mode, the following screen can be seen (Figure 23). The window on the right is called the O-Scope. It shows a single radar scan while moving the antenna around in an oscilloscope-style. The main data display window is a stack of colored single scans to form a radar profile in line scan format. The vertical scale can be the time, depth, or sample number depending on the setup. The command bar on the bottom shows six different toggles and functions, which will be explained later. Left of the main window is a parameter selection tree (Figure 23). 


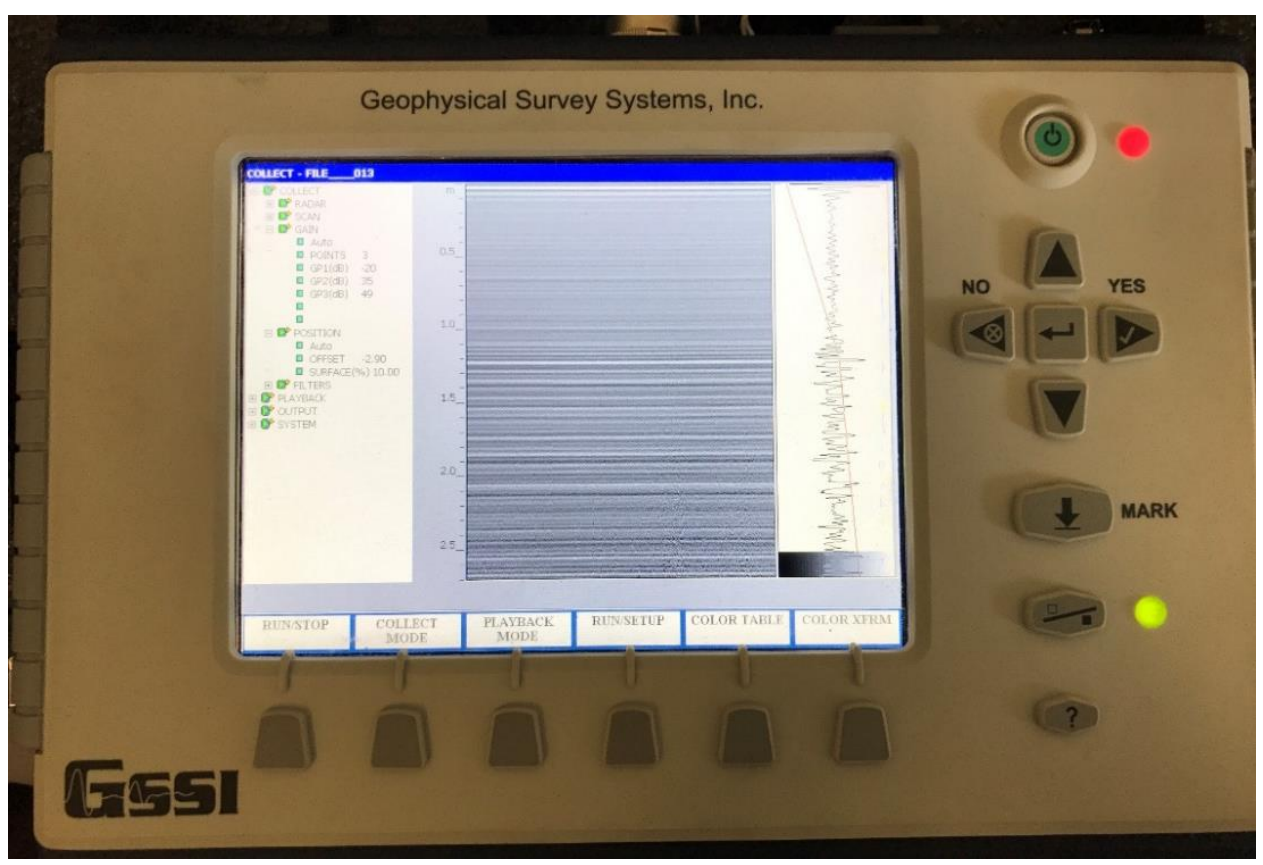

Figure 23. Starting window in TerraSIRch Mode.

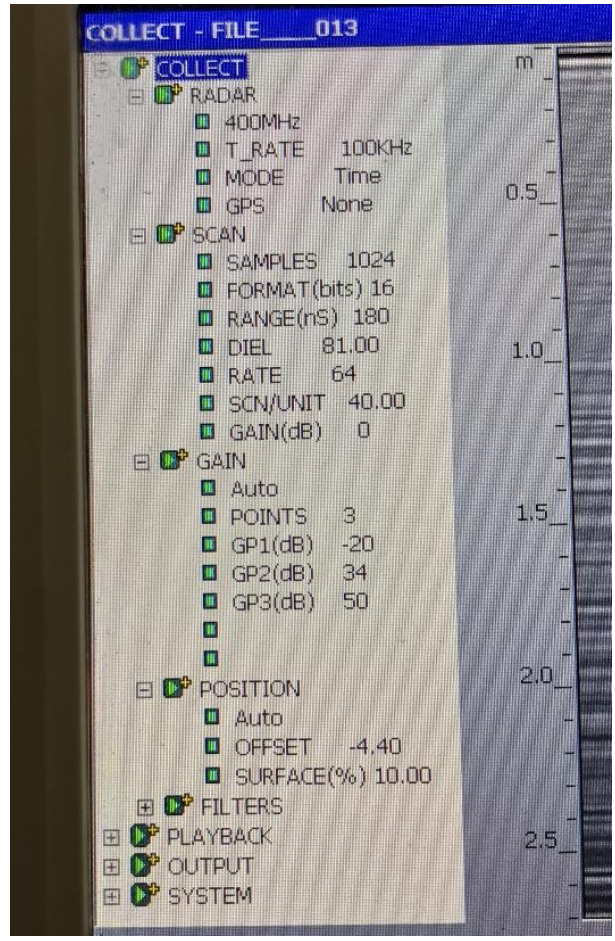

Figure 24. Parameter settings. 
The SYSTEM menu is used to change units, check the battery, and set a path to save the data; note that it has no influence on the measurements. The COLLECT menu contains five sub-menus (see Figure 24) which are used to customize the setup for the application. In the RADAR menu the antenna, the transmitting rate in $\mathrm{KHz}$, the GPS usage, and the mode can be set. There are three possible data collection modes; point, distance, or time-based. For both bridge and shallow rock surveys in the next chapters, a $400 \mathrm{MHz}$ antenna with a transmitting rate of $100 \mathrm{kHz}$ was used. A high transmitting rate means faster data collection ability. The TIME mode is used when the antenna is not used together with the measurement cart, for example when sitting in a floating device instead. The DISTANCE mode is used when the antenna is used together with the measurement cart. The GPS was not necessary for this study because the location of the scour features was not important; to find the maximum scour depth was the goal of the measurements. For the soil surveys the GPR was used in the area around boring logs and it was also not important to have GPS data.

The scan menu contains six additional menus: Samples, format, range, diel (dielectric number), rate, and scn/unit. With the 'sample' function the number of individual data points (scans) can be set. The higher the number of scans, the smoother the scan curve and the better the resolution. For the 'format' two options can be chosen, data can be collected in an 8-bit or 16-bit format. The 16-bit format is recommended for most applications due to a greater dynamic range (more information in the data). The number of 'range' will set the time window in 
nanoseconds, ns, that will record reflections, meaning the higher the number the higher the penetration depth because a longer range allows more time for the SIR to collect reflections from greater depth. For the application in the river a penetration depth around 2.8 meters is needed, which is equal to a range of 130 ns while operating in water. The range for the soil survey was adjusted depending on the locations to see as deep as possible to find the shallow rock layers. For a range over $100 \mathrm{~ns}$ the number of samples needs to be increased to 1,024 . The number of 'diel' refers to the dielectric value of the surveyed material, which depends on the electrical conductivity. Typical values of the dielectric value for different materials can be seen in Figure 25.

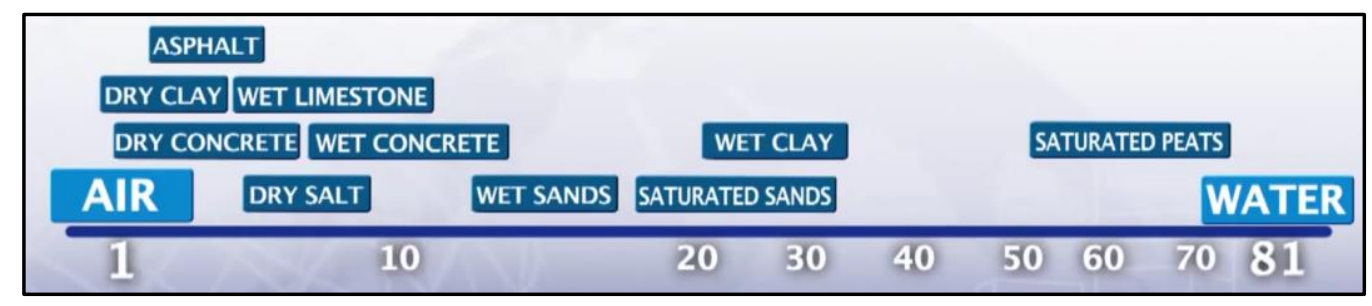

Figure 25. Dielectric value of different materials (GSSI, 2016).

A higher dielectric value results in a slower travel time of the waves. In general the travel time of a wave is increased by the water content of the material, as illustrated in Figure 26. The dielectric value of a material is critical for the depth calculation during a survey. 


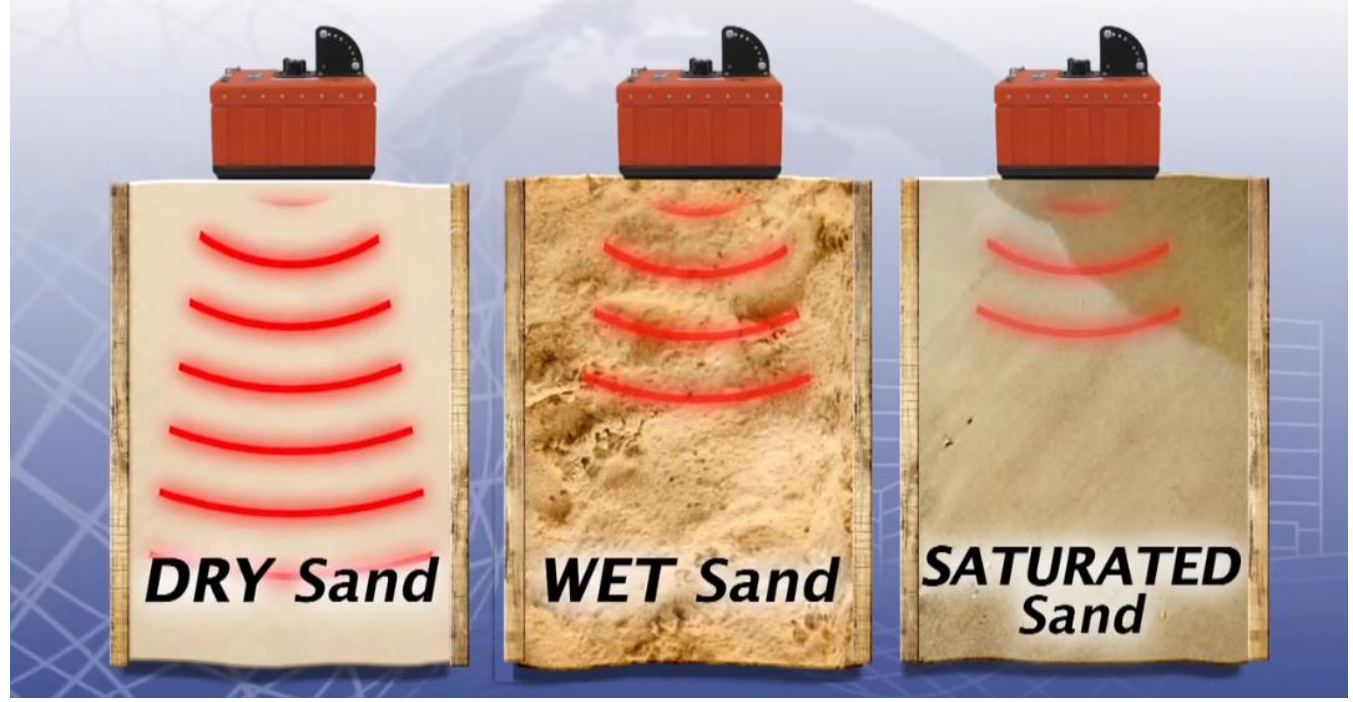

Figure 26. Illustration of Wave travel time in different materials (GSSI, 2016).

The next parameter in this menu is 'rate', which is the number of scans the system will record in RAM memory per second. While measuring in the time mode it means the number of scans saved in each second. The last option in the 'rate' menu is the gain parameter, which is a value for display options. It can help to make it easier to view data in real time on the display while doing a survey. The 'Scn/unit' mode controls the scans per unit of horizontal distance, which is only important for surveys with the surveying cart.

The next menu point under COLLECT is 'gain', which is an option to strengthen the radar signal as it travels into deeper soil. When the signal travels deeper through material it gets weaker because of reflection and absorption and the gain command can help to make weak data more visible. The automatic function is recommended because otherwise features in the data can be created which do not represent the real environment. However, if the data is 'over gained', 
or increased too much, data clipping can occur. To avoid this, the GPR has to be reset back to manual mode and then back to automatic mode, which will adapt the GAIN on the new environment.

The position menu helps control and locate the beginning of the scan, normally this is done automatically by the system itself. Only in specific applications does this need to be changed.

The filter menu allows the user to filter the data to remove interference or smooth noise. The factory setup is designed for the specific antenna types and should only be changed in special cases.

Recommended for a $400 \mathrm{MHZ}$ antenna is a Low Pass Filter of 800 and a High Pass Filter of 100. The Low Pass Filter will eliminate all frequencies over the entered value. In general the value for the HP Filter should be above the range where meaningful data is collected. The High Pass Filter will eliminate all frequencies under the entered value. The manual is recommending a cut off frequency at $1 / 4$ of the center frequency, meaning a cut off frequency of 100 for the $400 \mathrm{MHZ}$ antenna.

A summary of the parameters used for the bridge surveys later in this thesis is provided in Table 4. The table also contains short explanations of the different parameters. 
Table 4. Parameter Overview for the bridge surveys.

\begin{tabular}{|c|c|c|c|}
\hline $\begin{array}{l}\text { DISTANCE = meter } \\
\text { VSCALE = distance } \\
\text { Setup: }{ }^{(1)} \\
\text { Recall } \\
\text { Save } \\
\text { Path = Common } \\
\text { Backlight = } 4 \\
\text { Date/Time: check } \\
\text { Battery: check } \\
\text { Language: English }\end{array}$ & $\begin{array}{l}\text { COLLECT } \\
\text { Radar: } \\
400 \mathrm{MHz} \\
\text { T_RATE }{ }^{(2)}=100 \mathrm{kHz} \\
\text { MODE } \\
\text { GPS }=\text { none } \\
\text { Scan: } \\
\text { Samples } \\
\text { Format }=16 \text { bit } \\
\text { Range }^{(4)}=20-150 \mathrm{~ns} \\
\text { Diel }^{(6)}=81 \\
\text { Rate }^{(7)}=70 \\
\left(\mathrm{Scan}^{(3)} / \mathrm{Unit}\right. \\
\text { Gain }^{(9)}=6 \mathrm{db}\end{array}$ & $\begin{array}{l}\text { Points } \\
\text { GP1-5 } \\
\text { Position: } \\
\text { Auto } \\
\text { Offset }^{(11)} \text { : Do Not Change } \\
\text { Surface }^{(13)}=10 \% \\
\text { Filters: }^{(14)} \\
\text { LP_IIR }=800 \\
\text { HP_IIR }=100 \\
\text { LP_FIR }=0 \\
\text { HP_FIR }=0 \\
\text { Stacking }=0 \\
\text { BGR_RMVL }=0\end{array}$ & $\begin{array}{l}\text { PLAYBACK } \\
\text { Scan: }{ }^{(15)} \\
\quad \text { Diel/Surfac } \\
\text { e } \\
\text { Process: }{ }^{(16)} \\
\text { OUTPUT } \\
\text { Display: }{ }^{(17)} \\
\text { Transfer: }{ }^{(18)} \\
\text { DATA } \\
\text { COLLECTION } \\
\text { Connect USB } \\
\text { before turning } \\
\text { unit on } \\
\text { Recall/setup } \\
\text { parameters } \\
\text { Calibrate DMI } \\
\text { (see below) } \\
\text { Set Gain (Auto } \\
\text { then Manual } \\
\text { to lock in } \\
\text { values) } \\
\text { Press } \\
\text { Run/Stop to } \\
\text { turn } \\
\text { antenna on } \\
\text { Press } \\
\text { Run/Setup to } \\
\text { start/stop } \\
\text { recording data } \\
\text { after } 3 \text { beeps, } \\
\text { start } \\
\text { measurement } \\
\text { Save file }\end{array}$ \\
\hline \multicolumn{4}{|c|}{$\begin{array}{l}\text { (1) allows saving/recalling of the data collection parameters } \\
\text { (2) transmission rate capped at } 100 \mathrm{KHz} \\
\text { (3) distance based collection using DMI (scans/ft) } \\
\text { (4) samples/scan; as sample number increases, max. scan rate decreases and file size increases ( } 512 \\
\text { or } 1024 \text { recommended) } \\
\text { (5) two-way time window that system will record reflections ( } 20-100 \text { ns is recommended for } 400 \mathrm{MHZ} \\
\text { antenna) } \\
\text { (6) approximate setting of the dielectric constant of material which reflects the velocity of EM wave } \\
\text { through a material; higher values mean slower travel time and shallower penetration: asphalt (3-5), } \\
\text { concrete (5-8); water ( } 81 \text { ) } \\
\text { (7) number of scans system will record in RAM per second. If set too high, system will automatically } \\
\text { lower it to max. possible. If collecting data based on time, this is the number of scans that will be } \\
\text { saved each second. } \\
\text { (8) scans/ft; } 120 \text { scans/ft = } 10 \text { scans/inch } \\
\text { (9) display gain; this is not saved in data file } \\
\text { (10) initially set to Auto to get values, then turn to Manual and input same values to lock them in } \\
\text { (11) controls the position of time-zero }\end{array}$} \\
\hline
\end{tabular}


(12) this is a system parameter, do not change. Describes the time lag (ns) from the controller triggering the pulse until the signal is transmitted from the antenna; direct coupling is the pulse that travels inside the antenna housing directly from the transmitter to the receiver; use the direct wave to locate ground surface

(13) display option that sets a percentage of the data to display; system will set ground level near first positive peak of the direct coupling

(14) set automatically based on the antenna used; LP/HP = low pass/HP; Infinite Impulse Response

(IIR) and Finite Impulse Response (FIR)

(15) diel/surface options are duplicated here; they are the same as in "Collect"

(16) allows changing of filters; setting doesn't permanently alter data; only for display purposes

(17) change "look and feel" of data displayed on screen

(18) data transfer from internal memory to Flash or HD (hard drive)

(19) in setup mode-starts/stops antenna; in run mode-stops data collection and brings up crosshairs, push again to bring up save file window

\subsection{Data Processing in RADAN 7}

The software RADAN 7 was used for data processing in this thesis. This section provides background from the manual as well the steps that were performed to analyze the data from the surveys in the next chapter.

The goals for using the software are to display the data as a line scan or a wiggle trace and to use different color tables and color transform parameters to improve the data display to find features (GSSI, 2012). Furthermore, different filters can be applied to clear the data of unwanted noises and other disturbances.

Figure 27 shows the main screen after launching the software and shows the most important functions. 


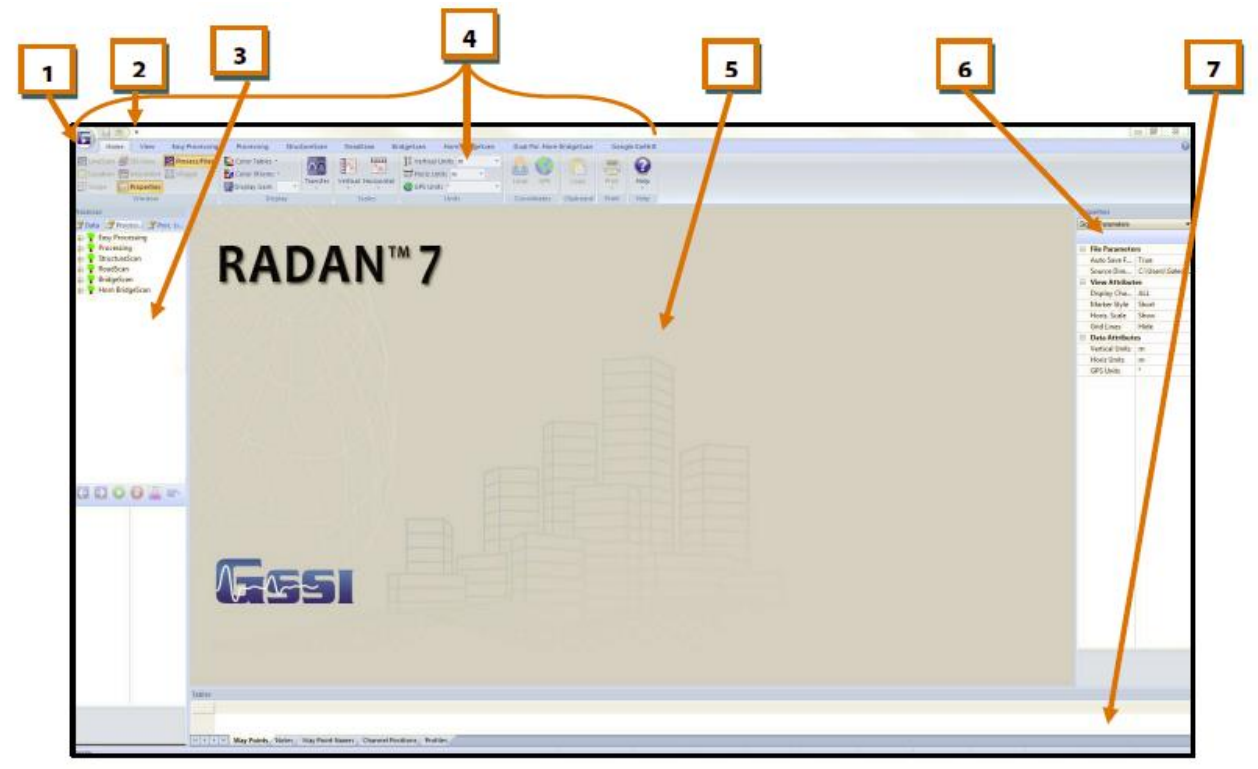

Figure 27. Main screen in RADAN 7 (GSSI, 2012).

The GSSI button (1) allows the user to import, export or save different data files. Tools which are used very often can be saved at the quick access toolbar (2). In the left column (3) a list of tabs is provided with guided steps to process data. The Ribbon (4) contains all options and processes for data depending on which application was used (Roadscan, Bridgescan, etc.). The data pane (5) will display the data when a file is imported. The properties pane (6) is an area for showing the global parameters which were used during a measurement. The table plane (7) will display different data base information which is also depending on the type of data which was collected.

The properties pane contains information about the data and provides an important overview about the setup (see Figure 28). This window allows the user 
to follow how the data was taken. The header file parameters contain the date and time when the data was taken and modified.

\begin{tabular}{|c|c|c|}
\hline \multicolumn{3}{|c|}{ Properties } \\
\hline \multirow[t]{5}{*}{$\Xi$} & \multicolumn{2}{|c|}{ Header File Parameters } \\
\hline & Original File Name & POND190NS \\
\hline & Created & May, 19 2017, 17:55:20 \\
\hline & Modified & May, 25 2017, 12:30:48 \\
\hline & Number of Channels & 1 \\
\hline \multirow[t]{4}{*}{$\Xi$} & \multicolumn{2}{|c|}{ Horizontal Parameters } \\
\hline & Scans / Sec & 64.00 \\
\hline & Scans / Unit (m) & 40.000 \\
\hline & Units / Mark (m) & 0.000 \\
\hline \multirow[t]{4}{*}{$\Xi$} & \multicolumn{2}{|l|}{ Vertical Parameters } \\
\hline & Samps / Scan & 1024 \\
\hline & Bits / Sample & 16 \\
\hline & Dielectric Constant & 81.00 \\
\hline$\Xi$ & \multicolumn{2}{|l|}{ Channel Information } \\
\hline & Channel & 1 \\
\hline & Antenna Type & $400 \mathrm{MHz}$ \\
\hline & Antenna Serial \# & 0 \\
\hline & Position (ns) & -19.00 \\
\hline & Range (ns) & 190.00 \\
\hline & Top Surface (m) & -0.317 \\
\hline & Depth $(m)$ & 3.167 \\
\hline & \# Sample Stacks & Unavailable \\
\hline & \# Scan Stacks & Unavailable \\
\hline & \multicolumn{2}{|l|}{$\Xi$ Processing History } \\
\hline & $\boxminus \quad$ IIR Filters & \\
\hline & $\square$ Vertical ( & \\
\hline & Low Pass & 800 \\
\hline & High Pass & 100 \\
\hline & $\square$ Position Corr & \\
\hline & Method & H.Drift Tracking \\
\hline & Shift (nS) & -6.02 \\
\hline & $\square$ Range Gain & \\
\hline & \# Of Points & 3 \\
\hline & Gain 1 & -11.00 \\
\hline & Gain 2 & 14.00 \\
\hline & Gain 3 & 56.00 \\
\hline
\end{tabular}

Figure 28. Properties Pane.

The horizontal parameters show the parameters which determine the horizontal resolution (scans/sec). The vertical parameters show the parameters which define the vertical resolution (samples/scan, bits/sample and dielectric constant). The channel information contains the antenna type and settings (position, range, active filters). 
The window shown in Figure 29 contains different options to process data and different options to display data. Each tab (home, view, etc.) contains specialized applications.

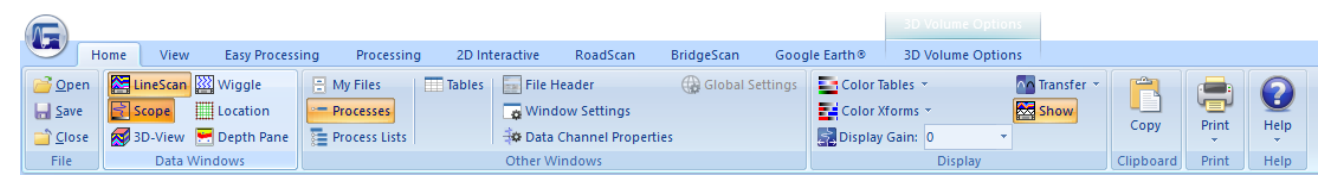

Figure 29. Structure and Functions Ribbon.

The linescan format can be seen in Figure. 30. By assigning a color to the recorded data with either a positive or negative amplitude value, a coloramplitude form is created. Different color tables and color transforms are available and explained later. Travel time or depth is the vertical scale while the horizontal scale shows the number of scans or the horizontal distance travelled with the antenna. Using the linescan view is the most useful display option for mapping man-made objects like pipes. 


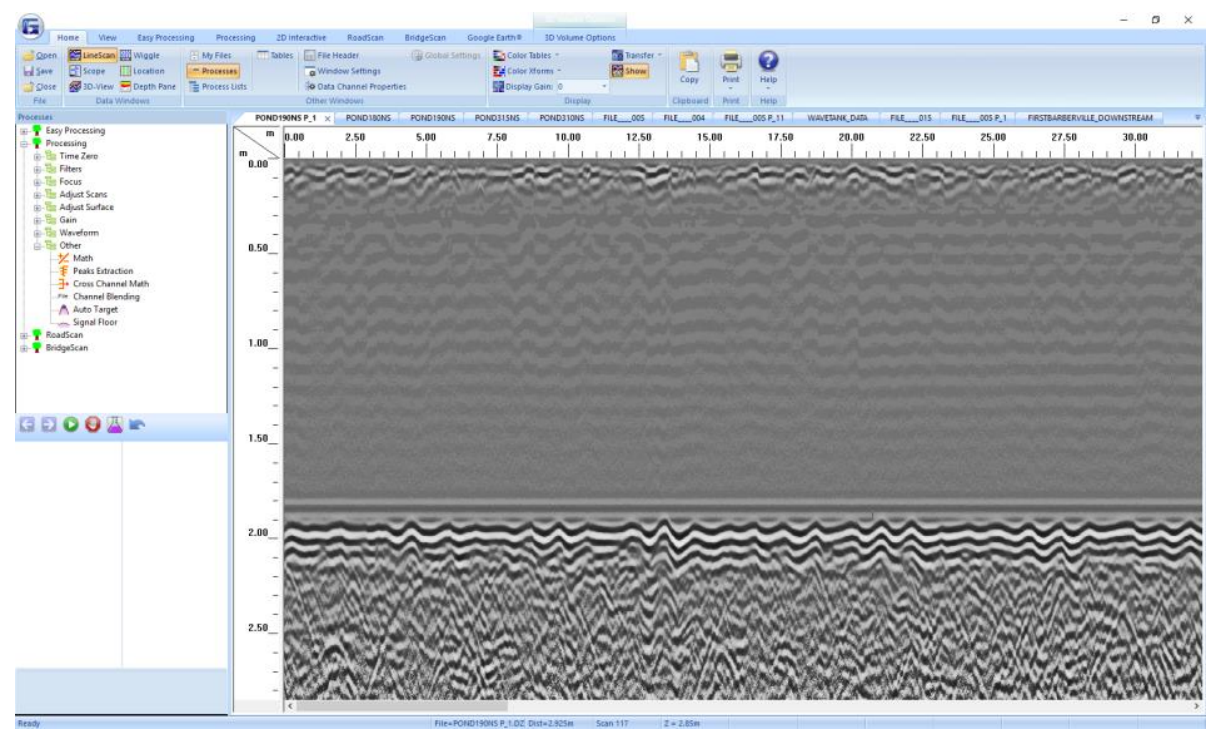

Figure. 30 Linescan mode.

In the wiggle mode (Figure 31), multiple of single radar scans can be seen. The scans are displayed in a waveform or "wiggle traces". This mode is useful when identifying geological features such as soil layers or water tables. The horizontal and vertical scale is the same as before in the linescan mode.

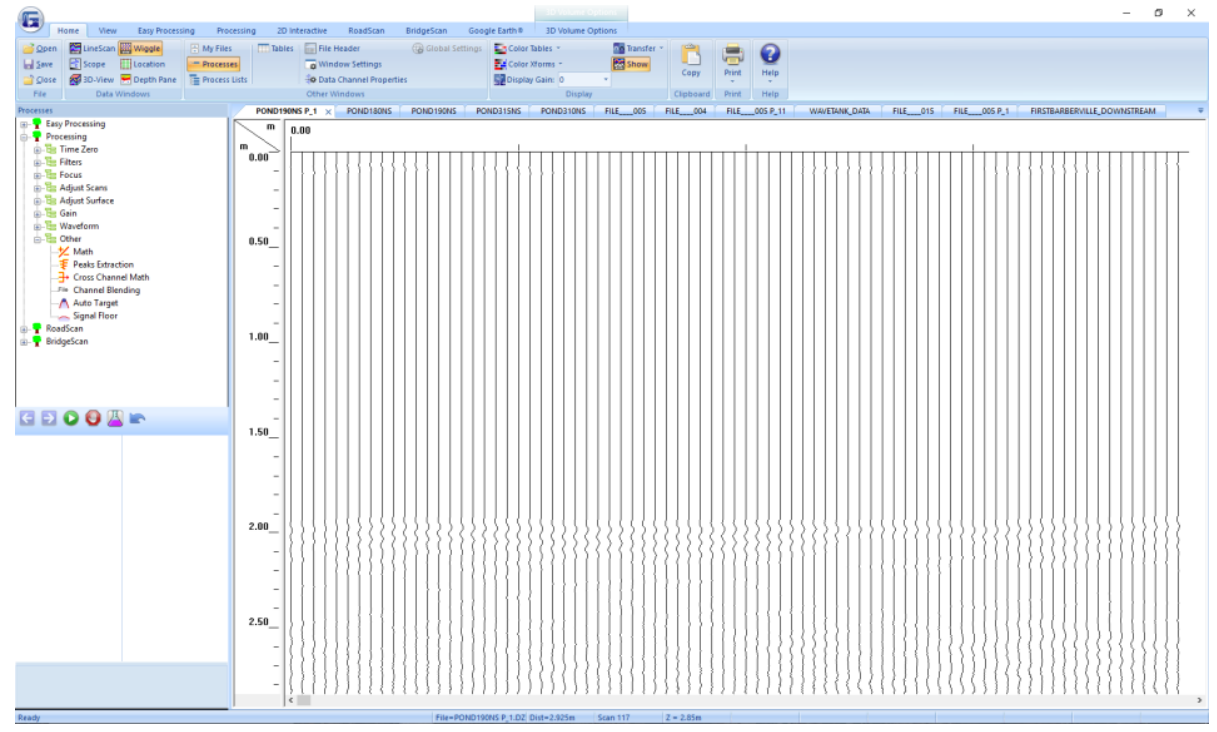

Figure 31 . Wiggle mode. 
The scope (Figure 32) will open an extra window to the right of the data window and display an O-Scope. Single scans can be reviewed while seeing the whole data.

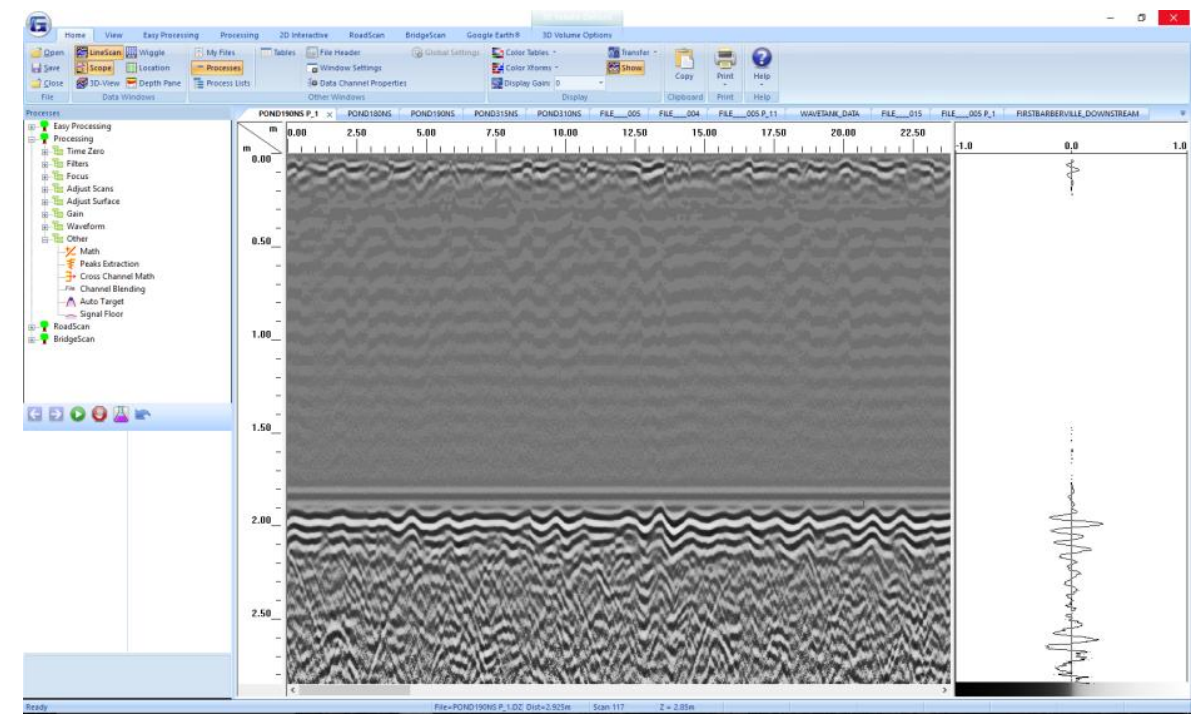

Figure 32. Scope.

The color tables in Figure 33 allow the user to choose an option out of 30 different tables to code the amplitude for the recorded signal. Strong signals are represented by the left colors of the spectrum while signals getting closer to zero (or weak) are represented by the middle colors. The colors to the right are displaying the positive site.

For example, in Figure 32 which is using color table 12, the white color shows a very strong reflection and corresponds to the highest positive amplitude pulse. Dark is the signal for low amplitude signal. The same data (Figure 32) is shown in a different color set (table option 1) and is shown in Figure 35. There is also the option to change the color transform, allowing an increase in weak amplitudes or 
small contrast reflectors (Figure 34). It can also be defined if the color scale applied to the radar wave's amplitude is linear, logarithmic, exponential, or customized. This function is useful to de-emphasize features. 


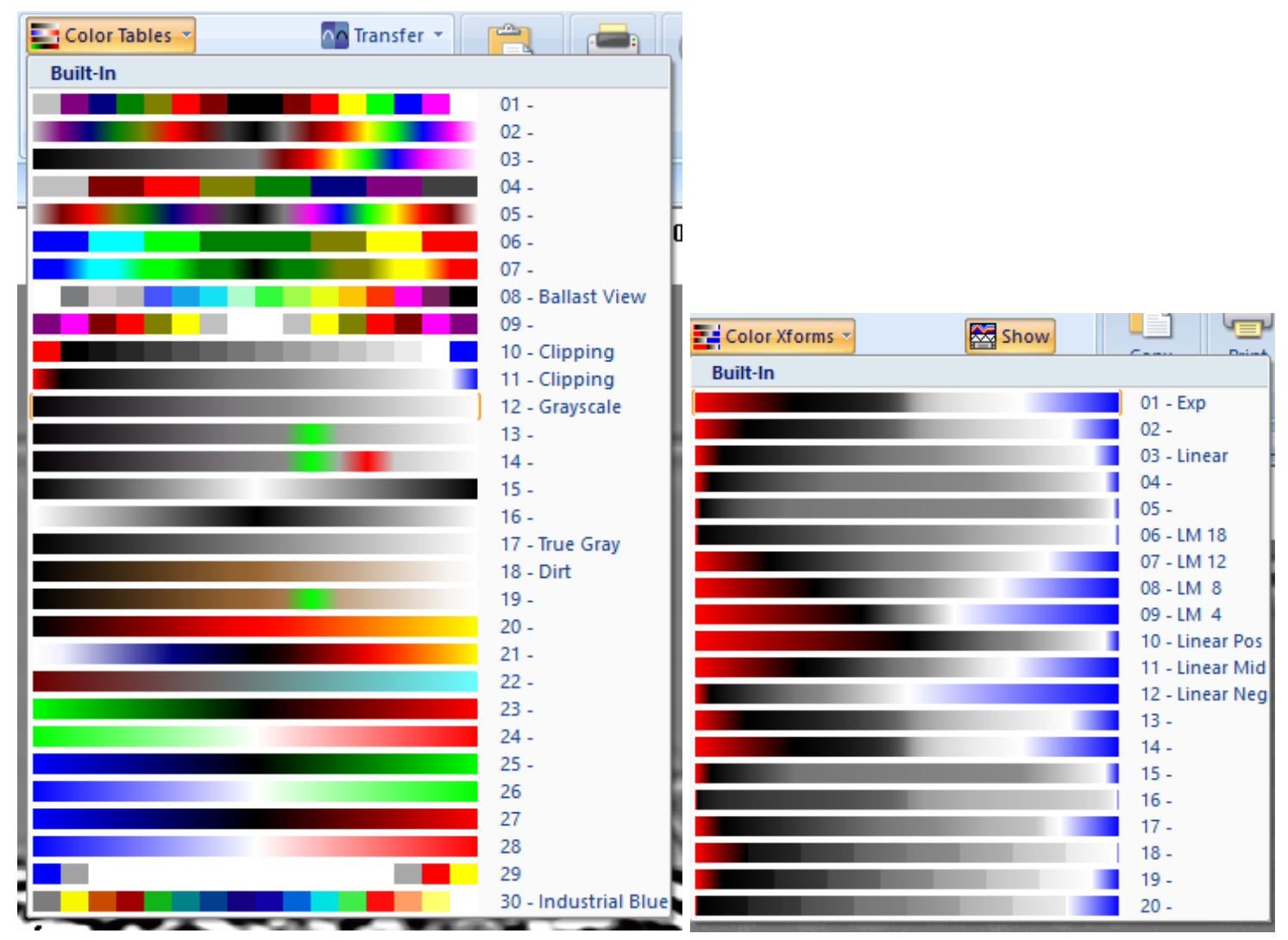

Figure 33. Color Table Options in Figure 34. Color Xforms in RADAN7. RADAN7.

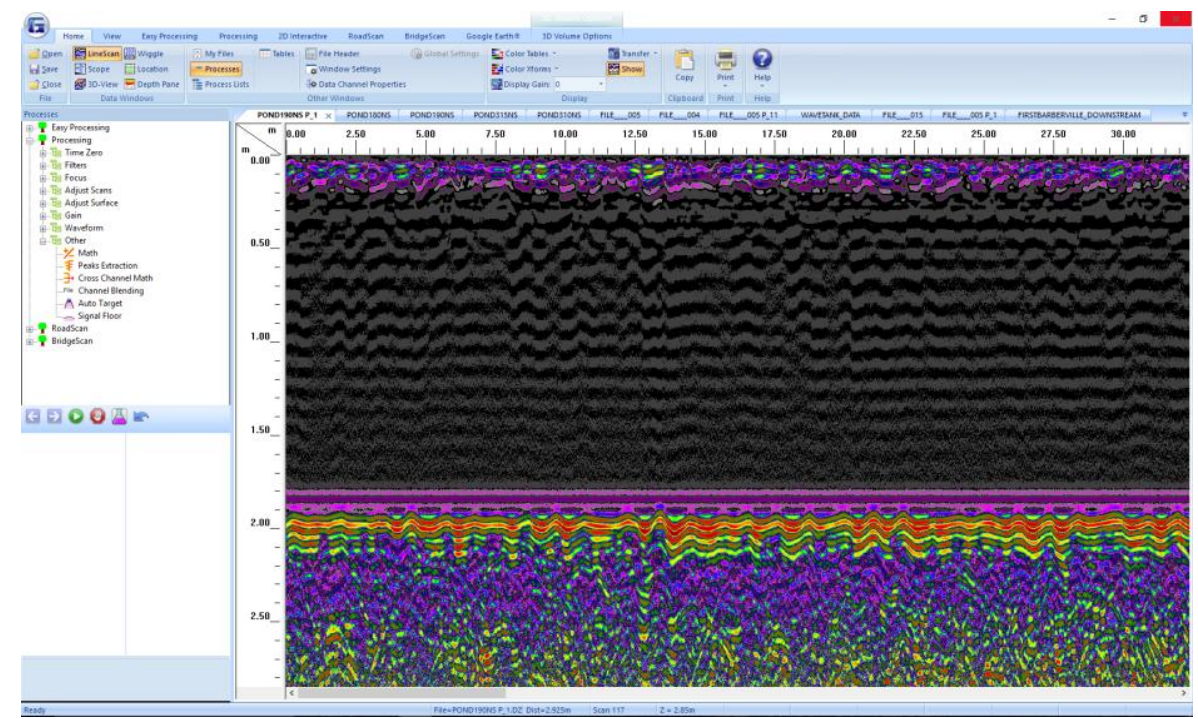

Figure 35. Color table 1 on the same data of figure 28. 
In a logarithmic map like LM 18 all low amplitude signals will have the same color range (compressed lower color range) while the range of high amplitude signals is increased. Figure 36 is showing how the data from Figure 32 looks with a different color Xform.

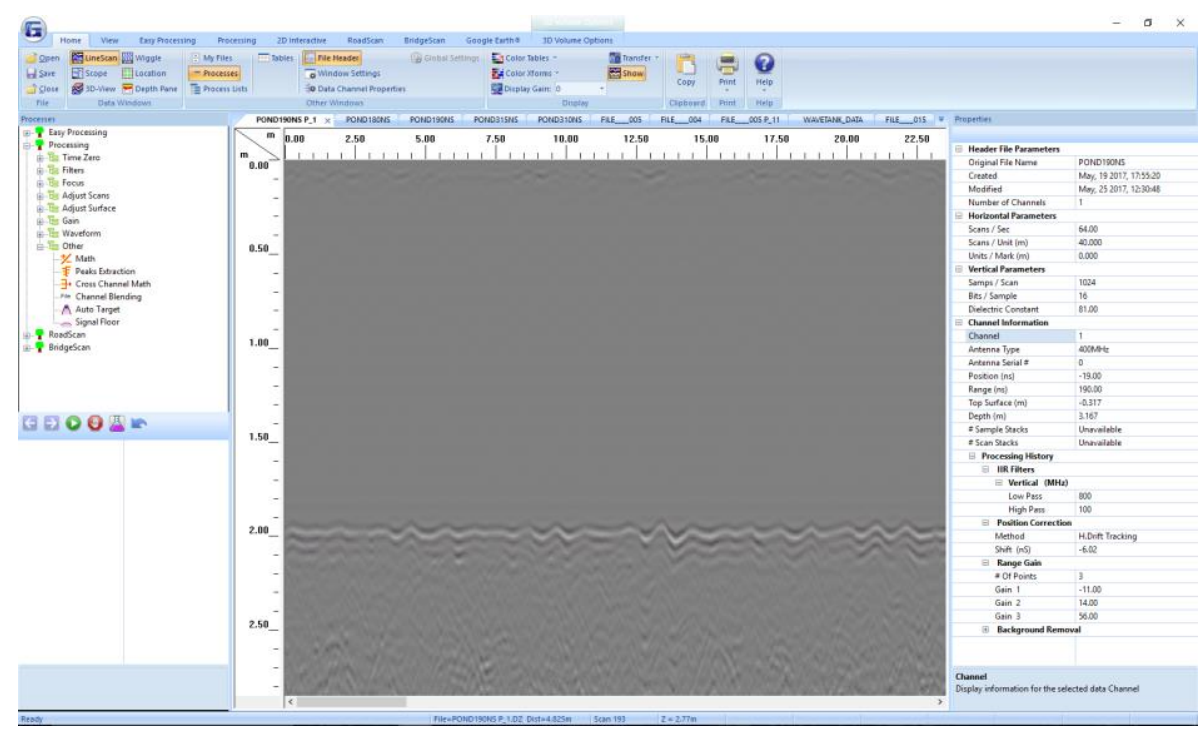

Figure 36. LM 18 on the same data like Figure 28.

There is also a gain function which can be used to make it easier to display low amplitude targets. The display option will change all samples but the data is unchanged in contrast to the gain function, which is explained in the next section for processing.

This section contains the process steps which change the data and were performed to analyze data in this thesis. Not all functions of RADAN are explained here but can be found in the manual (GSSI, 2012). 


\subsubsection{Position Correction}

The raw data must be corrected to get an accurate estimate of depth. The first reflection (called the direct wave) is caused by the antenna itself due to the fact that transmitting and receiving antenna are together in the box without a separation which allows a signal always travelling first to the receiver. This helps in fact for data processing, because the beginning of the real radar image is known. By moving the first positive peak of a wave to the top edge of the screen, the ground surface will move to the top of the window at "Time Zero". Figure 37 shows the difference before and after this processing step.
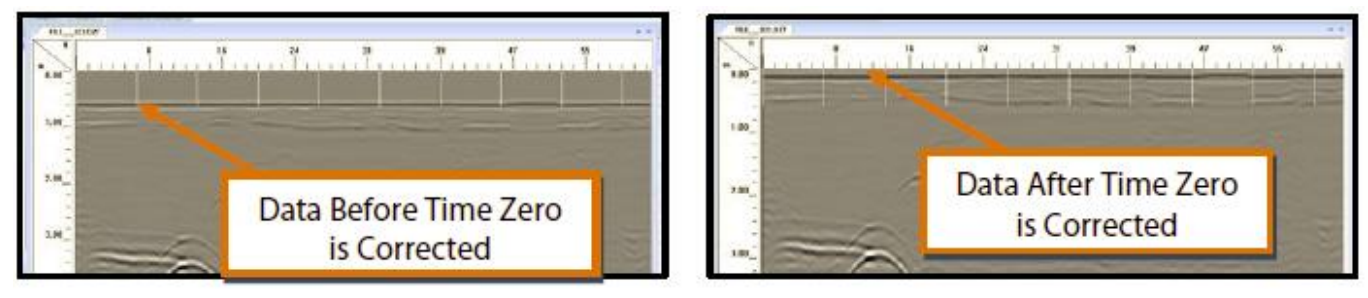

Figure 37. Data before and after time adjusting (GSSI, 2012).

Figure 38 shows how the time correction looks for a single wiggle. The signal before the first positive peak will be removed and the position will get changed. 


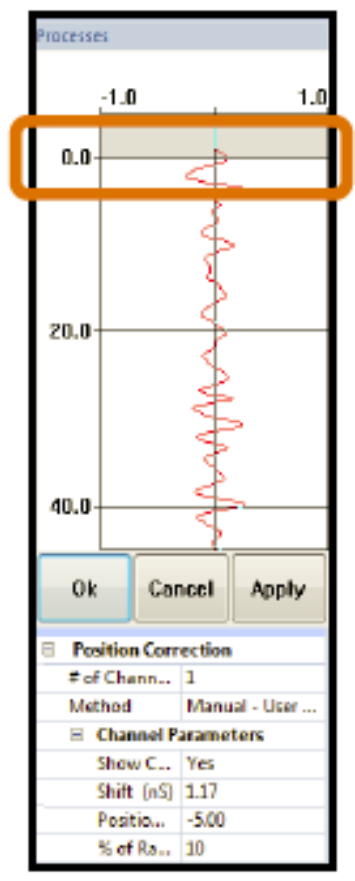

Figure 38. Time adjusting in the wiggle mode (GSSI, 2012).

\subsubsection{Filters}

An important filter is the background removal filter which can remove bands of ringing noise by removing low frequency features. The filter should only be applied on the scans in which the background noise appears. Otherwise continuous features within the data like soil layers or water table reflectors may be filtered out. Figure 39 shows an example data in which the horizontal noise was removed. 


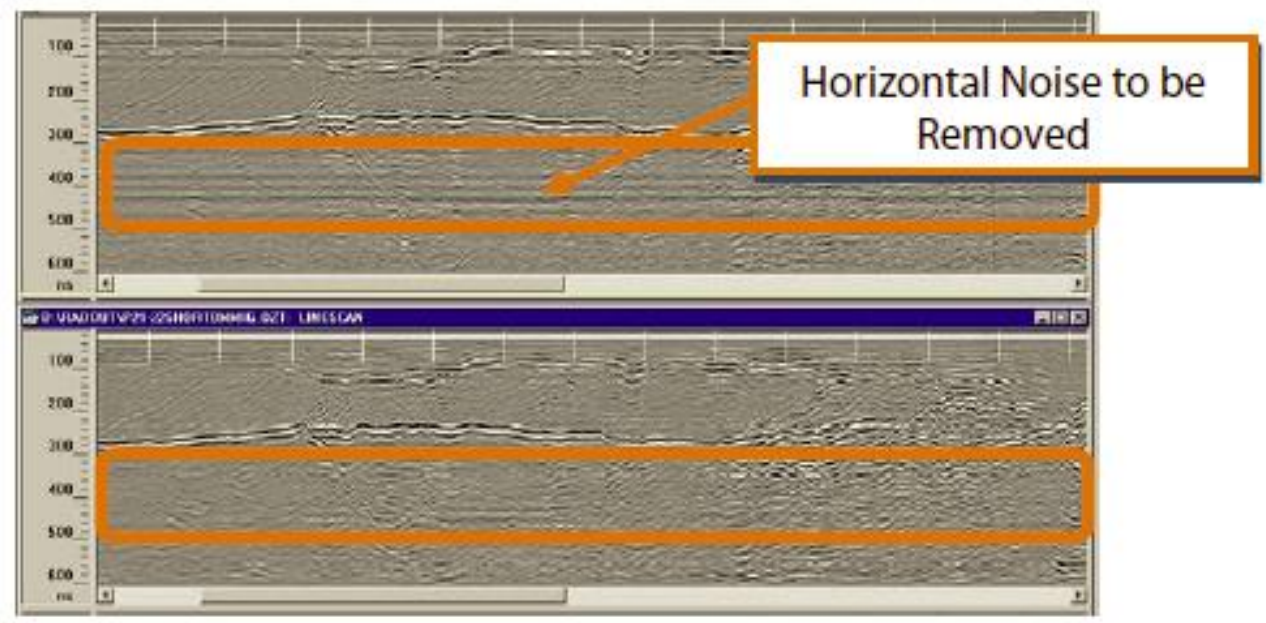

Figure 39. Background removal in RADAN (GSSI, 2012).

RADAN also provides other finite-duration impulse response filters (FIR), IIR filters, and FK filters which can be helpful with different applications. For the purpose of this study, only the FIR filters were used. The FIR filters ensure that the output is a finite filtered version of the object.

RADAN provides two types of FIR filters; the Boxcar Filter and the Triangular Filter. The Boxcar filter provides a running average of the data where sections of the data are averaged to produce a single point on the active window. The next section of data is chosen and another single point is produced at the center of the active window. Each data section is weighed equally. In contrast, the Triangular Filter takes a weighted moving average of the data sections. The center of the data sections are more heavily weighed than the data at the ends of the filters. 


\subsubsection{Focus}

One of the focus functions is the migration function, which helps to remove errors caused by the radar antenna using a wide beamwidth pattern to detect objects which are several feet away. The wide beamwidth pattern is the reason for the appearance of hyperbolic reflectors on the radar record. The antenna detects an object from far away and is then moved over the object. This can lead to an obscuring of deeper objects by shallower objects that appear as constructively interfering hyperbolic reflectors.

With help of the migration function, dipping reflectors can be corrected to their true position and hyperbolic diffractions can be collapsed. Radan provides two different methods of migration: the Kirchhoff and the Hyperbolic Summation. The advantage of the Hyperbolic Summation method is high speed of calculation, which unfortunately comes at the cost of reduced accuracy. On the other hand, the Kirchhoff method provides more accurate results but at a lower calculation speed. Depending on the user goals, either method can be used.

\subsubsection{Other Useful Functions}

Deconvolution is an advanced process function which can remove multiples or ringing when the radar signal bounces back and force between an object. The function is based on the method called 'Predictive Deconvolution'. When the antenna is coupled to the ground the method tries to approximate the shape of the transmitted pulse. It then will predict how data will look in a certain distance 
when the source wavelet is deconvolved from it. As a result the reflected wavelet gets compressed and predictable phenomena are removed from the data.

Another useful function for the interpretation of the GPR images is the 'EZ Tracker'. The tool allows the user to add targets or layers by interpolating data between points. The layers can be displayed in different colors and help making features more visible.

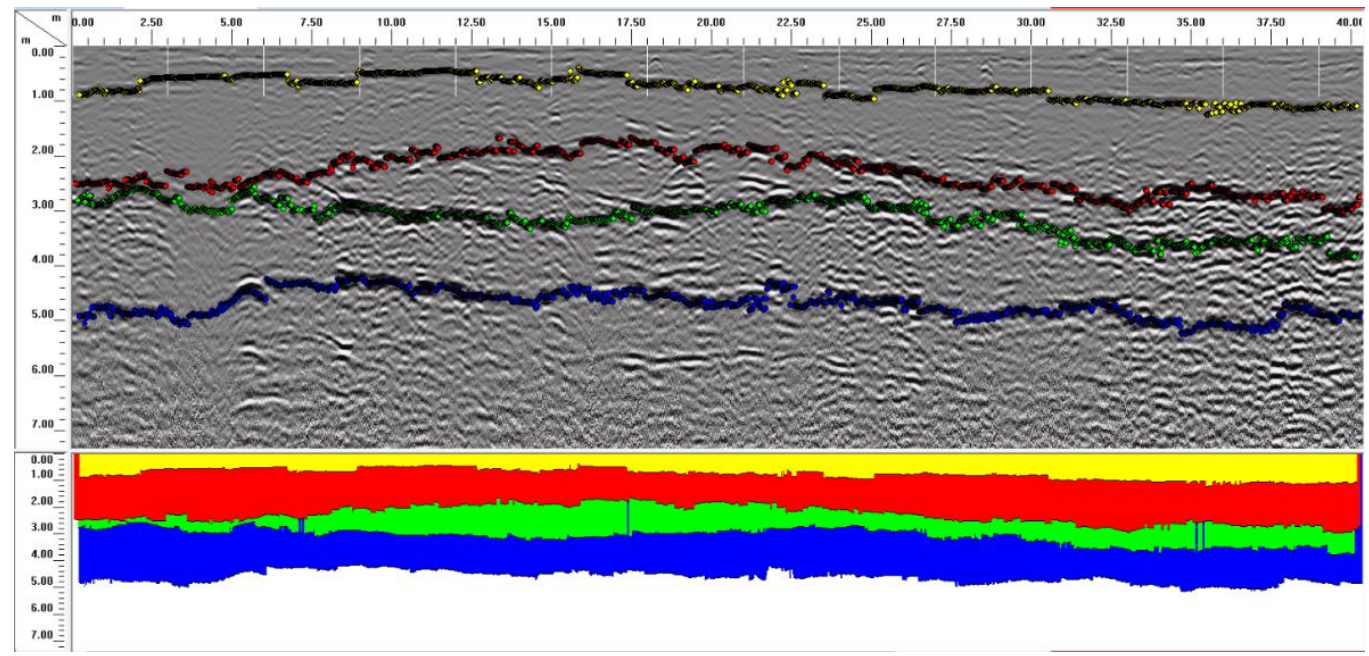

Figure 40. EZ Tracker used to show different soil layers.

Another function which was continuously used in this thesis is the 'Edit Block' function in the 'Adjust Scans' window to delete data or save single pieces to another file.

\subsection{Interpretation of Data}

The interpretation of radar data alone is often not possible. In practice, to improve and clear the interpretation of data, other survey methods have to be 
used in addition. These survey methods can be geological like boreholes or nongeological methods such as site maps or aerial photos.

Some basic rules exist which can help find features and interpret GPR data. Continuous horizontal signals in the whole data set are a strong indicator for a coherent system noise which could be indicating a system malfunction or an unusually flat stratum (D6432-11, 2011). Antenna ringing or a poor coupling can be other reasons for this effect. It is also important to take the environment into account because building foundations, bridge supports, and tree roots can cause reflections in the data which cause errors in the interpretation.

Hyperbolic shapes in the data indicate point reflectors which can have different reasons depending on the surveyed area. For example pipes, drums, tanks, old foundations, graves, boulders, cavities, etc. can cause the typical hyperbolic shape. Figure 41 shows the GPR image of a pipe in the soil. 


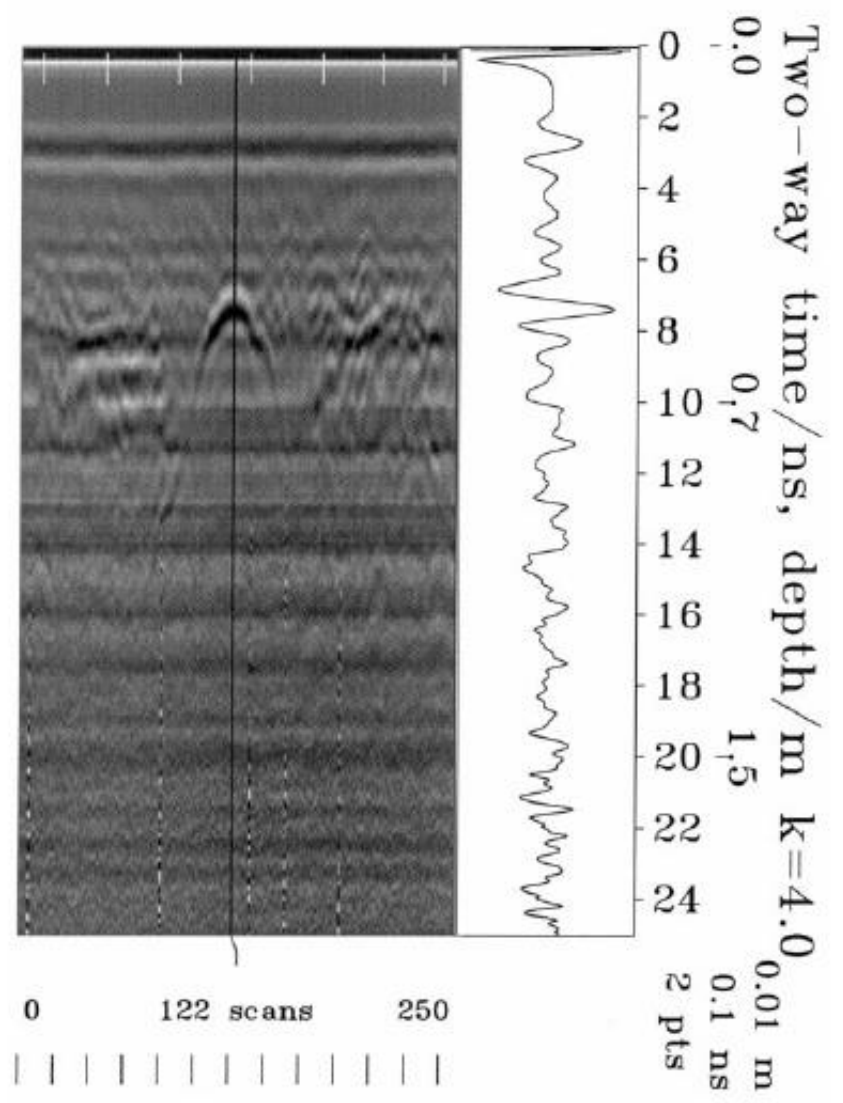

Figure 41. Example for a point reflector: a buried pipe in soil (Olhoeft, 1999).

Lateral changes emerging in the amplitude, phase, or reflection pattern of the GPR data are indicating changes in the soil through rocks, new soil, different moisture content, or the presence of contaminants. An example is provided in Figure 42 . 


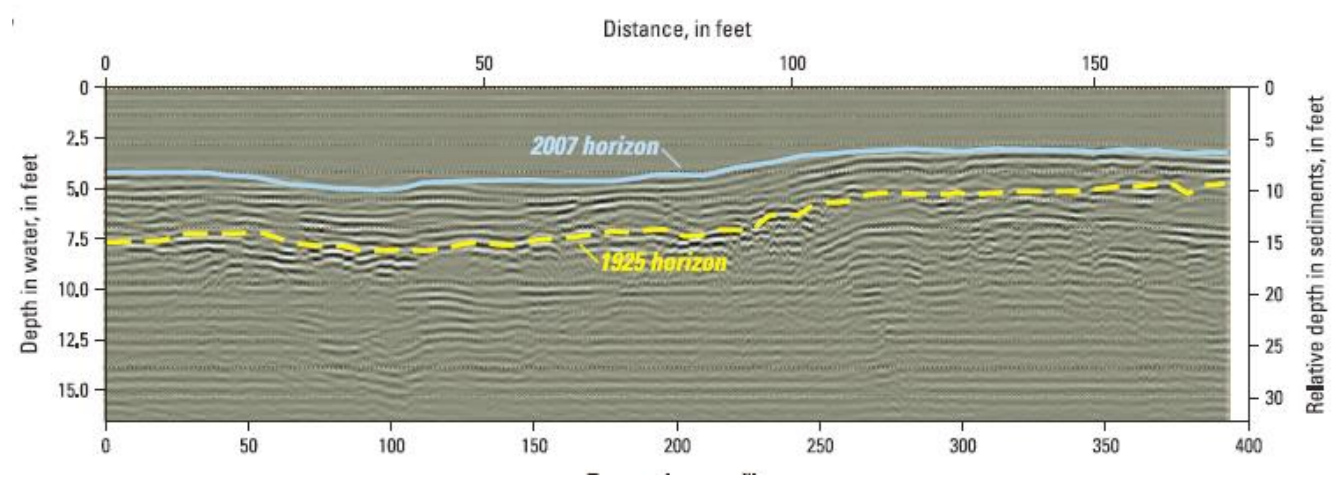

Figure 42. Example for lateral changes: a new soil layer in GPR data (Banks \& Johnson, 2007).

Another point in the interpretation is polarization. The black/white coloring (default color setup) is telling a great deal about the type of material. Positive waves are displayed in white and negative waves in black. The color is distinguished by whichever is the first dominant band in the interface. A weaker band of the opposite color can usually be seen on the top of the first dominant band (see Figure 43). There will also be a strong band of the opposite color below the first dominant band. This is an effect due to an imperfection in the received signal and is called the "halo" effect. 


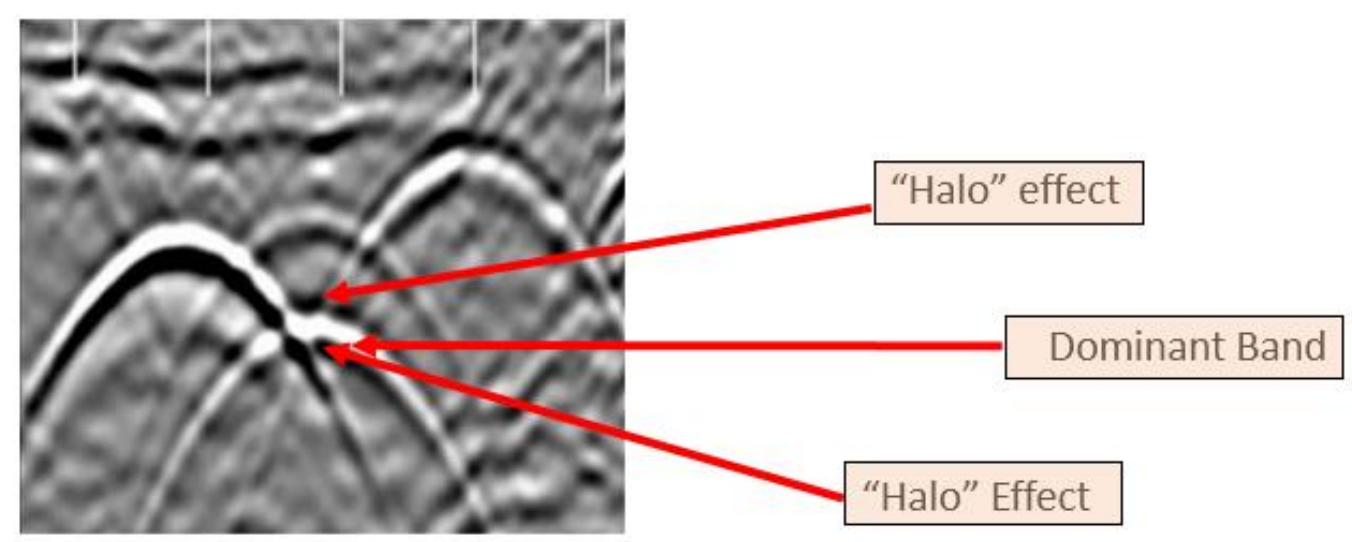

Figure 43. Halo Effect in GPR data.

A negative reflection is the result of an increase in speed of the radar wave when it reaches an object. The wave first travels through materials with higher dielectric constants and then through materials with lower dielectric constants. A positive reflection results from a decrease in speed of a radar wave. In contrast to the negative reflection, the wave originally travels in a medium with a lower dielectric constant and then through a material with a higher dielectric constant. The change in polarity gives a general idea of the object and can then be combined with the knowledge of the area.

Figure 44 on the next page provides the interpretation of some field examples of GPR reflections in relation to soil properties. 

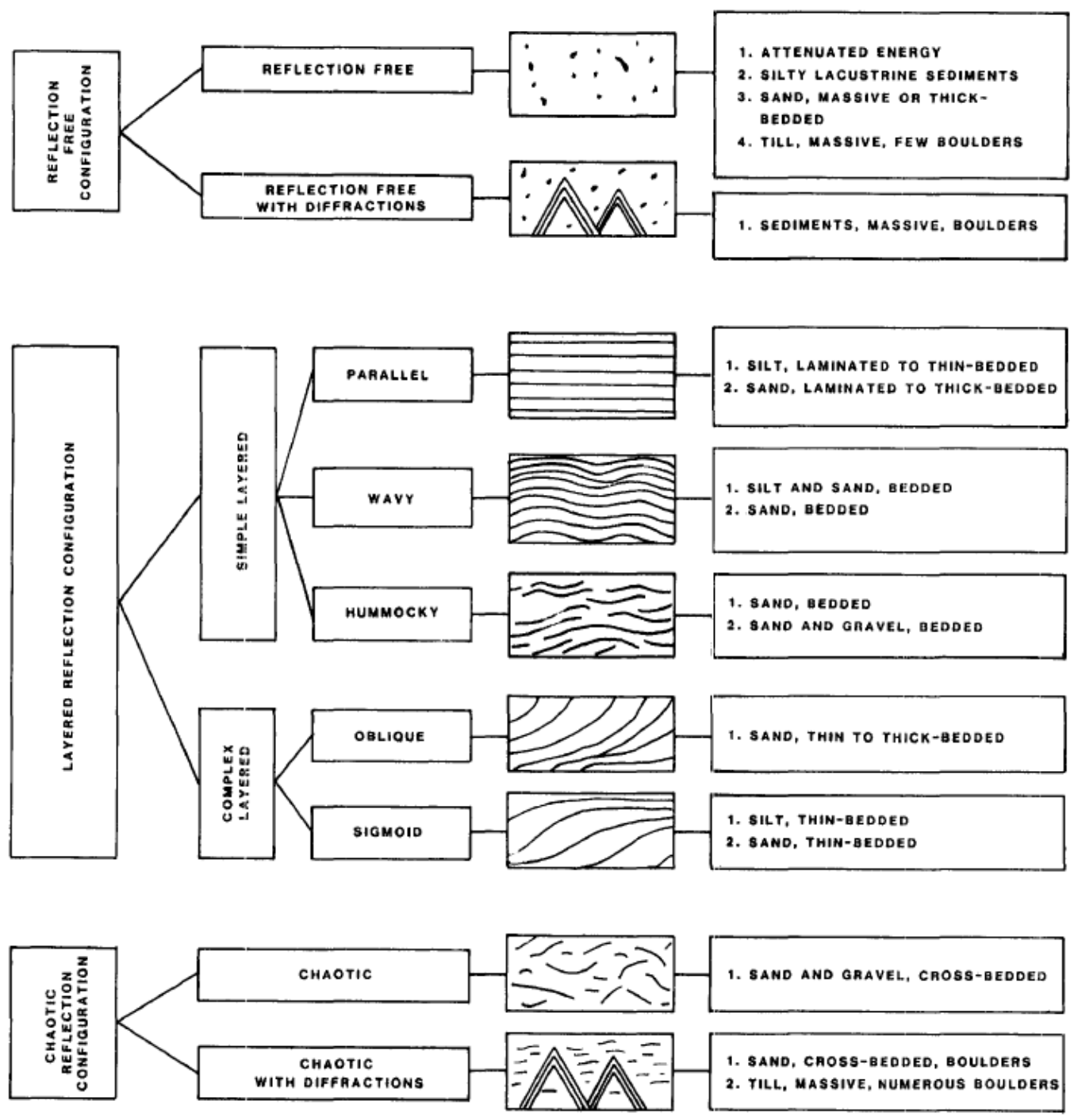

Figure 44. Relation between some radar reflections to soil properties (Milan \& Haeni, 1999). 


\section{Chapter 4}

\section{Investigation of GPR in a Controlled Environment}

This chapter analyzes GPR data collected from local sources other than the bridge scour or shallow rock locations to explore the extents of the GPRs data and test its limitations. The GPR was tested both in water and on soil using the research vessel and survey cart. These sites provided additional data to gain experience with data collection, interpretation, and the GPR set up. Because the site properties are already known, the GPR limits can be identified based on whether or not the GPR finds matching data to the previous tests. The test sites can be seen in Figure 45 .

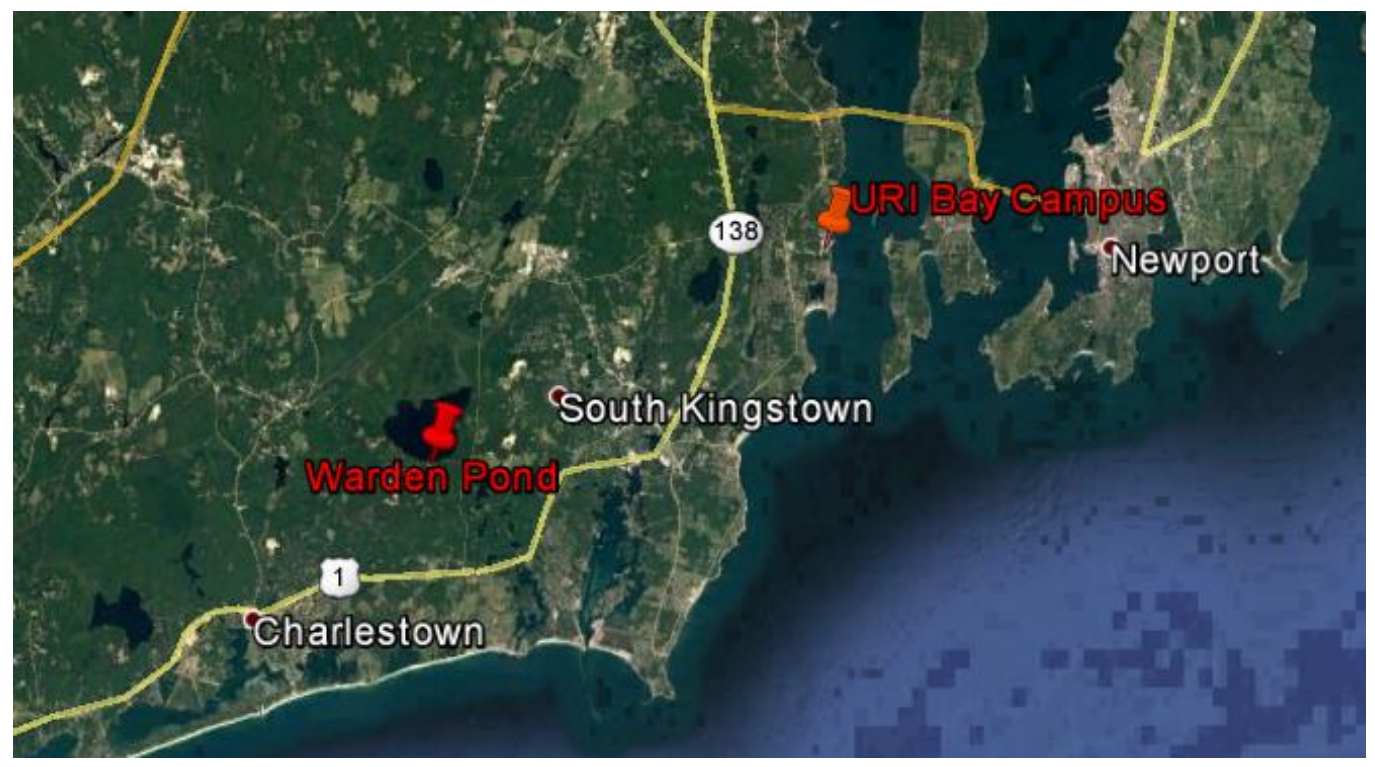

Figure 45. Location of the test sites. 


\subsection{URI Bay Campus, Wave Tank}

The first test was performed in the 100 foot-long wave tank of the Department of Ocean Engineering in the University of Rhode Island. The goal of this test was to become familiar with the GPR and how it functions. The wave tank test helped define parameters and the setup of the GPR in a known, controlled environment.

\subsubsection{Site Description}

The wave tank is shown in Figure 46. It has a length of $30 \mathrm{~m}$, a width of 3.6 $\mathrm{m}$, and a maximum depth of $1.8 \mathrm{~m}$. The tank features an elevation change (a "beach"), gaining water depth from the left to the right. The bottom of the first 22.8 m (75 feet) has metal plates laying on a concrete floor which can be seen in the Figure 46 when the bottom of the tank turns from light green in color to a darker green.

The tank has a towing carriage with a maximum speed of $2 \mathrm{~m} / \mathrm{s}$ which was used to move the research vessel and the GPR in the tank. 


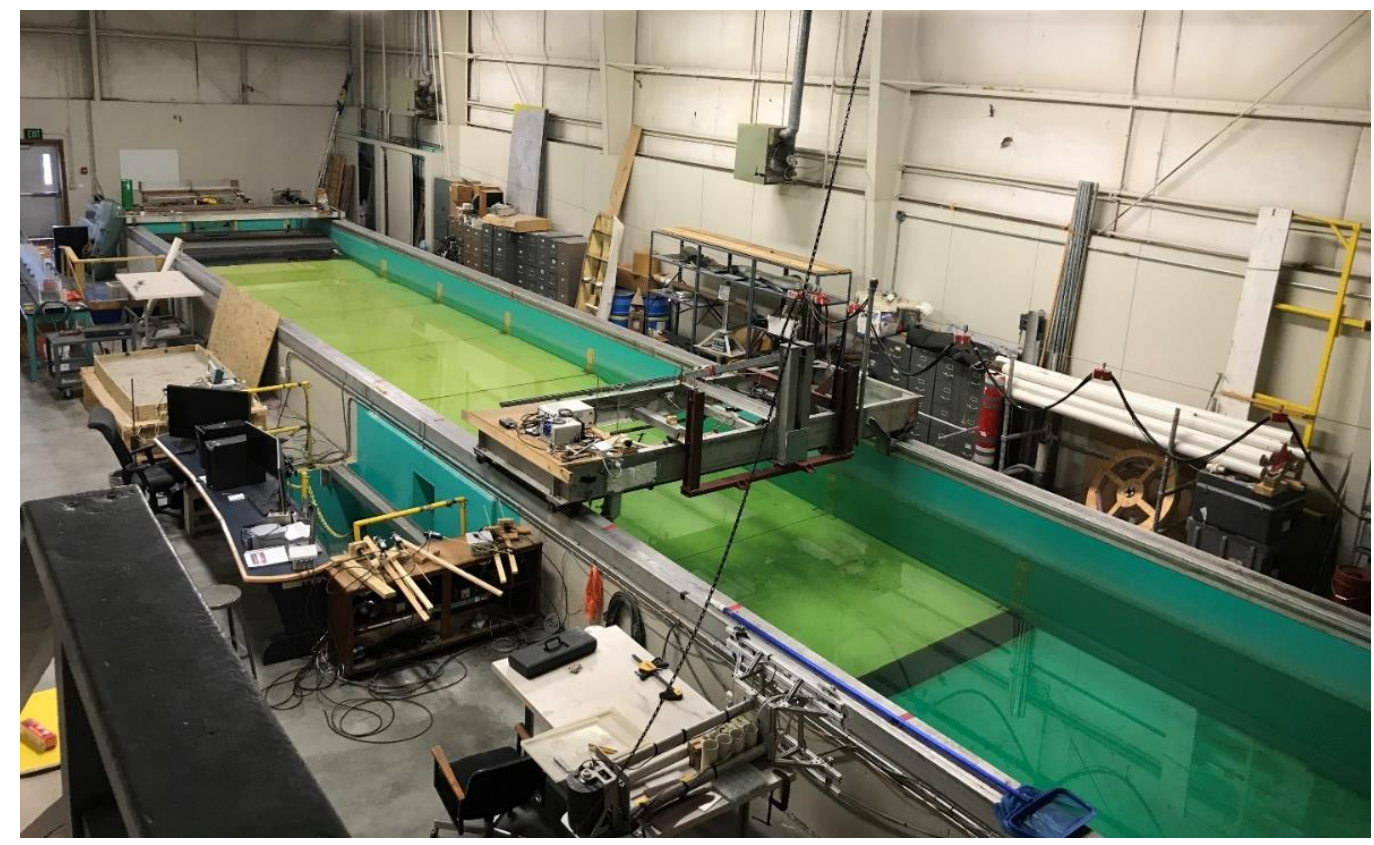

Figure 46. 100 foot-long wave tank at the University of Rhode Island.

\subsubsection{Data collection}

The first test was performed with an inflatable boat which can be seen in Figure 47. The boat was fixed to the crane runaway and then pulled with a constant velocity through the wave tank. The antenna was placed in the boat and the SIR3000 was held by the operator. After a line of measurement, the boat was put in the same position and a new run was started. 


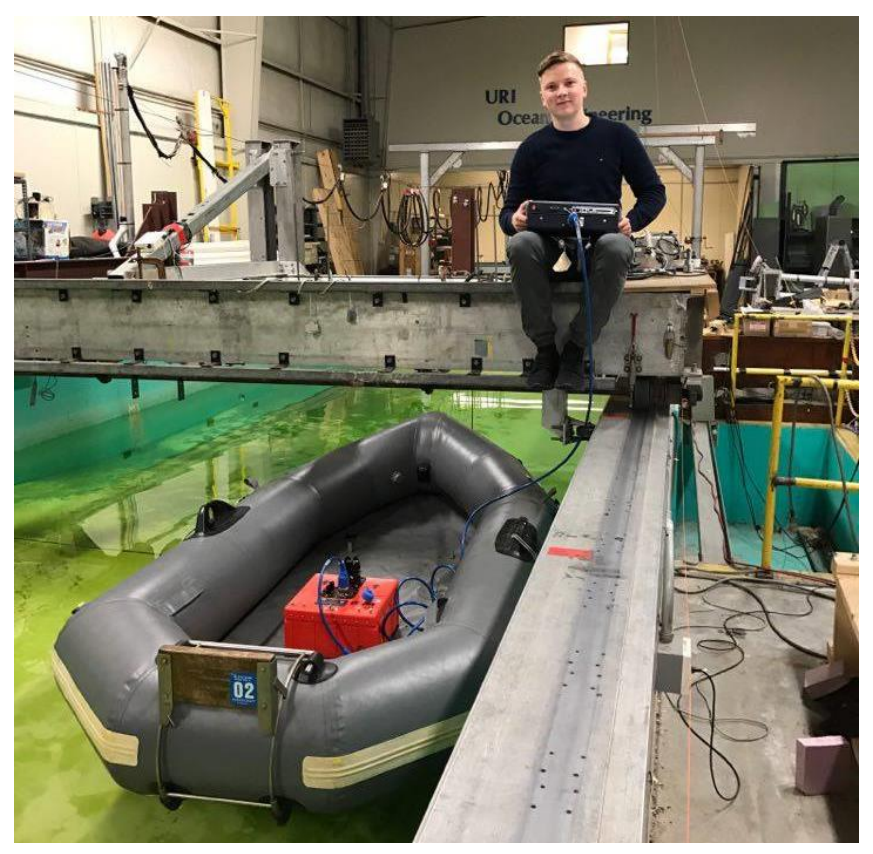

Figure 47. Wave tank test setup.

The parameters for the test can be seen in Figure 48. The test was repeated in different set ups but only the best resolution is shown in this chapter. 


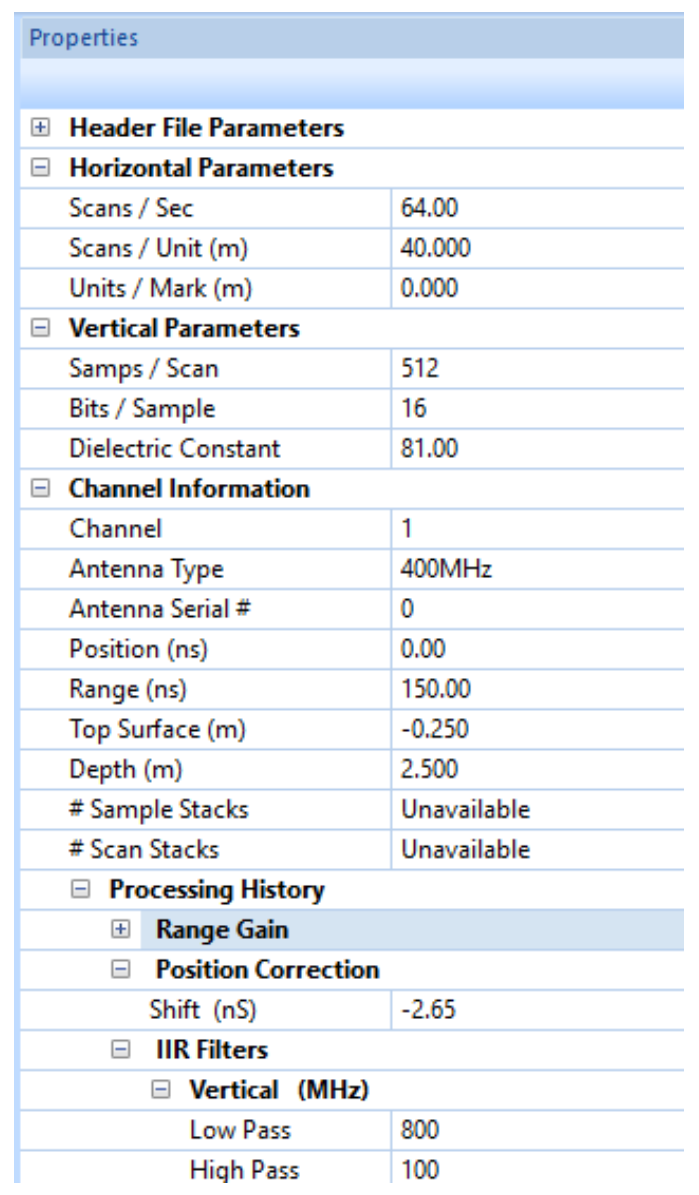

Figure 48. Parameters for wave tank test.

\subsubsection{Results}

The first step in analyzing the results was to process the data in RADAN. A background removal filter was applied together with the time zero function to calculate the real depth profile. Also, a different color xform was chosen to display all features. The difference can be seen in Figure 49 and Figure 50. The most significant differences are the optimized depth profile because of the removal of the direct wave, the less intense multiple features, and the removed hyperbolic features. 


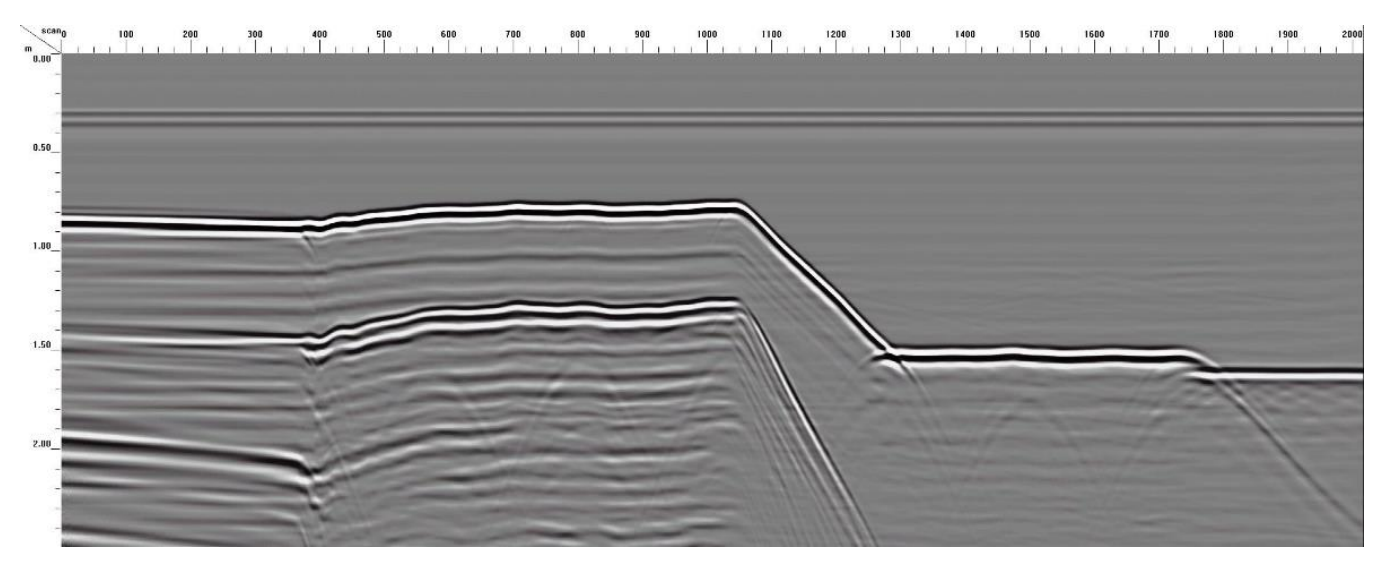

Figure 49. Unprocessed wave tank data.

The unprocessed data in Figure 49 shows the direct wave at $0.3 \mathrm{~m}$. The Figure also displays the changing water depth from the wave tank from $0.8 \mathrm{~m}$ to $1.5 \mathrm{~m}$; note that this is not real depth because time zero function was not applied. The bottom of the wave tank shows a big reflection going along with the halo effect (black - white - black). The first reflection is black, this comes from a negative polarization which means that the waves sped up when they reached the depth of $0.9 \mathrm{~m}$. The data confirms there are metal plates laying on the bottom of the wave tank. The metal plates have a very strong reflection which causes multiples in the data, which are clearly defined because of the same shape of the returning signal. The radar records and analyzes the amount of time it takes to receive a reflection and the strength of the reflection. Strong reflections will cause ongoing reflections at a regular time interval.

Under the metal plates at a depth of $1.7 \mathrm{~m}$ a returning signal of hyperboles can be seen. They are most likely coming from the side walls of the wave tank because the radar signal cannot penetrate through the metal plates. At the end 
of the measurement, at the right side on the radar image, the end of the metal plates and the change to the concrete floor can be seen. The polarization changes from a white to a black top reflection due to the changing wave speed. Concrete has a lower dielectric constant (dielectric of 8) than water (dielectric of 81), which allows the waves to travel faster.

The processed data in Figure 50 shows the real depth of the profile, $0.5 \mathrm{~m}$ to $1.2 \mathrm{~m}$. The hyperboles have been removed because they are not actual features and the multiples are less intense.

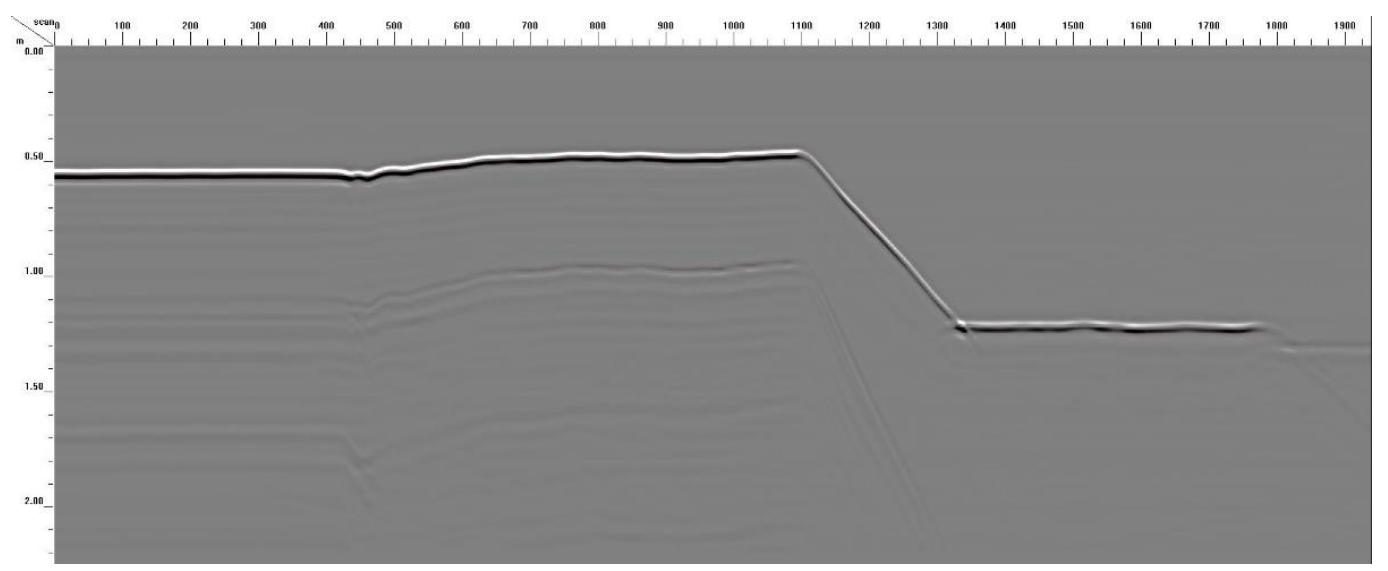

Figure 50. Wave Tank Data (processed).

The test was successful and proved that it was possible to collect satisfying bathymetry data and other features with the setup. The inflatable boat as the floating device worked in the controlled lab, but was altered so that the small antenna could not move around the boat when there was rough water movement. The new pontoon boat was introduced in Section 3.1 in which a water proof box for the antenna was mounted between two lifting bodies. 
Although the setup was successful, the test also showed a problem with the parameter setup. GPR applications in water are a challenging environment because water has a very high dielectric constant. When the GPR is using the GAIN function and it comes to a high change in polarity, for example when the radar wave hits the bottom of the tank and the reflection is also strong, the so called 'clipping effect (over gain)' can occur. Figure 51 shows a single scan of the data next to the linescan. At the depth of $0.8 \mathrm{~m}$ the clipping effect is visible. Data clipping occurs when the transmitted pulse reflected back to the receiver is increased higher than the maximum recordable amplitude because of the gain function. The gain function is used by the GPR to strengthen signals from deeper down. A true reflection will always be weaker than the transmitted pulse, so if the scan is not increased (whether display or time-variable) there is no need to worry about clipping. However, even if data clipping occurs, it is possible to still see a feature. The only aspect lost on a clipped waveform is the maximum amplitude of a reflection. By running a time-variable gain (or range gain in RADAN) to decrease the amplitude, data will no longer appear clipped. 


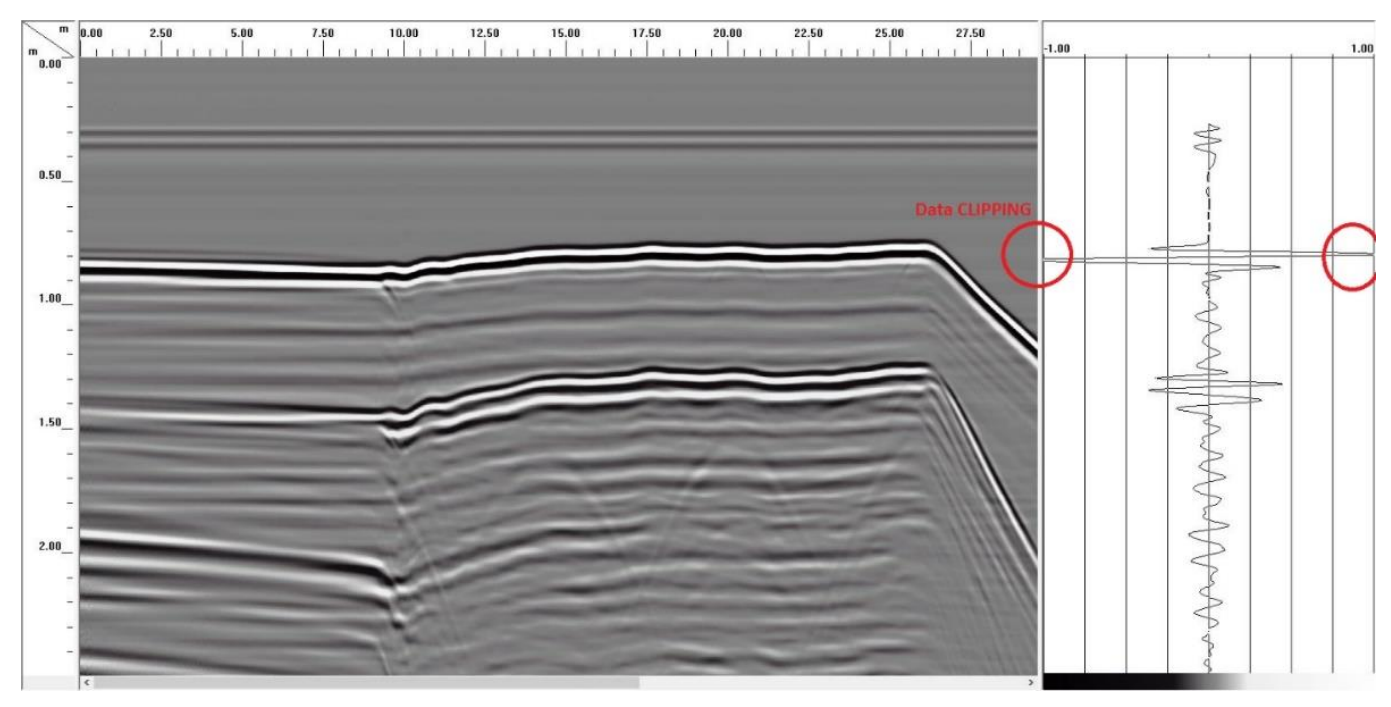

Figure 51. Clipping effect at $0.8 \mathrm{~m}$ depth.

\subsection{URI Bay Campus, Sandbox}

A sandbox was previously constructed and used in the Sheets Building of the Department of Ocean Engineering for dynamic cone penetration tests (Parent, et al., 2017). The soil conditions (different layering) are known and provide a controlled environment to test the GPR.

\subsubsection{Site Description}

The sandbox consists of three soil layers. The bottom layer is of gravel, the middle layer is a $50 / 50$ mix of sand and $3 / 4$ " minus gravel and the top layer is $20 \%$ silt, $30 \% 3 / 4$ " minus gravel, and $50 \%$ sand (Parent, et al., 2017). The soil material was shoveled in the tank, raked, leveled, and compacted (see Figure 52 and Figure 53). 


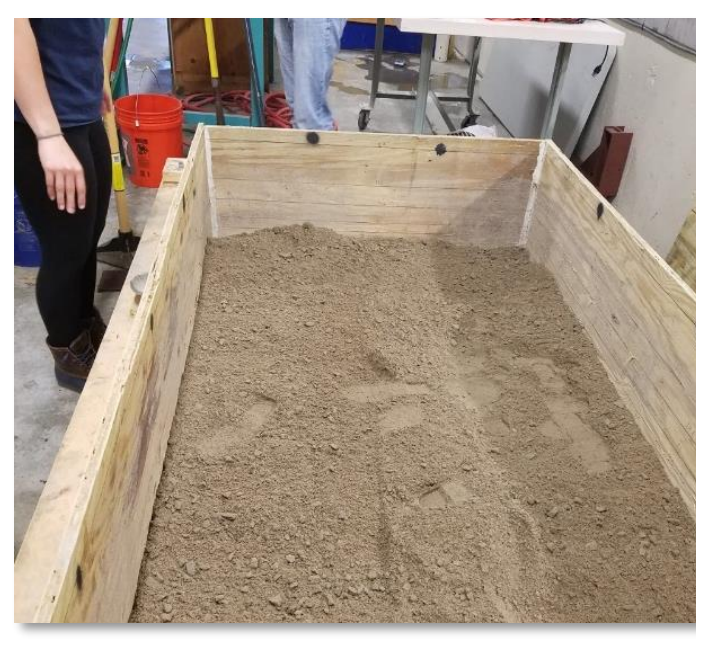

Figure 52. Layer 1 construction (Parent, et al., 2017).

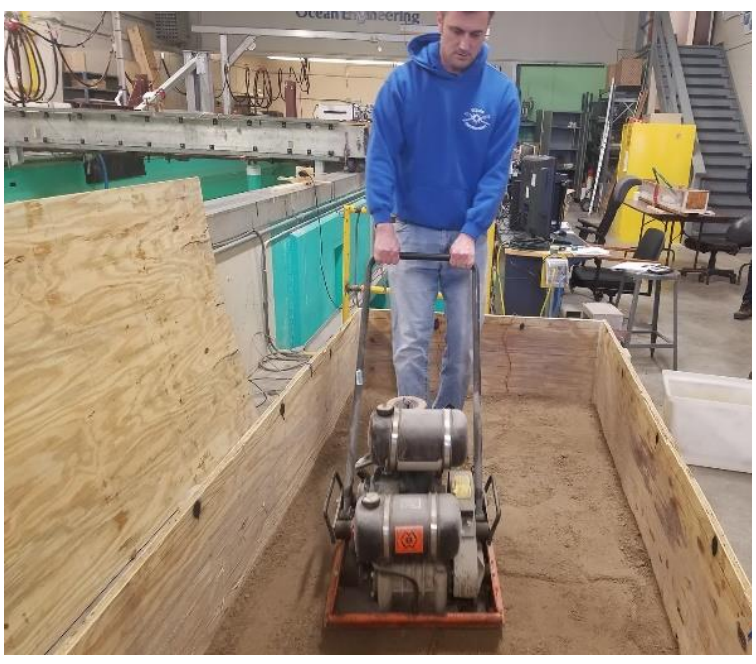

Figure 53. Layer 1 compaction (Parent, et al., 2017).

The first layer had a height of 8 inches after compaction. The second and third layer had a thickness of 7 inches each after compaction.

\subsubsection{Data Collection}

A cross-sectional GPR profile was collected as shown in Figure 54. The setting for the GPR was in the time mode, because the sandbox was too small for the cart (distance mode). The other parameter settings are shown in Table 5. The dielectric constant of dry sand is between three and six. It was changed to 5 for the test. The range was adjusted to $15 \mathrm{~ns}$ to see only the sandbox without features underneath. 


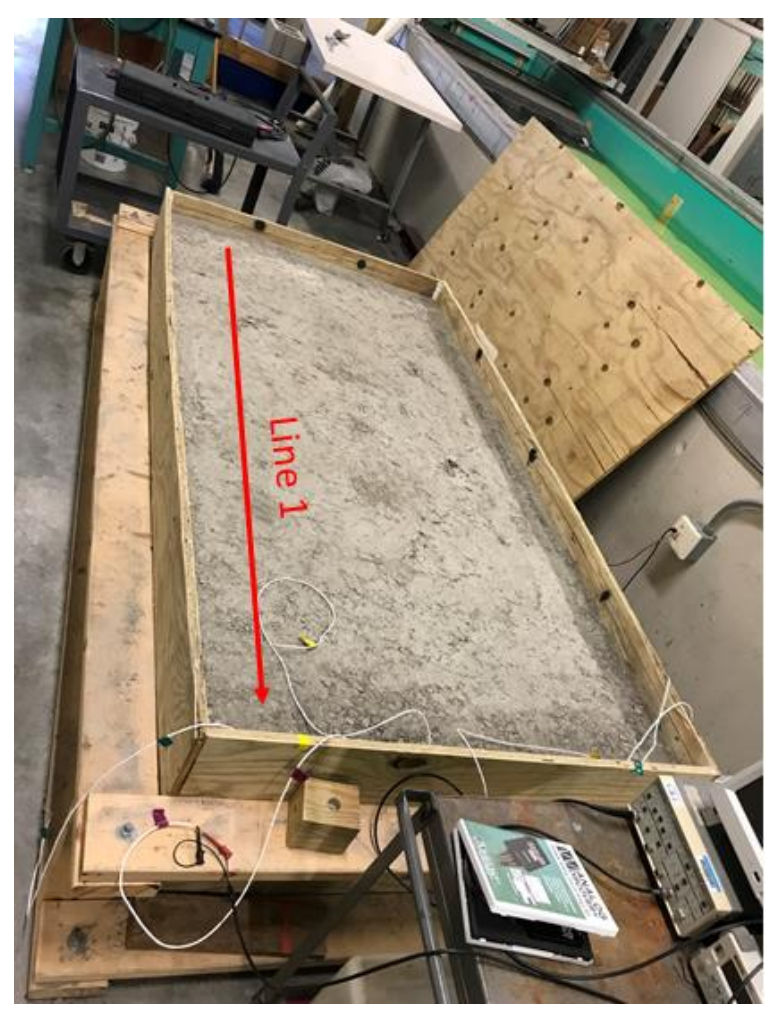

Figure 54. Measurement line in the sandbox.

Table 5. Parameter setup at the sandbox test.

\begin{tabular}{|c|c|}
\hline Paramter & Value \\
\hline Antenna type & $400 \mathrm{MHZ}$ \\
\hline Scans/Sec & 64 \\
\hline Samps/Scan & 1024 \\
\hline Bits/Scan & 16 \\
\hline Dielectric Constant & 7.95 \\
\hline Range (ns) & 15 \\
\hline Low Pass IIR Filter & 800 \\
\hline High Pass IIR Filter & 100 \\
\hline
\end{tabular}




\subsubsection{Results}

The radar image after processing can be seen in Figure 55. The soil layers are not visible in the data. The first clear change of polarity is at around $0.45 \mathrm{~m}$, which is the interface of the sandbox and the concrete underneath it. The reason for that is explained in Section 2.2.4. Equation (5) can be used to calculate the difference in the dielectric constant (relative permittivity) between the different layers. The relative permittivity of dry sand and gravel is nearly the same. The contrast between the materials is too small to see layering. Another factor to be considered is the vertical resolution of the antenna, which is around $20 \mathrm{~cm}$ for a $400 \mathrm{MHZ}$ antenna in dry sand. The soil layers in the sand box are thinner than that, about $10 \mathrm{~cm}$, which could also be the reason for the missing reflections.

Furthermore, the depth calculation is not $100 \%$ accurate due to the estimated dielectric constant of the material in the sandbox which is a mix of different dielectric constants. 


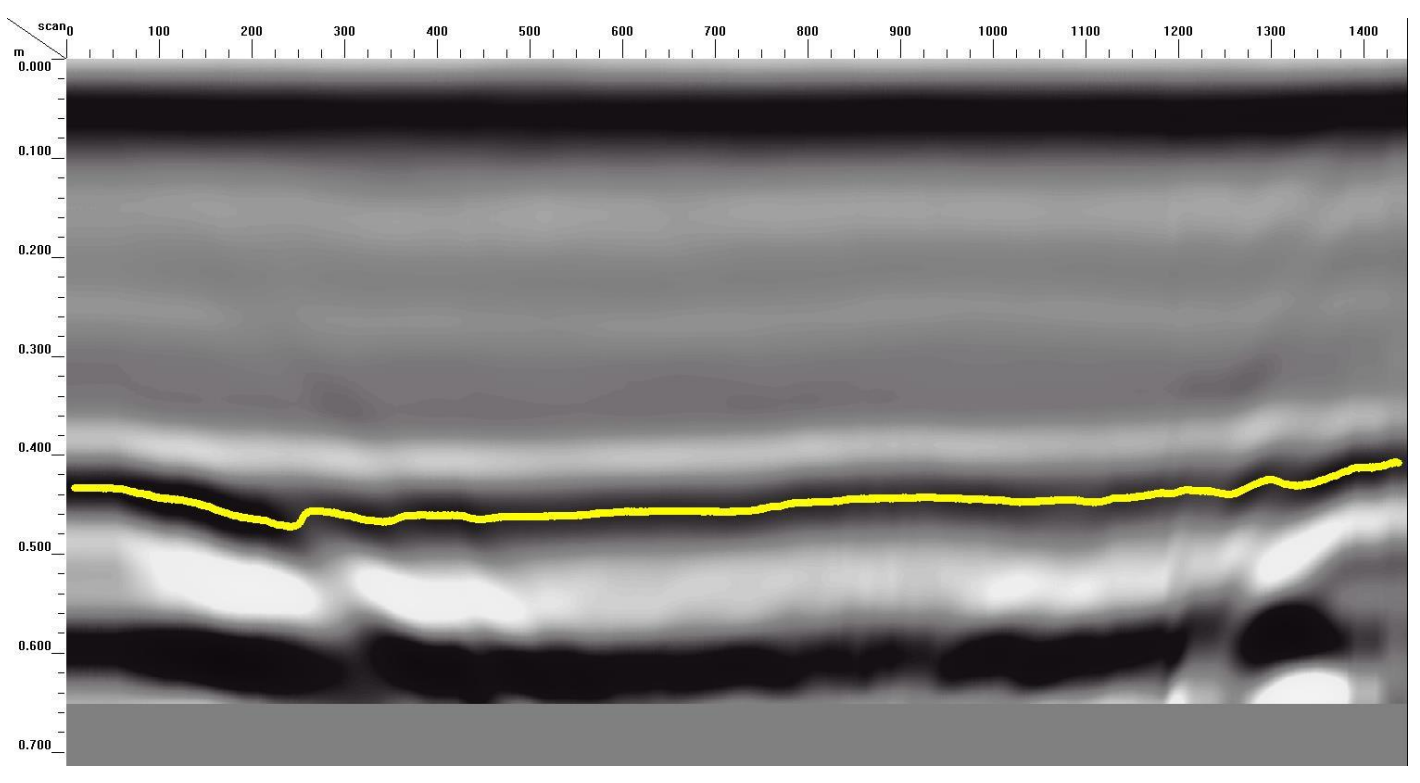

Figure 55. Processed \& Interpreted Sandbox data. 


\subsection{Worden Pond}

\subsubsection{Site Description}

Worden Pond is a 1,043 ac freshwater lake located in Wakefield, Rhode Island (Figure 56 and Figure 57). The lake was chosen due to its easy access and because it has fine bed material, which is an easy soil to investigate with the GPR. Although there was no previous data taken on Wardens Pond, the homogeneity of the bed material guaranteed that the radar waves would not have strong reflections. This survey allowed for the range of the GPR to be tested, or in other words helped find the depth limit on the GPR in fresh, still water. This site was also a beneficial test site because it mirrored the basic conditions of the upcoming bridge surveys (Chapter 6).

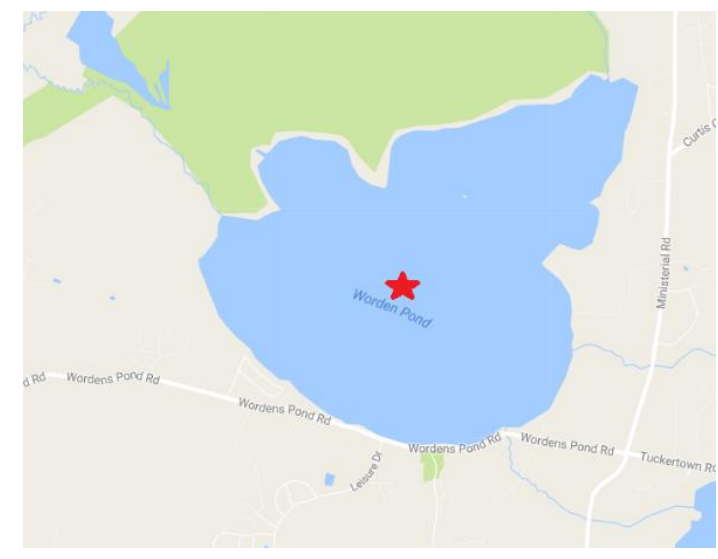

Figure 56. Location of the Worden Pond near Wakefield, RI (Google Maps, 2017).

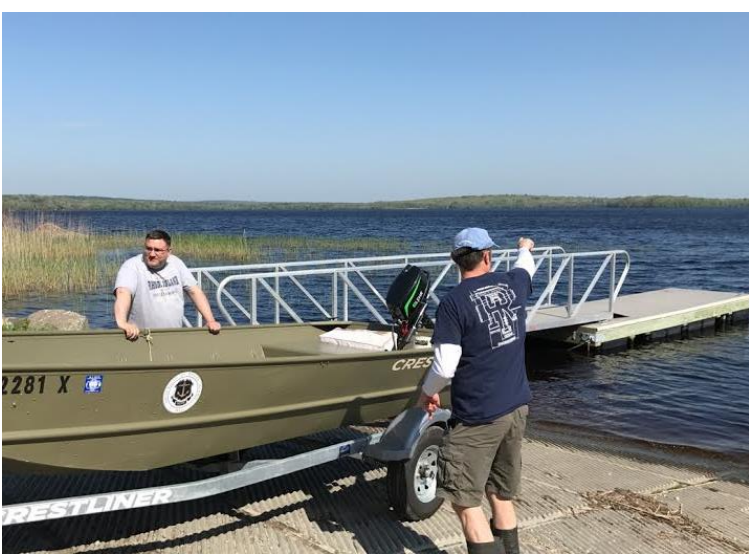

Figure 57. Worden Pond near Wakefield, RI. 


\subsubsection{Data Collection}

The GPR was used together with a hummingbird sidescan sonar system in a 15-foot Jon Boat (Figure 58). The GPR was placed in the pontoon boat and was pulled alongside the boat. The sidescan sonar was used to confirm the depth calculation of the GPR.

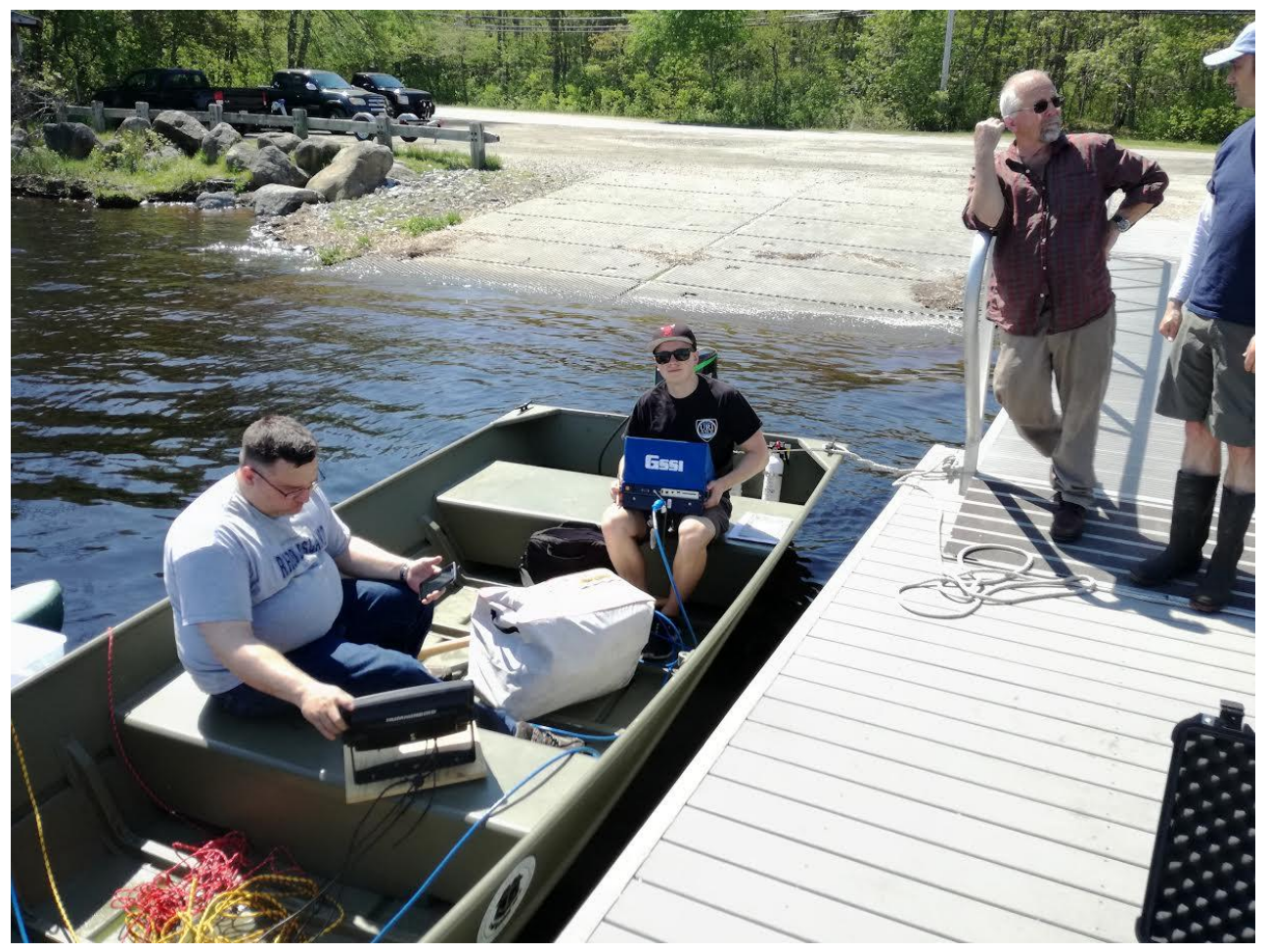

Figure 58. Test set up at the Worden Pond.

The parameters for a survey in water were all set after the test in the wave tank. The only parameter which was not defined was the range/depth of the GPR. The test was performed multiple times with different range parameters to test the vertical resolution (Table 6). The measurements were not taken at the same 
locations. It was not important to compare the images for specific features but only to see how the vertical resolution changes.

Table 6. Parameter Set Up at the Worden Pond.

\begin{tabular}{|c|c|}
\hline Paramter & Value \\
\hline Antenna type & $400 \mathrm{MHZ}$ \\
\hline Scans/Sec & 64 \\
\hline Samps/Scan & 1024 \\
\hline Bits/Scan & 16 \\
\hline Dielectric Constant & 81 \\
\hline Range (ns) & $100,180,250,310$ \\
\hline Low Pass IIR Filter & 800 \\
\hline High Pass IIR Filter & 100 \\
\hline
\end{tabular}

\subsubsection{Results}

Figure 59 and Figure 61 show the processed radar image with 180 ns and 310 ns of range. In Figure 59, the bathymetry and soil features are easily identifiable. The horizontal axis is the number of scans and the vertical axis is the depth. In Figure 60 the water depth is at $1.6 \mathrm{~m}$ (yellow) when the first soil layer begins (between yellow and green). There are different horizontal reflectors which indicate different soil layers at $1.6 \mathrm{~m}, 2.0 \mathrm{~m}$, and $2.5 \mathrm{~m}$. The horizontal, black reflections between the yellow and green line are assumed as multiples from the strong first reflection of the soil. Some boulders can also be found at scans 1000 - 2000. 


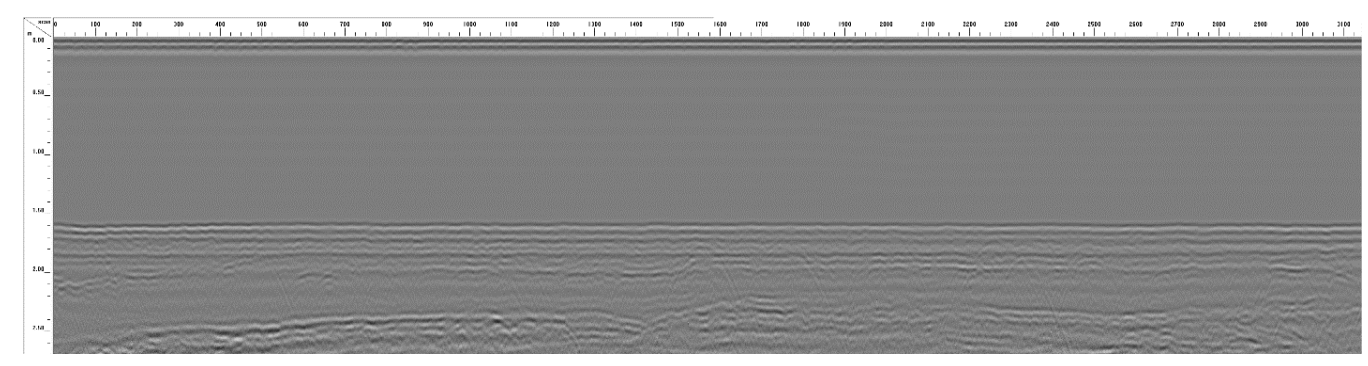

Figure 59. Worden Pond with 180 ns range (processed).

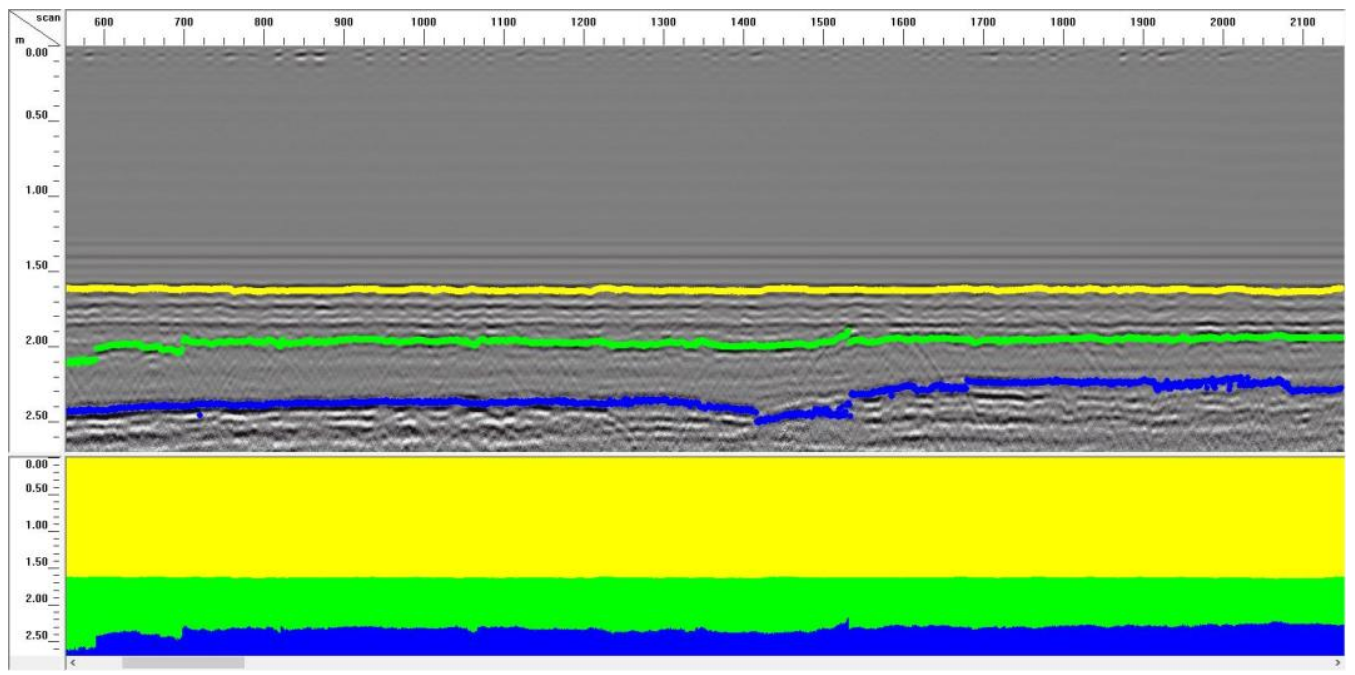

Figure 60. Worden Pond with 180 ns range (interpreted, not whole measurement is shown).

Figure 61 shows the 310 ns radar image; note that there is no resolution lost but that more data has to fit on the same size screen, so it is simply the appearance of the radar image. It is possible to see the water depth at around $1.3 \mathrm{~m}$, and at around $3 \mathrm{~m}$ the data becomes blurry, which is an indicator for the limit of the vertical resolution. Features such as different soil layers or boulders are hard to see, meaning that the 310 ns radar image would not be ideal for the bridge survey tests. 
Figure 61. Worden Pond with 310 ns range (processed).

The sonar confirmed the depth calculation of the water depth. The tests were successful in determining the best setup for the bridge applications.

\subsection{Discussion of Surveys and Results}

The three test setups provided important information for the surveys planned in the next chapters. The test in the wave tank showed that bathymetry data could be collected but strong reflections together with too high gain function can lead to over gain and the clipping effect in data. The scour surveys will have a similar setup and strong reflection could lead to the same effect, which is especially problematic due to the small features of interest in that kind of surveys.

The sandbox test uncovered another difficulty for both the scour and the shallow rock surveys. If the change in the dielectric constant of the materials is not high enough, there is no high amplitude and no change in polarity and features like the layering in the sandbox were not visible. This means that during scour surveys, a scour hole has to be filled with a different material to be visible in a GPR image. If it is filled with the same material as its surroundings, the GPR will not locate it. 
The test in the Worden Pond showed that the $400 \mathrm{MHZ}$ antenna has its vertical penetration limit in the water environment (water depth around 1.5) at around $3 \mathrm{~m}$. Fortunately that is not a problem and was expected because the water depth of the later surveyed streams is shallower and the features of interest are not deep in the soil. 


\section{Chapter 5}

\section{Investigation of Shallow Rock using GPR}

All four locations (Figure 62) in this Chapter were chosen because previous research identified the depth to bedrock from borings and shear wave velocity profiles (Wulff, 2016). Due to the previous work all four locations provide shear wave velocity profiles and three of the four sites have boring longs. This provided a base point to which the GPR analysis could be compared.

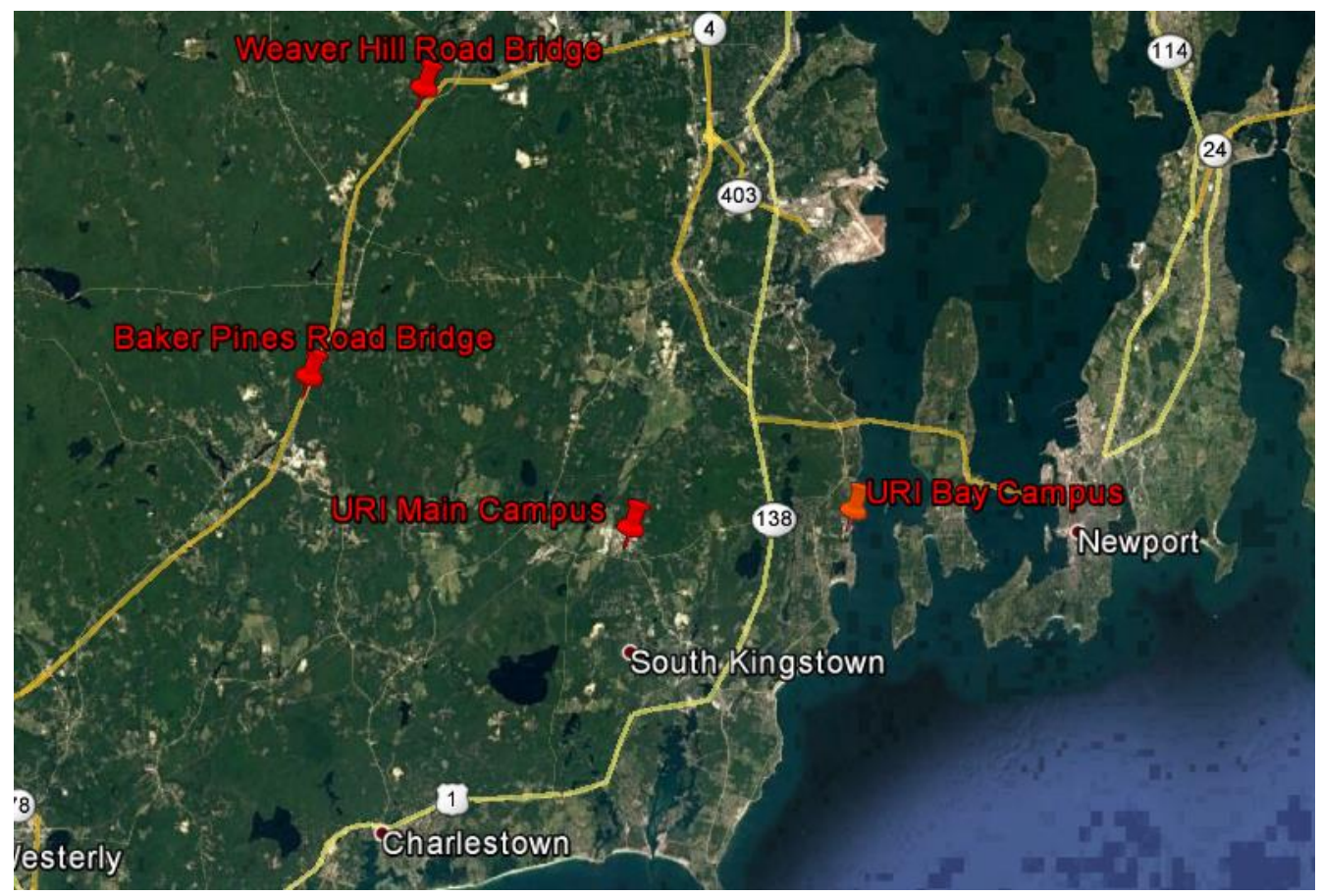

Figure 62. Shallow rock survey locations.

The GPR suitability map for Rhode Island is provided in Figure 63. New England in general provides good survey ground and should not be a problem for the survey sites. 


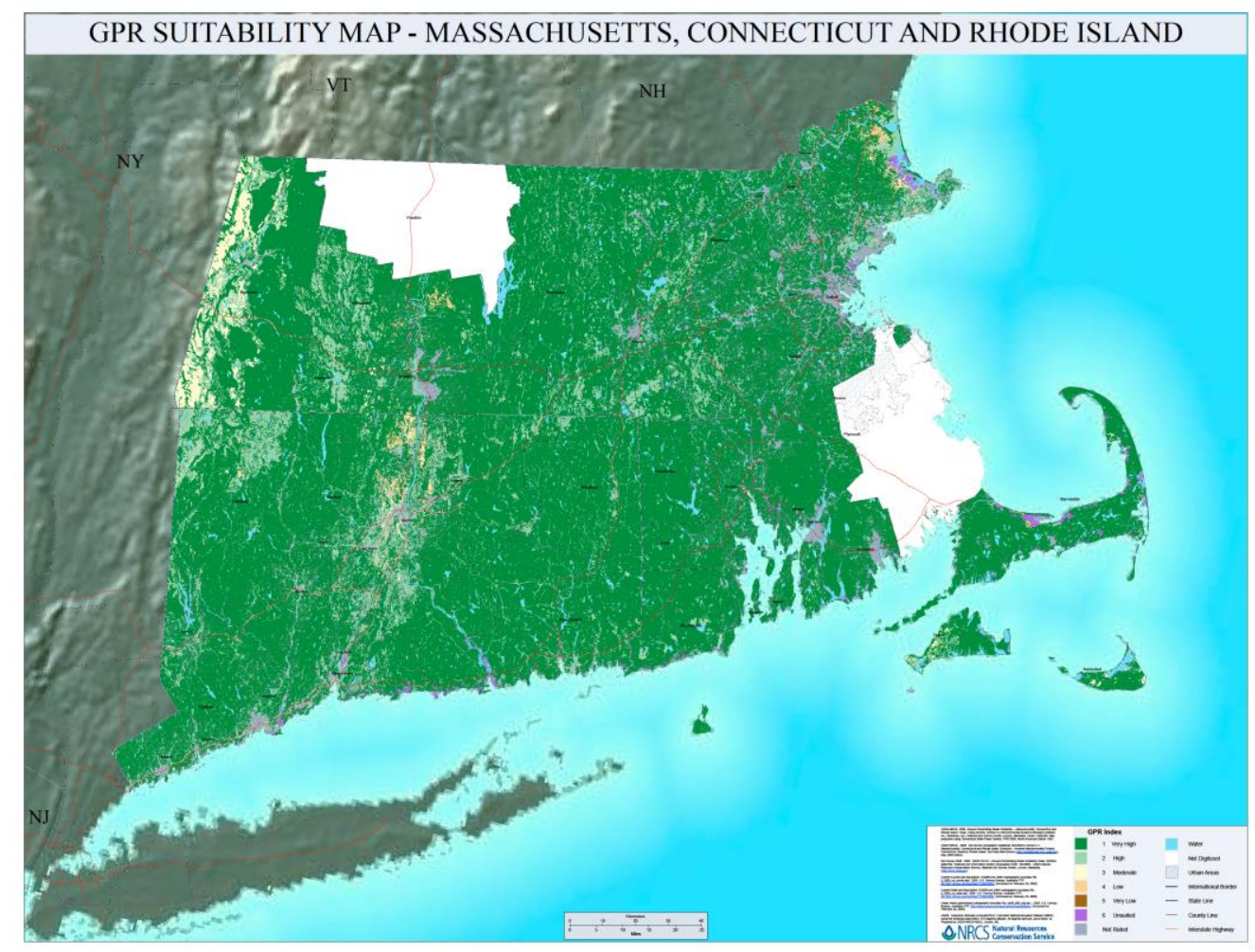

Figure 63. GPR suitability map for Massachusetts, Connecticut and Rhode Island (USDA, 2009).

\subsection{URI Main Campus}

The location on the URI Main Campus was tested as a way to confirm the GPR's data against data previously taken.

\subsubsection{Site Description}

Geotechnical borings were performed in 2016 at URI for the design and construction of the new Engineering building and quad. GZA Geoenvironmental, Inc. conducted twelve borings conducted twelve borings (Figure 64) for the design 
of the new building. Three of the borings identified the presence of shallow rock and were used in Wulff's study in 2016. Unfortunately for this study, the construction had already begun and there was limited accessibility to the exact boring locations. The closest accessible location is near the boring GZ-4 and can be seen in Figure 65.

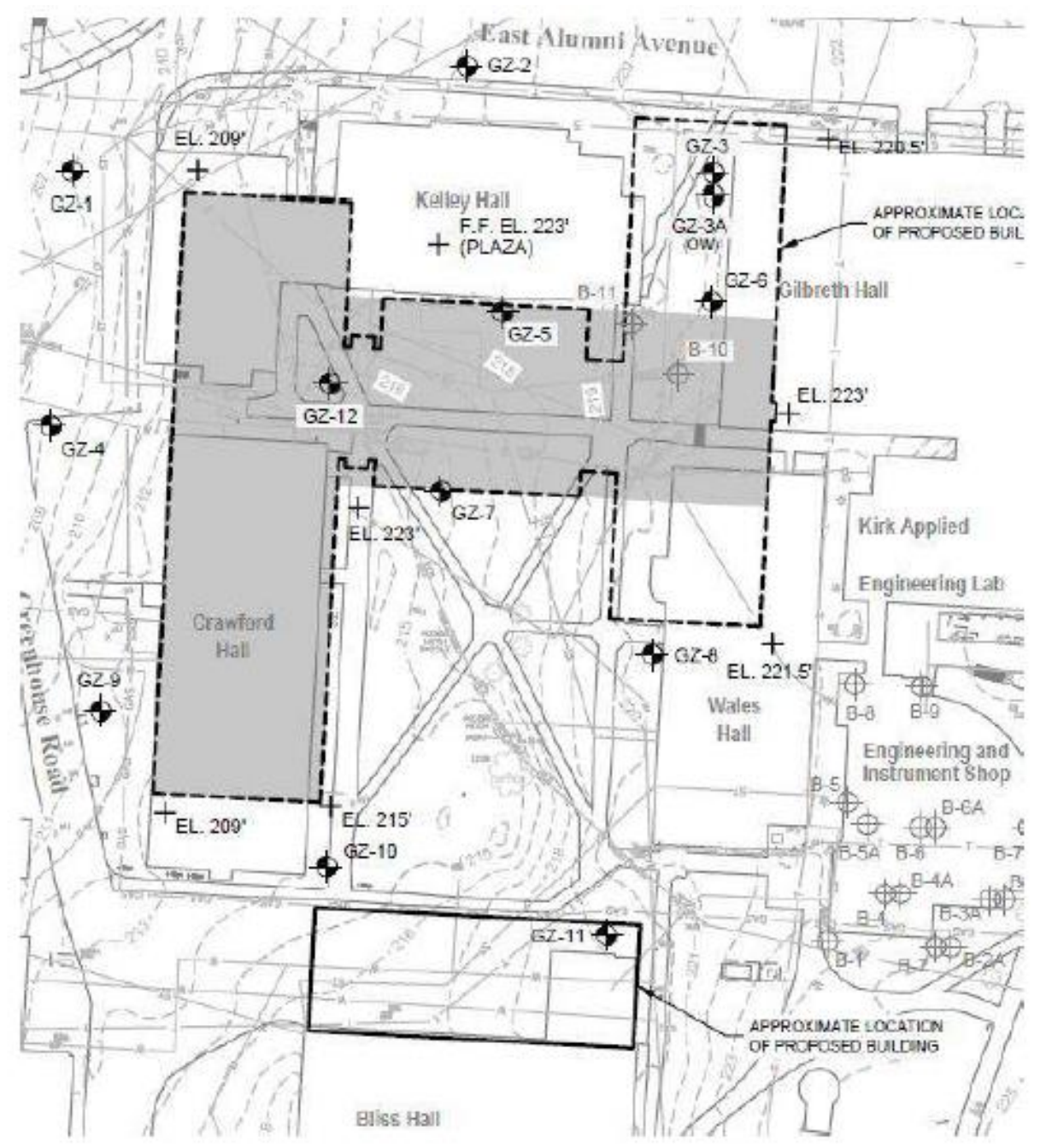

Figure 64. Boring Locations at the URI Main Campus. 


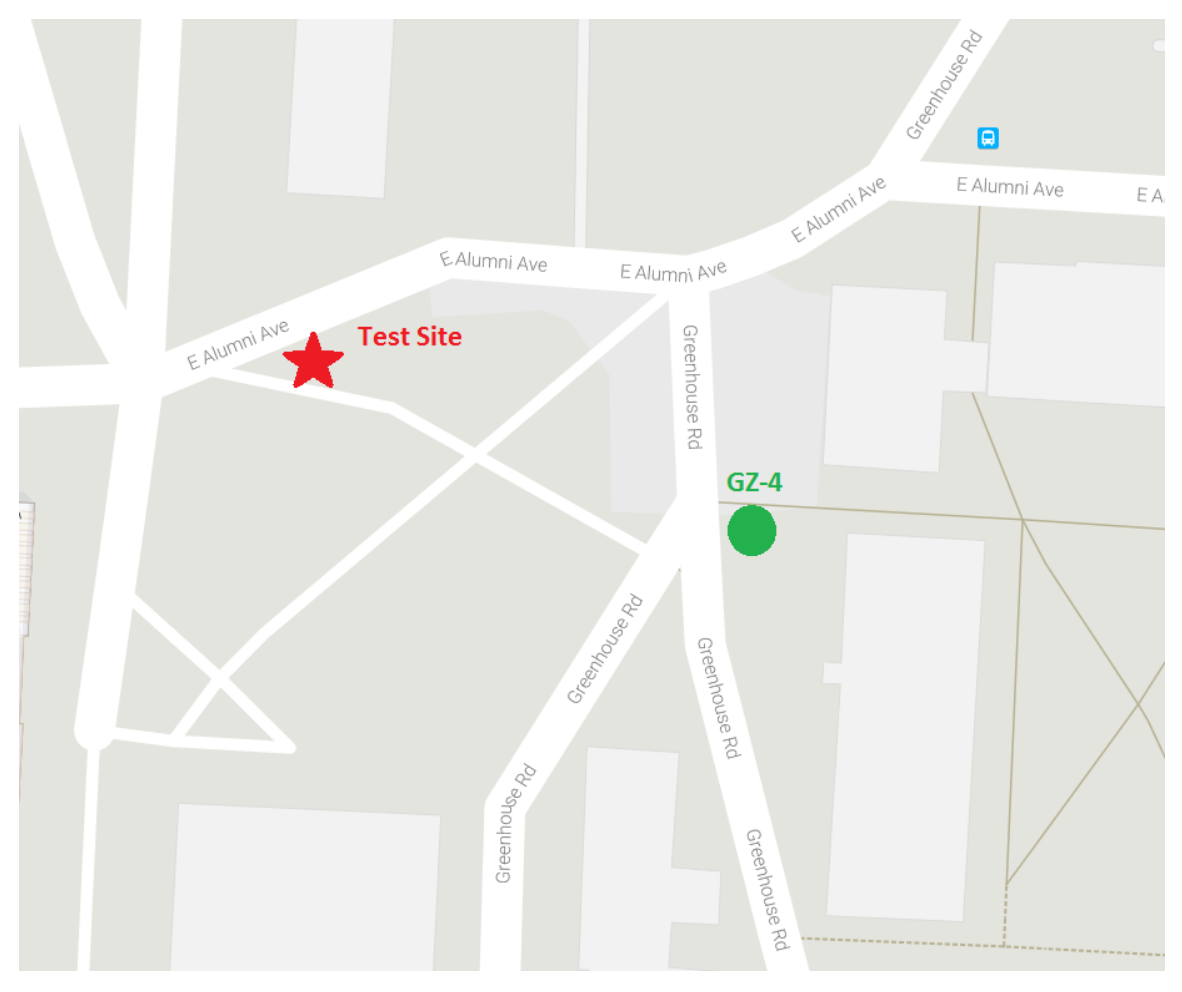

Figure 65. Closest accessible location for the GPR survey (red) and boring location GZ-4 (green).

The test site is an area south of E. Alumni Ave between the roadway and a paved walking way connecting E. Alumni Ave and Greenhouse Rd.

The boring profiles and the shear wave profiles can be seen in Figure 66. The boring profile shows a thin topsoil followed by dense, medium dense, and loose fine sand with a trace of gravel and silt. At a depth of 2.8 meters, the rock layer starts. The shear wave velocity profiles confirm the start of the rock layer. 


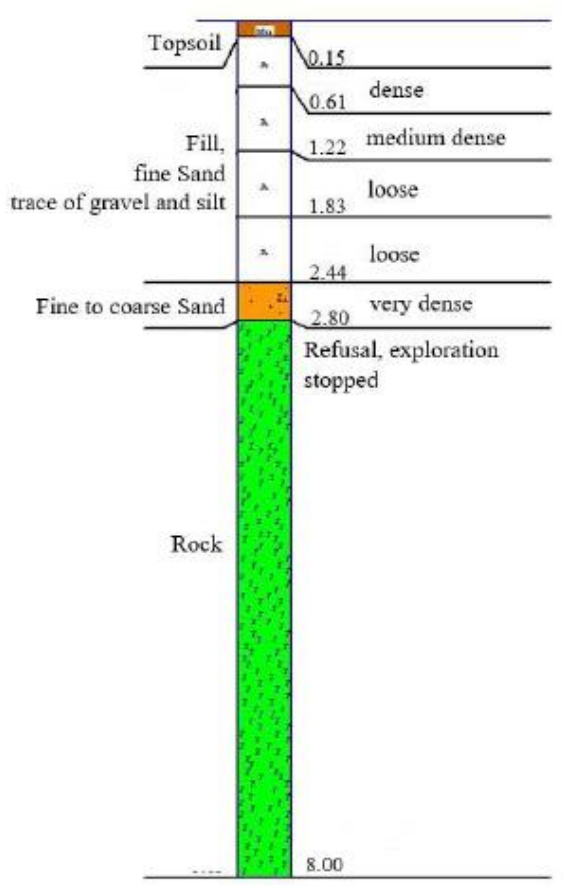

(a)

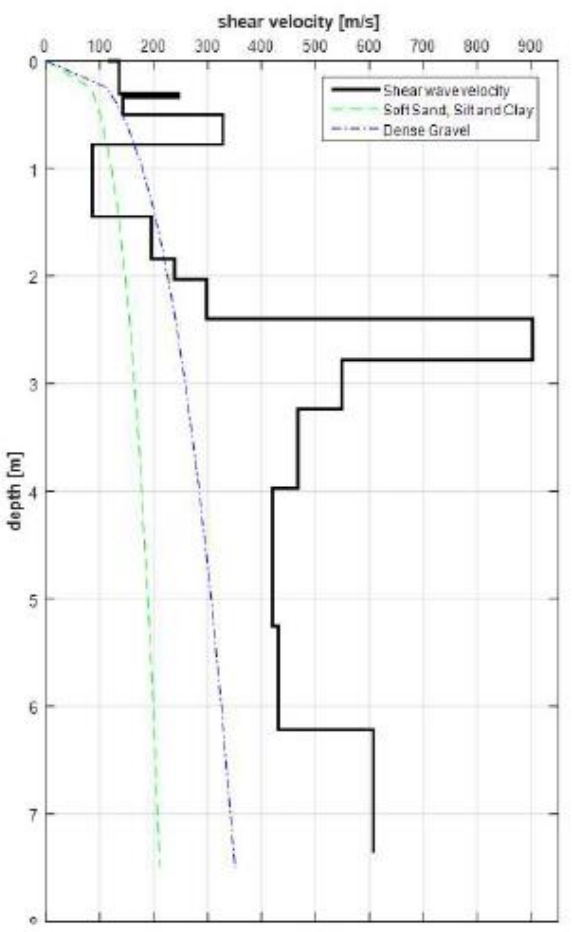

(b)

Figure 66. a) Boring log and b) shear wave velocity profile at URI Main Campus GZ-4 (Wulff, 2016).

\subsubsection{Data Collection}

Data was collected in a line on the grassy area as displayed in Figure 67 and Figure 68. Table 7 displays the parameter set up for the test. 


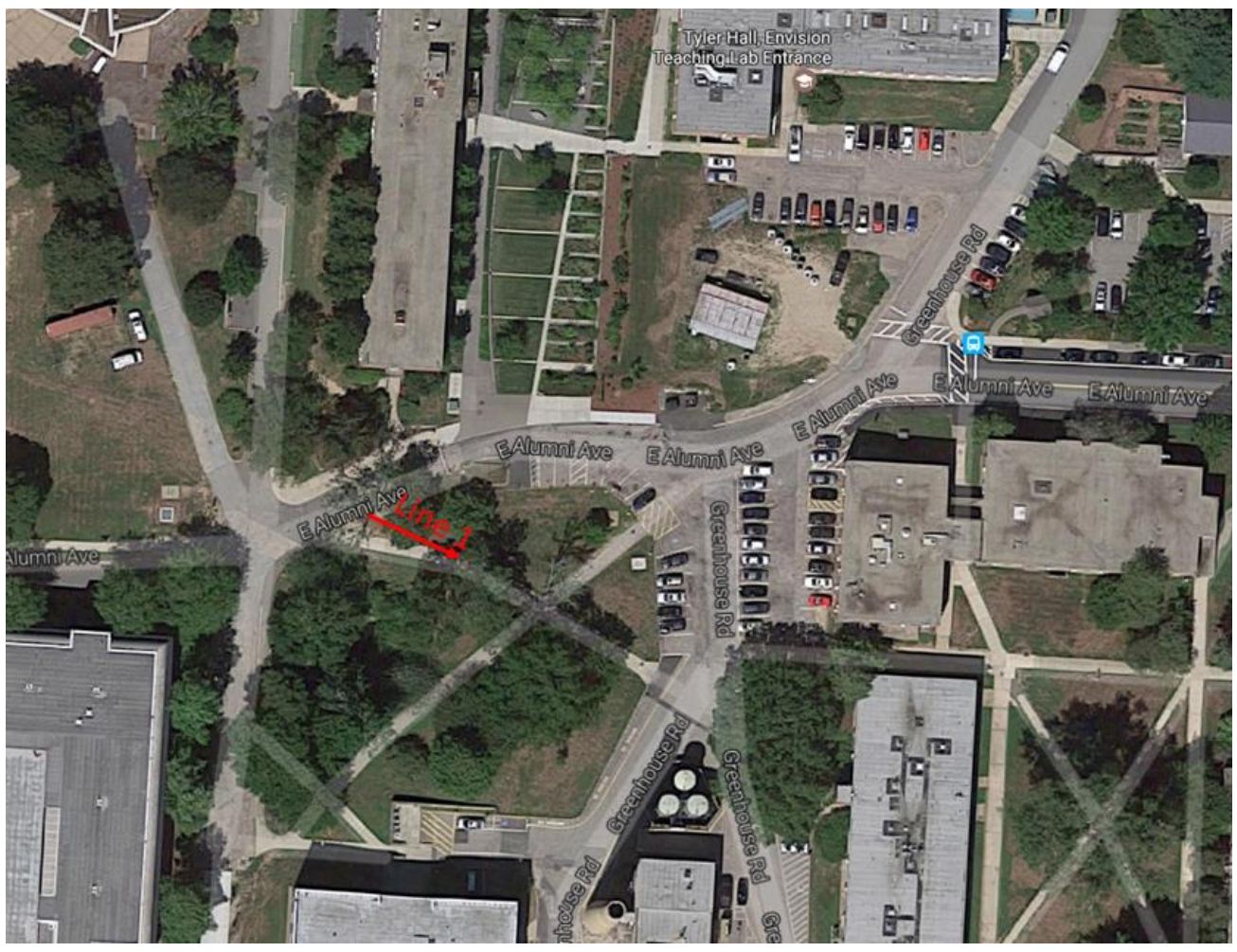

Figure 67. Measurement Line at URI Main Campus.

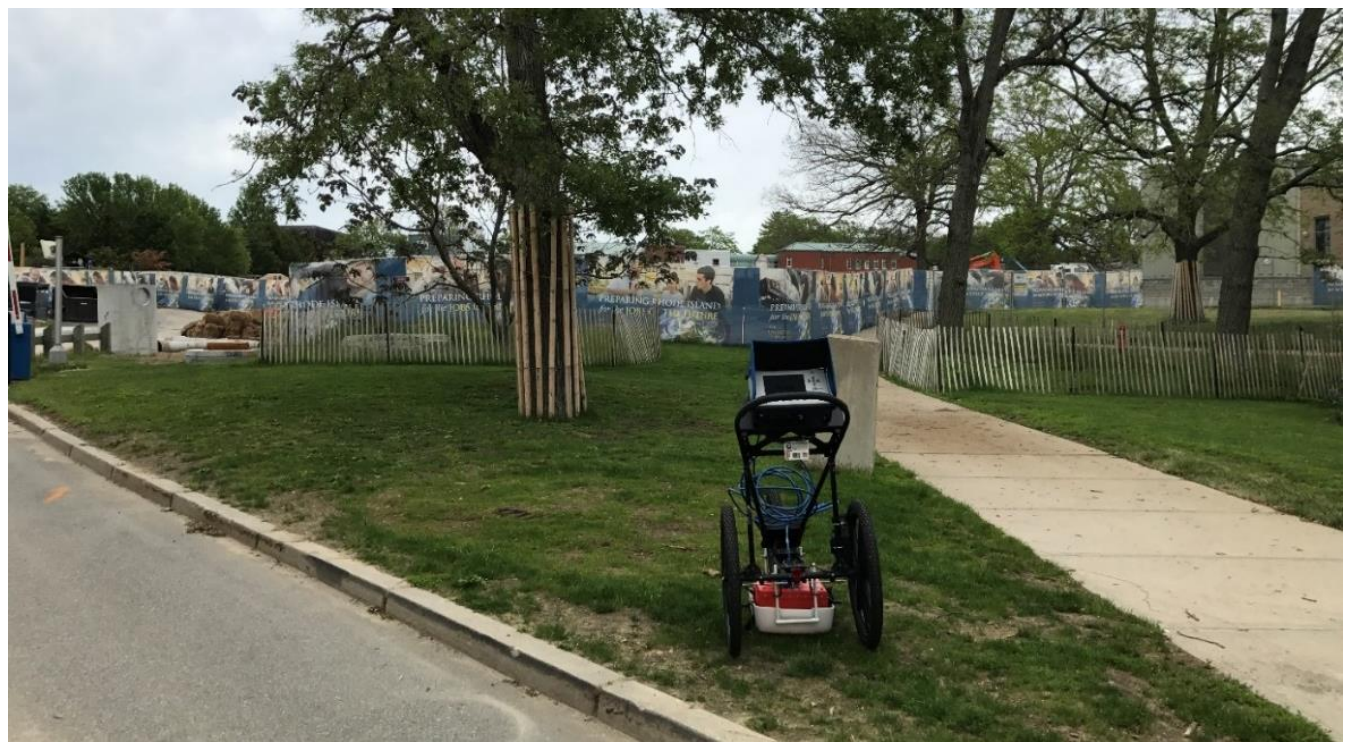

Figure 68. Measurement Line and Orientation at URI Main Campus (Construction Site can be seen in the Back). 
Table 7. Parameter Set Up at the URI Main Campus.

\begin{tabular}{|c|c|}
\hline Paramter & Value \\
\hline Antenna type & $400 \mathrm{MHZ}$ \\
\hline Scans/Sec & 64 \\
\hline Samps/Scan & 1024 \\
\hline Bits/Scan & 16 \\
\hline Dielectric Constant & 7.95 \\
\hline Range (ns) & 155 \\
\hline Low Pass IIR Filter & 800 \\
\hline High Pass IIR Filter & 100 \\
\hline
\end{tabular}

\subsubsection{Results}

The survey results can be seen in Figure 69 and Figure 70. In the interpreted version the topsoil is marked with a yellow line at an average thickness of about $20 \mathrm{~cm}$. The next layer lays between the yellow and the red line and is most likely a mix of the fine sands and a trace of gravel and silt, which is known from the boring logs at location GZ-4. In the layer some hyperbole features can be found which are created by strong reflections due to bigger gravel or small rocks in the sand layer. At around $3 \mathrm{~m}$ depth the GPR image shows a strong reflection and becomes blurry, which is an indicator of rock. At around 4.5 meters the image stops because the penetration depth is at its limits, beyond this the data is blurry with no features. This site is classified as the Narragansett Pier Granite (USGS, 2017), and from the boring logs exhibits little to no weathering can be seen. Bedrock maps for all the sites tested are included in the Appendix. 


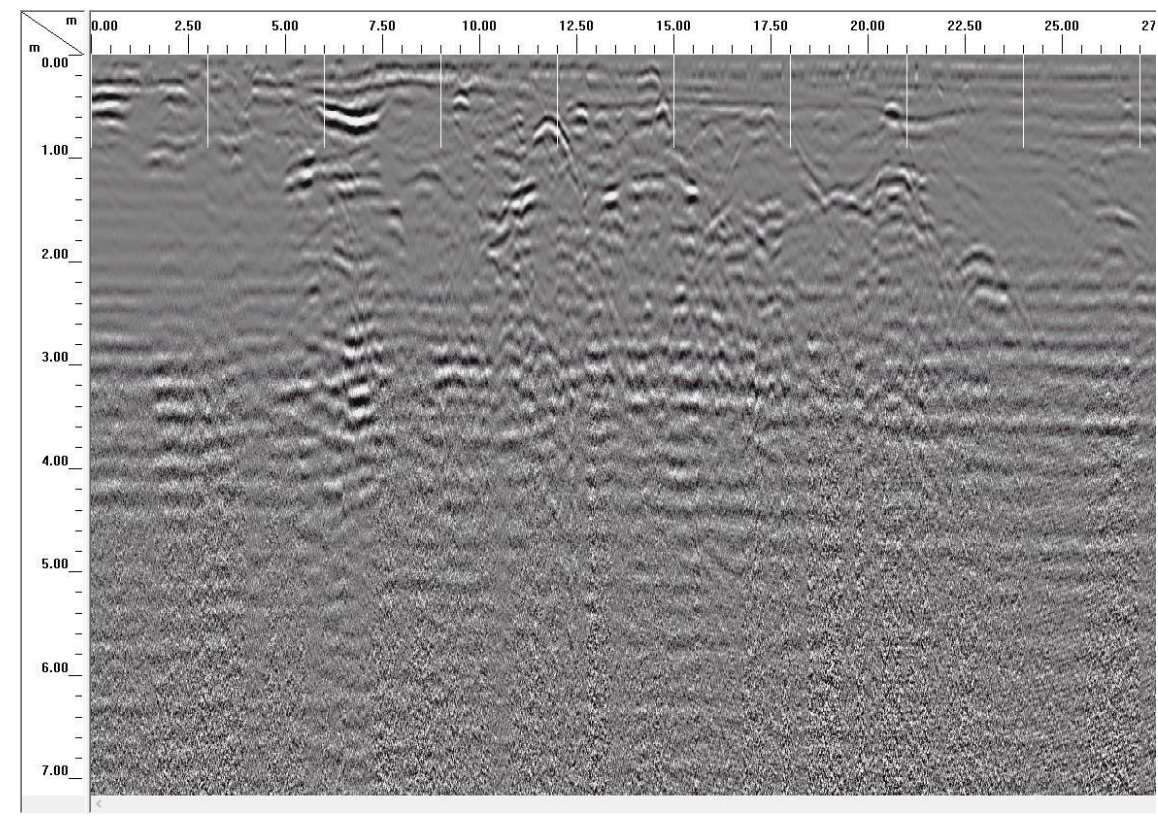

Figure 69. Processed GPR Image at URI Main Campus.

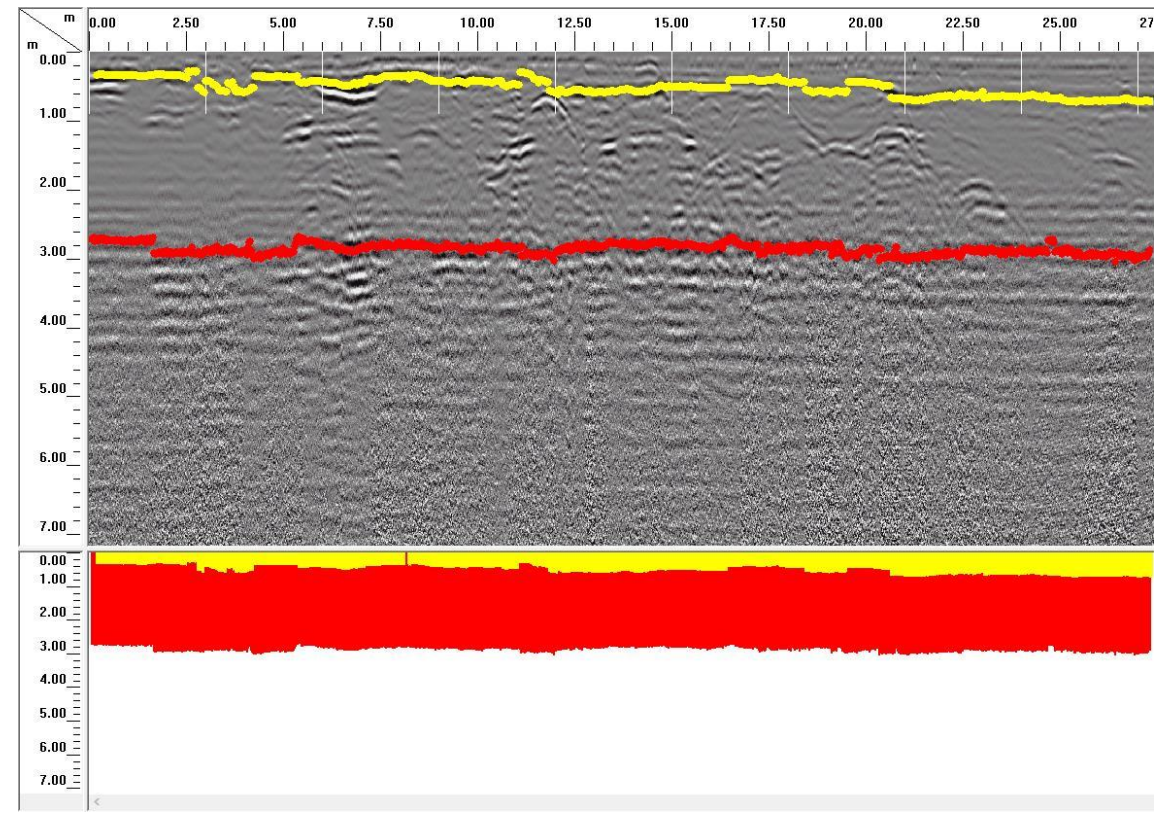

Figure 70. Processed and interpreted GPR Image at URI Main Campus. 


\subsection{URI Bay Campus, Middleton Building}

The URI Bay Campus location was tested as a way to confirm the GPRs data against data previously taken by a different research project.

\subsubsection{Site Description}

The Middleton Building is located at the URI Bay Campus in Narragansett. The GPR survey was done on a grassy area next to the building (Figure 71). The location was chosen due to its easy access and the availability of shear wave velocity profiles from Wulff in 2016. In general, the previous knowledge from other data sources, like the shear wave profiles, can help to interpret the GPR data.

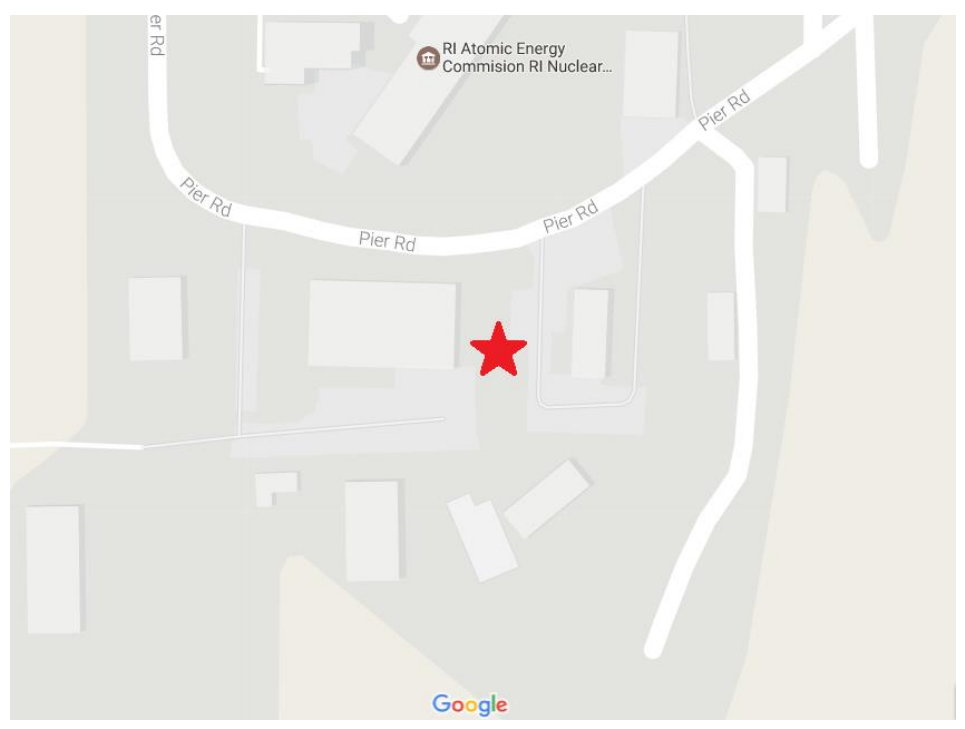

Figure 71. Location of the survey: Middleton Building, URI (Google Maps, 2017).

The first 3 meters, as seen in Figure 72, show a shear wave velocity from 100 $\mathrm{m} / \mathrm{s}$ to $500 \mathrm{~m} / \mathrm{s}$ which are typical values for dense gravel or till (Wulff, 2016). The 
deeper layers show velocities up to $950 \mathrm{~m} / \mathrm{s}$ which could suggest a rock layer starting there.

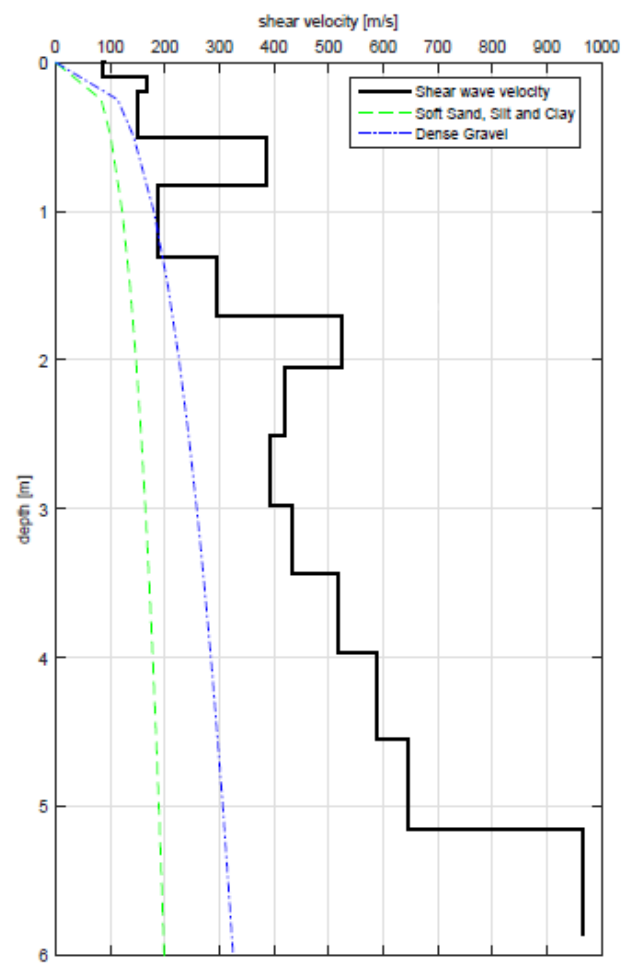

Figure 72. Shear wave velocity profile at the Middleton Building, URI (Wulff, 2016).

\subsubsection{Data Collection}

The data was collected with a survey cart for GPR antennas (Figure 74). A cross-sectional GPR profile was collected as shown in Figure 73. The distance mode was used in combination with the cart. The parameters are shown in Table 8. 


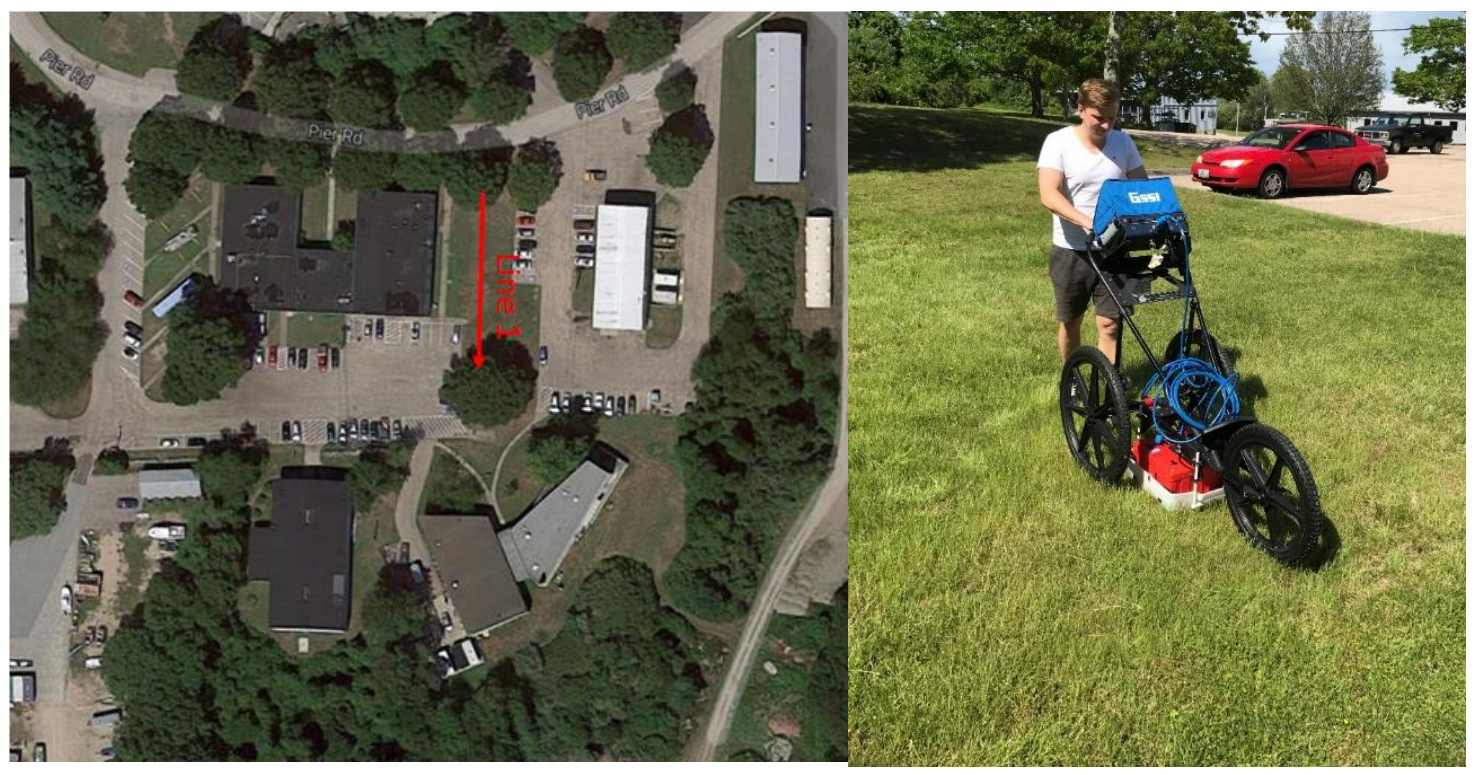

Figure 73. Measurement Line at the URI Bay Campus.

Figure 74. Data collection with the help of the survey cart at the Middleton Building, URI.

Table 8. Parameter set up at the Middleton Building, URI.

\begin{tabular}{|c|c|}
\hline Paramter & Value \\
\hline Antenna type & $400 \mathrm{MHZ}$ \\
\hline Scans/Sec & 64 \\
\hline Samps/Scan & 1024 \\
\hline Bits/Scan & 16 \\
\hline Dielectric Constant & 7.95 \\
\hline Range (ns) & 155 \\
\hline Low Pass IIR Filter & 800 \\
\hline High Pass IIR Filter & 100 \\
\hline
\end{tabular}




\subsubsection{Results}

The processed data for the Middleton Building is shown in Figure 75. A layer of topsoil with a thickness of around $10 \mathrm{~cm}$ (yellow line) can be seen. Layering is not visible beneath the topsoil which seems to be logical due to the results from Wulff (Figure 51) which show the existence of gravel or till. Gravel and till have similar dielectric values and for the same reasons as the sandbox described earlier layering is not visible. On the other hand, it was expected that there would be stronger reflections deeper down where the shear wave velocities reached up to $950 \mathrm{~m} / \mathrm{s}$. There are no strong reflections visible but as in the interpreted Figure 76 can be seen, there is a horizontal reflection at a depth around $3 \mathrm{~m}$ and the radar image changes and starts to get blurry. This can be assumed to be beginning of the bedrock.

Some hyperbolic features can be seen at a depth of $1 \mathrm{~m}$ which are most likely from bigger rocks because no pipes or electric lines were located in this area. Another feature is the appearance of vertical blurry lines starting at $2 \mathrm{~m}$ depth every $0.5 \mathrm{~m}$. This kind of signals is typically associated with interferences from cell phone signals.

The survey showed that the GPR was able to find shallow rock layers with the use of additional data. The shear wave velocity profiles helped to determine the depth at which the rocks was expected to start. This knowledge helps to focus on a specific area in the radar image and clarify features. 


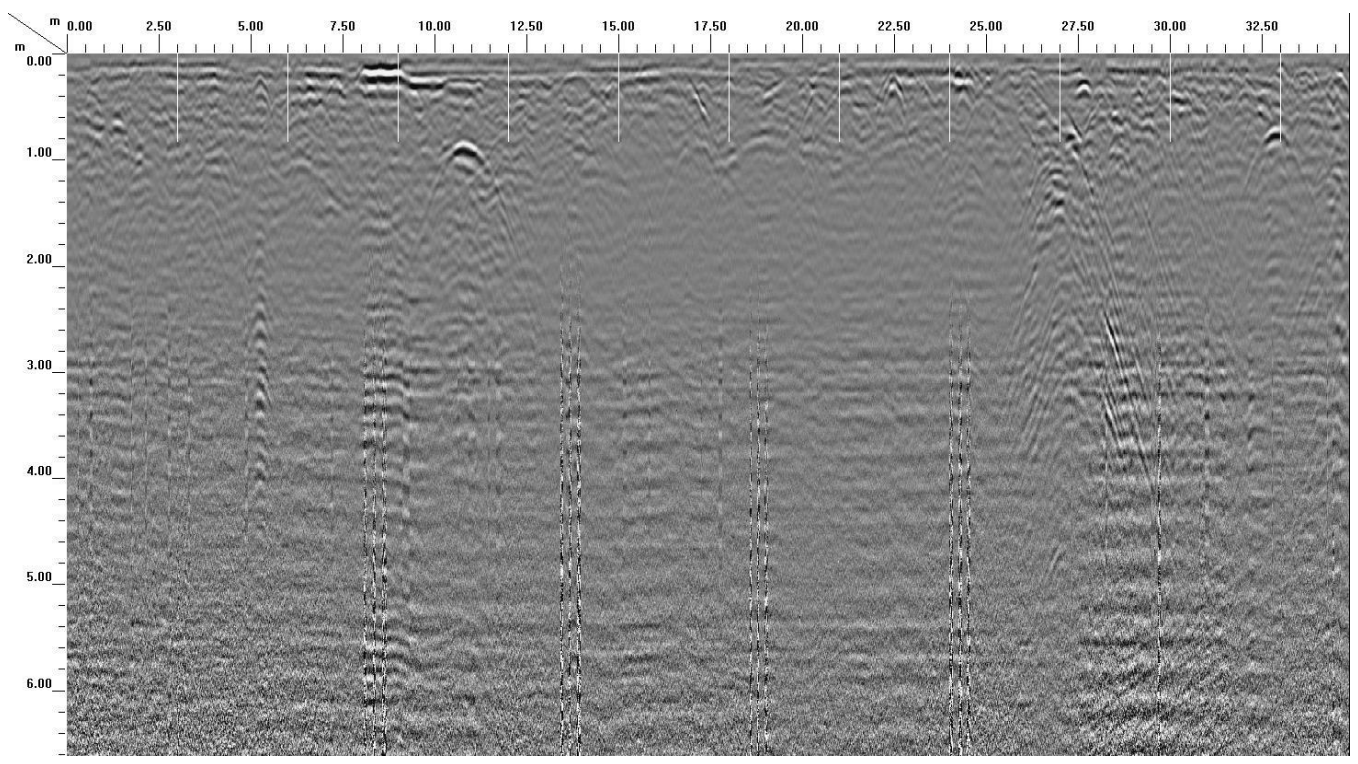

Figure 75. Processed radar image at the Middleton Building, URI.

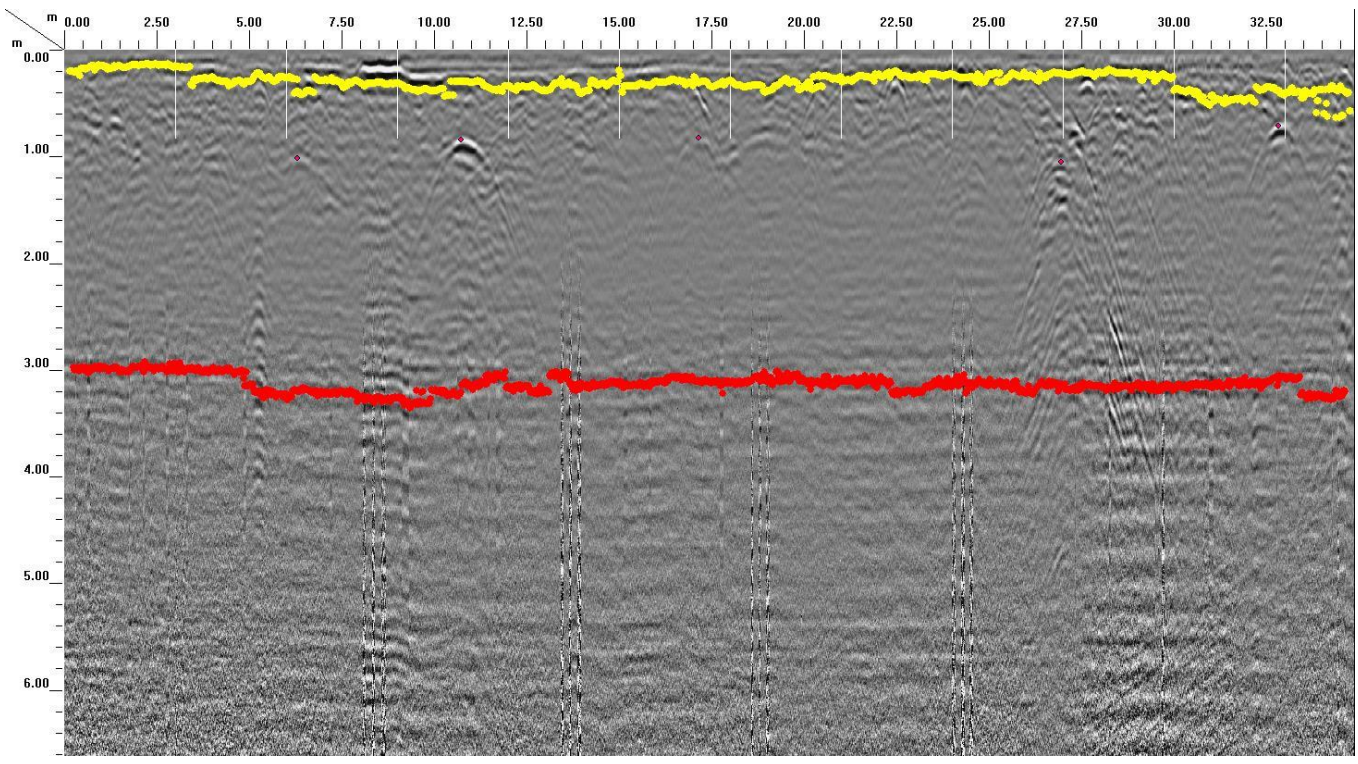

Figure 76. Interpreted radar image at the Middleton Building, URI.

\subsection{Weaver Hill Road Bridge}

The Weaver Hill Road Bridge location was tested to compare the GPRs data against data previously taken in different studies. 


\subsubsection{Site Description}

The Weaver Hill Road Bridge (Figure 79) is located along highway I-95, north of West Greenwich Rhode Island (Figure 77). The location was part of Wulff's soil investigations in 2016 (Wulff, 2016) and has also boring information which were taken before the bridge construction in 1965. The two locations shown in Figure 77 were suitable for the GPR testing. They both were easy to access and had an even ground surface for easy use of the GPR survey cart. Both locations were a grassy area next to the street. Location 1 was west of the bridge and lies between I-95 and RI-3, location 2 was east of the bridge in between I-95 and RI-3.

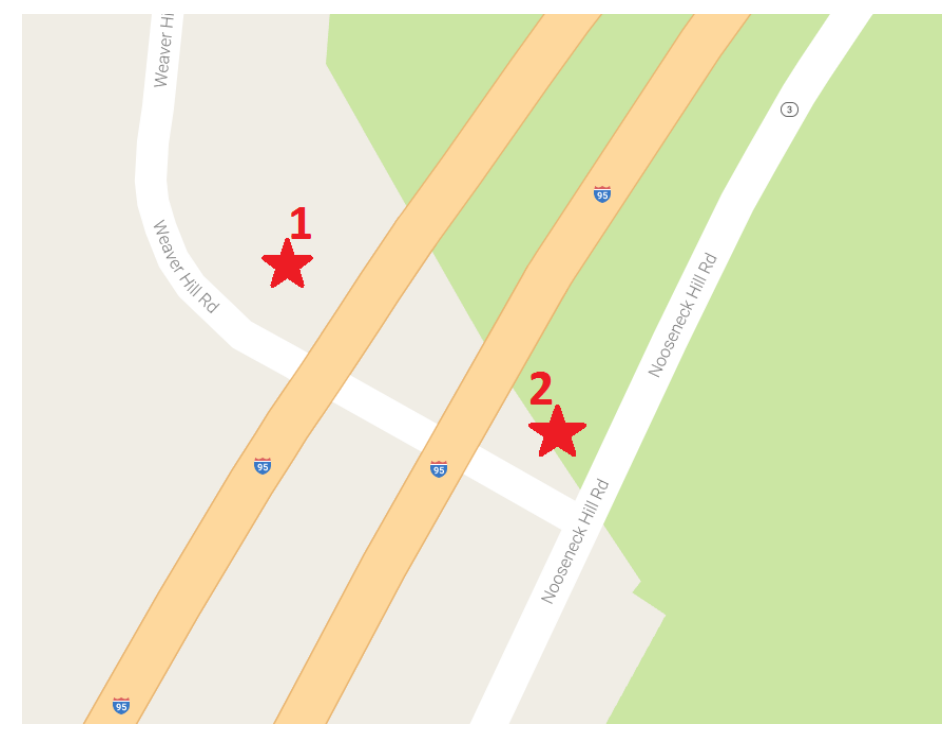

Figure 77. Measurements at Weaver Hill Road Bridge (Google Maps, 2017). 


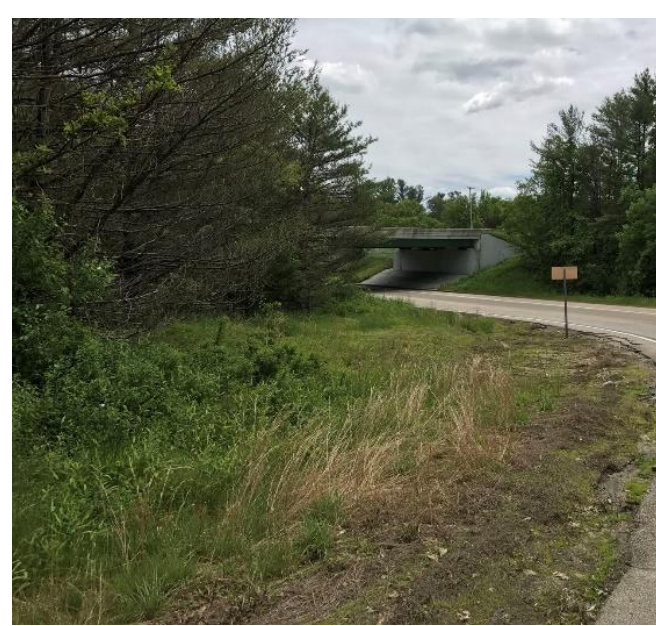

Figure 78. Weaver Hill Road Bridge, Test Location 1.

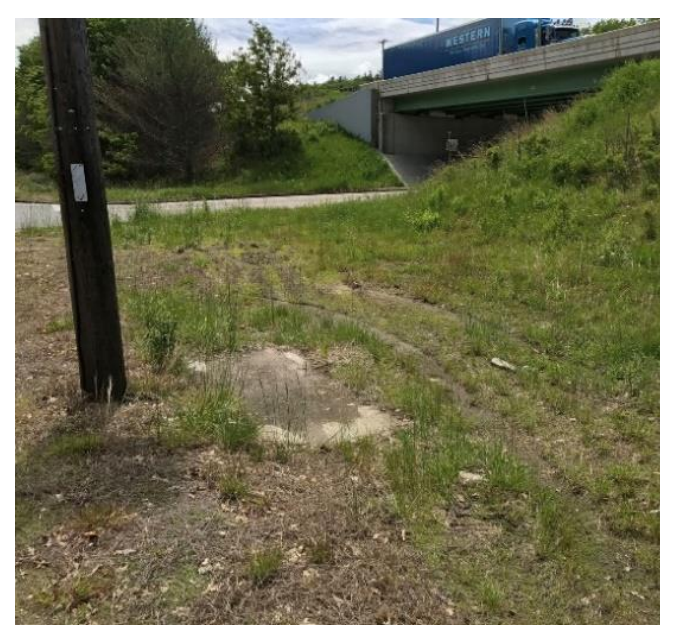

Figure 79. Weaver Hill Road Bridge Test Location 2.

The boring logs as well the shear wave velocities for measurement location one and two are provided in Figure 80 and Figure 81 . At location 1 the boring shows the beginning of rock at $3.35 \mathrm{~m}$, with a layer of dense sand and top soil above it. The shear wave velocity profile is comparable to the findings of the boring. The first $5 \mathrm{~m}$ show a dense to very dense soil, followed by a shear wave velocity of $500 \mathrm{~m} / \mathrm{s}$ indicating the beginning of rock. 


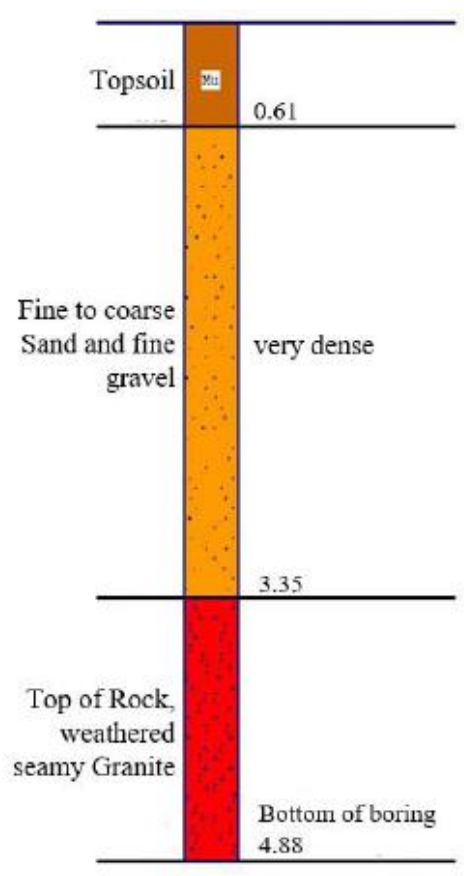

(a)

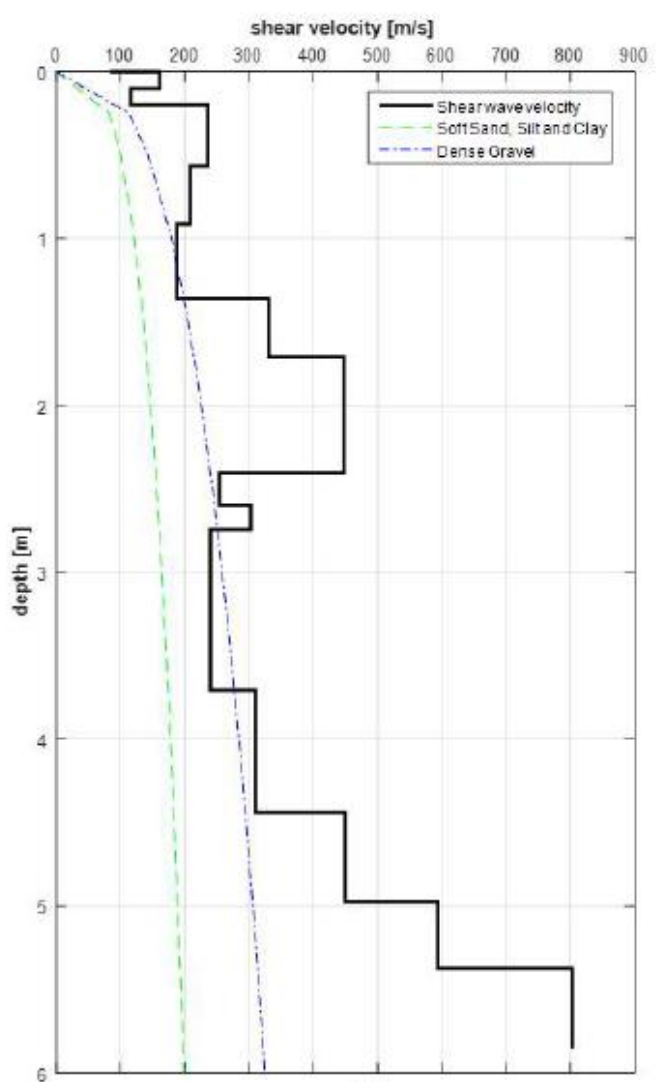

(b)

Figure 80. a) Boring log and b) shear wave velocity profile at location 1 at Weaver Hill Road Bridge (Wulff, 2016).

Figure 81 shows measurement location 2. The boring shows a topsoil layer of $0.61 \mathrm{~m}$, followed by medium dense sand until $3.35 \mathrm{~m}$ where the rock is starting. The shear wave velocity profile shows typical values for dense gravel up to a depth of $2.5 \mathrm{~m}$. The beginning of the rock layer was determined at the depth of around $5 \mathrm{~m}$ due to the shear wave velocity higher than $500 \mathrm{~m} / \mathrm{s}$. 


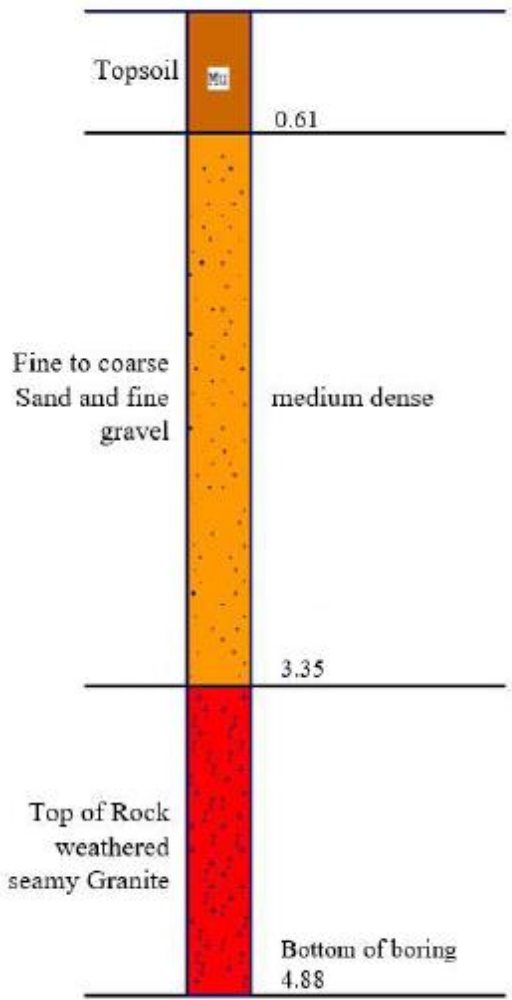

(a)

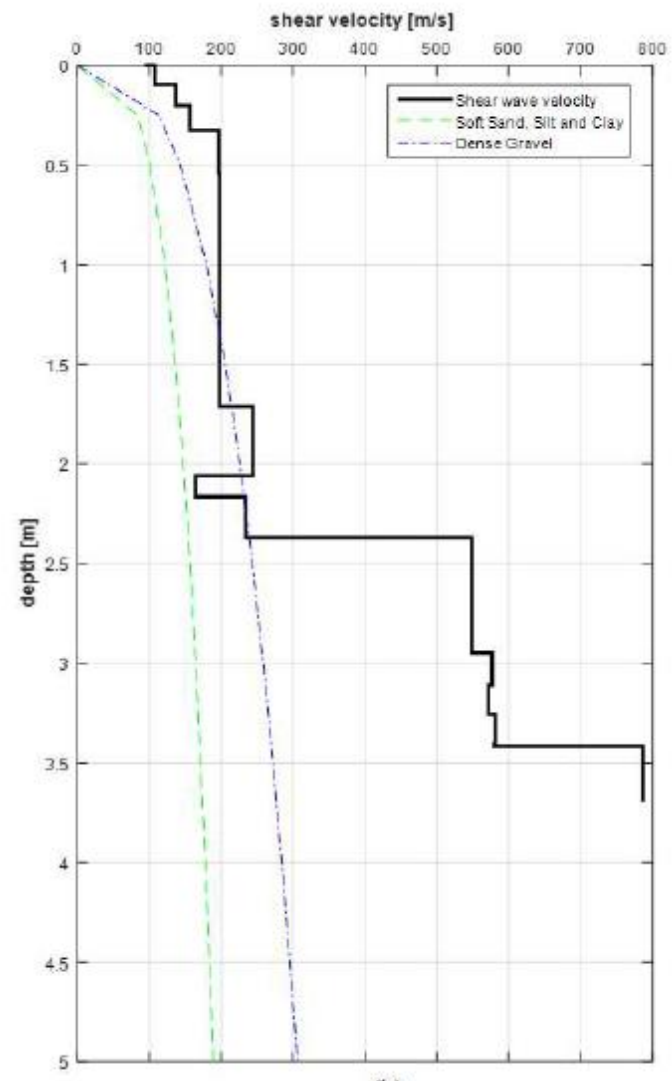

(b)

Figure 81. a) Boring log and b) shear wave velocity profile at location 2 at Weaver Hill Road Bridge (Wulff, 2016).

\subsubsection{Data Collection}

The data was collected in two lines at locations 1 and 2 as seen in Figure 82.

The survey cart and the orientation of the measurement can be seen in Figure 83 and Figure 84. 


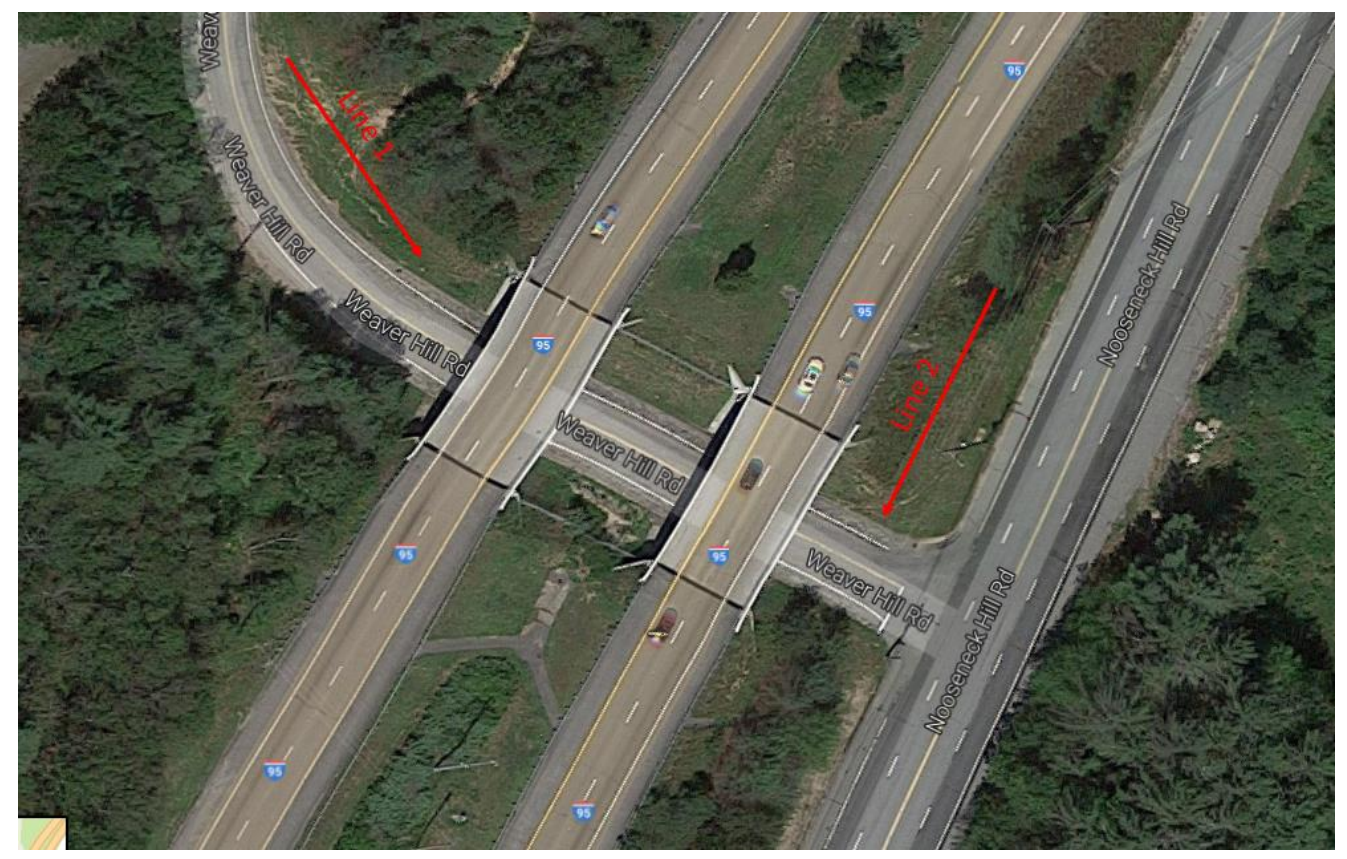

Figure 82. Measurement Lines at Weaver Hill Road Bridge.

The parameters for the survey are shown in Table 9. Due to the boring profiles in Figure 80 and Figure 81 it was known that dense sand can be expected in the first meters of soils which is the reason for the dielectric constant of 6 . The range was changed in situ to make sure to see all relevant features. 


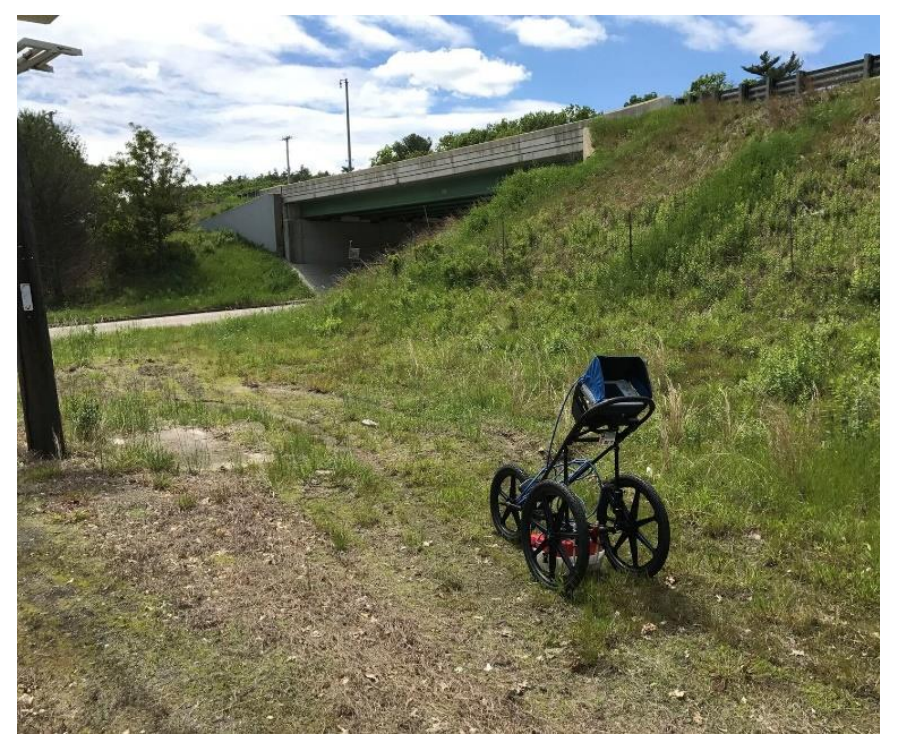

Figure 83. Data Collection at Line 1 Weaver Hill Road Bridge.

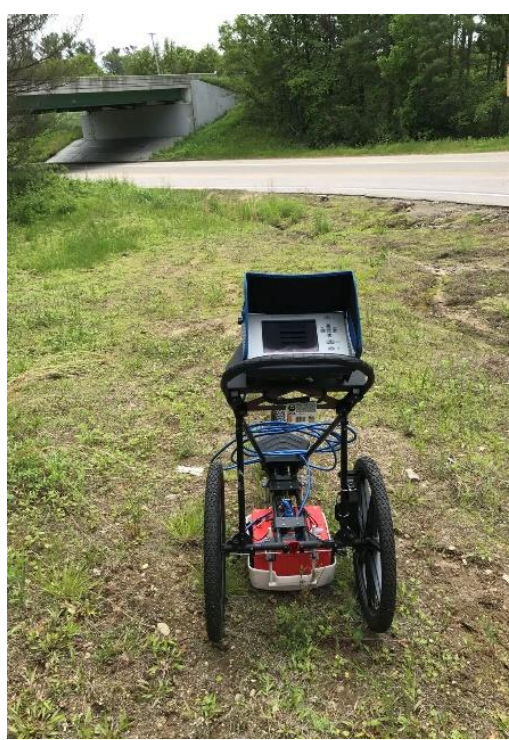

Figure 84. Data Collection at Line 2 Weaver Hill Road Bridge.

Table 9. Parameter Setup at Weaver Hill Road Bridge.

\begin{tabular}{|c|c|}
\hline Paramter & Value \\
\hline Antenna type & $400 \mathrm{MHZ}$ \\
\hline Scans/Sec & 64 \\
\hline Samps/Scan & 1024 \\
\hline Bits/Scan & 16 \\
\hline Dielectric Constant & 6 \\
\hline Range (ns) & 130 \\
\hline Low Pass IIR Filter & 800 \\
\hline High Pass IIR Filter & 100 \\
\hline
\end{tabular}




\subsubsection{Results}

The data was processed in RADAN7. Background removal and time zero correction were used for both Figure 85 and Figure 86 . The raw and processed data can be found in the appendix. With the help of the boring information and the shear wave velocities the soil layers for the locations can be interpreted as seen in Figure 85 and Figure 86.

Location 1 in Figure 85 shows a top layer (yellow line) with a layer thickness up to $80 \mathrm{~cm}$. The boring profile showed a topsoil of around $61 \mathrm{~cm}$ which is acceptable because the boring is only at one location while the GPR image shows the soil at a continuous length of $17.5 \mathrm{~m}$. The next layer (red line) ends at $2.5 \mathrm{~m}$ deep and is a fine to coarse sand and fine gravel according to the boring log in Figure 80. Underneath the red line the reflections are getting stronger, suggesting the beginning of the rock layer.

Location 2 in Figure 86 shows a topsoil with a layer thickness from $0.6 \mathrm{~m}$ to 1 m (yellow line), followed by a layer of fine to coarse sand and fine gravel until a depth of $3.35 \mathrm{~m}$ (between yellow and green line). Strong horizontal reflections can be found underneath the green line. As the boring log in Figure 81 shows, the top of rock, classified as weathered seamy granite, begins. However, in the first ten meters of the GPR measurement (red line), the horizontal reflections start at a depth of two meters, which is higher than the boring logs indicate. This could mean that the rocky layer does not have a uniform depth. The strong reflection at around $19 \mathrm{~m}$ (horizontal axis) of the measurement is not an actual feature, 
because at this point of the measurement the soil was bumpy and the antenna could not perform it correctly.

At both locations, 1 and 2, the reflections below $3 \mathrm{~m}$ appear chaotic in the radar image. The reason for that is that the granite at this depth is weathered and seamy, which creates disordered reflections unlike the location of the URI Main Campus where the granite is a solid block of rock. A review of bedrock maps for Rhode Island (USGS, 2017) indicates that the underlying bedrock at both Weaver Hill Road Bridge and Baker Pines Road Bridge (next section) consist of Seituate Granite Gneiss which may account for the increased weathering.

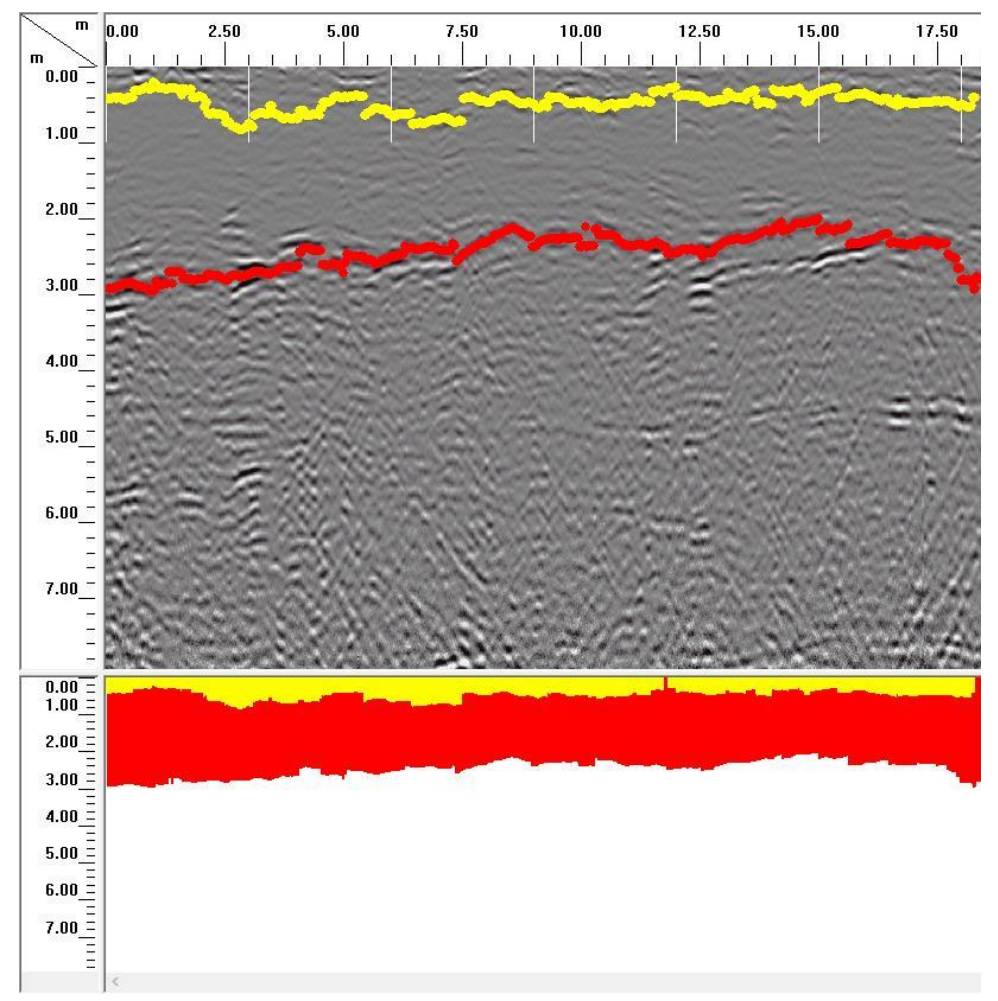

Figure 85. Interpreted data at location 1. 


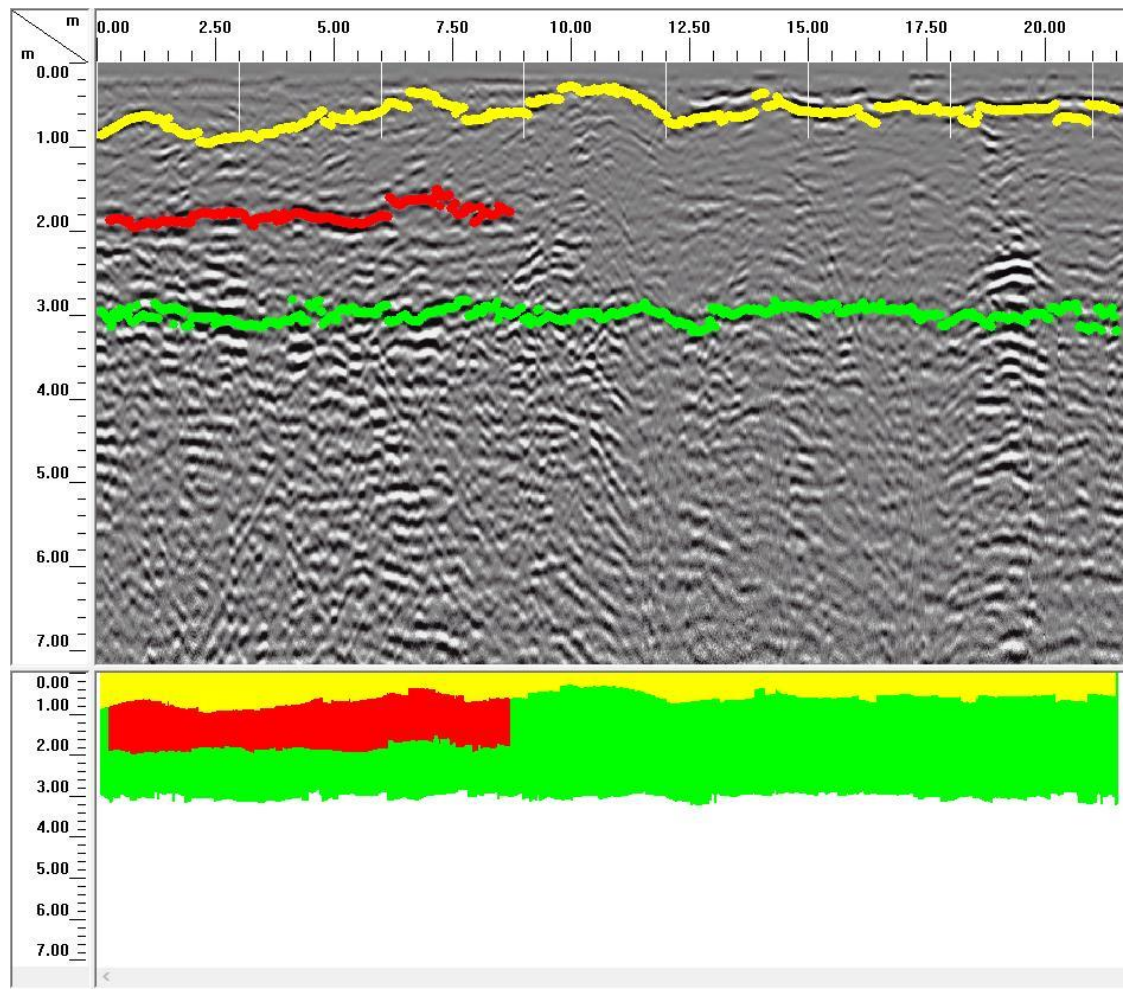

Figure 86. Interpreted data at location 2.

\subsection{Baker Pines Road Bridge}

The Baker Pines Road Bridge location was tested to compare the GPRs data against data previously taken in different research approaches.

\subsubsection{Site Description}

The location of the Baker Pines Road Bridge can be seen in Figure 87. It is along the highway I-95 north of Richmond, Rhode Island. The location provides eight borings conducted in 1965 when the bridge was constructed. In addition to that, shear velocity tests were performed close to two of the borings done by Wulff in 2016. Two locations were suitable for a GPR survey (Figure 87). Location one 
is pictured in Figure 88. Both areas consisted of a surface of sand and some gravel.

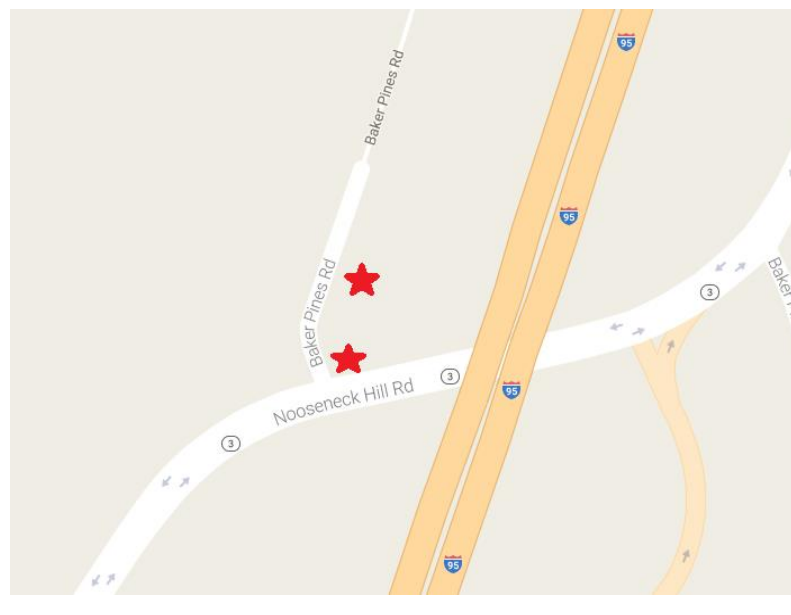

Figure 87. Measurement locations at Baker Pines Road Bridge (Google Maps, 2017).

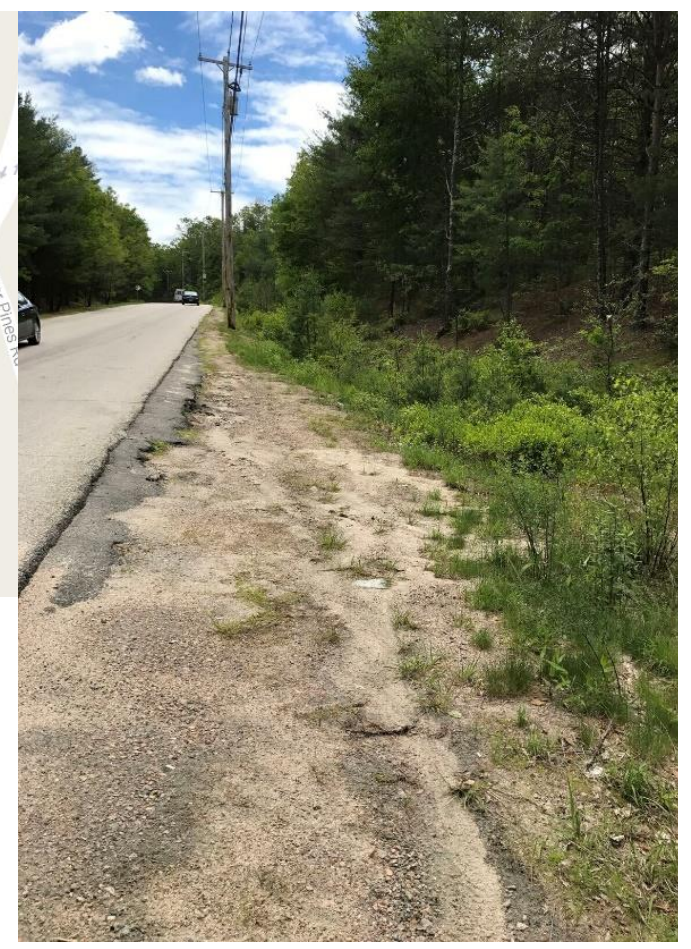

Figure 88. Measurement location.

The boring log and shear wave velocity profiles are shown in Figure 89. The boring log shows an initial layer of loose topsoil around $0.76 \mathrm{~m}$ thick. The layer is followed by medium to fine sand, trace silt and coarse to fine gravel until $2.74 \mathrm{~m}$ when the granite layer starts. The shear wave velocity matches with the boring profile. The only significant difference is the topsoil which is not loose in comparison to the boring log. 


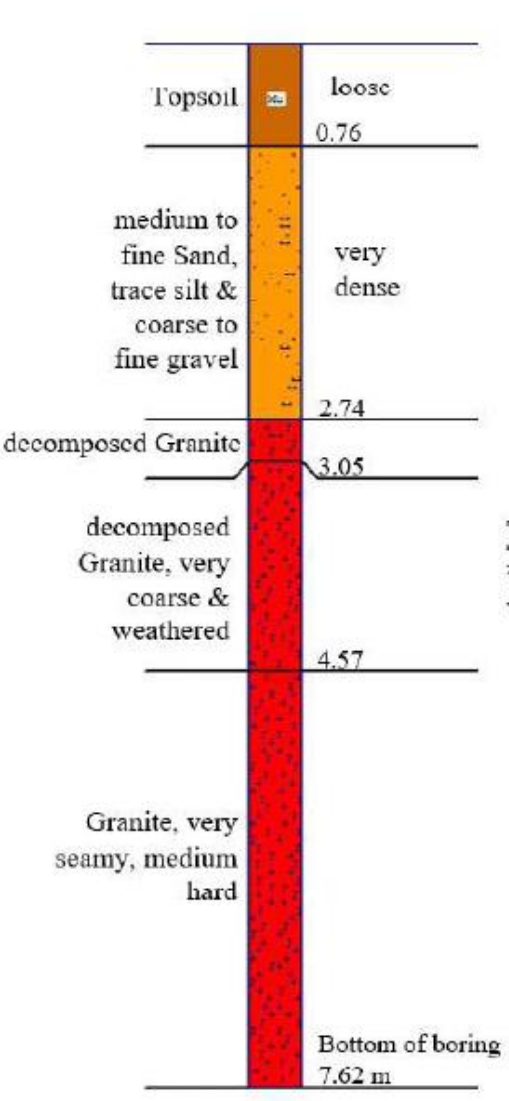

(a)

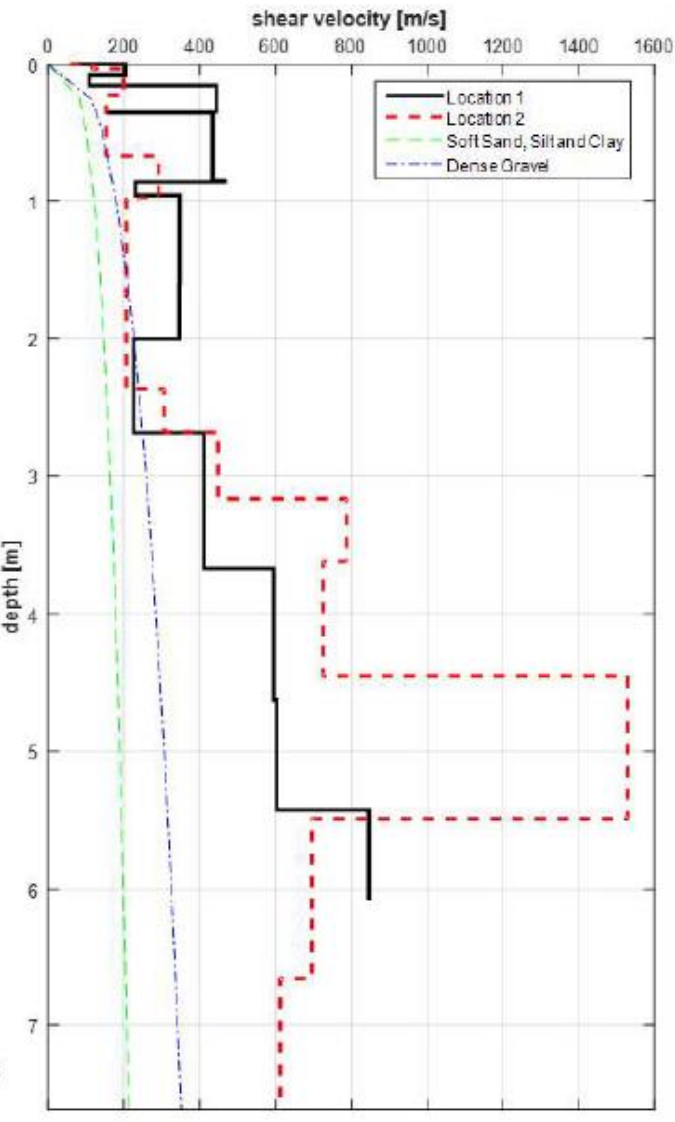

(b)

Figure 89. a) Boring log and b) Shear wave velocity profile at location 1 (black) and 2 (red) at Baker Pines Road (Wulff, 2016).

\subsubsection{Data Collection}

Data was collected in two lines at location one and two (Figure 90). The boring logs helped to set the parameters (Table 10). In the first $3 \mathrm{~m}$ fine sand was 
expected why the dielectric value was changed to six. The orientation of the measurement in location one can be seen in Figure 91.

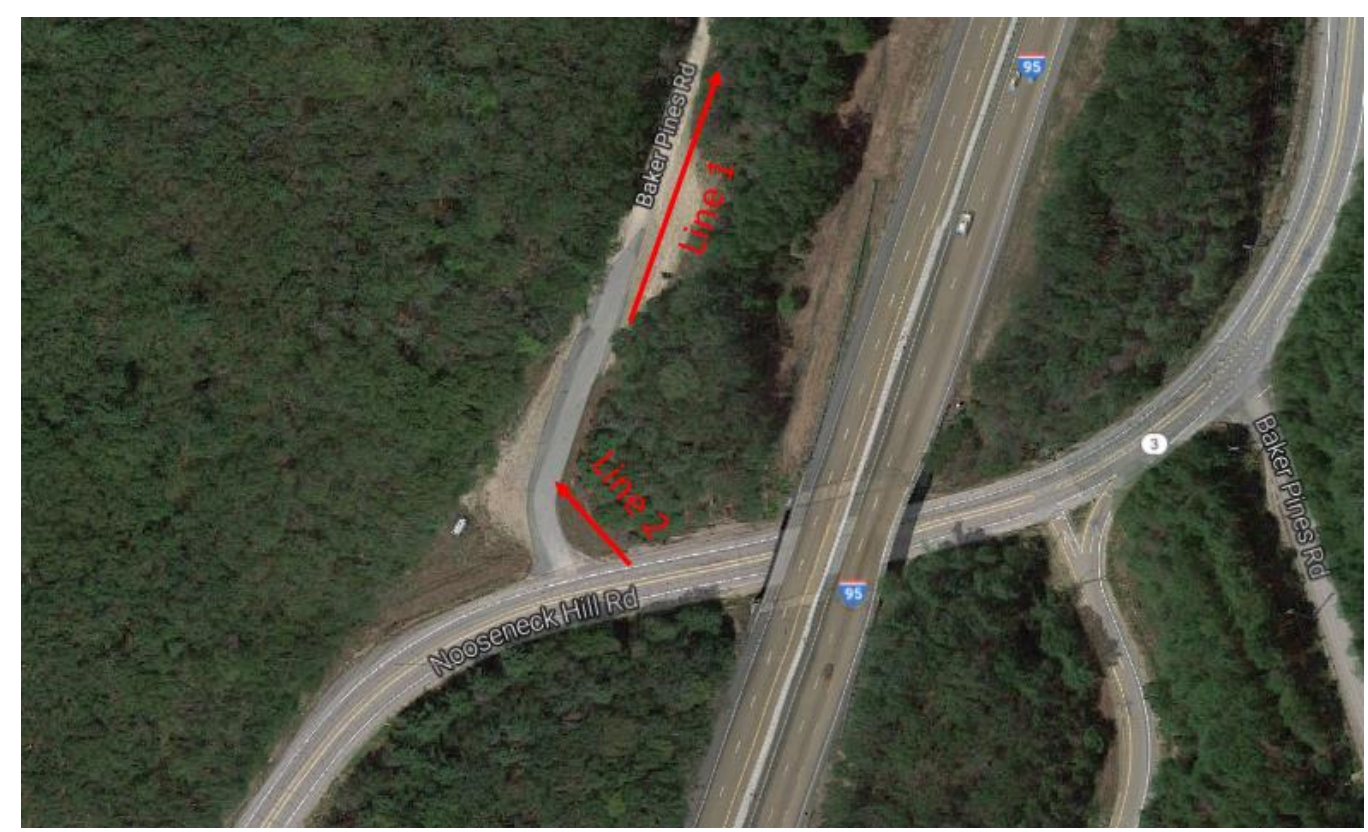

Figure 90. Measurement Lines at Baker Pines Road Bridge. 


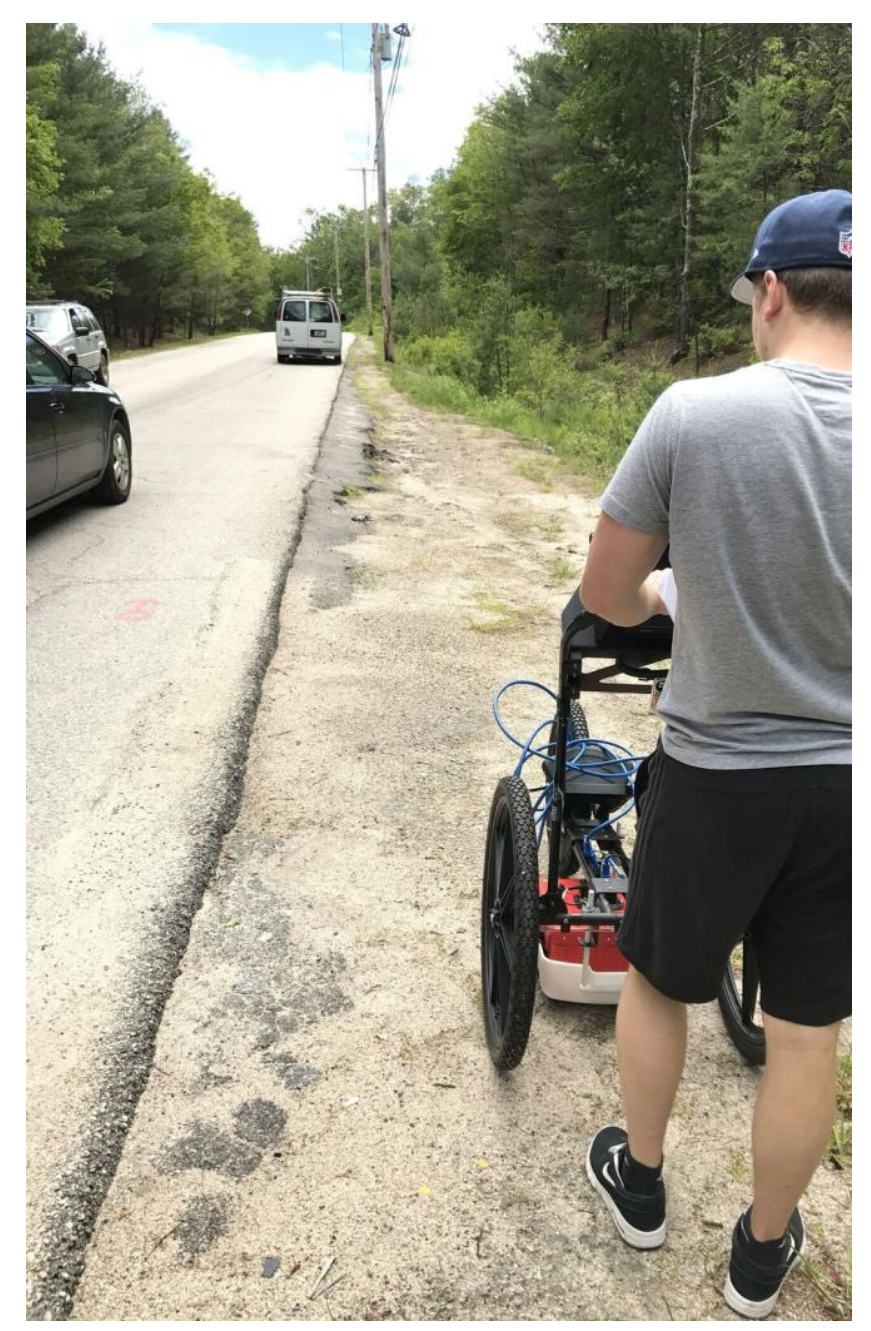

Figure 91. Data collection at Baker Pines Road Bridge.

Table 10. Parameter Setup at Baker Pines Road Bridge.

\begin{tabular}{|c|c|}
\hline Paramter & Value \\
\hline Antenna type & $400 \mathrm{MHZ}$ \\
\hline Scans/Sec & 64 \\
\hline Samps/Scan & 1024 \\
\hline Bits/Scan & 16 \\
\hline Dielectric Constant & 6 \\
\hline Range $(\mathrm{ns})$ & 155 \\
\hline
\end{tabular}




\subsubsection{Results}

The processed and interpreted GPR images for location one and two are displayed in Figure 92 and Figure 93. Both data sets were processed with a background removal filter, the time zero correction, a FIR filter, and a range gain.

The topsoil in the GPR image in Figure 92 for location one (yellow line) varies in depth from $0.8 \mathrm{~m}$ to $1 \mathrm{~m}$ over the length of the measurement. The next layer ends at the red and green line and varies in depth from $2 \mathrm{~m}$ to $3 \mathrm{~m}$ and, according to the boring log, is a layer of medium to fine sand, trace silt, and coarse to fine gravel. Close to the red layer another layer can be found (green line). The layer has a depth of around $3 \mathrm{~m}$ to $5 \mathrm{~m}$ and could result from the decomposed granite. At $5 \mathrm{~m}$ another strong horizontal reflection is visible. The horizontal reflection underneath could indicate a new layer but the shape of the line is very similar to the red one which is an indicator for a multiple. The radar image shows another strong horizontal reflection underneath $4.57 \mathrm{~m}$ when the decomposed coarse and weathered granite changes to seamy, medium hart granite. Without further investigation it is unclear whether this is a change in rock or a multiple. At this location the reflections below $3 \mathrm{~m}$ appear chaotic in the radar image. The reason for that is that the granite at this depth is weathered and seamy, which creates 
disordered reflections unlike the location of the URI Main Campus where the granite is a solid block of rock.

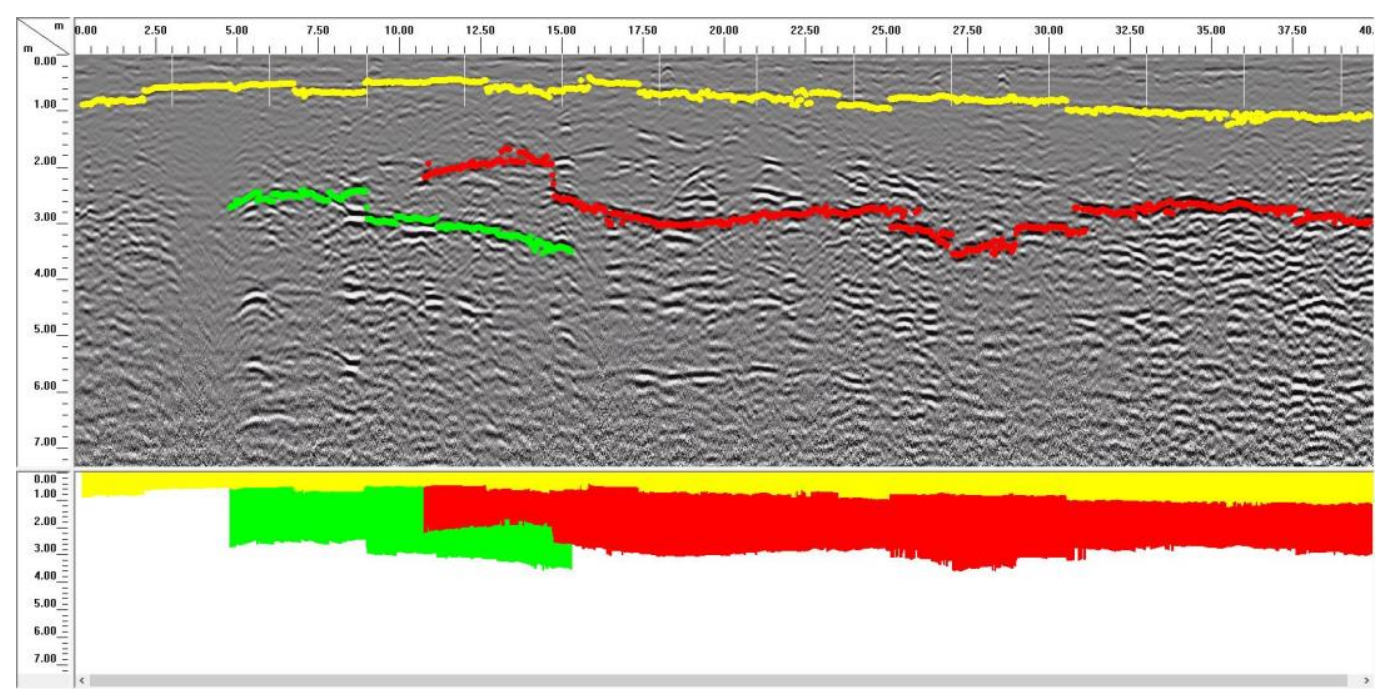

Figure 92. Processed and interpreted data at location 1.

Figure 93 shows the GPR image at location 2. The yellow line marks the first strong horizontal reflection of the topsoil layer with a thickness of 0.4 to $0.5 \mathrm{~m}$. According to the boring log, a layer of medium to fine sand, trace silt and coarse to fine gravel is located between the topsoil and the beginning of the granite layer. However, the radar image shows a clear horizontal recflection (red line) at a depth of $1.0 \mathrm{~m}$ to $1.2 \mathrm{~m}$. At the depth of $2.8 \mathrm{~m}$ to $3.0 \mathrm{~m}$ the reflections are getting stronger, indicating the beginning of the decomposed granite layer. The image starts to get blurry at the depth of $4.0 \mathrm{~m}$ showing the end of the antenna range. 


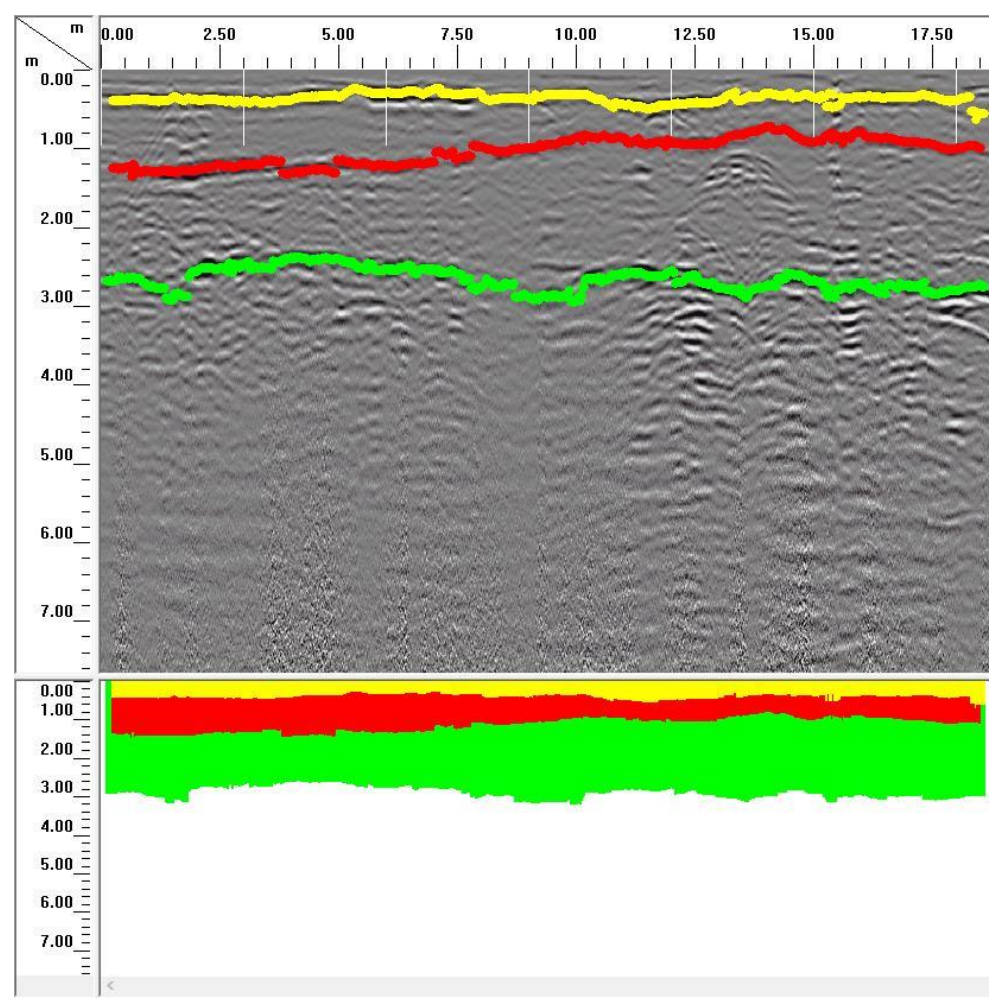

Figure 93. Processed and interpreted data at location 2.

\subsection{Discussion of Surveys and Results}

In Chapter 5 the GPR was used at the URI Main Campus, URI Bay Campus and two Road Bridges to identify shallow rock layers. The interpretation of soil layering was possible with the GPR. However, all of this locations had further soil information due to other researches. That fact helped to plan the surveys and made the interpretation of the data possible. RADAN 7 was able to provide all features to process and interpret the data. In some cases the data was already good enough for interpretation even without processing. 
The surveys on land turned out to be very simple to perform. The GPR and its cart could be disassembled and were easy to transport. The surveys were performed by two people, however it is possible to perform the surveys on land even alone. 


\section{Chapter 6}

\section{Investigation of Scour at Bridge Sites using GPR}

Chapter 6 presents the results of GPR surveys and processed data at two different bridge locations. The bridge locations are shown in Figure 94. The locations were chosen from a list of scour critical bridges in Rhode Island. They were also used in a previous study by (Laurent, 2016), who modeled the flow and compared the scour predictions with the actual scour occurrence. Due to the GPR's inability to work in saline conditions, not all bridge location can be considered in this study.

The results of Laurent's study showed that the HEC18 scour equations overestimated the scour in nearly all cases. However, the methods Laurent used only allowed her to see visible features in the bathymetry data, meaning that infilled or hidden scour holes were not recorded. The usage of the GPR should provide knowledge of the soil and find infilled scour holes. With this information, a more accurate and inclusive statement on the accuracy of scour prediction equations should be available. 


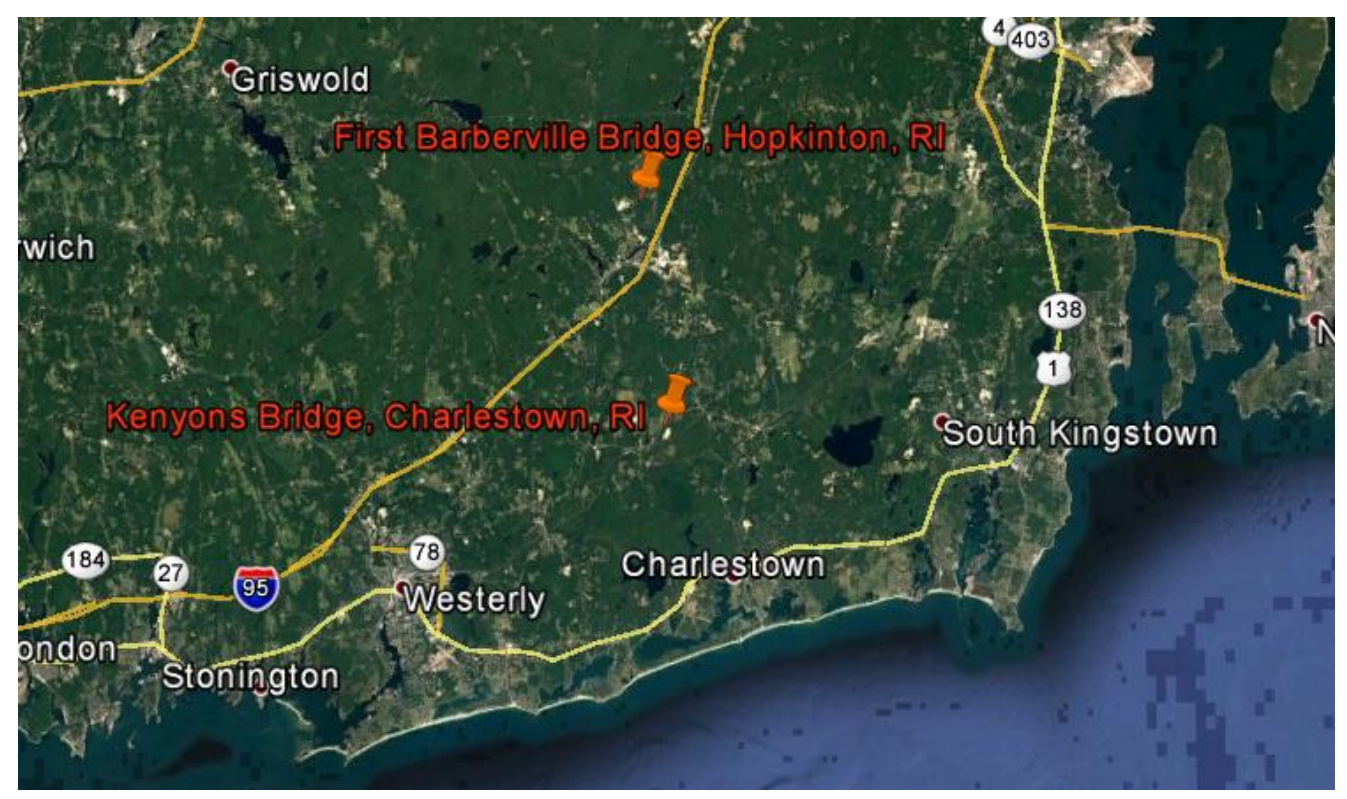

Figure 94. Survey Locations of scour critical bridges.

\subsection{Kenyons Bridge, Charlestown RI}

This section presents the results of the field survey of Kenyons Bridge in Charlestown, Rhode Island. A characterization of the site, how data was collected and the results are provided.

\subsubsection{Site Description}

The location of the Kenyons Bridge (RI DOT Bridge No. 020601) is shown in Figure 95 and crosses the Pawcatuck River near Charelstown in Rhode Island (Figure 96). Kenyons Bridge was constructed 91 years ago in 1926 and was reconstructed in 1984, resulting in an expansion of the bridge width (Laurent, 2016). The bridge is a single span arch bridge made of concrete and is about 
$15.5 \mathrm{~m}$ long, $13.6 \mathrm{~m}$ wide, and carries two lanes of traffic. The clearance is around $1.5 \mathrm{~m}$ during normal flow conditions.

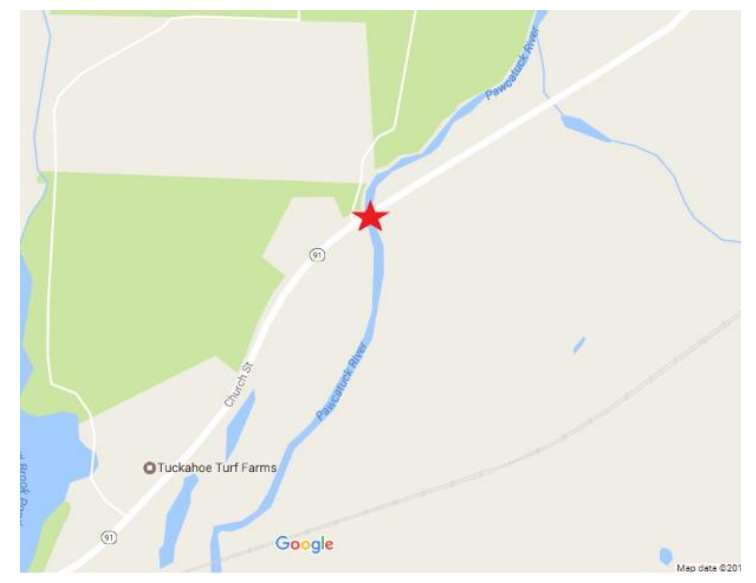

Figure 95. Location of the Kenyons Bridge (Google Maps, 2017).

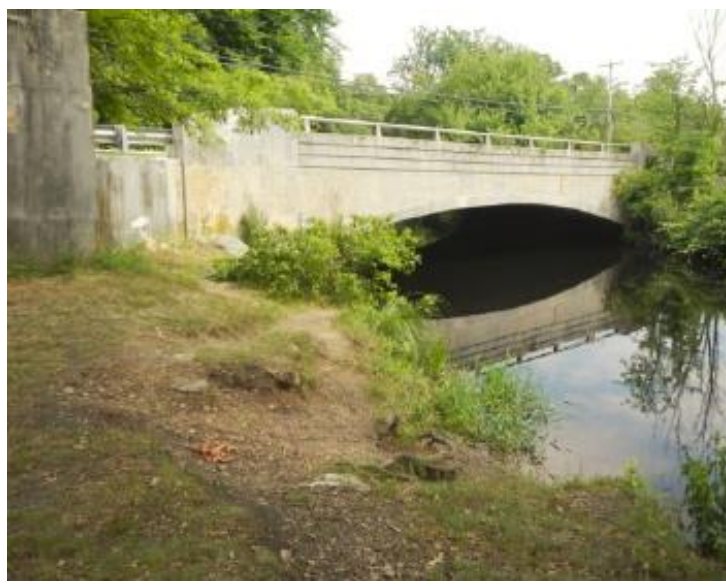

Figure 96. Kenyons Bridge (Laurent, 2016).

The bed conditions can be seen in the grain size distribution in Figure 97. The median grain size ranges from 22 millimeters to $0.38 \mathrm{~cm}$. The picture from the riverbed of the Pawcatuck under the bridge in Figure 98 shows a surface with lots of cobbles and boulders. 


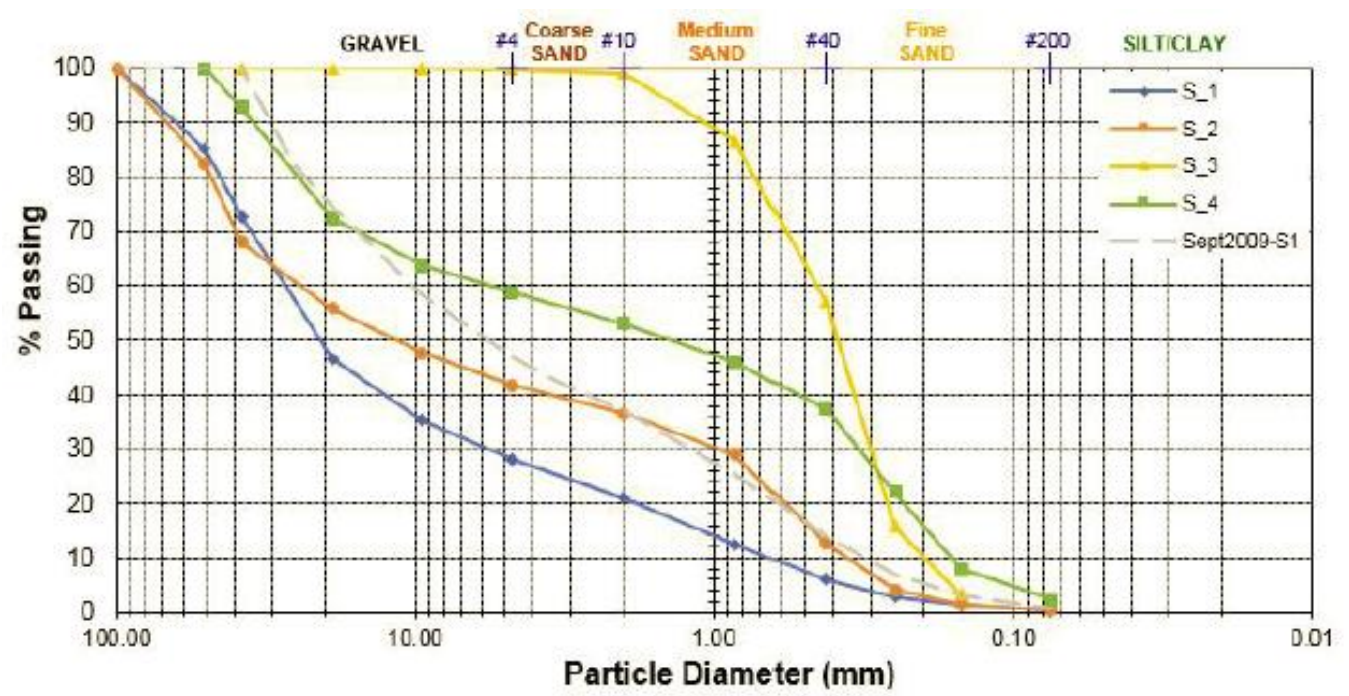

Figure 97. Grain size distribution for Kenyons Bridge, RI (Laurent, 2016).
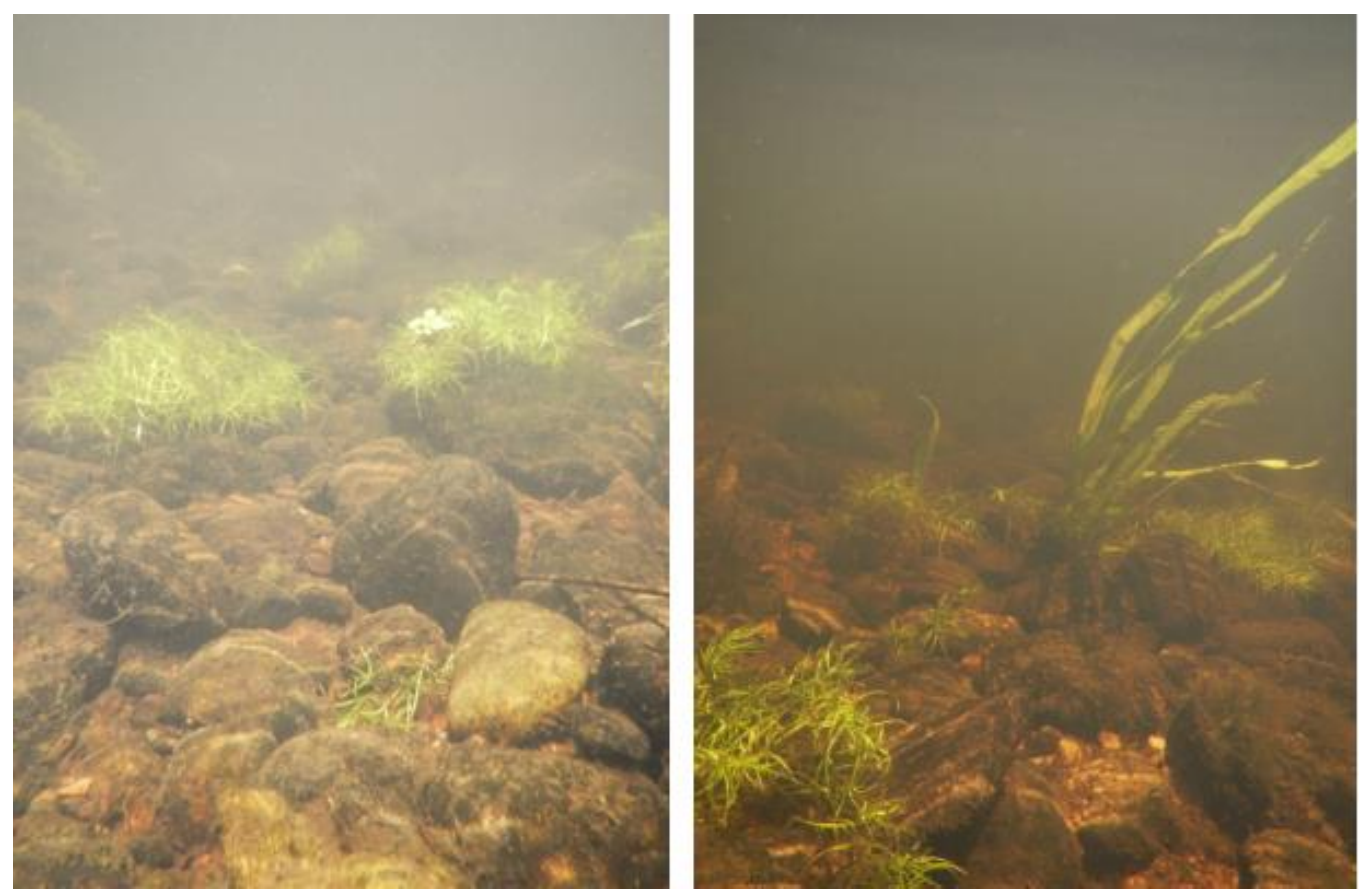

Figure 98. Bottom conditions in the Pawcatuck River downstream the Kenyons Bridge (Laurent, 2016).

The bathymetric surface at the Kenyons Bridge is illustrated in Figure 99. Laurent's study could not observe any scour along the abutments although scour up to $3 \mathrm{~m}$ was predicted based on the 2010 flow (100-year flow) using the HEC- 
18 Scour Equations. The area near the abutments, where usually the highest amount of scour can be expected, is surprisingly shallower than the middle of the channel.

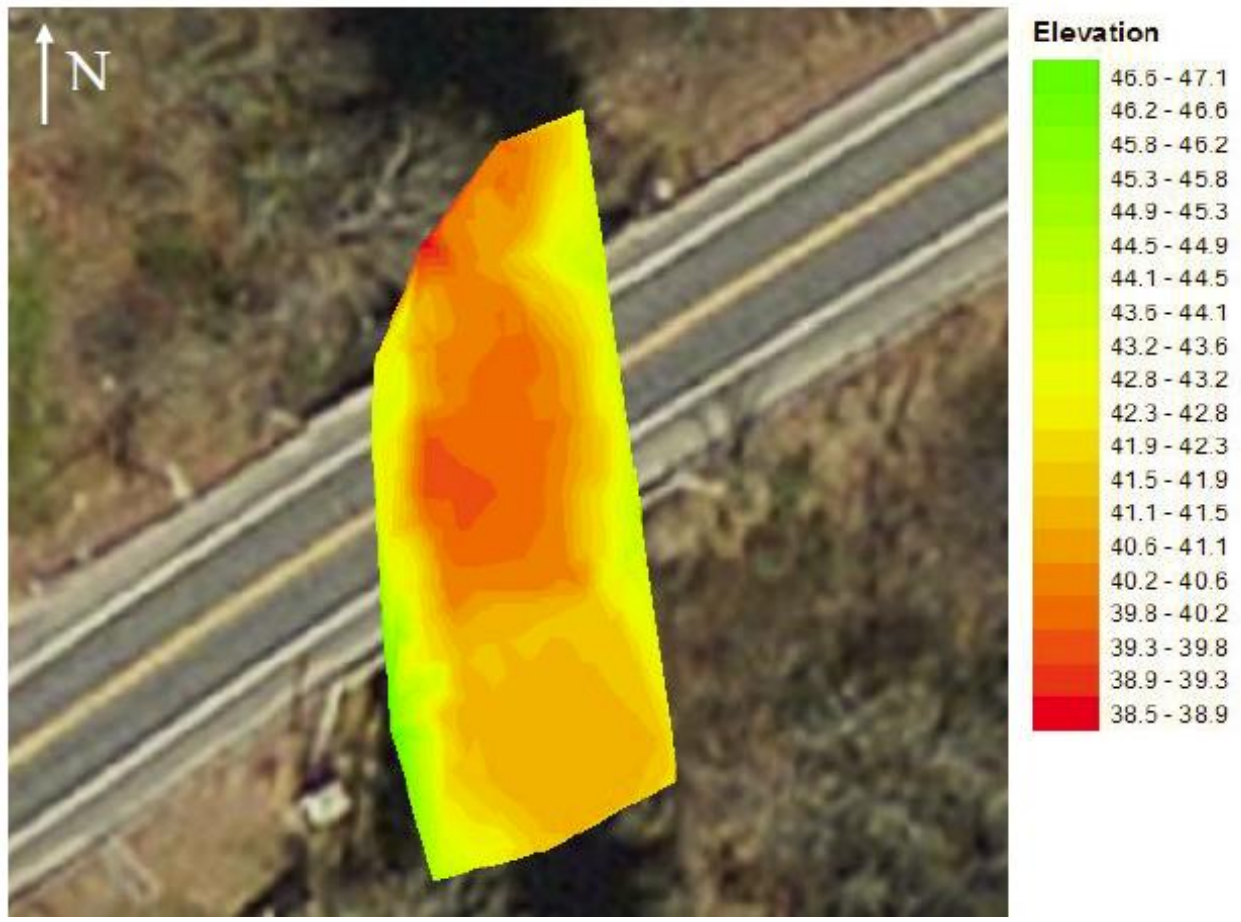

Figure 99. Bathymetric surface at the Kenyons Bridge in $\mathrm{ft}$ (Laurent, 2016).

\subsubsection{Data Collection}

Cross-sectional GPR profiles were collected upstream and downstream of the bridge. The data was collected in two lines as shown in Figure 100 from the left bank of the river to the right bank of the river.

The research vessel was placed in the water (Figure 101) and then pulled from one river side to the other while the SIR3000 was operated from the top of the 
bridge (Figure 102). By pulling the ropes tight, the RV had a straight track in the water.

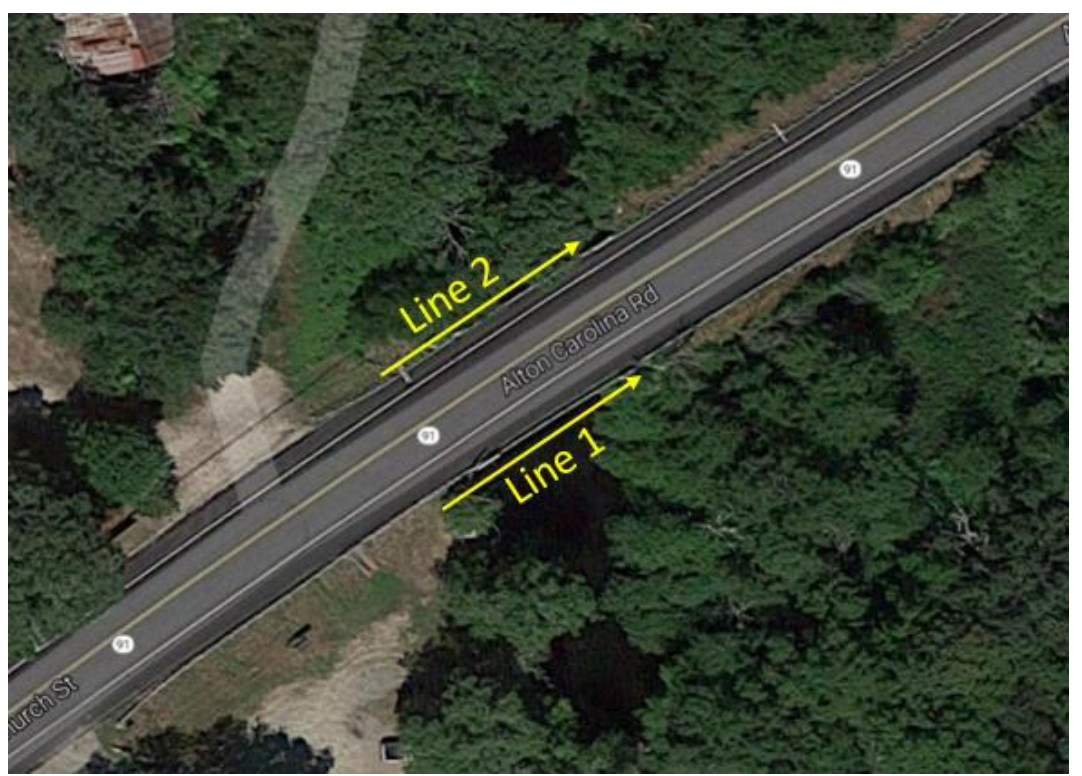

Figure 100. Measurement lines at the Kenyons Bridge.

The data was collected with the GPR parameters in Table 11.

Table 11. Parameter settings at Kenyons Bridge.

\begin{tabular}{|c|c|}
\hline Paramter & Value \\
\hline Antenna type & $400 \mathrm{MHZ}$ \\
\hline Scans/Sec & 64 \\
\hline Samps/Scan & 1024 \\
\hline Bits/Scan & 16 \\
\hline Dielectric Constant & 81 \\
\hline Range (ns) & 180 \\
\hline Low Pass IIR Filter & 800 \\
\hline High Pass IIR Filter & 100 \\
\hline
\end{tabular}




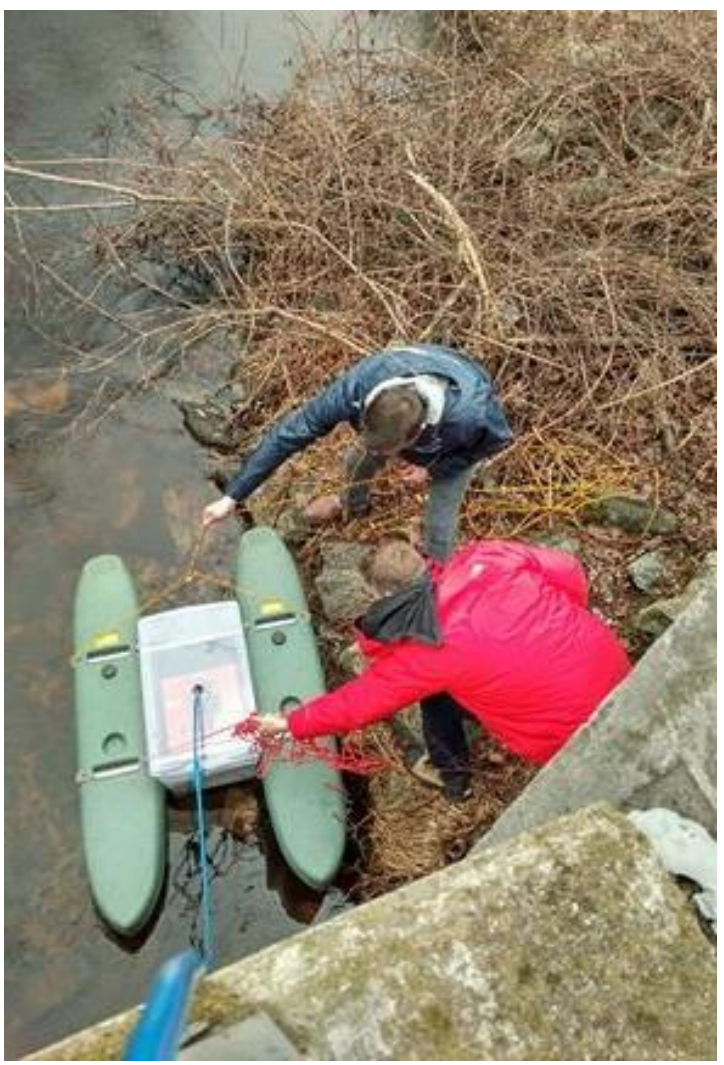

Figure 101. Research Vessel in the Pawcatuck River.

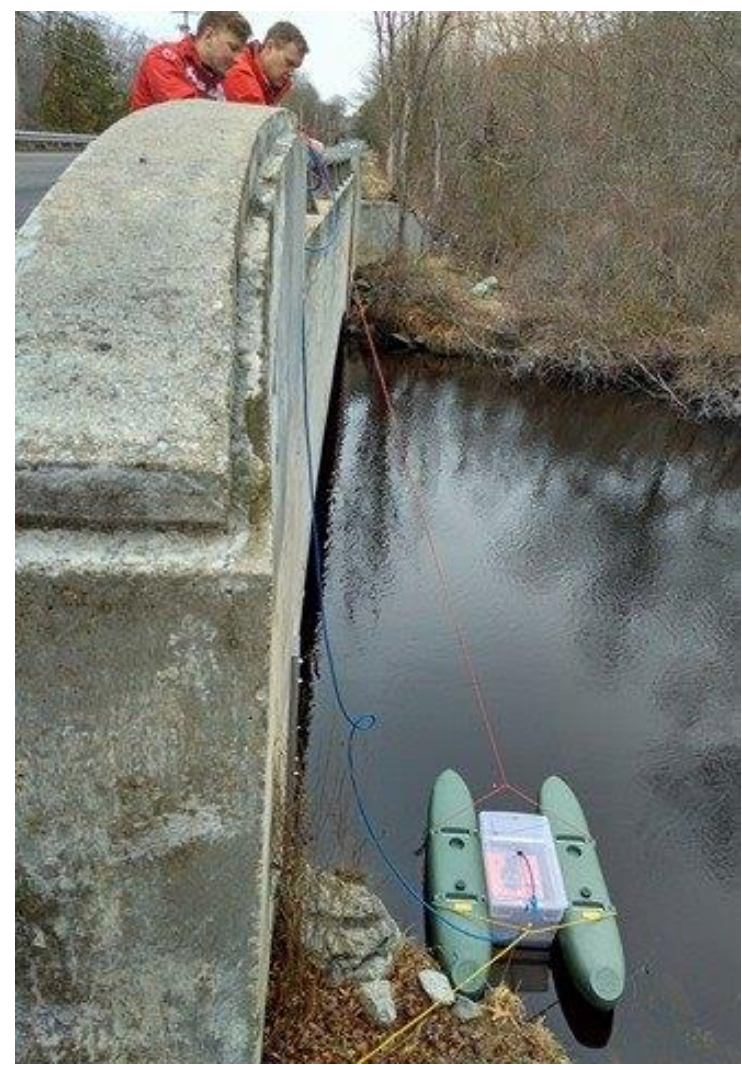

Figure 102. GPR System operated from the Bridge Deck.

\subsubsection{Results}

A part of the raw data from the upstream cross section is illustrated in Figure 103 and shows a streambed with strong hyperbolic reflectors. The hyperboles are coming from boulders and cobbles. The riverbed conditions in Figure 97 and Figure 98 are confirming the radar image. The horizontal scale shows the number of scans and the vertical scale is the depth in meters. The data is presented in a gray scale and a linear color xform.

There are two problems: First the o-scope to the right, shows a problem with the data. The same problem, but magnified, has occurred in the wave tank test 
from chapter three. Due to the high change in polarity from 81 (water) to approximately 7 (sand or cobbles) in combination with the high amplitude of the reflection from cobbles and the gain used in the survey causing data clipping. The SIR3000 cannot record the whole signal. The problem was noticed after the surveys and had to be corrected by processing in RADAN. Another problem caused by the cobbles is the high amount of hyperboles which overlap the data.

Figure 98 confirms the significant amount of cobbles on the riverbed.

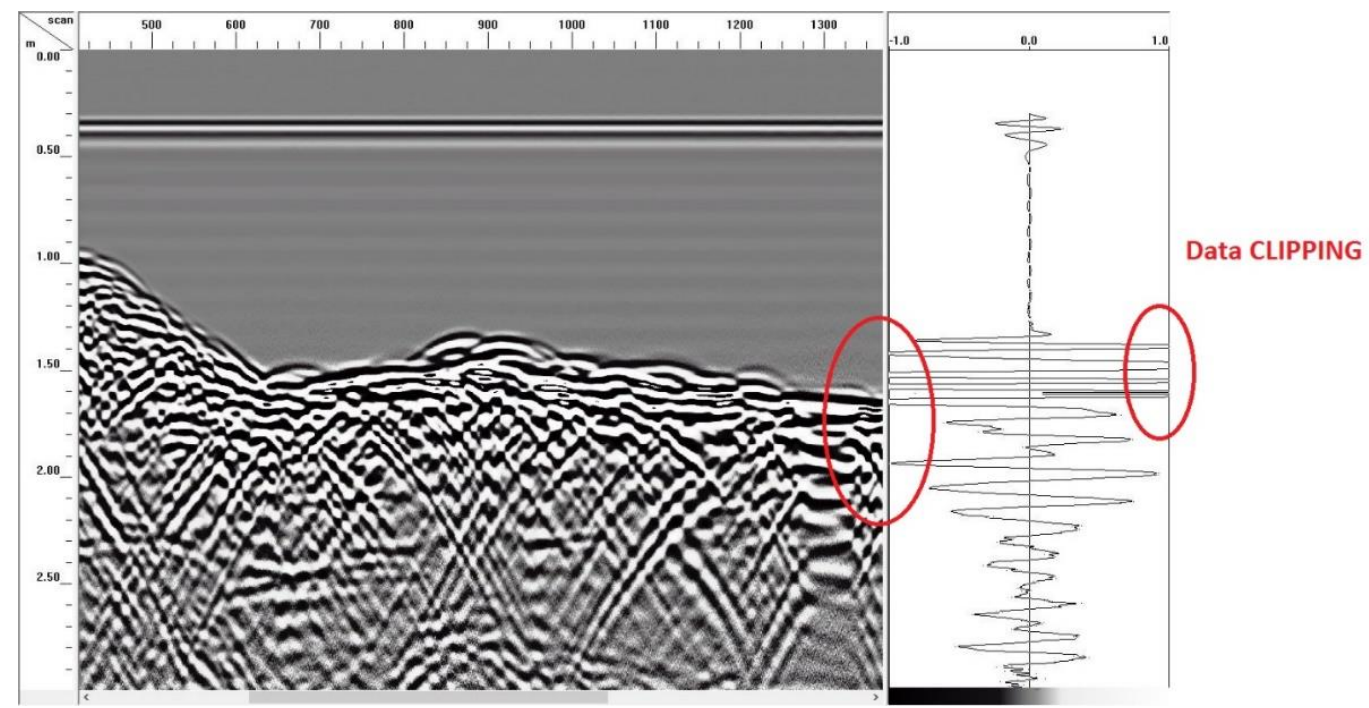

Figure 103. Unprocessed data and data Clipping Problem at upstream cross section at Kenyons Bridge.

In order to perform an interpretation, the data needed significant processing. The data in Figure 103 was processed with a background removal filter, an improved depth calculation by time corrections, a migration function to remove the hyperboles, FIR filters to remove unwanted reflections created by the migration function and a range gain to see features in the soil. The final image 
can be seen in Figure 104. After these processing steps the data allows an interpretation.

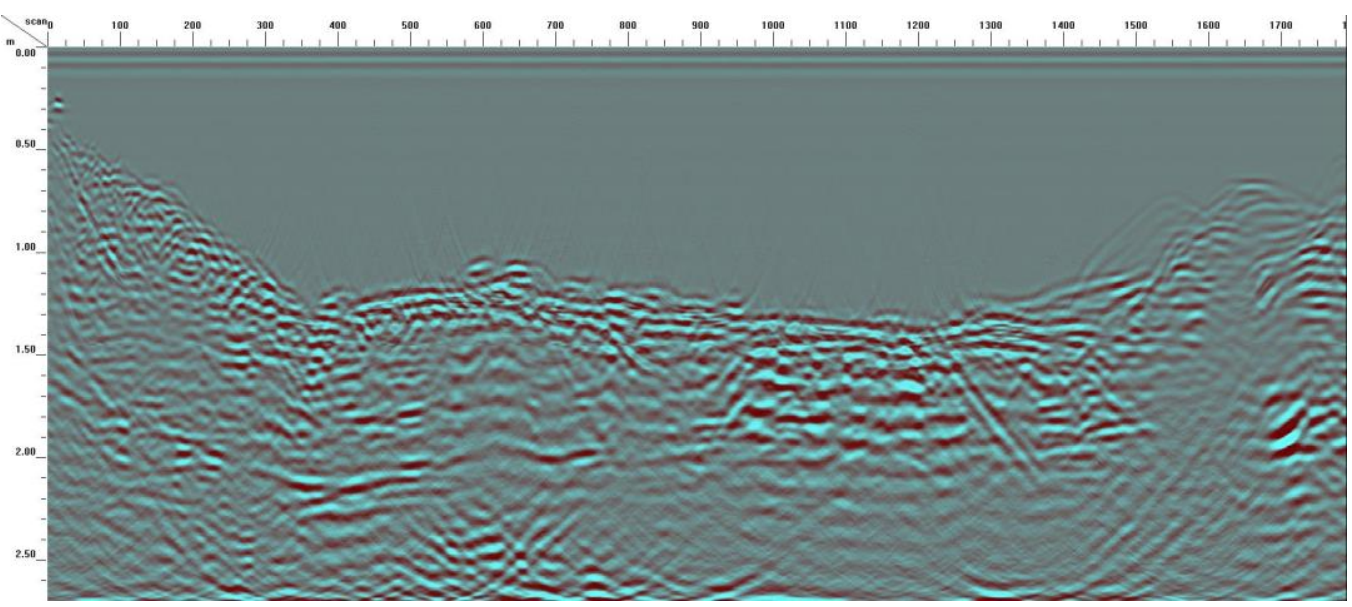

Figure 104. Processed Radar Image Downstream at Kenyons Bridge.

The maximum channel depth in Figure 105 is around $1.0 \mathrm{~m}$. The channel has a lower water depth at the sites close to the abutments. This was already noted from the bathymetry data in Figure 99. The armoring layer of the riverbed starts at the yellow line and ends at the red line. Note that the depth calculation is only precise for the water depth in the channel because the dielectric value of water was used.

At a depth of $2 \mathrm{~m}$ the green line marks a significant horizontal reflection. This reflector can be an indicator for a soil layer. It is unlikely that this is an indicator for an infilled scour feature because of the significant continuous armoring layer above the reflection that the stream would be unable to reproduce if it was eroded away. Upon observation, the armoring layer had cobbles that the current flow rate would be unable to carry. This reflection could also be a multiple created by the 
strong river bed reflection or even a normal soil layer, but there is no way to confirm these statements without digging into the soil.

At a depth of $2 \mathrm{~m}$ the green line marks a significant horizontal reflection. This reflector can be an indicator for an infilled scour feature, meaning that in a previous flooding event, the fine sediments under the armoring layer was removed. When the stream velocity slowed down after the flooding event, new sediment was placed over the 'old' armoring layer. This could be the reason for this reflection. The flooding event could be way back in the past when the river was bigger. But there is no way to confirm this statement without digging into the soil. This reflection could also be a normal soil layer.

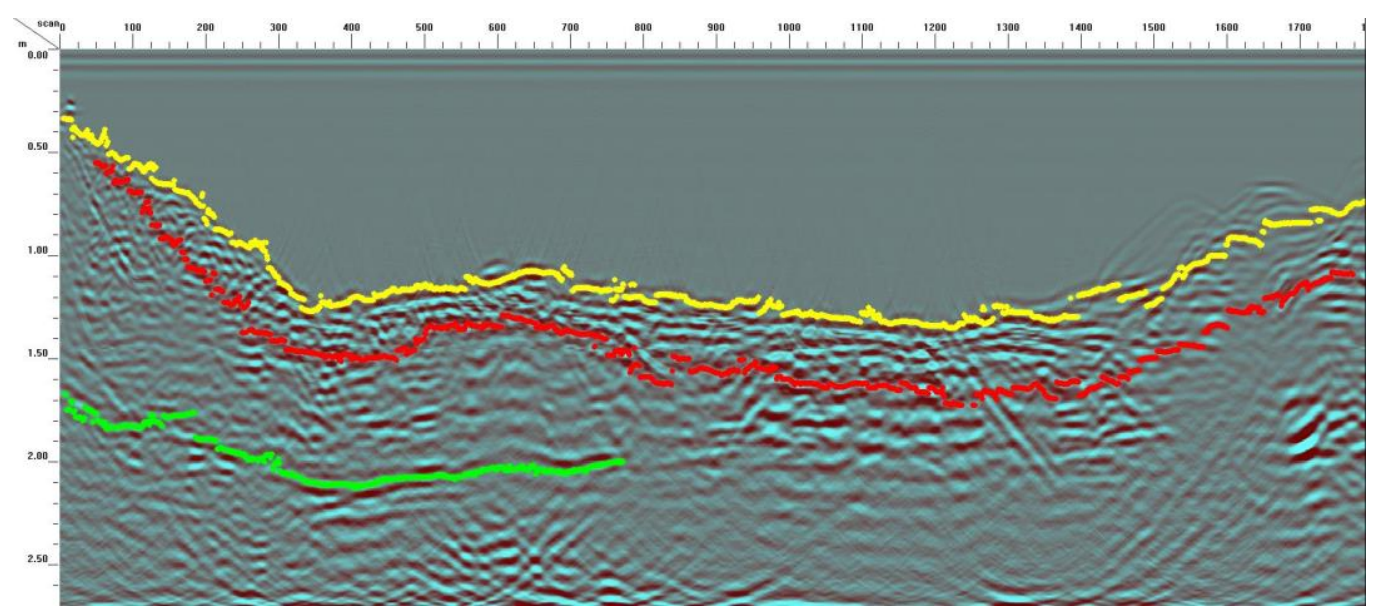

Figure 105. Interpreted Radar Image Downstream (with Migration) at Kenyons Bridge.

The upstream cross section in Figure 106 shows similar strong reflections coming from cobbles and boulders. The maximum channel depth is at around 1.5 $\mathrm{m}$ and deeper than the downstream channel. The armoring layer between the 
yellow and the red line seems to be a little thicker than the downstream section. A clear horizontal reflection underneath the armoring layer as in the cross section of the downstream image before can be not found. However, there is a horizontal reflection, which could be the same layer as before or a multiple from the strong armoring layer reflections.

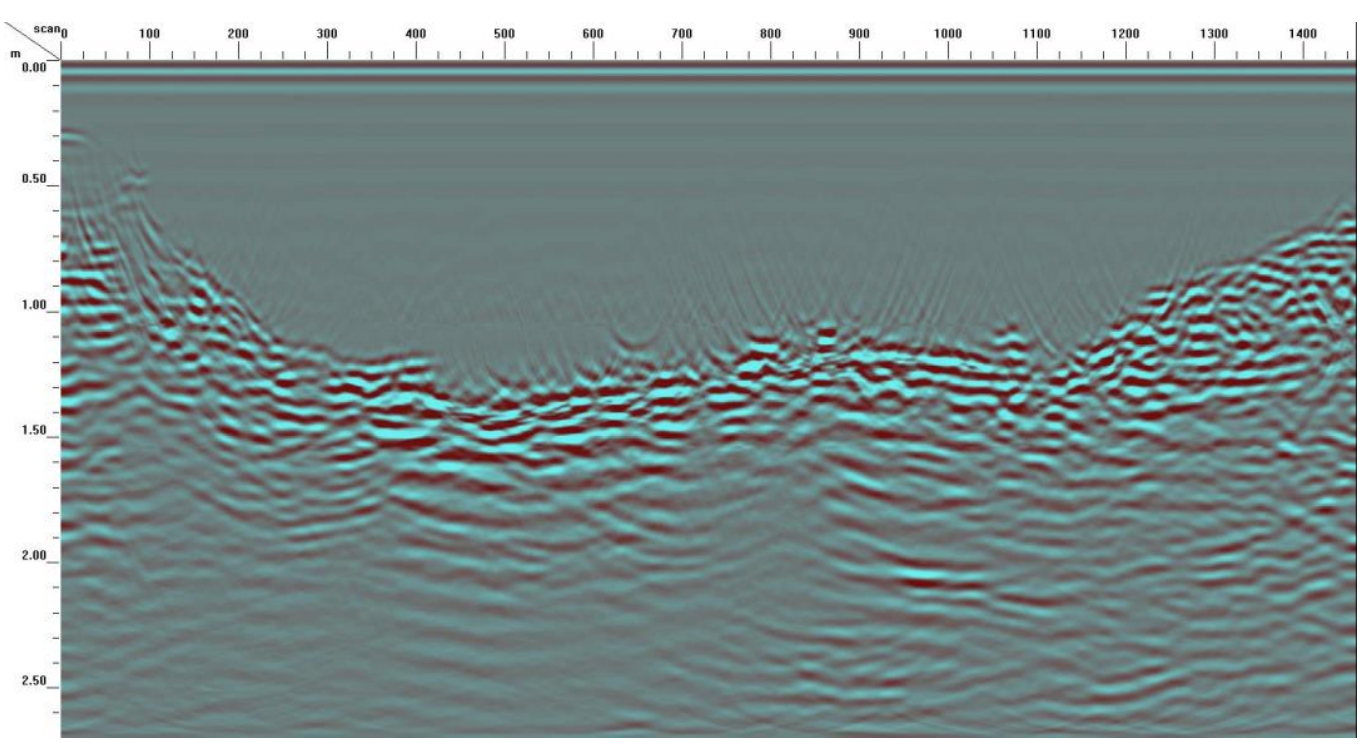

Figure 106. Processed Radar Image Upstream at Kenyons Bridge.

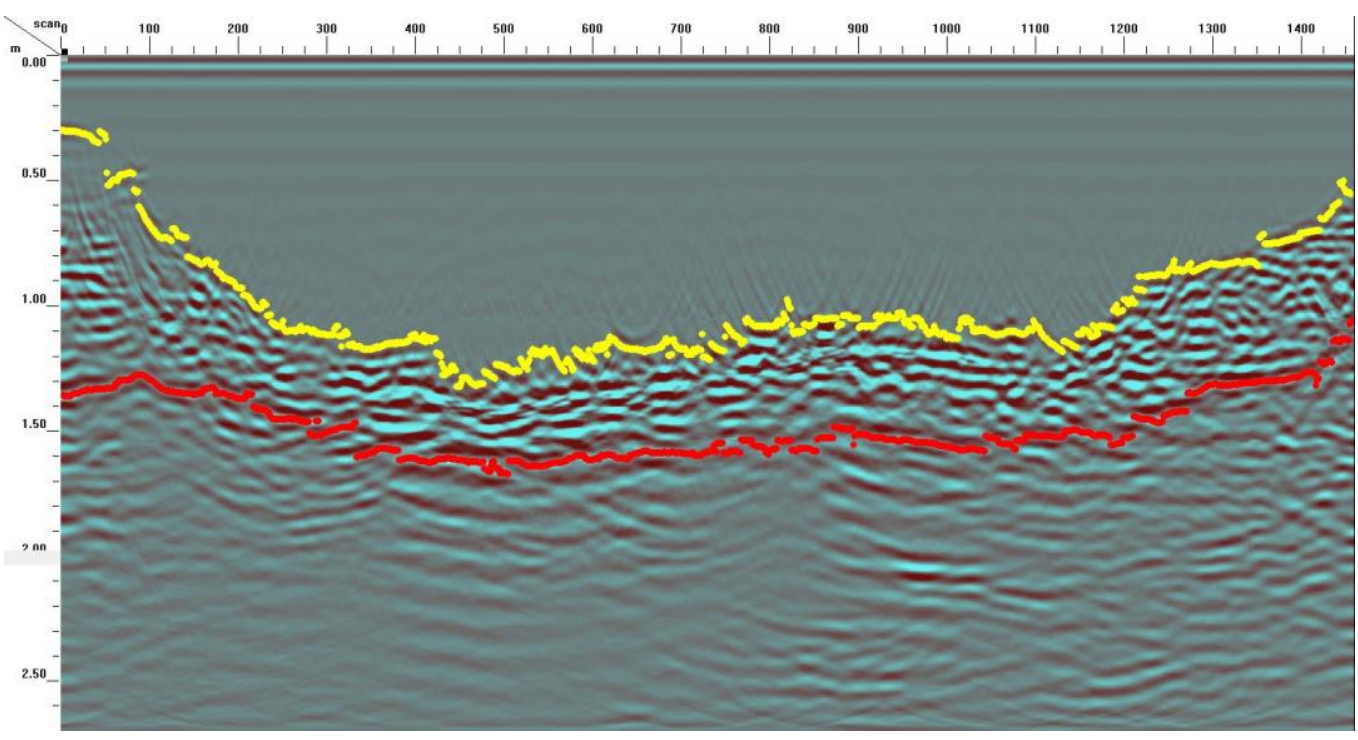

Figure 107. Processed \& Interpreted Radar Image Upstream at Kenyons Bridge. 
Both radar images adumbrate a new layer with different properties exists underneath the first layer of cobbles. At a depth around $2 \mathrm{~m}$ the hyperboles become less intensive and other features are visible. One interpretation of this feature could be a soil layer. However, a confident statement is not possible due to the layer of cobbles which causes strong reflections and overlay other features.

\subsection{First Barberville Bridge, Hopkinton, RI}

This section presents the results of the field survey of the First Barberville Bridge in Hopkinton, Rhode Island. A characterization of the site, how data was collected and the results are provided.

\subsubsection{Site Description}

The First Barberville Bridge (No. 004101), built in 1925, crosses the Wood River in Hopkinton, RI (as seen in Figure 108 and Figure 109). The bridge has a span of $14.6 \mathrm{~m}$ and carries two lanes of traffic (Laurent, 2016). As Figure 109 shows, a small dam is located about $10 \mathrm{~m}$ upstream of the bridge and controls the hydronamics of this site.

After scour features were observed the bridge was repaired in 2010 and then again in 2015, the scour countermeasures taken include rip-rap along the river channel. 


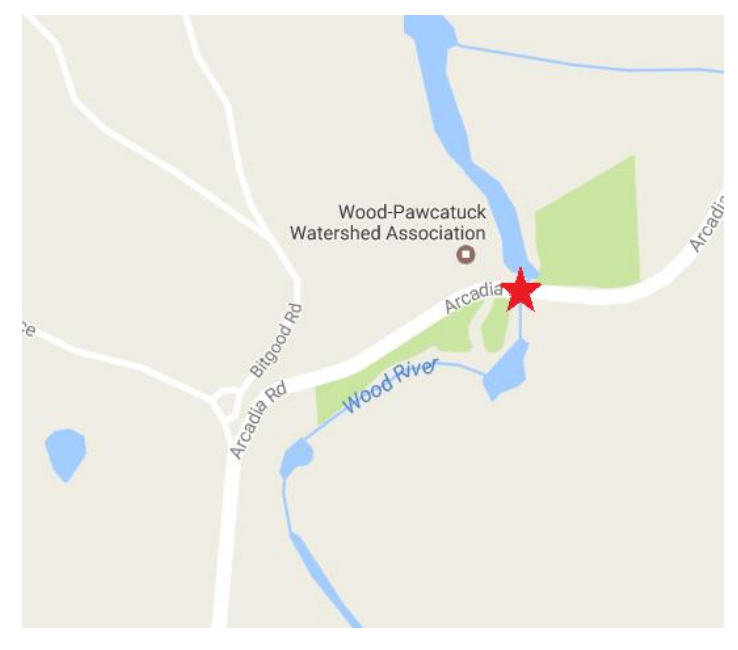

Figure 108. Location of the First Barberville Bridge, Hopkinton, RI

(Google Maps, 2017).

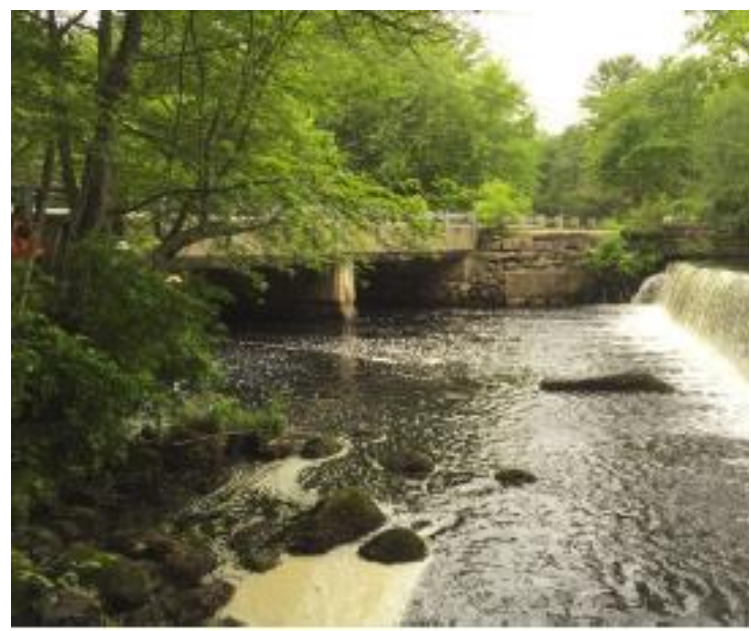

Figure 109. First Barberville Bridge (Laurent, 2016).

The bed conditions can be seen in the grain size distribution in Figure 110. The data is from 1994, making it dated and most likely inaccurate after repairs works in 2010 and 2015 which included the placement of rip-rap. The picture from the riverbed of the Wood River under the bridge in Figure 111 shows a surface with lots of cobbles and boulders as well as the visible rip rap. 


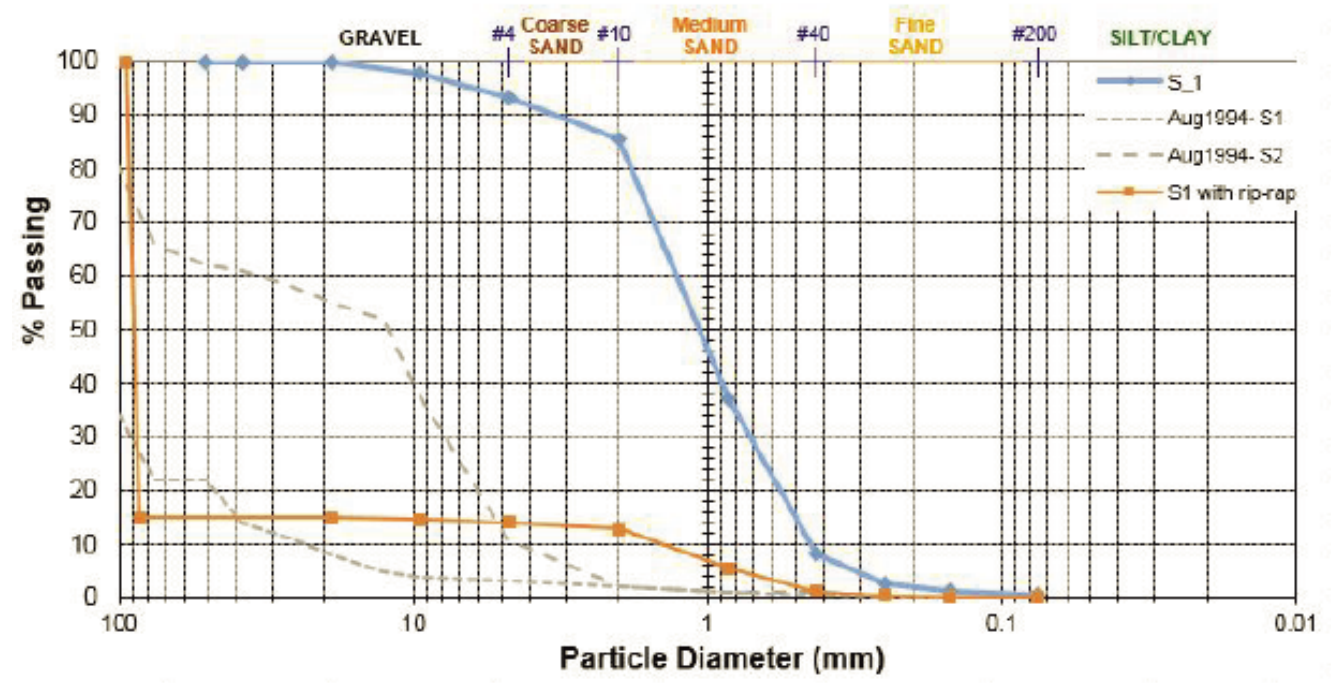

Figure 110. Grain size distribution at First Barberville Bridge (Laurent, 2016).
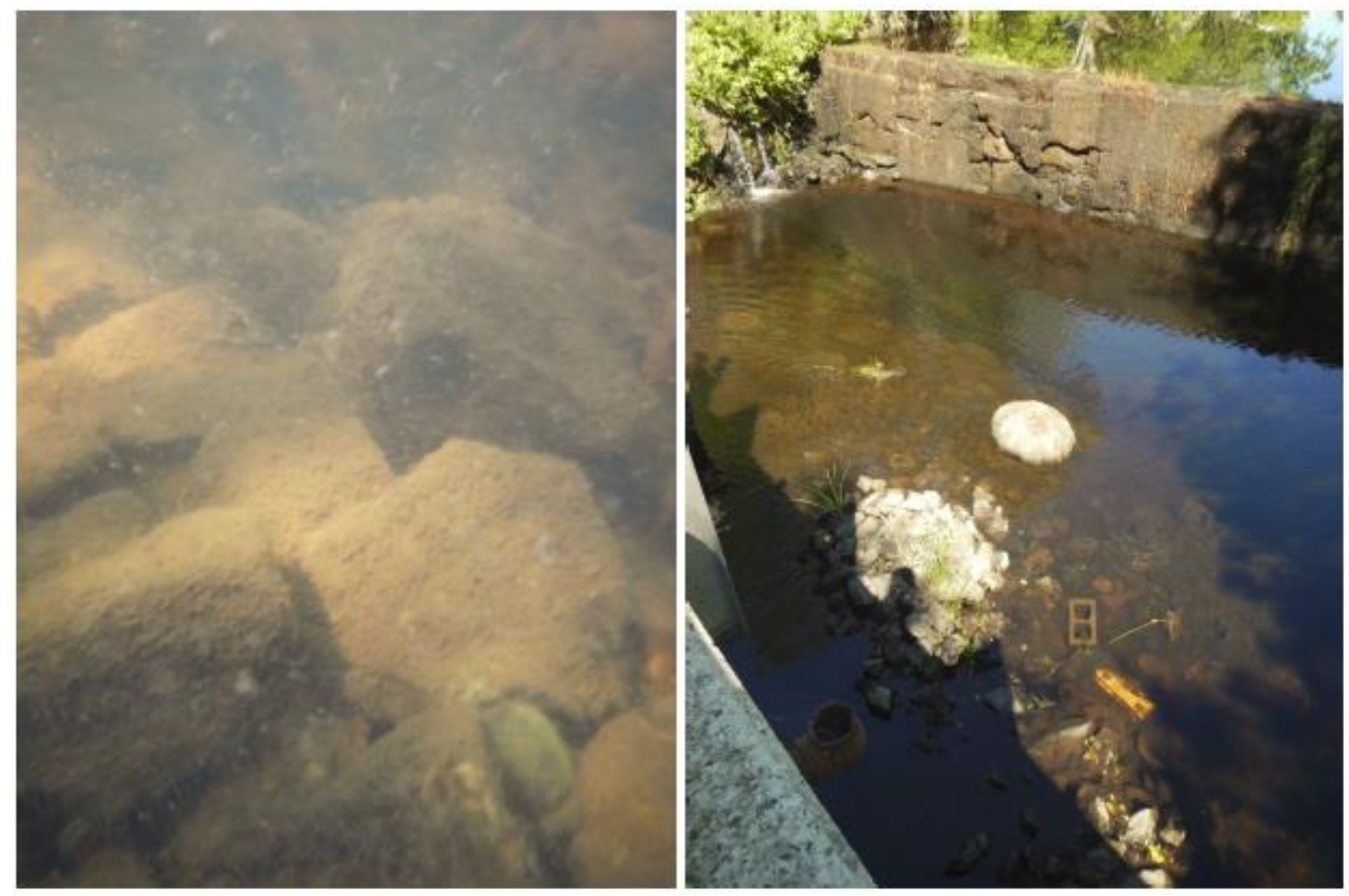

Figure 111. Bottom conditions in the Wood River at the First Barberville Bridge (Laurent, 2016).

The bathymetry at First Barberville Bridge is illustrated in Figure 112. Laurent's study could not observe any scour features along the abutments due to the armor layer which was placed there in 2015. 


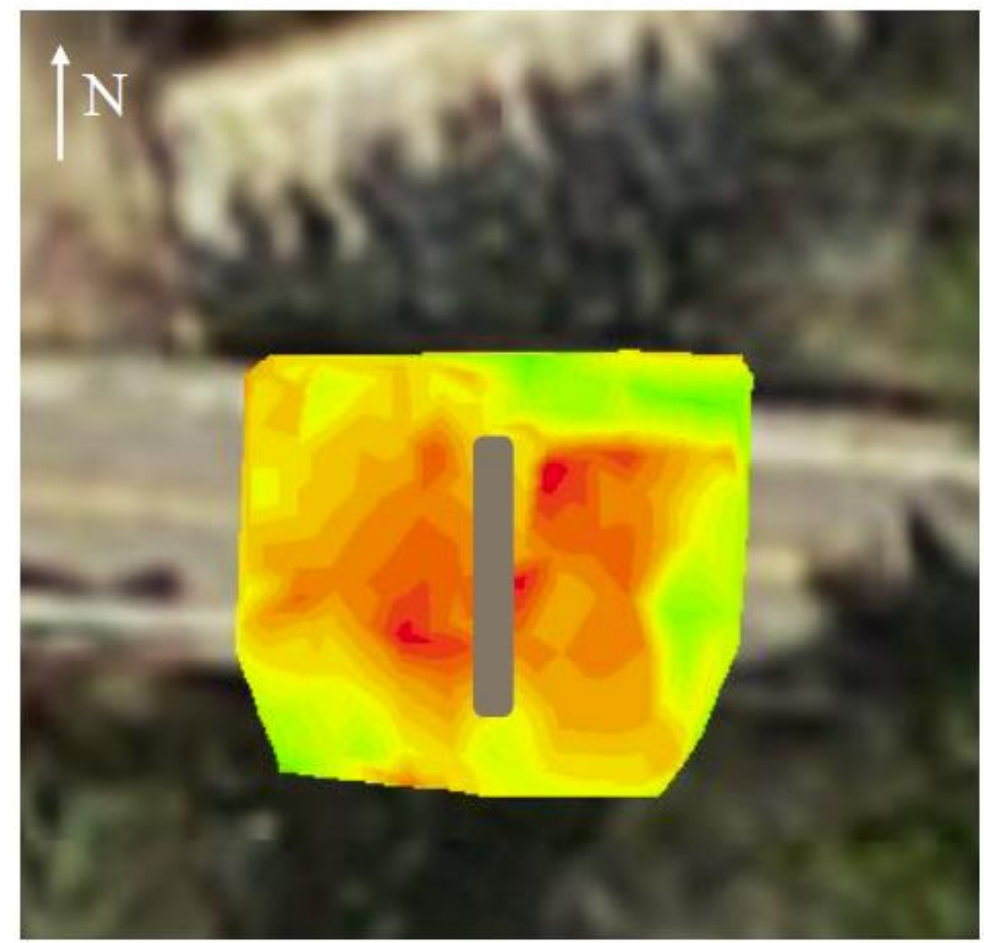

Figure 112. Bathymetric surface data at the First Barberville Bridge in $\mathrm{ft}$ (Laurent, 2016).

\subsubsection{Data Collection}

The data collection was planned in the same way as the survey at Kenyons Bridge. Cross-sectional GPR profiles were collected upstream and downstream of the bridge. The data was collected in two lines as shown in Figure 113 from the right bank of the river to the left bank of the river.

The research vessel was placed in the water (Figure 114) and then pulled from one river side to the other while the SIR3000 was operated from the top of the bridge (Figure 115). In contrast to the Kenyons Bridge survey, the velocity of Wood 
River was higher than the Pawcatuk River and the RV could not be pulled in as straight of a line as it was before.

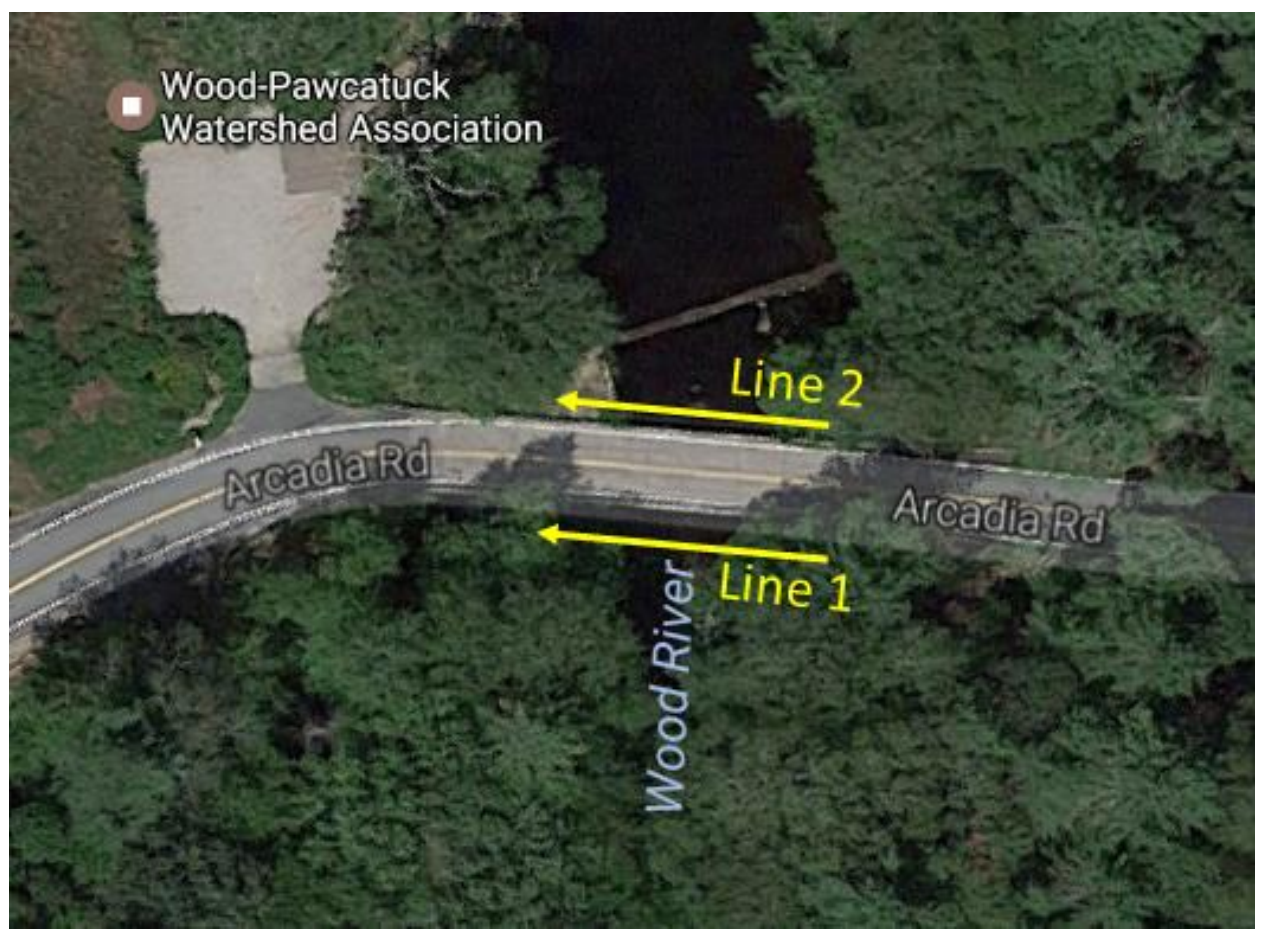

Figure 113. Measurement lines at the First Barberville Bridge.

The data was collected with the GPR paramters in Table 12.

Table 12. Parameter settings at the First Barberville Bridge.

\begin{tabular}{|c|c|}
\hline Paramter & Value \\
\hline Antenna type & $400 \mathrm{MHZ}$ \\
\hline Scans/Sec & 64 \\
\hline Samps/Scan & 1024 \\
\hline Bits/Scan & 16 \\
\hline Dielectric Constant & 81 \\
\hline Range (ns) & 180 \\
\hline Low Pass IIR Filter & 800 \\
\hline High Pass IIR Filter & 100 \\
\hline
\end{tabular}




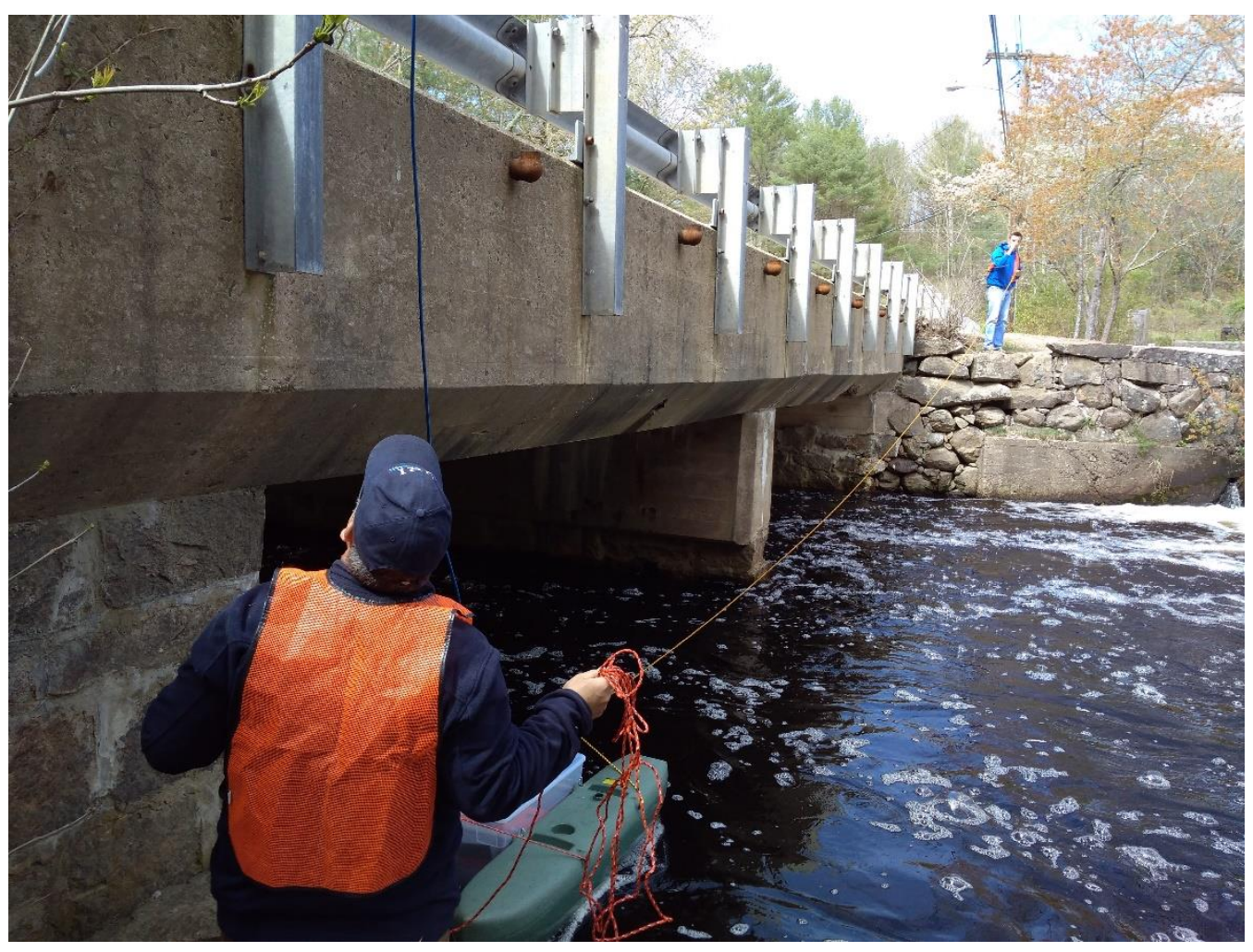

Figure 114. Data collection at the First Barberville Bridge. 


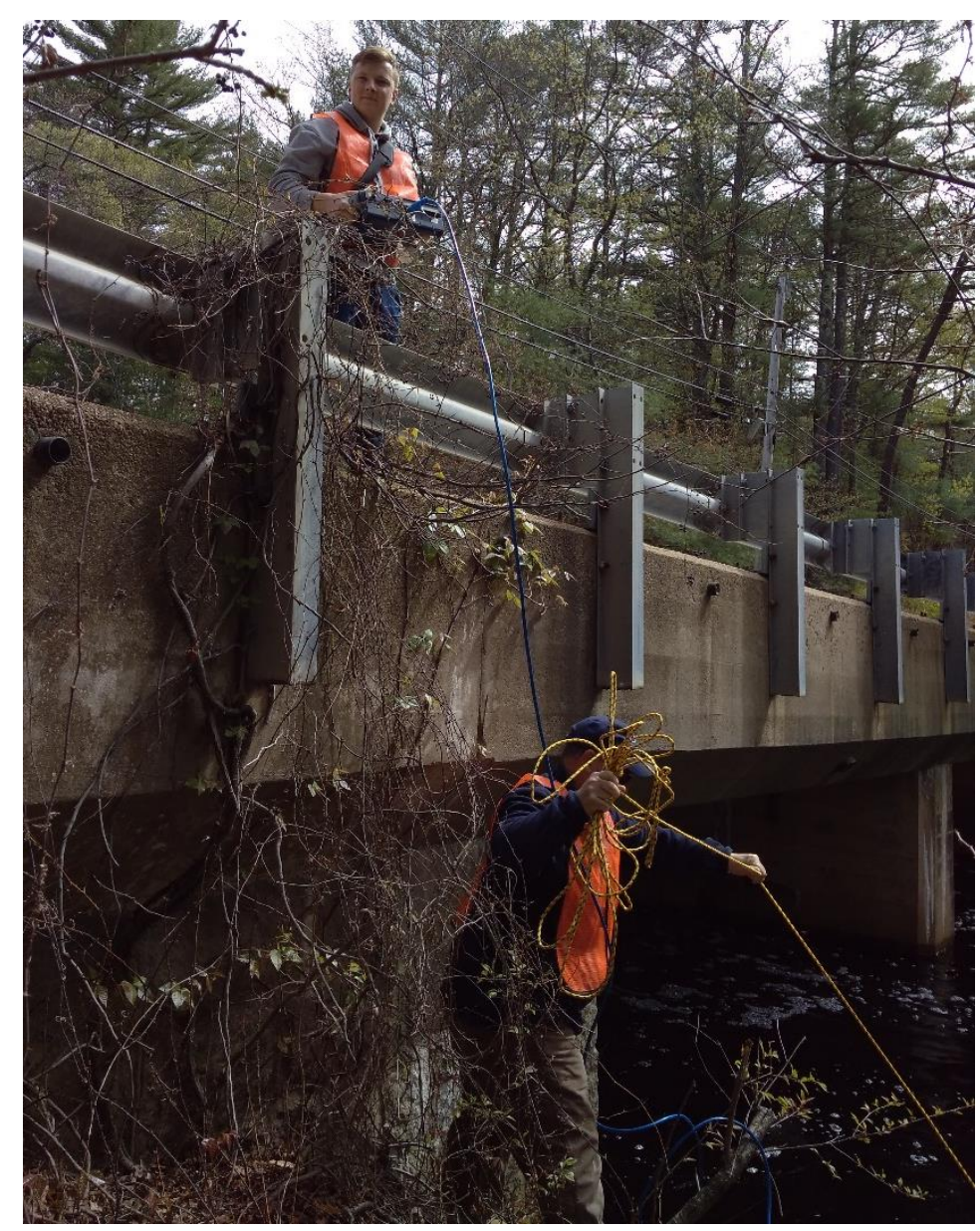

Figure 115. SIR3000 operated from the bridge deck.

\subsubsection{Results}

The data from the First Barberville survey is illustrated in Figure 116 and Figure 118. The horizontal scale shows the number of scans and the vertical scale is the depth in meters. The data is presented in a green/gray scale and a linear color xform. The data has the same problem as the Kenyons Bridge. The raw data (Figure A 9) and the clipping effect (Figure A 8) can be seen in the appendix. Both bridges show the same characteristics. The First Barberville Bridge has a more 
challenging environment due to the existing rip-rap. The data was again processed with a background removal filter, an improved depth calculation by time corrections, a migration function to remove the hyperboles, FIR filters to remove unwanted reflections, created by the migration function and a range gain to see features in the soil.

The downstream cross section shows an undulating streambed of strong boulder reflectors. The maximum water depths located on the left of the river and is $1 \mathrm{~m}$ deep. The depth decreases in the middle of the river and then dips back down to $0.9 \mathrm{~m}$ in depth just right of the river center. The radar image shows strong reflections starting from the surface. The reflections are stronger and through the whole soil layer in comparison to Kenyons Bridge. A possible explanation for the continuous reflections is the rip rap that was laid down in 2010 and 2015.

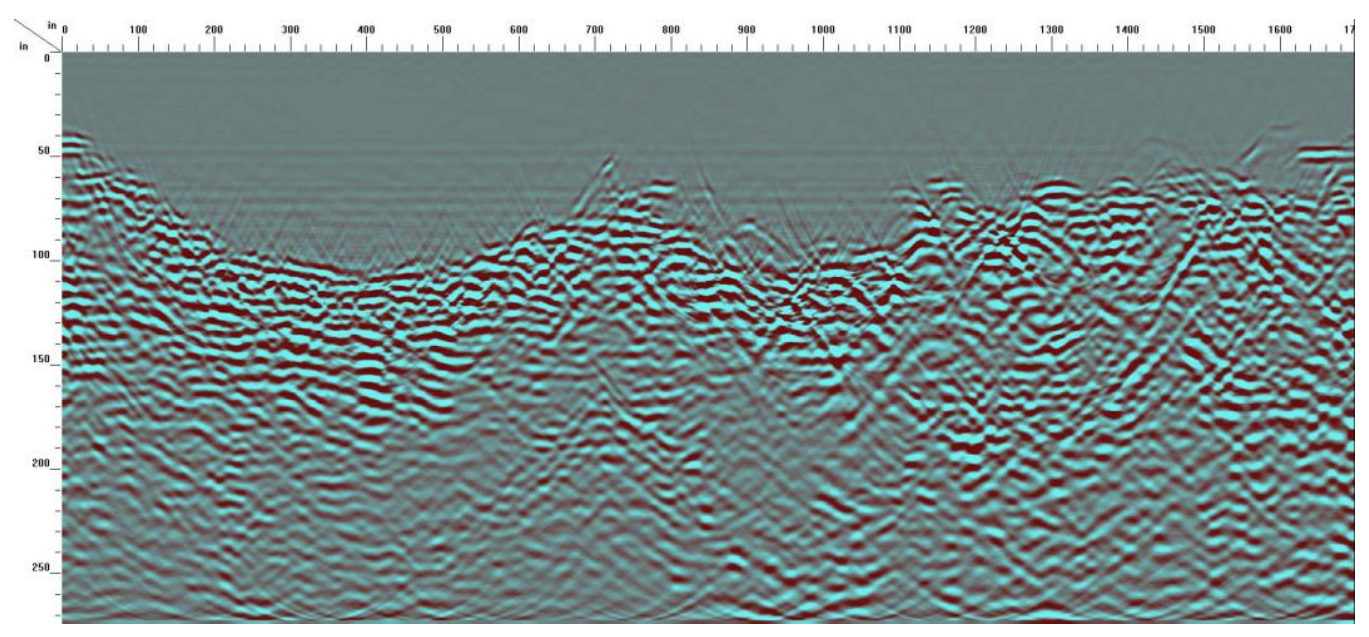

Figure 116. Processed Radar image downstream at First Barberville Bridge. 
The interpreted Figure 117, shows only the beginning of the armoring layer from the yellow line and the end at the red. Other features in view of scour features is not possible.

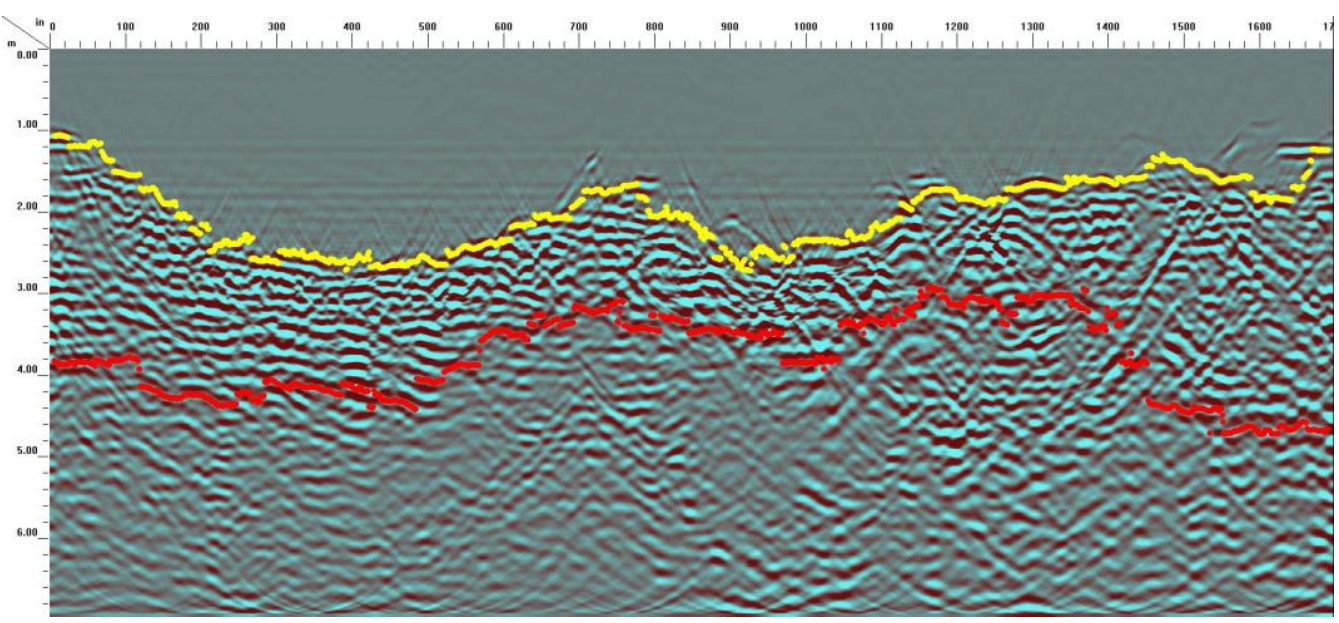

Figure 117. Processed and interpreted radar image downstream at First Barberville Bridge.

The upstream cross section has a maximum water depth of $0.9 \mathrm{~m}$. The radar image shows the same strong boulder reflections which dominate the image. Because of the reflections, a statement about other features is not possible. As in the downstream figures only the armoring layer is possible to determine. 


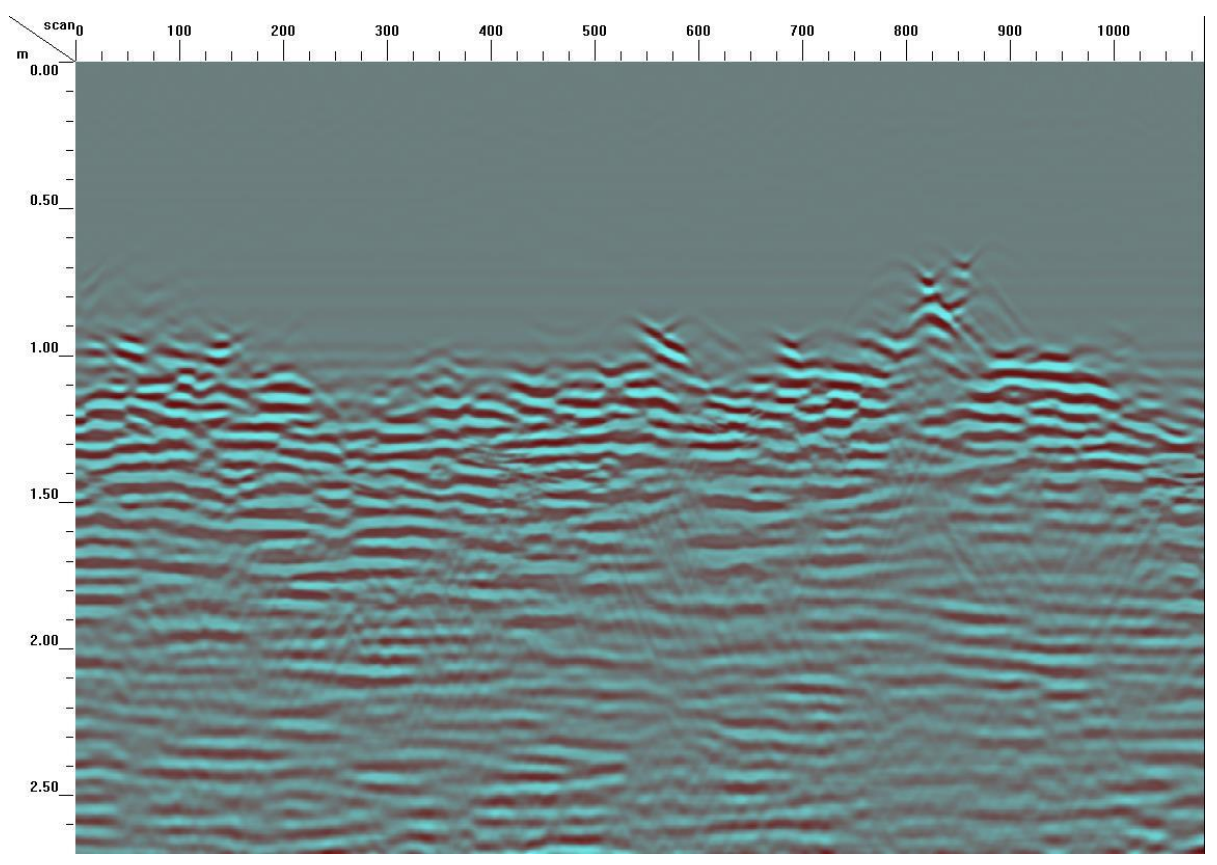

Figure 118. Processed Radar Image Upstream at First Barberville Bridge.

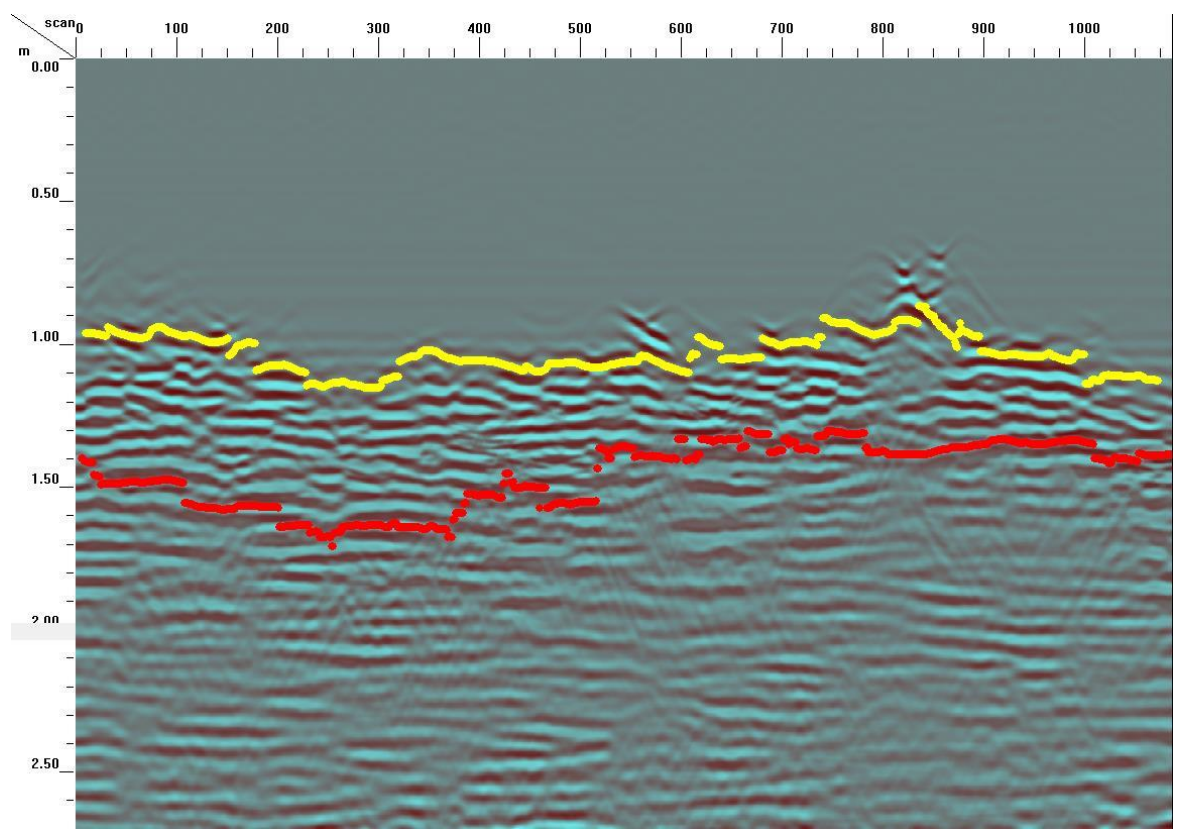

Figure 119. Processed and interpreted GPR image upstream at First Barberville Bridge. 
Figure 120 shows results of investigations following (Pechillo, 2010). There was clear evidence of scour o the upstream side of the west span (Abutment \#2). This prompted the placement of riprap in the channel. Figure 119 shows that the bathymetry is quite level and no past scour features below the rip rap were observable.

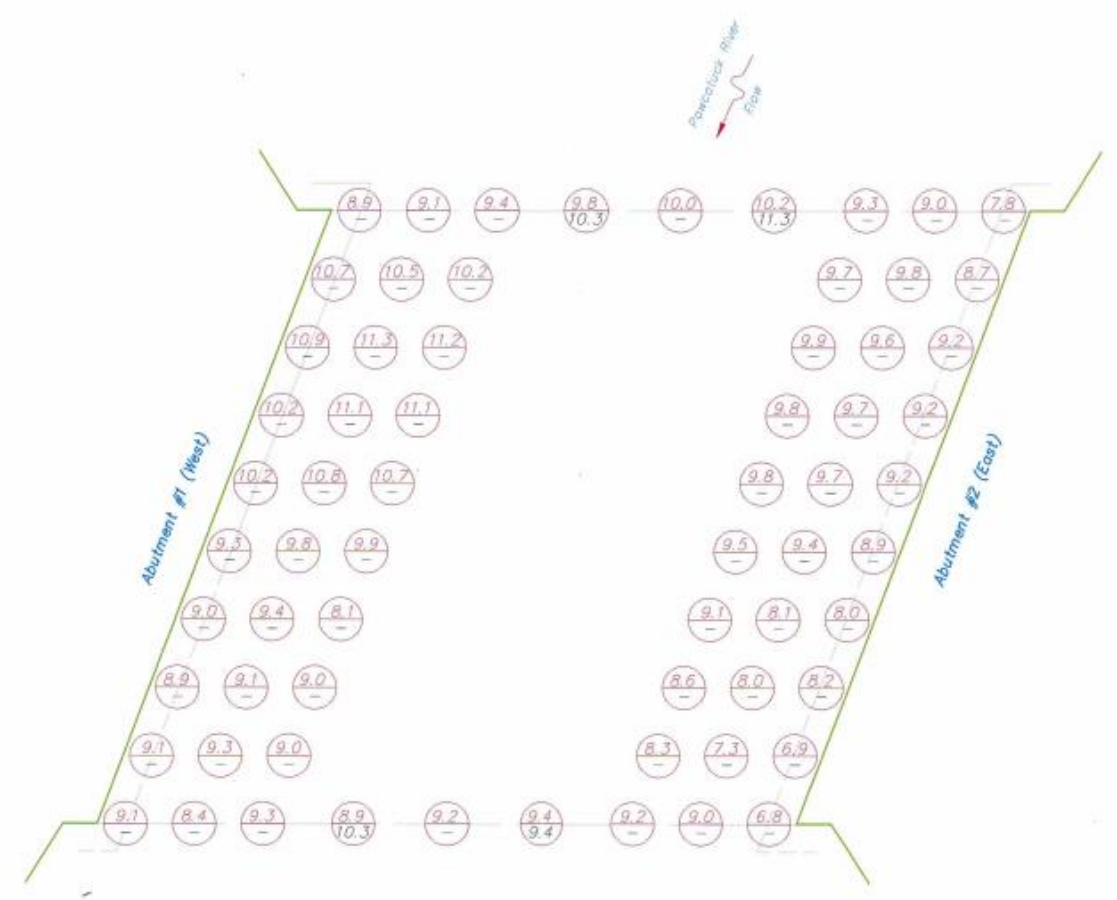

Figure 120 Sounding plan at First Barberville Bridge (Pechillo, 2010)

\subsection{Discussion of Surveys and Results}

The goal of using the Ground-penetrating Radar at these bridge sites was to measure the depth of infilled scour holes. The surveys had only limited success. The surveys were conducted as planned, in which the pontoon boat was pulled 
from one side to the other and the GPR was able to collect data. The GPR was able to determine the bathymetry, but the rocky bottom conditions at both locations prevented further analysis in the range of interest. The scour features which the study was looking for are relatively small and the area of interest in the data is disturbed by the rocks. Another significant issue is that scour holes can only be detected if the hole is infilled with a different material as its environment. The dielectric value needs to be significantly different to make the holes visible with GPR.

Both bridge locations had a distinct armoring layer in form of cobbles and boulders, making the data difficult to read. The data was also only taken at one time for each bridge, so a comparison over time in unavailable. The literature review presented studies where the GPR was able to determine infilled scour holes. However, Olimpio et. al. (2000) took GPR measurements two years after their first measurements. The repetition of the tests and availability of more data made scour developments, new features, and infilled scour holes easier to detect. The research of Webb et. al. (2002) used two different antennas to determine scour features. Furthermore, their locations were without distinct armoring layers and had additional information from Lithologic logs and bridge construction plans to improve the interpretation of the GPR profiles.

In comparison to the surveys from Chapter 5 the interpretation was nearly impossible not only because of the many hyperboles in the data but also because not existing additional data. In Chapter 5 the locations had even two other data resources which shows how important additional data sets are. 
Another problem was the equipment which was not able to collect perfect data sets. The SIR3000 could not record the whole data due to high amplitudes caused by the cobbles. The consequence was data clipping and RADAN had to be used to estimate the data between points where no data existed. 


\section{Chapter 7}

\section{Conclusion}

Ground Penetrating Radar data was collected, processed, and interpreted in an effort to test the tool's ability to image shallow rock layers on land locations and in-filled scour features in shallow Rhode Island waterways. Multiple GPR profiles were collected at every location. To be considered as an effective nondestructive evaluation technique, the method must be relatively fast, accurate, and inexpensive.

The first tests performed for this thesis were GPR surveys in a controlled environment with known properties. The test results showed what the GPR was capable of and what its limitations were. The GPR can be adjusted to fit the needs of the survey locations quickly; the continuous data profiles can be displayed in real time and immediately allow interpretations in some setups without processing. Two limitations were discovered in the tests. First, features can only be detected when a significant difference in dielectric value between materials exists. Second, high amplitudes in challenging setups can create data clipping. Both of these limitations have negative effects for land and water applications in this thesis.

The geophysical equipment for the surveys on land was mounted on a survey cart and could easily maneuvered by an operator pushing it along the measurement lines. The equipment can be disassembled in single pieces and does not take up much space. For surveys on water, the GPR was operated from 
the bridge deck and the antenna was sitting in a small research vessel. The vessel was easily maneuvered by two operators from one river side to the other. Both equipment configurations for surveys on land and on water were fast, safe, and easy to transport, which fulfills the first requirement of an effective nondestructive evaluation technique.

Based on the analysis from Chapter 4 the GPR proved to be a useful, cost effective tool in identifying shallow rock layers on on-land locations. However, for the interpretation of the images, additional information from boring logs and shear wave velocity profiles was available. This made the identification of some features possible. The accuracy of the depth of the soil layers is hard to determine. In most cases, without any knowledge about the soil, the dielectric constant is assumed and the depth calculation is inaccurate without the exact dialectic value or a fixed point in the soil. In addition, if there are no abrupt changes between layer boundaries and the dielectric values are similar, no strong reflections are created and a determination of layering is not possible. The sandbox experiment confirmed this. The literature review showed that an accurate determination of the soil layering was possible but the data was interpreted with the knowledge of the real soil profile due to shoveling a hole. In other applications for the detection of layering, for example in pavements, additional information such as constructions plans are available. From it is concluded that a GPR image alone cannot replace a destructive survey method like boring holes. A more efficient method could be to perform a GPR survey before the borings or to perform GPR between borings to tie-in stratigraphic 
features like bedrock throughout the profile. Areas of interest with complex soil properties could be determined and then surveyed with borings. Money would be saved and more information about the soil would be provided, eliminating the danger of missing important soil structures.

The GPR usage in Chapter 5 had only limited success. The GPR was able to image the channel bottom, but could not identify any infilled scour holes with high certainty. The bridge locations were very challenging to distinguish armoring layers in the form of cobbles and boulders. Furthermore, it was found that the equipment had limitations in that kind of environment, preventing a high enough resolution solution. The GPR was used only a few times in the past for monitoring bridge scour. In those studies, the detection of infilled scour holes was only possible due to multiple surveys at different times, the usage of different antennas together, or the existence of an easy environment.

Moving forward, this study has generated a number of questions and recommendations for further surveys.

- Collect multiple GPR data sets at different times at the same challenging locations to possibly allow interpretations about infilled scour holes.

- Collect data with different GPR antennas at the same challenging location to possibly allow interpretations about infilled scour holes. 
- Use a $900 \mathrm{MHZ}$ antenna in combination with a SIR4000 to have a higher resolution and no clipping effect. Note for using the $900 \mathrm{MHZ}$ antenna, the streams have to be shallow like the ones in this thesis.

- Try to determine the length of the survey lines at challenging locations for example by using a distance laser. The knowledge of the horizontal distance can be used in RADAN to normalize the horizontal distance which improves the data 


\section{Chapter 8}

\section{Appendix}

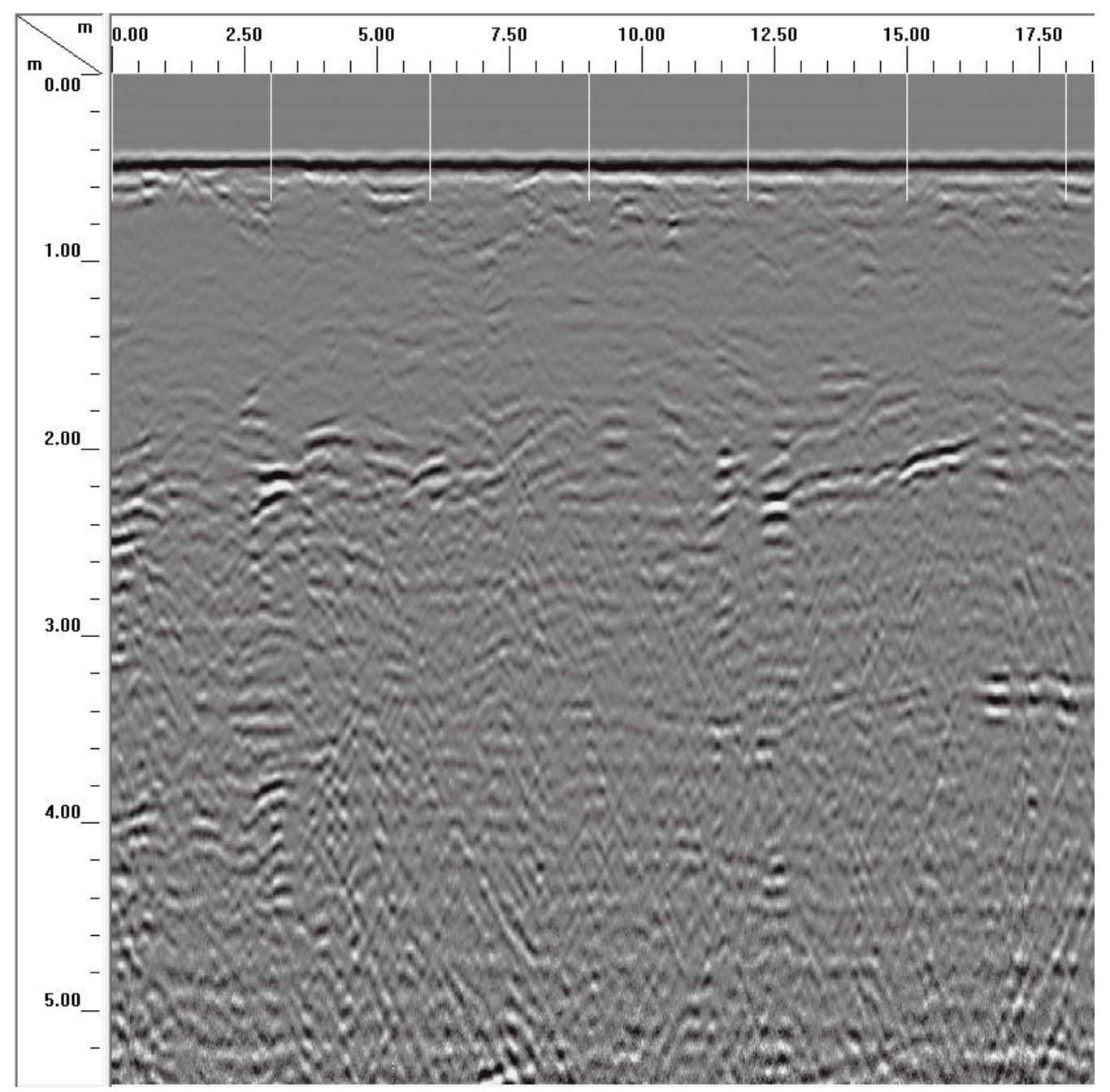

Figure A 1 Unprocessed Data at Weaver Hill Road Bridge Location 1 


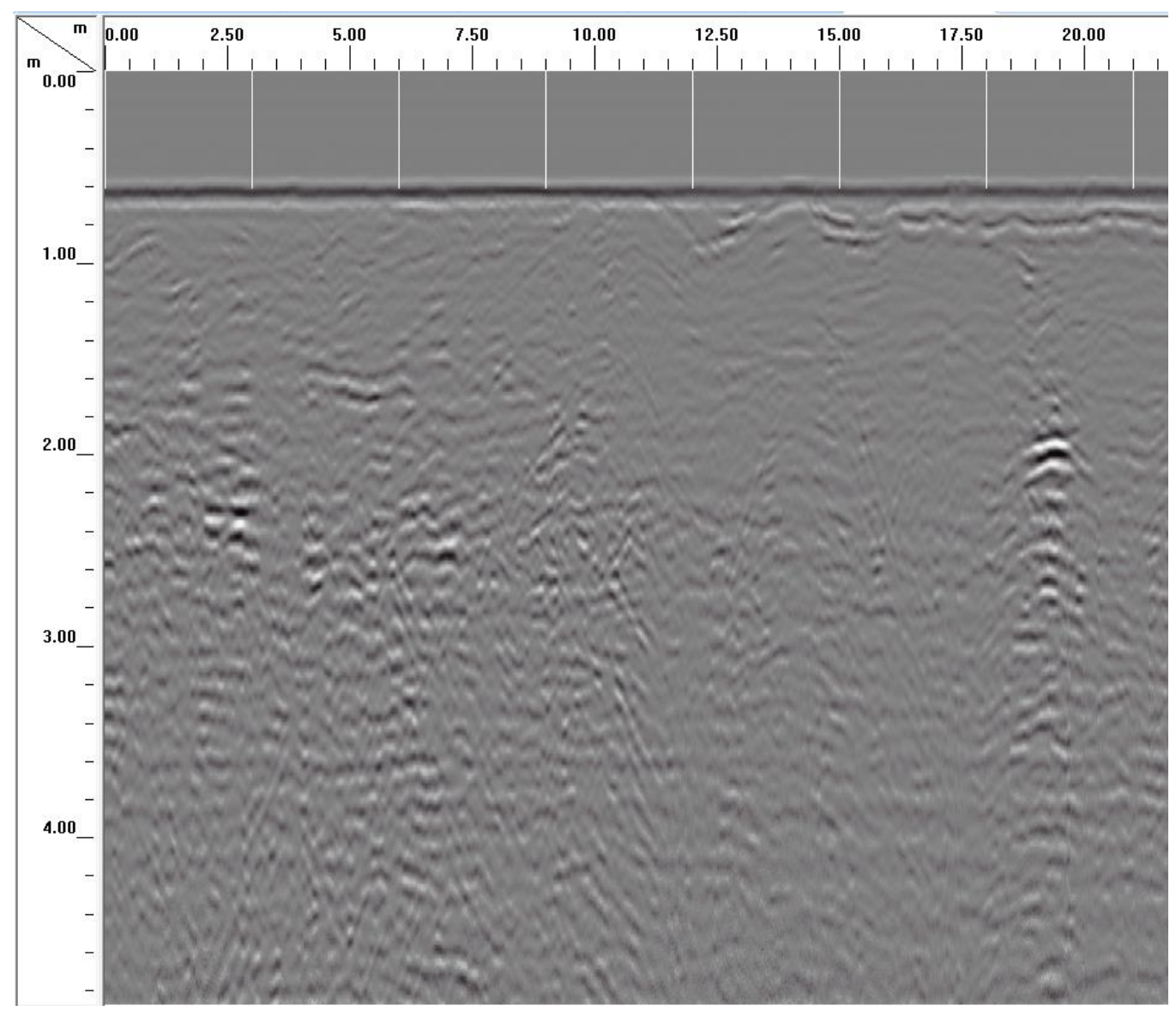

Figure A 2 Unprocessed Data at Weaver Hill Road Bridge Location 2

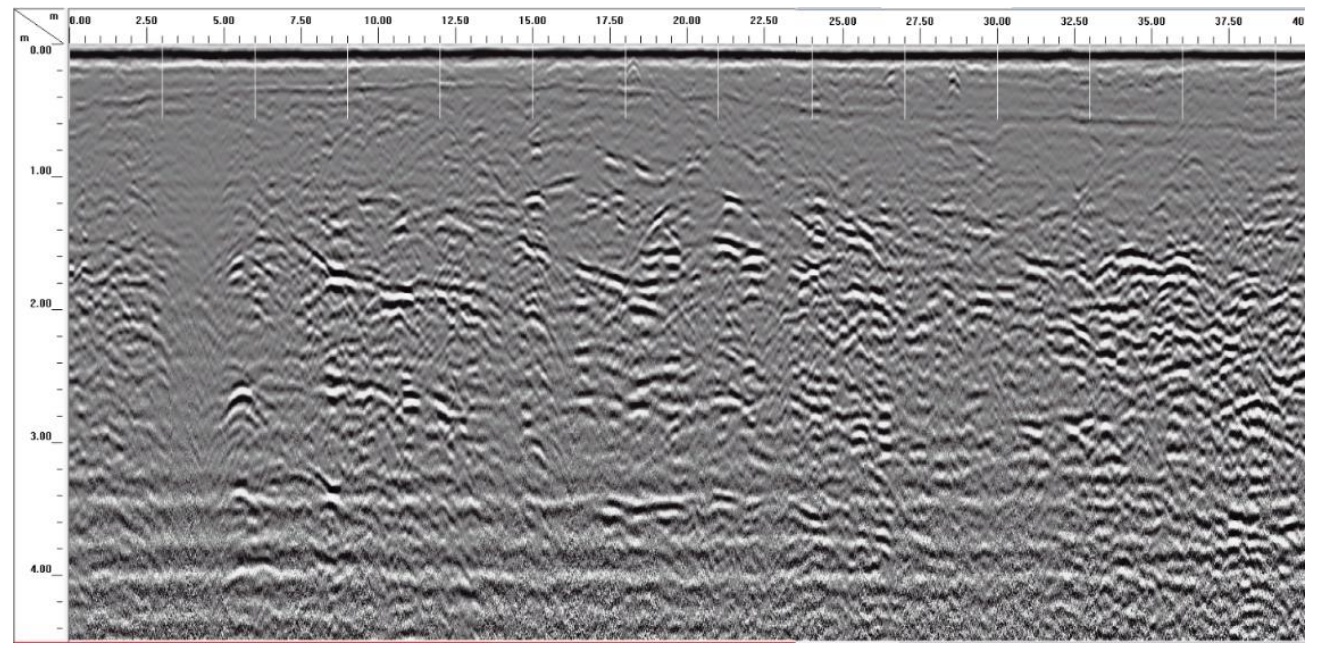

Figure A 3 Unprocessed Data at Baker Pines Road Bridge Location 1 


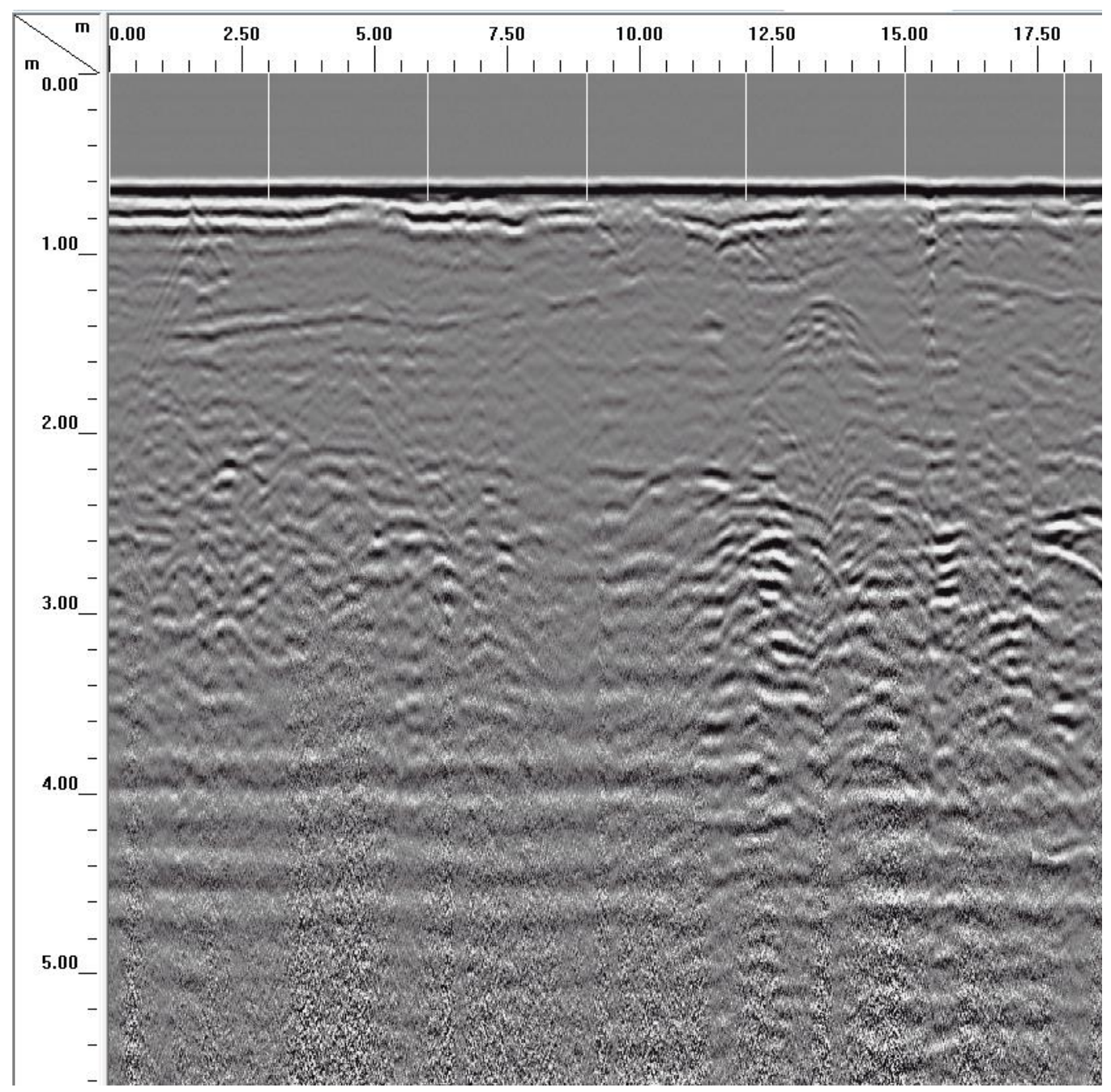

Figure A 4 Unprocessed Data at Baker Pines Road Bridge Location 2 


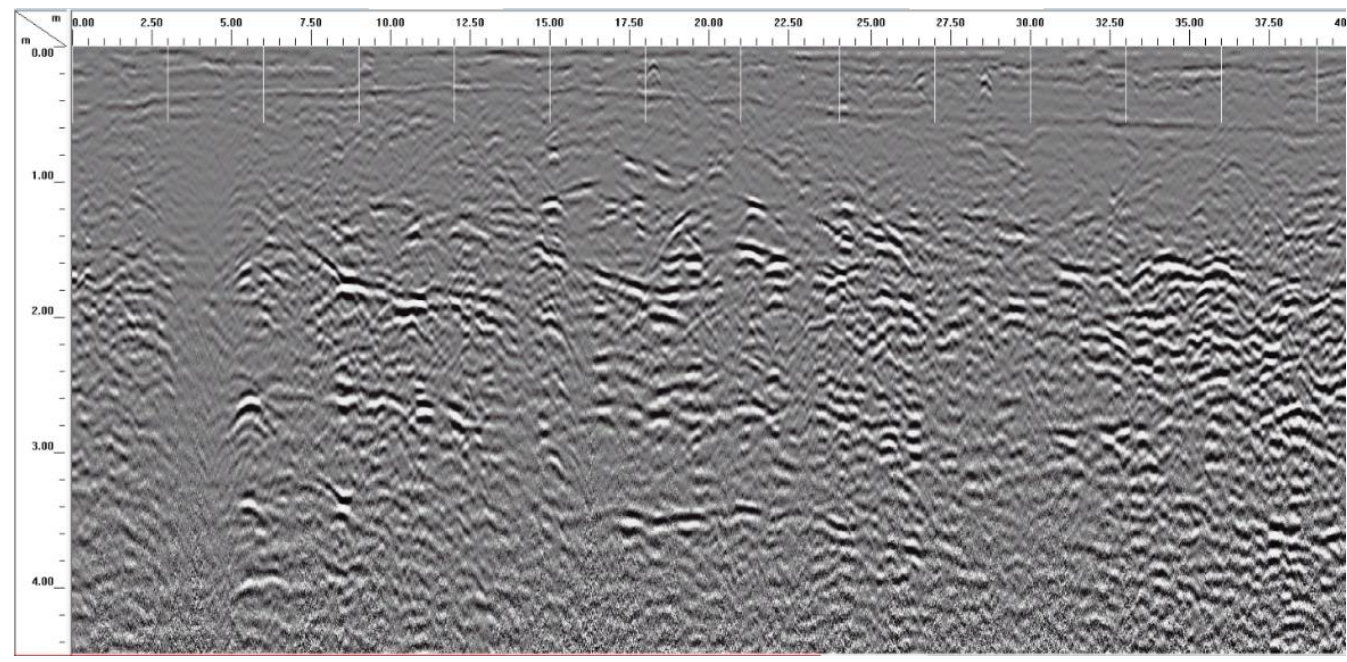

Figure A 5 Processed Data at Baker Pines Road Bridge Location 1

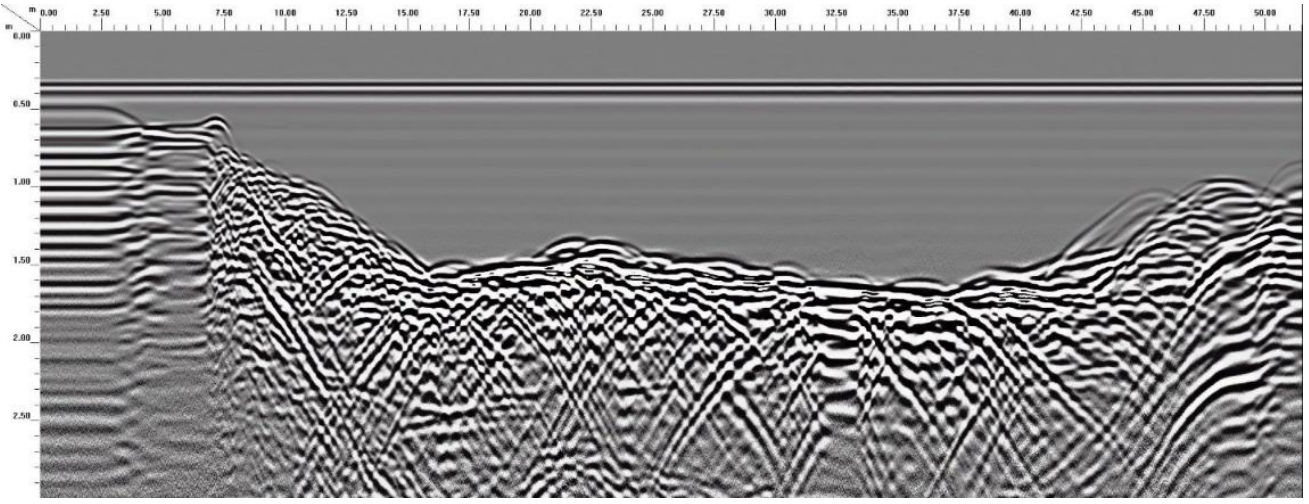

Figure A 6 Unprocessed Radar Image Downstream at the Kenyons Bridge 


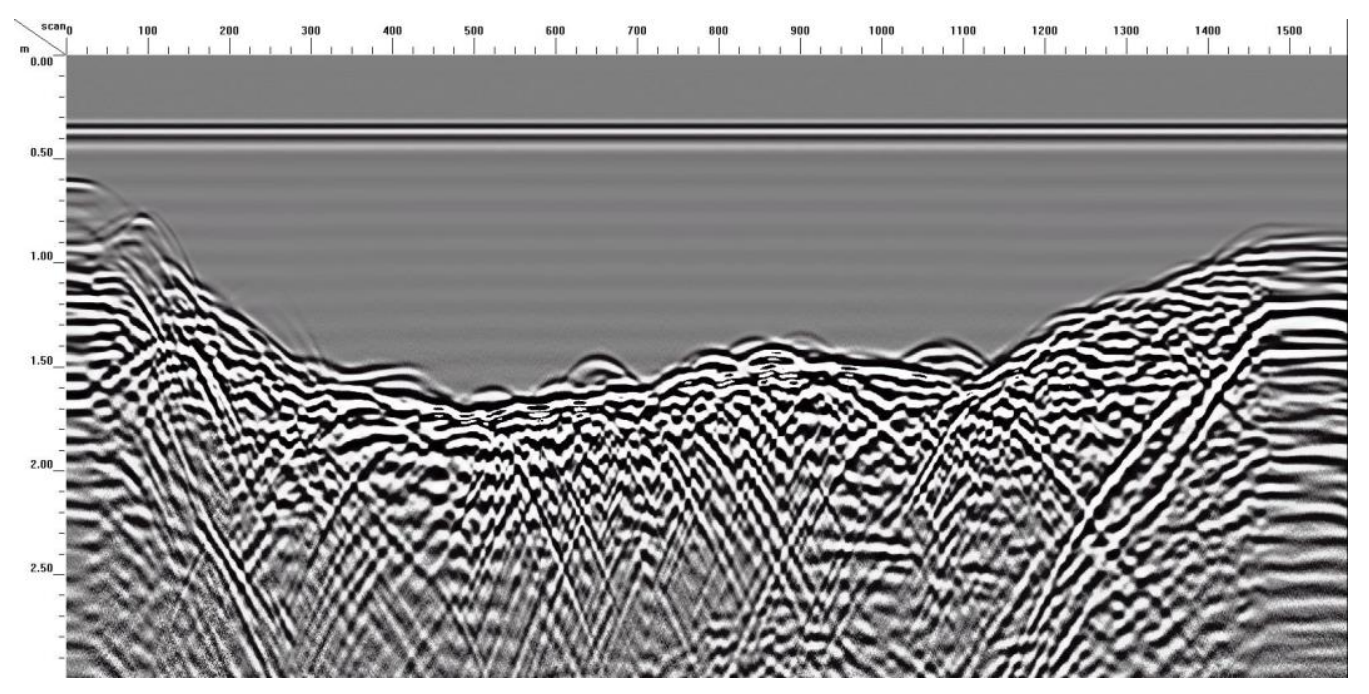

Figure A 7 Unprocessed Radar Image Upstream at the Kenyons Bridge

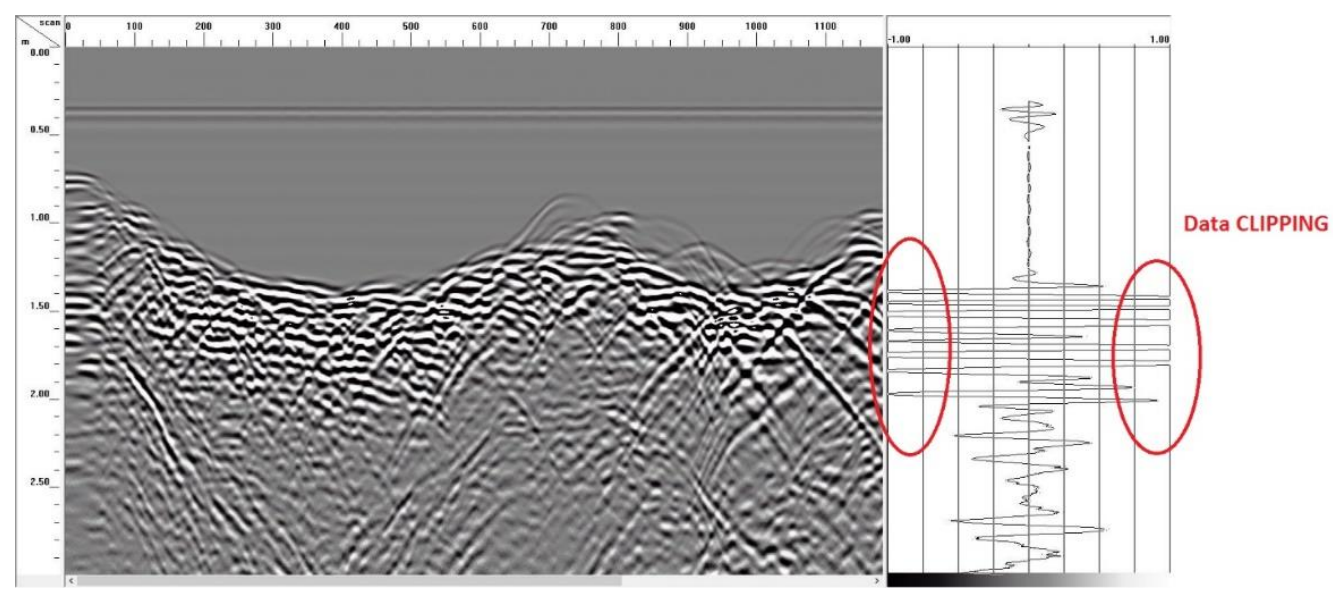

Figure A 8 Data Clipping at the First Barberville Bridge

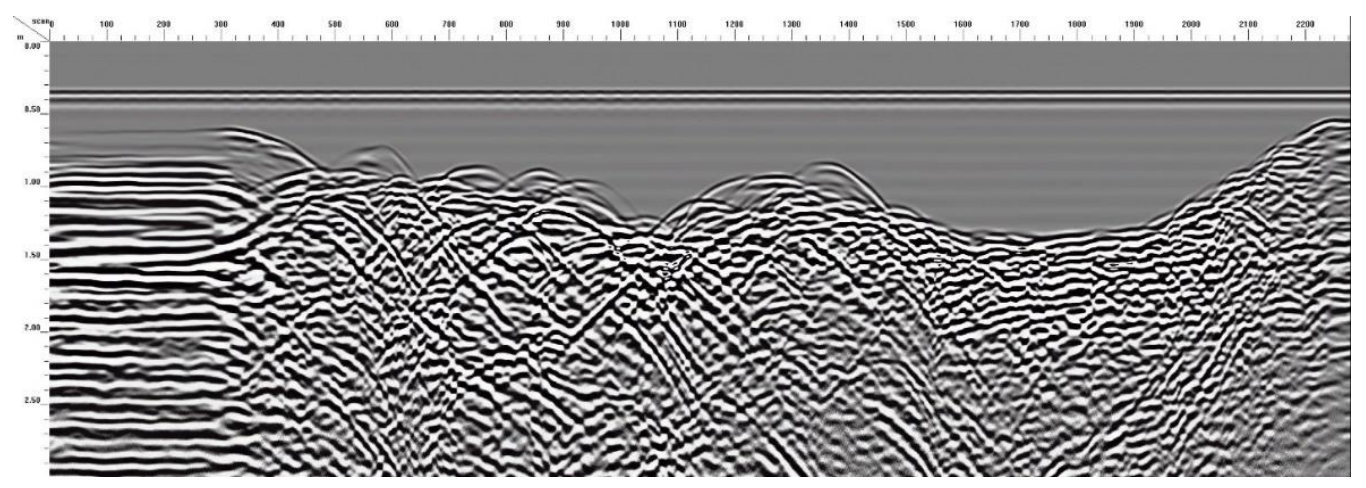

Figure A 9 Unprocessed Downstream GPR image at the First Barberville Bridge 


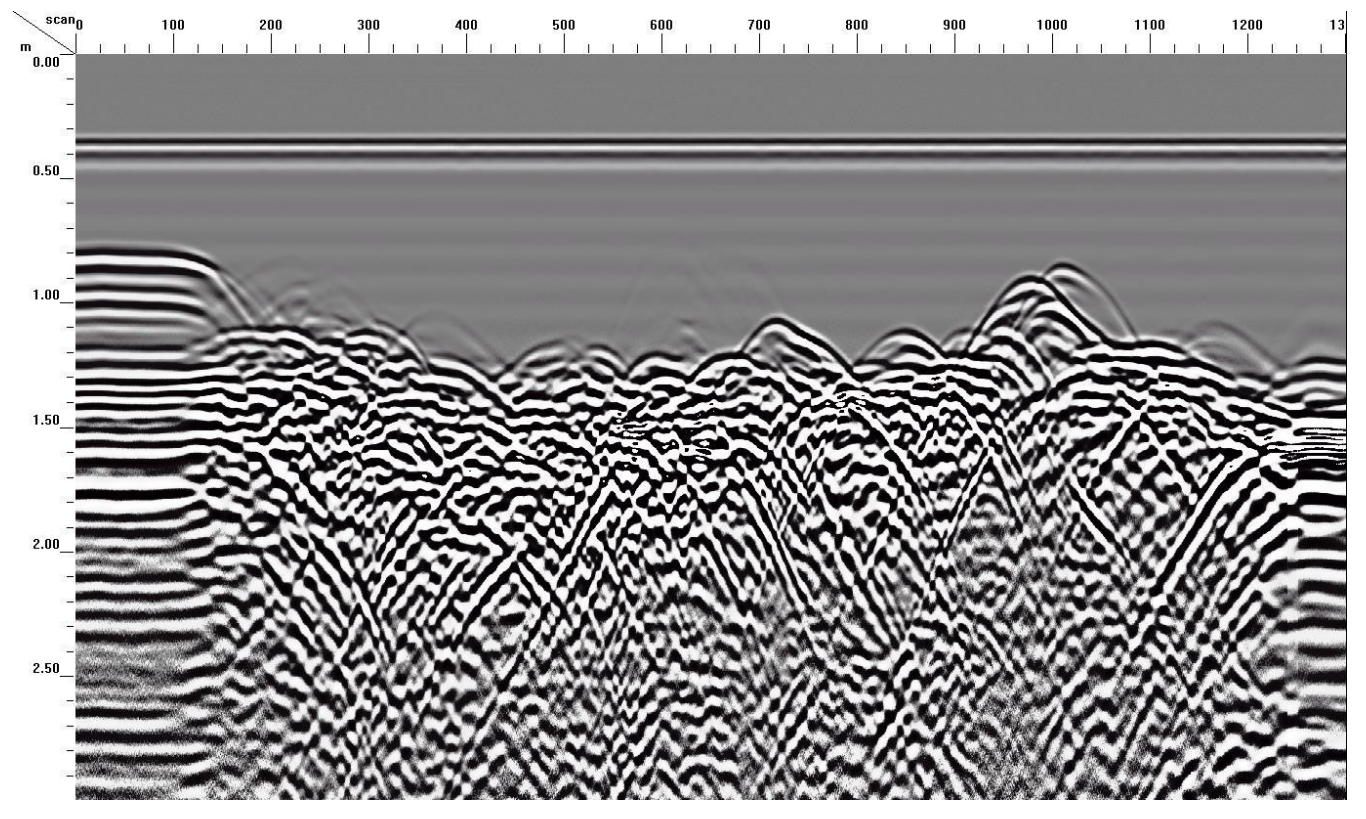

Figure A 10 Unprocessed Upstream GPR image at the First Barberville Bridge 

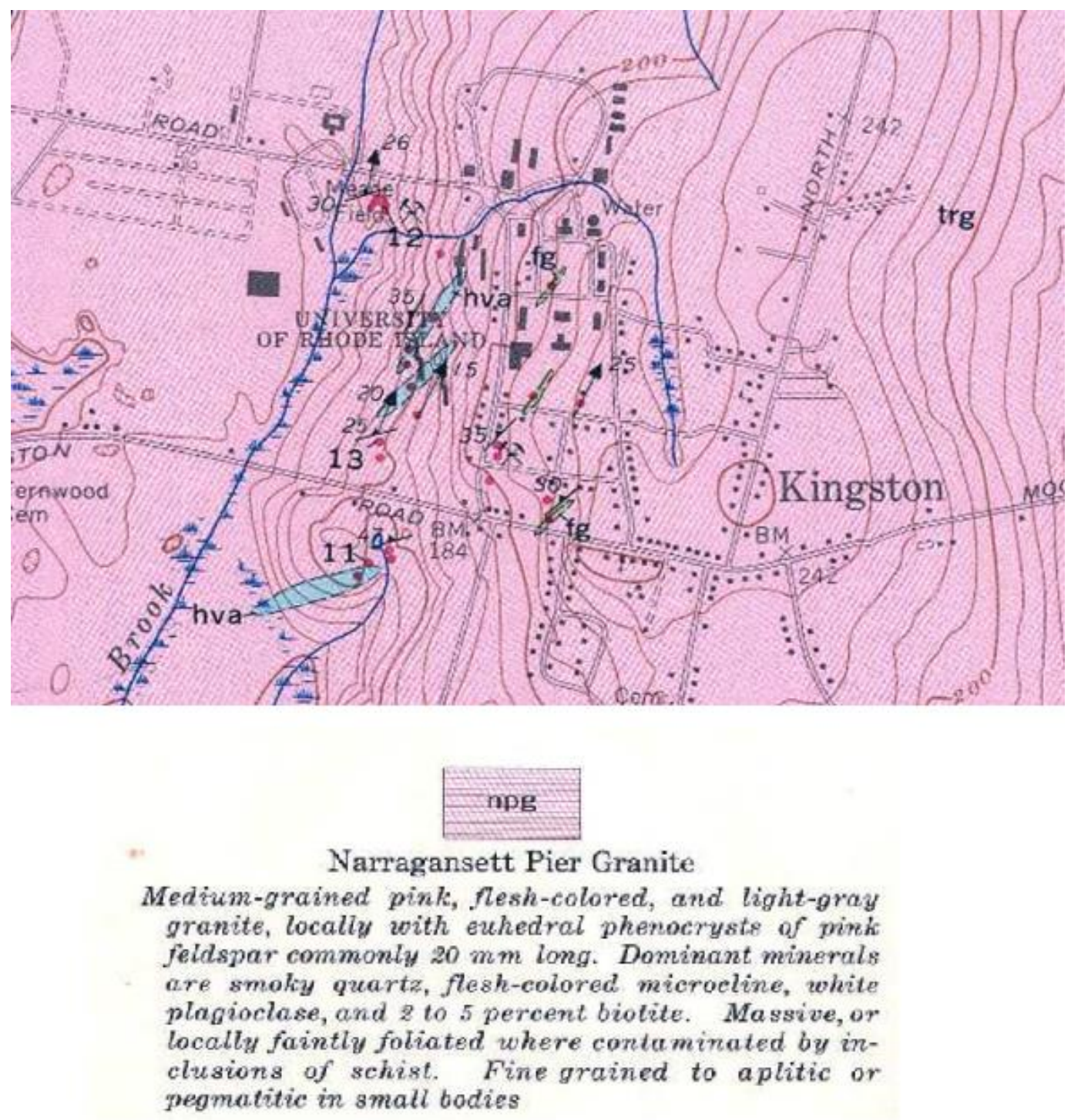

Figure A 11 Bedrock Map for Kingston 

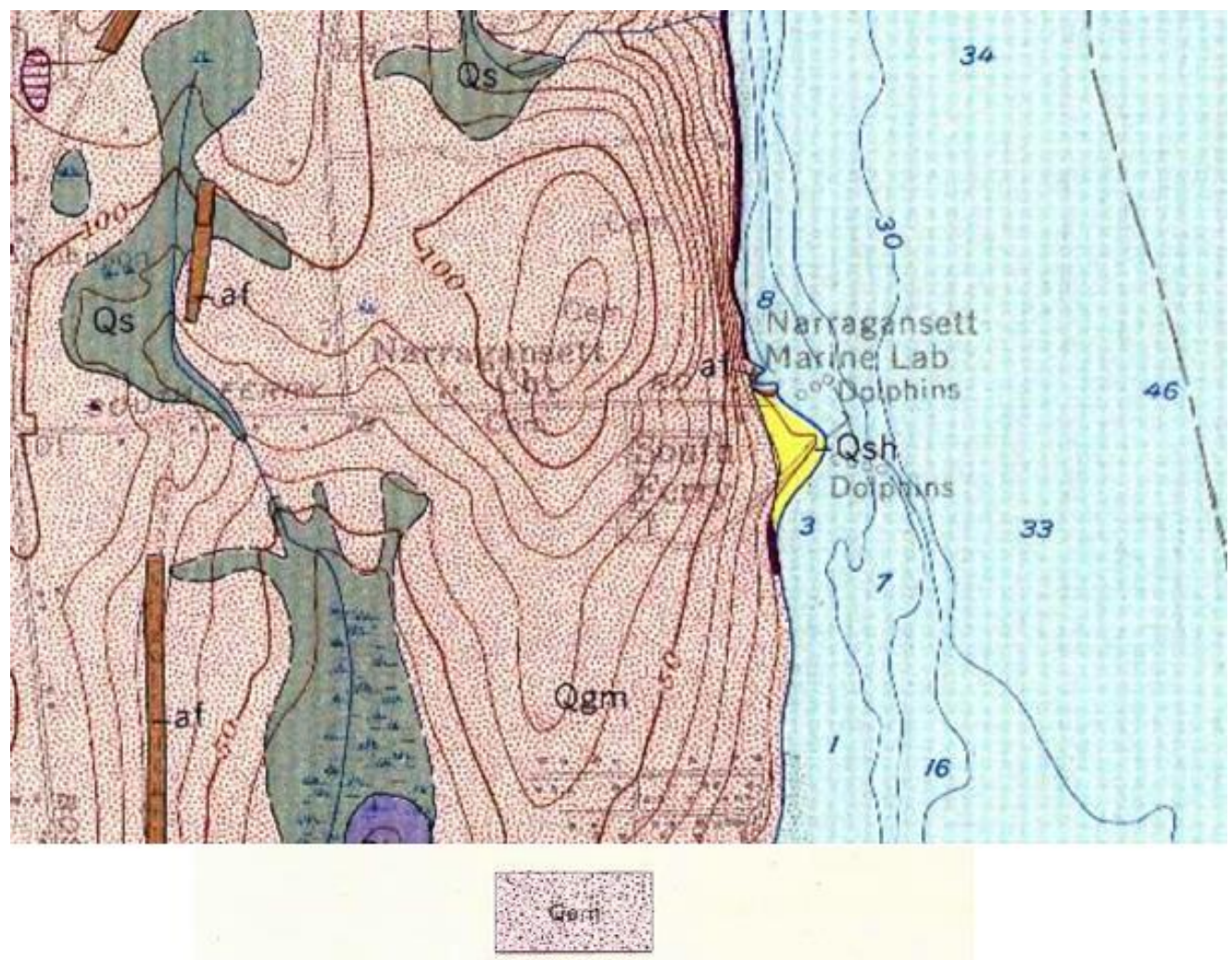

End moraine

Point Judith moraine, composed of till, gravel, sand, and sill

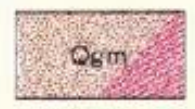

Ground moraine

Till; Lhin layers and lenses of gravel and sand in some plnees. Obliquely lined areas have a more irregular topograpiy and a langer proportion of gravel and sond

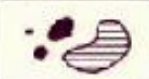

Bedrock outcrops

Ruled areas are groups of closeiy spaced outcrops

Figure A 12 Bedrock Map for Narragansett 


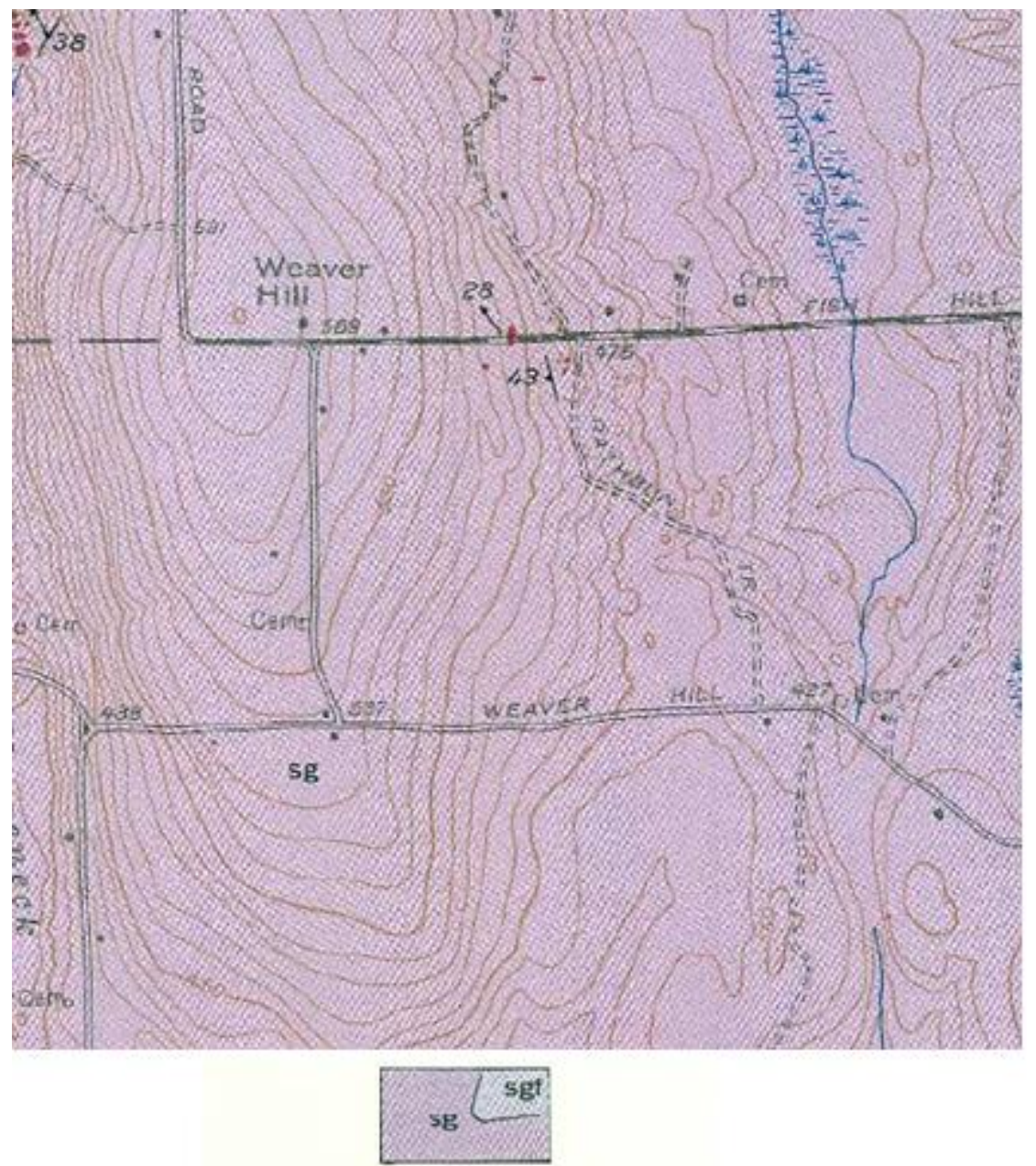

Scituate granite gneiss

Pinkish-gray to flesh. colored medium-to course. graised granite gngiss; strong lineation and weak to moderate foliation in nost piaces: characterised by oral splotches of biatite commonly $50 \mathrm{~mm}$ long; dominontly guartz, approximately equal amoxnts of pink micro. cline and white plogio. clase, and biotile; com. noniy porphyritic, phe. nocrysts of microcline as much as $40 \mathrm{~mm}$ long. sgf, fine-grained fapies; faciss is fine-to medi. um-srained and has narrower and fewer splotches of biotite and better foivation than the courser-graized jacies of the Scituate

Figure A 13 Bedrock Map for Weaver Hill area 


\section{Chapter 9}

\section{Bibliography}

Anderson, I. et al., 2015. Scour Damage to Vermont Bridges and Scour Monitoring, Vermont: UVM Transportation Research Center Report 15-002.

Anderson, N. L., Ismael, A. L. \& Thanop, T., 2007. Ground-Penetrating Radar: A Tool for Monitoring Bridge Scour. Enviromental \& Engineering Geoscience, Vol. XIII, No. 1, February, pp. 1-10.

Arneson, L., Zevenbergen, L., Lagasse, P. \& Clopper, P., 2012. EVALUATING SCOUR AT BRIDGES. Hydraulic Engineering Circular No. 18.

Banks, W. S. \& Johnson, C. D., 2007. Collection, Processing, and Interpretation of Ground-Penetrating Radar Data to Determine Sediment Thickness at Selected Locations in Deep Creek Lake, Garrett County, Maryland, 2007. s.I.:USGS.

Benedetto, A. \& Pajewski, L., 2015. Civil Engineering Applications of Ground Penetrating Radar. s.l.:Springer.

Bradshaw, A., 2015. Study of Scour at Rhode island Bridges, Kingston: University of Rhode Island.

Bristow, C. S. \& Jol, H. M., 2003. An introduction to ground penetrating radar (GPR) in sediments, London: Geological Society of London. 
D6432-11, 2011. Standard Guide for Using the Surface Ground Penetrating Radar Method for Subsurface Investigation, West Conshohocken, PA: ASTM International.

Daniels, D. d. J., 2004. Ground Penetrating - 2nd Edition. London: The Institution of Electrical Engineers.

Doolittle, J., 2009. Soils, Peatlands, and Biomonitoring. In: Ground Penetrating Radar: Theory and Applications. s.l.:Elsevier Science, pp. 179 - 202.

Gindy, M., 2013. GPR - Setup Table, Kingston: Univiersity of Rhode Island.

GSSI, 2012. RADAN 7 Manual. New Hampshire: Geophysical Survey Systems, Inc..

GSSI, 2016. SIR 3000 Manual. Nashua, New Hampshire : Geophysical Survey Systems, Inc..

Higgins, C., 2012. Stopping Scour. Transportation Blog, pp. Accessed on $\begin{array}{llll}\text { November } & \text { 11th } 2016 . & \text { Available: }\end{array}$ http://blog.udot.utah.gov/2012/05/bridge-scour-inspections-riprap/.

Hollmann, M., 2007. Christian Huelsmeyer, the inventor. Retrieved from http://www.radarworld.org/huelsmeyer.html: Radar World.

Laurent, W., 2016. FIELD STUDY OF SCOUR CRITICAL BRIDGES IN RHODE ISLAND. Kingston: University of Rhode Island.

Lee, J. \& Park, I., 2004. Assessment of Bridge Scour and Riverbed variation by a Ground Penetrating Radar. Delft (Netherlands), s.n. 
Milan, B. \& Haeni, F., 1999. Application of Ground-Penetrating-Radar Methods in Hydrogeologic Studies. Ground Water Vol. 29 No. 3, pp. 375-386.

Møller, I., 2006. Groundwater Resources in Buried Valleys. Hannover, Germany: Leibniz Institute for Applied Geosciences (GGA-Institut).

$\begin{array}{lll}\text { N.N., } & 2017 . & \text { Radio-Electronics. }\end{array}$ Available at: http://www.radioelectronics.com/info/formulae/capacitance/capacitors-dielectric-constantpermittivity.php [Accessed 2108 2017].

Olhoeft, G. R., 1999. Maximizing the information return from ground penetrating radar. Golden, CO 80401-1887 USA: Department of Geophysics, Colorado School of Mines.

Olimpio, J. R., 2000. Use of a Ground-Penetrating Radar System to Detect Pre-and Post-Flood Scour at Selected Bridge Sites in New Hampshire, 1996-98, Pembroke, NH: Water-Resources Investigations Report 00-4035.

Parent, C., Fratus, K. \& Hetland, N., 2017. ARL Project-Dynamic Cone Penetration testing in a Sandbox to determine California Bearing Ratios, Kingston: University of Rhode Island.

Pechillo, T. H., 2010. Supplemental Scour Inspection, Charestown: State of Rhode Island Department of Transportation.

Persico, R., 2004. Introduction to Ground Penetrating Radar. s.I.:Wiley-IEEE Press. 
$\begin{array}{llll}\text { Rouse, } & \text { M., } & 2015 . & \text { techtarget. }\end{array}$ Available at: $\quad$ http://whatis.techtarget.com/definition/dielectric-constant [Accessed 2108 2017].

Twizere, C., 2011. Use of GPR techniques for Landmines. Rome, Italy: ROMA TRE UNIVERSITY.

Ullberg, J., 2011. Recommendations for guidline for the use of GPR in road construction quality control, Rovaniemi: INTERREG.

USDA, 2009. Ground-Penetrating Radar Soil Suitability Maps, s.I.: United States Department of Agriculture, Natural Resources Conservation Service.

USGS, 2017. USGS.

[Online] Available at: $\quad$ https://ngmdb.usgs.gov/ngmdb/ngmdb home.html [Accessed 2208 2017].

Webb, D. J. et al., 2002. Ground Penetrating Radar (GPR): A Tool for monitoring bridge scour, Jefferson City: Department of Geology and Geophysics, University of Missouri-Rolla.

Wulff, F., 2016. USE OF SURFACE WAVE TECHNIQUES FOR THE IDENTIFICATION OF, Kingston: University of Rhode Island. 